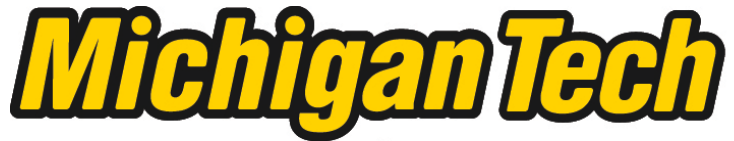 \\ Michigan Technological University Create the Future Digital Commons @ Michigan Tech
}

\section{Evaluating Karner Blue Butterfly (Lycaeides Melissa Samuelis Nabokov) Habitat Selection in the State of Wisconsin, USA}

Anna Nahuel Hess

Michigan Technological University

Follow this and additional works at: https://digitalcommons.mtu.edu/etds

Part of the Biology Commons, Entomology Commons, Natural Resources and Conservation Commons, and the Natural Resources Management and Policy Commons Copyright 2013 Anna Nahuel Hess

\section{Recommended Citation}

Hess, Anna Nahuel, "Evaluating Karner Blue Butterfly (Lycaeides Melissa Samuelis Nabokov) Habitat Selection in the State of Wisconsin, USA", Dissertation, Michigan Technological University, 2013.

https://doi.org/10.37099/mtu.dc.etds/665

Follow this and additional works at: https://digitalcommons.mtu.edu/etds

Part of the Biology Commons, Entomology Commons, Natural Resources and Conservation Commons, and the Natural Resources Management and Policy Commons 
EVALUATING KARNER BLUE BUTTERFLY (LYCAEIDES MELISSA SAMUELIS NABOKOV) HABITAT SELECTION IN THE STATE OF WISCONSIN, USA

By

Anna N. Hess

\begin{abstract}
A DISSERTATION
Submitted in partial fulfillment of the requirements for the degree of

DOCTOR OF PHILOSOPHY

In Forest Science
\end{abstract}

MICHIGAN TECHNOLOGICAL UNIVERSITY

2013

(C) 2013 Anna N. Hess 

This dissertation has been approved in partial fulfillment of the requirements for the Degree of DOCTOR OF PHILOSOPHY in Forest Science.

School of Forest Resources and Environmental Science

Dissertation Advisor: Andrew J. Storer

Committee Member: Christopher R. Webster

Committee Member: Amy M. Marcarelli

Committee Member: Deahn Donner Wright

School Dean: $\quad$ Terry L. Sharik 

To my parents, for your constant support, knowledge and gas money.

To my sister for your unrestricted sense of humor.

To Hans and Jill Schabel, for maintaining that I would someday work in entomology.

To the uniquely dedicated group of people that strive for recovery of this species and the places it calls home.

And to the Karner Blue butterfly, a constant in my life since 1992, may it remain a constant on the landscape. 



\section{Table of Contents}

List of Tables xiv

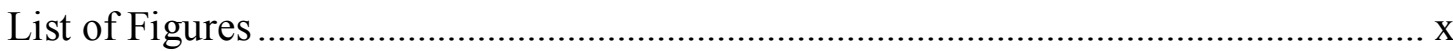

Abstract 1

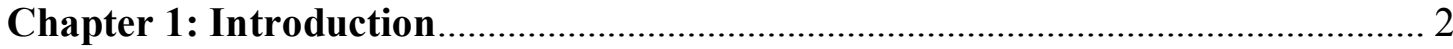

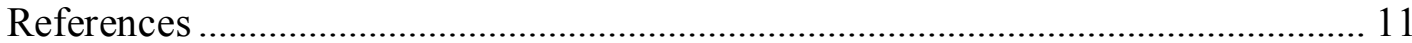

\section{Chapter 2: Karner Blue Butterfly Habitat Conservation in Wisconsin: A Brief} Overview of Historical, Current, and Developing Management. ......................... 22

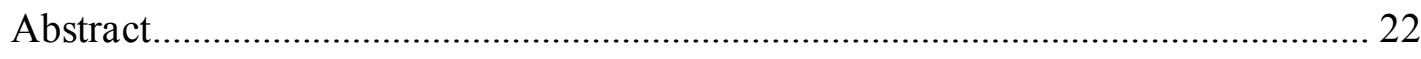

Oak/Pine Grassland Communities and the Karner Blue Butterfly ........................... 23

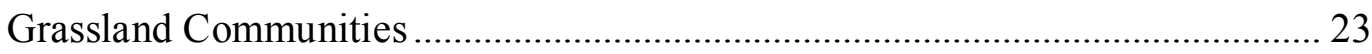

Karner Blue Morphology, Behavior and Habitat Selection................................... 24

Development of Karner Blue Conservation Efforts ................................................ 27

Habitat Conservation Plan Partnership ............................................................... 28

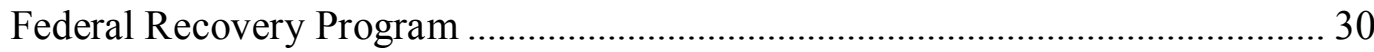

Wisconsin Statewide Recovery Program............................................................... 32

Development of Management Policies....................................................................... 35

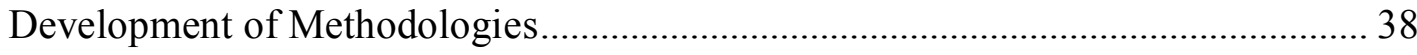

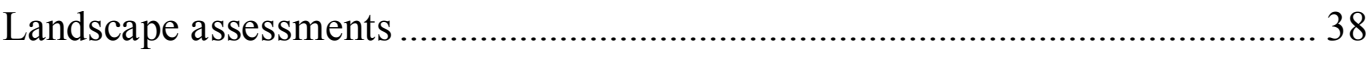

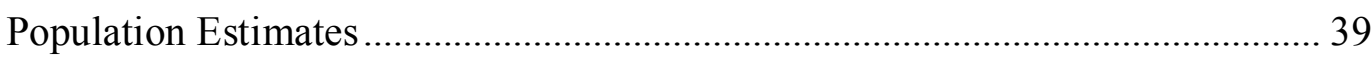

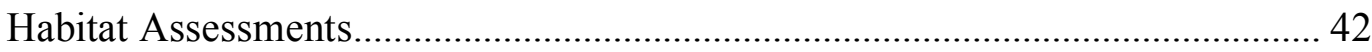

Conclusions: Habitat Management and Monitoring Needs ..................................... 44

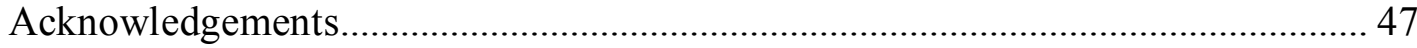

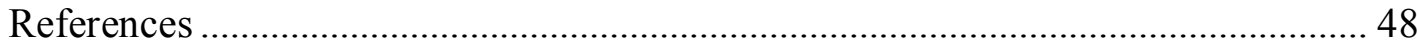


Chapter 3: Habitat suitability models for the identification and evaluation of Karner blue butterfly habitat using a Multi-Criteria Risk Modeling approach......

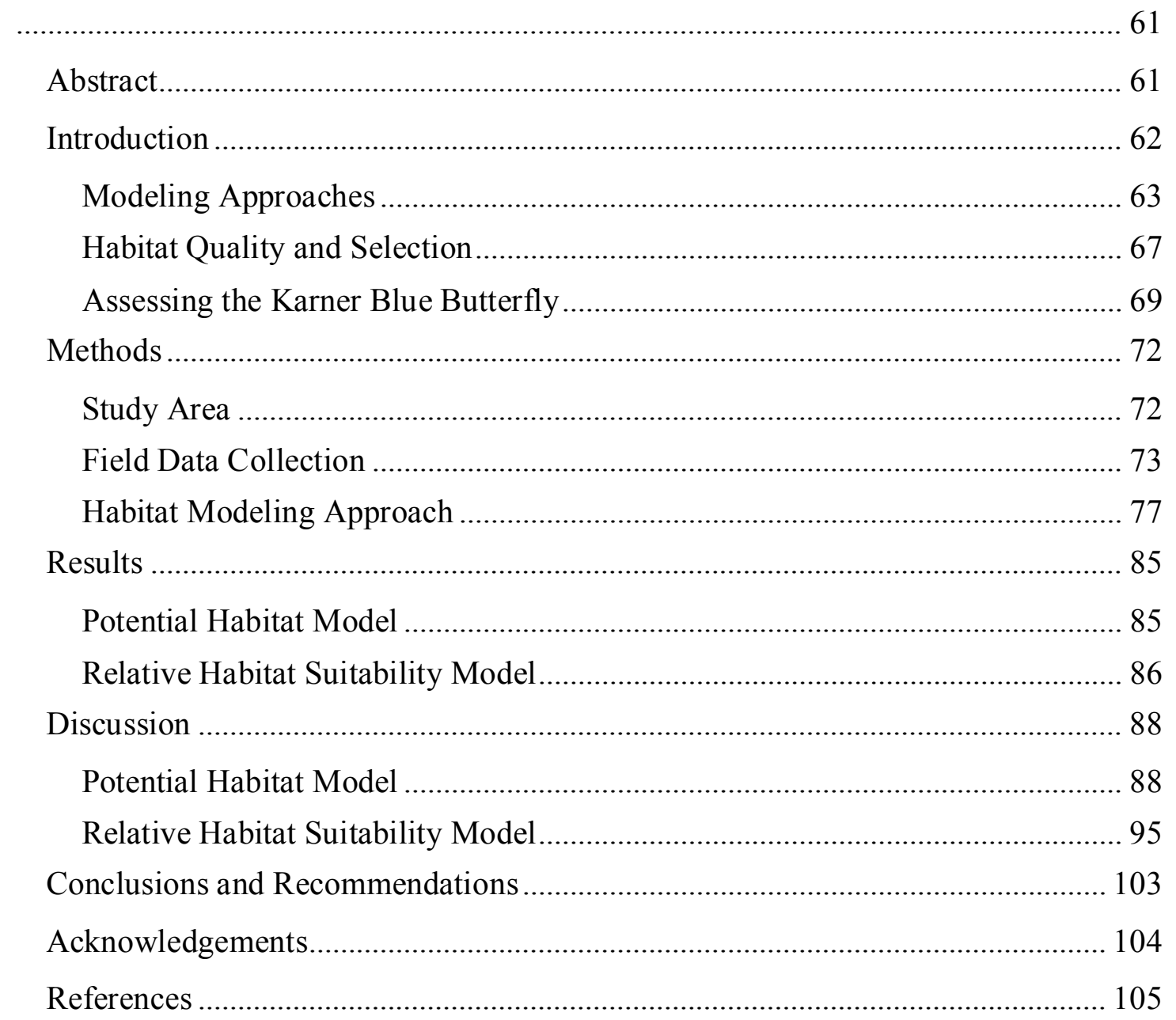

\section{Chapter 4: Do American bison influence distribution of a specialist Lepidopteran}

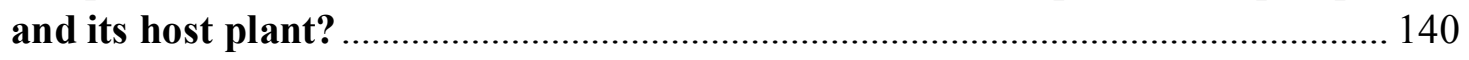

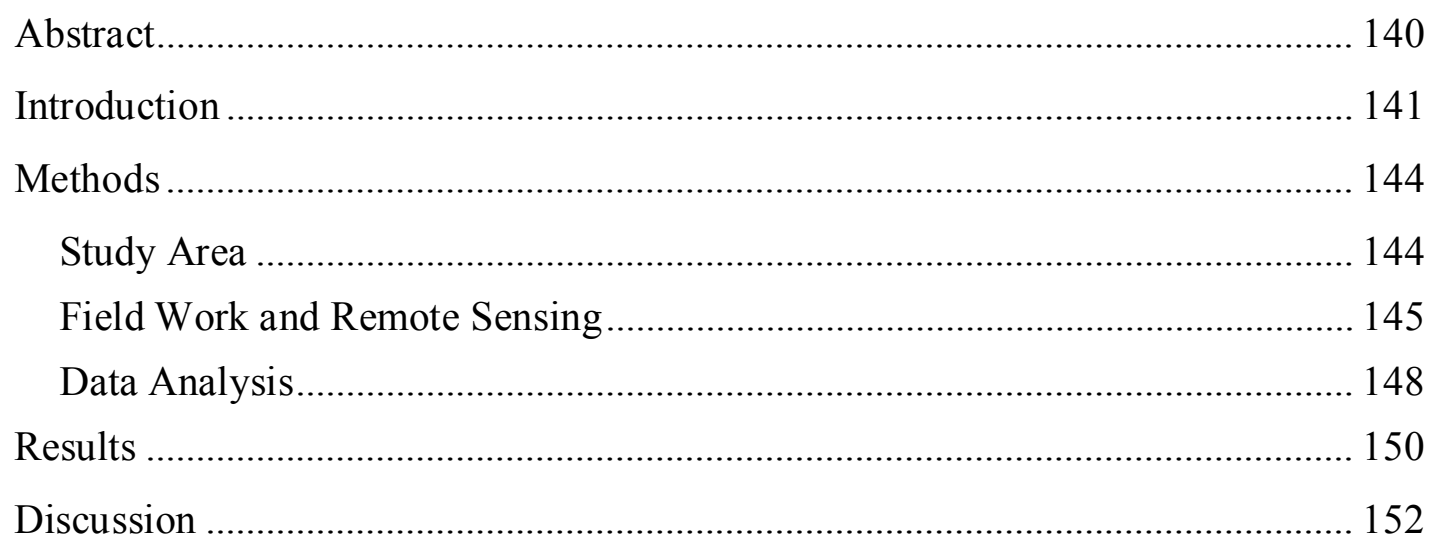

viii 


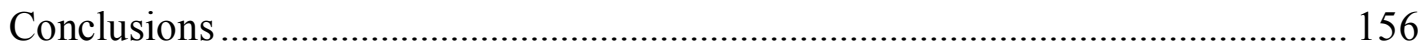

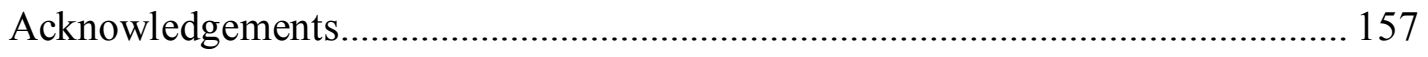

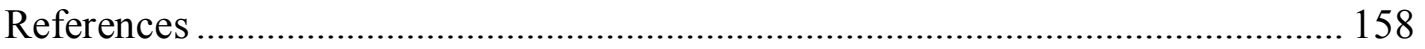

Chapter 5: Analyses of $C: N$ ratio, nitrogen and phenolic content in host plant wild blue lupine (Lupinus perennis) relative to habitat for a specialist

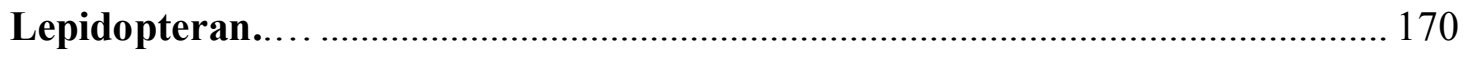

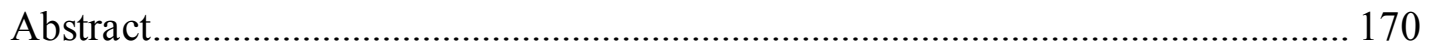

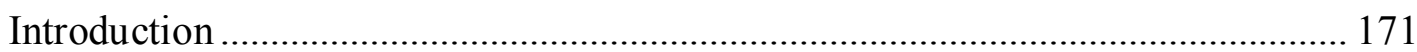

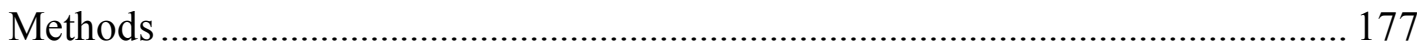

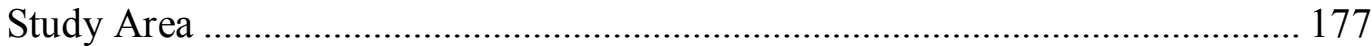

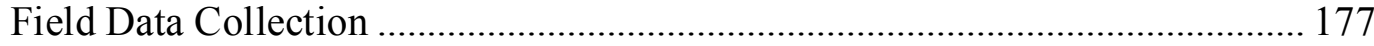

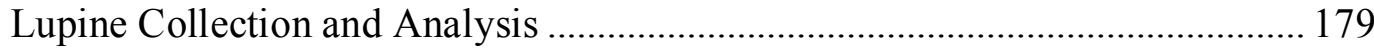

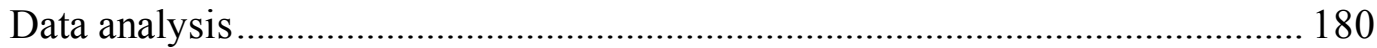

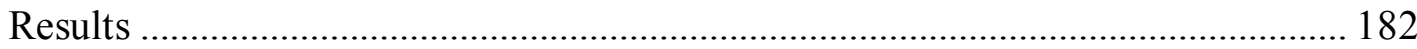

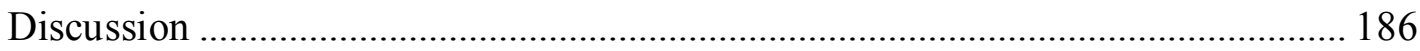

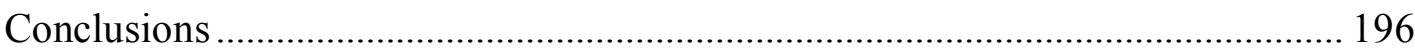

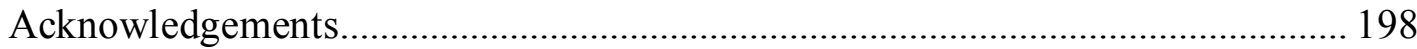

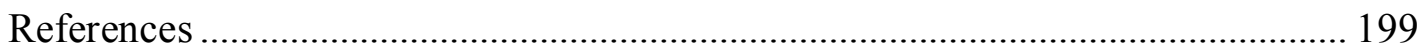

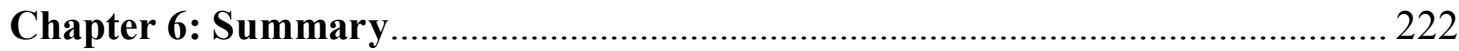

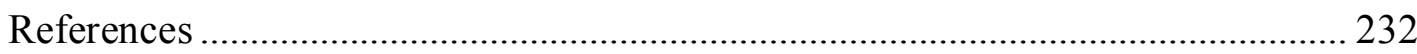

Appendix 1: Potential Habitat Model Outputs................................................................. 238

Appendix 2: Relative Habitat Suitability Model Outputs ........................................... 248 


\section{List of Figures}

Figure 2.1: Current and historic Karner blue butterfly habitat range and current wild blue lupine range across North America.

Figure 2.2: Karner blue butterfly underwing, adult male and adult female. Photos by A Hess.

Figure 2.3: Karner blue butterfly lifecycle overlaid with the approximate lifecycle of host plant wild blue lupine.

Figure 2.4: Timeline of events in Karner blue habitat management in Wisconsin. ......58

Figure 2.5: Demarcations on the Wisconsin statewide recovery program distance sampling pole used for Karner blue butterfly population estimate surveys.

Figure 2.6: Illustration of the distance sampling detection function $\mathrm{g}(\mathrm{x})$ used to calculate a total population estimate count.

Figure 3.1: Study sites across the Karner blue butterfly range and demarcated Karner

blue butterfly recovery zones in Wisconsin.

Figure 3.2: Example of the sample design used across small-scale sample areas to collect ground measurements at Michigan Tech research sample areas.

Figure 3.3: Flow-chart representing the basic steps of producing the Potential Habitat Model.

Figure 3.4: Flow-chart representing the basic steps of producing the Relative Habitat Suitability Model.

Figure 3.5: Example of the Potential Habitat Model output for identifying Karner blue butterfly habitat within a state property in the Karner blue range in Wisconsin.........133

Figure 3.6: Ground-validation of derived shrub/tree cover from 2010 NAIP orthophotos

Figure 3.7: Comparison of the area for 30 sample areas in Potential Habitat Model suitability categories.

Figure 3.8: Comparison of the area for 30 sample areas in Potential Habitat Model suitability categories to the Karner blue encounter rate per sample area for $2.25 \mathrm{~m}$...136 
Figure 3.9: Relative Habitat Suitability Model output for seven validation sample areas, evaluating Karner blue butterfly habitat suitability in Wisconsin.

Figure 3.10: Percent of Karner blue populations and random points identified in the Relative Habitat Suitability Model in loamy-sand sample areas.

Figure 3.11: Percent of Karner blue populations and random points identified in the Relative Habitat Suitability Model in loamy-sand sample areas.

Figure 4.1: The Sandhill Wildlife Area, Wisconsin, interior bison pasture and study site. Transects used for estimating Karner blue butterfly populations and establishing sample plots are represented by black lines.

Figure 4.2: Example of sample plot development in the bison pasture at the Sandhill Wildlife Area, Wisconsin.

Figure 4.3: Karner blue 'hot spots' of the peak of the Karner blue flight in relation to areas of bison-caused mineral-soil disturbance at the bison pasture, Sandhill Wildlife Area, Wisconsin.

Figure 4.4: Comparison of the 2011 and 2012 Karner blue populations within 5, 15, and $15+\mathrm{m}$ of designated High and Low potential sample plots in the bison pasture at the Sandhill Wildlife Area, Wisconsin....

Figure 4.5: Percent of sample plots where Karner blues were present in relation to habitat variables at Sandhill Wildlife Area, Wisconsin.

Figure 4.6: Percent of sample plots where lupine was present in relation to habitat variables at Sandhill Wildlife Area, Wisconsin.

Figure 5.1: Locations of field sites in relation to the approximate range of Lupine perennis in Wisconsin.

Figure 5.2: Illustration of the strategic systematic sampling design for selecting lupine foliage at field sites in Wisconsin......

Figure 5.3: Comparison of variation in $\mathrm{C}: \mathrm{N}$ in lupine across all sample plots, plots where Karner blues were absent or present, and common legume cover crops.

Figure 5.4: Comparison of variation in percent nitrogen in lupine across all sample plots, plots where Karners were absent or present, and common legume cover crops.

Figure 5.5: Comparison of variation in percent Phenolics in lupine across all sample plots, plots where Karners were absent or present. 
Figure 5.6: Kruskal-Wallis ANOVA pairwise comparisons of four groups of sample plots according to \% cover of shrub/tree and ground litter, and focal nectar plant abundance.

Figure 5.7: Scatter-plot representations of lupine nutrients and defense compounds in relation to percent cover of shrub/tree, percent cover of ground litter, and focal nectar plant abundance for all sample plots across Wisconsin

Figure 5.8: Scatter-plot representations of lupine nutrients and defense compounds in relation to percent cover of shrub/tree, percent cover of ground litter, and focal nectar plant abundance for five high density lupine field sites in Wisconsin.

Figure 5.9: Comparison of Karner blue encounter rates (observations/linear $\mathrm{m}$ ) to nutrient or defensive compounds across all sample plots in Wisconsin (322 plots)...220

Figure 5.10: Comparison of Karner blue encounter rates (observations/linear m) to nutrient or defensive compounds for five high density lupine field sites in Wisconsin..

Figure A1.1: Potential Habitat Model for Crex Meadows Wildlife Area.

Figure A1.2: Potential Habitat Model for Fish Lake Wildlife Area.......................... 240

Figure A1.3: Potential Habitat Model for the Black River State Forest.. .................. 241

Figure A1.4: Potential Habitat Model for Bauer Brockway Barrens State Natural Area..

Figure A1.5: Potential Habitat Model for the Sandhill Wildlife Area. ................... 243

Figure A1.6: Potential Habitat Model for Hartman Creek State Park........................ 244

Figure A1.7: Potential Habitat Model for Emmons Creek Fishery Area.................... 245

Figure A1.8: Potential Habitat Model for Greenwood Wildlife Area......................... 246

Figure A1.9: Potential Habitat Model for White River Marsh Wildlife Area......... 247

Figure A2.1: Relative Habitat Suitability Model for Crex Meadows Wildlife Area, sample area BU52.).

Figure A2.2: Relative Habitat Suitability Model for Black River State Forest, sample area C16. 250 
Figure A2.3: Relative Habitat Suitability Model for Black River State Forest, sample

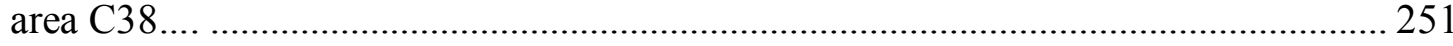

Figure A2.4: Relative Habitat Suitability Model for Bauer Brockway Barrens State Natural Area, sample area BBB.............................................................................. 252

Figure A2.5: Relative Habitat Suitability Model for the Hartman Creek State Park,

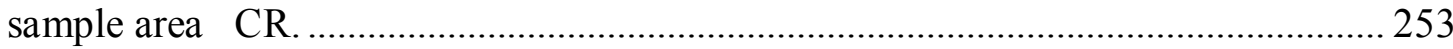

Figure A2.6: Relative Habitat Suitability Model for the White River Marsh Wildlife Area, sample area TN....................................................................................... 254

Figure A2.7: Relative Habitat Suitability Model for White River Marsh Wildlife Area, sample area W. 255 


\section{List of Tables}

Table 3.1: Comparison of 30 sample areas used in model development and validation throughout the study.

Table 3.2: Habitat suitability categories applied to Potential Habitat Model across all used Karner blue butterfly sample areas in Wisconsin.

Table 3.3: Habitat suitability categories applied to Relative Habitat Suitability Model percent groundcover categories at Karner blue butterfly sandy sample areas in Wisconsin.

Table 3.4: Habitat suitability categories applied to Relative Habitat Suitability Model percent groundcover categories at Karner blue butterfly loamy-sand sample areas in Wisconsin.

Table 5.1: Best-fit regression model results for $\mathrm{C}: \mathrm{N}$, nitrogen content and phenolic content for all lupine sample plots in Wisconsin. 


\section{Acknowledgements:}

This research would not have been possible without the contributions of many people. This project was a collaborative effort between Michigan Technological University, the Wisconsin Department of Natural Resources, the U.S. Fish and Wildlife Service, the University of Wisconsin-Stevens Point, and the U.S. Forest Service, to address lingering questions about the Karner blue, to quantify habitat characteristics in areas of interest, and especially to generate modeling tools that could help in making our restoration efforts more successful.

The Wisconsin Karner Blue Butterfly Recovery Coordinator, my father Robert Hess, was responsible for coordinating field crews to collect all population data used in this study, as well as contributing many hundreds of field hours himself. Rebecca Schroeder, my Wisconsin DNR supervisor for the majority of this project, provided much needed project support in numerous forms. U.S. Fish and Wildlife Federal Recovery Coordinator Cathy Carnes aided by providing access to unpublished technical papers and by lending much-needed field workers. Additional support was provided by Wisconsin DNR staff David Lentz (now retired), Gregor Schuurman (now National Park Service), Darrel Zastrow, and Erin Crain.

Many field workers contributed to collecting data: the UW-Stevens Point crew led by Dr. Michael Demchik, Endangered Resources Services, LLC, Robert, Joy and Julie Hess, Jennifer Resch, Jessica Kempke-Lewis, Kris Ponchek, Michael J. Falkowski, 
Julius Dewald, Jill Utrup, Linda C. Lyons, and Jodi Shaw and Beverly S Paulan (who both deserve special thanks).

All property managers and staff from the state properties evaluated in this study contributed to site access and site knowledge at one time or another, including Steve Hoffman, Wayne Hall, Armund Bartz and Pete Engman, Paul Samerdyke, James Holzwart, Raymond Paisley, Brandon Stefanski, James Tomasko, Nancy Christel, and Peter Bakken. Many thanks to all of you.

Organic analyses for this study were conducted at the U.S. Forest Service Northern Research Laboratory in Rhinelander, Wisconsin by lab technician Bruce Birr.

I would like to thank my advisor, Andrew J. Storer, for helping with this project.

Many thanks to the staff at SFRES including Ruth Ojala and Andrea Longhini, and also to Nancy Byers-Sprague and Debra Charlesworth, all of whom were extremely helpful.

Lastly I'd like to thank several friends that were present for the duration: Jen and Jon Riehl, for input on organic analyses, dinners, and microbrew lessons; Keri Deneau, for amazing spontaneous road trips; John Bennett for confusing me so much it kept my mind off of things; Kaitlin Chin, just for being Kaitlin Chin; Roberta Sosof-Esquina for late night conversations; and especially Abigail Bostwick, for her endless string of emails and observations on life. 


\begin{abstract}
The federally endangered Karner blue butterfly (Lycaeides melissa samuelis Nabokov) persists in rare oak/pine grassland communities spanning across the Great Lakes region, relying on host plant wild blue lupine (Lupinus perennis). Conservation efforts since 1992 have led to the development of several programs that restore and monitor habitat. This study aims to evaluate Karner blue habitat selection in the state of Wisconsin and develop high-resolution tools for use in conservation efforts. Spatial predictive models developed during this study accurately predicted potential habitat across state properties based on soils and canopy cover, and identified $\sim 51-100 \%$ of Karner blue occurrences based on lupine and shrub/tree cover, and focal nectar plant abundance. When evaluated relative to American bison (Bison bison), Karner blues and lupine were more likely to occur in areas of low disturbance, but aggregated where bison were recently present in areas of moderate/high disturbance. Lupine $\mathrm{C}: \mathrm{N}$ ratio increased relative to cover of shrubs/trees and focal nectar plant abundance and decreased relative to cover of groundlitter. Karner blue density increased with lupine $\mathrm{C}: \mathrm{N}$ ratio, decreased with nitrogen content, and was not related to phenolic levels. We strongly suggest that areas of different soil textures must be managed differently and that maintenance techniques should generate a mix of shrubs/tree cover (10-45\%), groundlitter cover $(\sim 10-40 \%)$, $>5 \%$ cover of lupine, and establish an abundance of focal nectar plants. This study provides unique tools for use in conservation and should aid in focusing management efforts and recovery of this species.
\end{abstract}




\section{Chapter 1: Introduction}

Understanding the habitat selection dynamics of a species is necessary for setting efficient and feasible recovery goals and management options for endangered species and their habitats. This involves isolating what factors influence species occurrence as well as density in complex landscapes (Rosin et al. 2011). This study evaluated habitat selection by the Karner blue butterfly (Lycaeides melissa samuelis Nabokov), or the Karner blue, in order to better understand the natural mechanisms driving Karner blue persistence and to develop tools best suited for management needs. This was conducted by reviewing the history of Karner blue conservation in Wisconsin and the tools currently used for management purposes; generating spatial-prediction models for identifying potential habitat, and evaluating habitat quality; evaluating relationships resulting from natural mineral-soil disturbance caused by American bison among Karner blue and host plant occupancy and distribution; and evaluating the effects of habitat quality on the Karner blue host plant, wild blue lupine (Lupinus perennis).

Butterflies provide a unique medium for the evaluation of habitat selection dynamics due to their specific preferences and great mobility. Butterfly species richness and density may be affected by connectivity of the landscape (Luoto and Kuussari 2002), the matrix between potential habitat (Ricketts 2001), and field size (Öckinger and Smith 2006; Steffan-Dewenter and Tscharntke 2000; Krauss et al. 2003). 
For example, specialist butterfly abundance generally increases with increasing habitat size due to increased resource availability. Butterfly species richness in grassland habitat patches is greater in landscapes dominated by grasslands (Öckinger and Smith 2006). Field-level barriers may be as simple as a hedge (Woiwod and Thomas 1993) while a $1 \mathrm{~km}$ forested area may not act as a barrier at all (Pauler-Fürste et al. 1996). Habitat quality, or patch quality, can promote or eliminate a species from an area, because host specialist (monophagous) species require specific resources (Dover and Settele 2009). Non-linear habitat, or patches, display high butterfly species richness and density due to the edge-effect of linear habitat (Clausen et al. 2001). At the same time, linear habitat is more likely to capture butterfly immigrants (Clausen et al. 2001). These factors differ significantly between butterfly species (Lindell and Maurer 2010; Dover and Settele 2009).

For overall species management at a landscape-scale, and to avoid creating sub-optimal habitat for associated species the field quality, size, connectivity, and the surrounding landscape matrix should also be considered (Dover and Settele 2009; Prugh et al. 2008; Mazerolle and Villard 1999). However, for any given species, high-quality patches are far more important determinants of population size than landscape connectivity or other factors (Lindell and Maurer 2010; Thomas et al. 2001).

The Karner blue is a species that appears to rely on a variety of landscape and fieldlevel habitat factors. Listed as federally endangered in 1992, this species has since 
become a flagship in conservation efforts across its range within the Great Lakes Region, and specifically in Wisconsin where the largest remnants of its native biological communities persist. These oak/pine barrens, savannas, and dry prairie communities once spanned across the Great Lakes to the eastern seaboard, and are reduced to $0.01 \%$ of their original habitat area (Pickens and Root 2008; Curtis 1959). These communities are established on the sandy, well-drained soils deposited by the most recent continental glacier retreat, $\sim 12,000$ years ago (Anderson et al 1999; McNab and Avers 1994). Habitat pockets historically ranged from small groves ( $<5$ ha) to large expanses of open forest (> $1000 \mathrm{ha})$.

The Karner blue and associated species are thought to have historically existed in patchy mosaics of closed- and open-canopy habitat resulting from constant, varying levels of disturbance (Schweitzer 1990). Historically these oak/pine dominated, opencanopy communities relied on restrictive edaphic and substrate conditions (Hutchinson et al. 1986; Whitford and Whitford 1971) insect infestations such as Jack-pine budworm (Radeloff et al. 2000), as well as herbivory, wind storms and especially natural fire disturbance (Schulte and Mladenoff 2005; Frelich 2002; Tyndall 1992) for their persistence on the landscape. The combination of disturbance mechanisms generated the sporadic, open-canopy cover characteristic today (Leitner et al. 1991; Chandler et al. 1983; Dorney 1981; Heinselman 1981; Vogl 1970, 1964; Curtis 1959). 
The activities of American bison (Bison bison) also played an important role in maintaining the open-canopy required by these grassland communities, browsing on vegetation, creating mineral-soil disturbance, and influencing the overall vegetation structure and composition (Fox et al. 2012; Trager et al. 2004; Knapp et al. 1999). The activities of these megaherbivores caused such large degrees of mineral-soil instability that a constant turnover of ruderal and perennial species resulted in the shifting mosaic of disturbance effects that barrens and savannas are known for today (Fox et al. 2012; Trager et al. 2004; Knapp et al. 1999).

Megaherbivore activities and fire, together, helped to generate the edaphic conditions, cycling of nutrients and the shifting mosaic landscape required for the persistence of these species-rich biological communities (Polley and Wallace 1986; Polley and Collins 1984). It is not known how significantly megaherbivore activities influence the distribution of Karner blue populations, or the distribution of lupine, though many butterfly species rely on grazing activities to maintain open-canopy complexes (Feber et al. 2001). The Karner blue butterfly relies on lupine, which in turn is reliant on constant disturbance (Swengel 1995). Both Karner blue abundance and wild blue lupine density increases in disturbed management units (Pickens 2006; Forrester et al. 2005; Smallidge et al. 1996; Smith et al. 2002). Further studies examining possible relationships could improve our understanding of the underlying ecological mechanisms and natural disturbance regimes that drive Karner blue persistence. This information could then be used to adjust and improve habitat maintenance techniques. 
Lupine serves as the Karner blue host plant and is ultimately the most limiting factor to Karner blue persistence. This species, similar to its primary biological community, requires disturbance (Swengel 1995; Boyonoski 2002). Lupine density increases in burned or otherwise managed units (Pickens 2006), and is abundant along powerline corridors (Forrester et al. 2005; Smallidge et al. 1996), within military establishments (Smith et al. 2002) and are often found along highway corridors. Though this plant grows more robustly in open areas, it also grows in areas of heavier canopy and vegetative cover (Pavlovic and Grundel 2009; Smith et al. 2002).

The Karner blue inhabits a variety of biological communities in which lupine distribution and abundance vary. Lupine can be limited in potential habitat areas by the competition of grasses, invasive species and especially high levels of canopy cover. Host plant quality is a growing area of importance in the evaluation of butterfly richness and abundance (Pickens and Root 2008). The quality of these plants is heavily influenced by surrounding habitat structure (Grundel et al. 1998a; Stanton 1982), which in turn influences overall butterfly populations. Insect larval food is allocated at a critical stage in development, and these resources determine the reserves that are later used for adult growth, development and reproduction (Sun and Ge 2011).

Lepidopterans, specifically, require a great deal of carbohydrates and nitrogen for growth and development (Boggs 2009), as well as carbon allocation for egg production 
(O’Brien et al. 2002; Pivnick and McNeil 1987). At the same time, defense compounds produced by plants to combat insect herbivory and pathogens can compete with and inhibit larval growth (Boggs 2009; Hwang et al. 2008; Bede et al. 2007). These defense compounds are stored as secondary metabolites within the plant systems. Overall, a suboptimal diet ingested at the larval stage, influenced by unfavorable habitat conditions, can seriously effect Lepidopteran populations (Boggs, 2009; Awmack and Leather 2002).

Soil nutrient levels (Weiss 1999; Hwang et al. 2008), and overall canopy cover influence the growth and biomass production of the host plant and consequently affect nutrient content (Sun and Ge 2011; Häring et al. 2006). Lupine grows more abundantly in open areas where larval foraging is higher, while Karner blue oviposition is greater in shaded areas (Grundel et al. 1998a; Grundel et al. 1998b). Lower nitrogen content in leaves is associated with greater foraging rates by larvae as well (Pickens and Root 2008). Greater overall lupine quality tends to be associated with cooler, more shaded areas. If these heterogeneous habitat factors, or within-patch variability, are known to affect Karner blue adult populations, these factors may also affect host plant quality, and consequently the host plant favorability of Karner blue populations. It is not known whether overall $\mathrm{C}: \mathrm{N}$ ratios or defense compounds such as tannins and phenolics affect Karner blue populations. If so, and if these factors are in fact influenced by habitat composition and structure, this information could be used to improve habitat overall. 
Many successful and groundbreaking management and monitoring efforts have been developed and implemented in an attempt to restore this species to the landscape. Conservation of this species began with the formation of the first state-wide habitat conservation plan, the Karner Blue Habitat Conservation Plan Partnership, in 1999. Since its formation nearly 500 similar plans have evolved across the nation. The Federal Recovery Program, formed in 2003, established recovery goals for all states within the Karner blue range, from Minnesota to the eastern seaboard. The Wisconsin State Recovery Program, formed in 2007, annually monitors trends in Karner blue populations, assesses habitat, and aids landowners and property managers in restoration efforts. These conservation efforts have evolved to include the combined efforts of private landowners and programs, county, state and federal properties, and citizen-based science groups and volunteers.

Several comparable management policies have been developed through these separate agencies, based on expert knowledge and scientific information available at the time. Most management is focused and implemented at a landscape-scale; however, this type of management is difficult due to changing dynamics involved at various interacting scales within the landscape. Successful detection, evaluation and subsequent visualization of habitat selection dynamics improve the overall success of these types of management efforts. Tools have been developed for evaluating Karner blue habitat and flight dynamics at the landscape-scale. A High Potential Range map was developed to identify potential habitat across the landscape. This tool is very effective for identifying 
regional areas that contain potential Karner blue habitat; however, the low resolution (400 m resolution) and lack of geographical details inhibits that ability to identify potential habitat at the field-level. A finer scale model could greatly improve the prediction of potential habitat at both large and small-scales.

The Emergence Model is a quantitative model that produces estimated dates of Karner blue emergence and flight peak during the first and second flights. This model is based on available degree dates from weather stations located across the Karner blue range in Wisconsin. This information is used to help estimate emergence when monitoring for the Karner blue, to determine when field-crews should move to field-sites to begin population estimates. Though this tool is effective and aids in population monitoring, it would be additionally useful to understanding where Karner blues are selecting habitat within field-sites to best focus monitoring efforts.

Multi-criteria risk modeling was developed for the purposes of overlaying multiple landscape-scale layers in an effort to produce maps that demonstrate levels of habitat quality favorable to a species in question, thereby predicting the likelihood of their occurrence (Jager and Overton 1993). Though these models were developed originally for invasive species, they can also be used in the evaluation of endangered species across different scales. Additionally they can be used to better understand species habitat selection, density, and movement. Advanced models such as these could be constructed through the use of high quality mediums such as remotely sensed data and 
in situ measurements, or through the use of expert knowledge in the absence of existing, high-quality digitally referenced data (Hess et al. 2013; Store and Kangas 2001).

Potential habitat for the Karner blue may exist, but remains unevaluated and underutilized. There is an innate need for the ability to scientifically and systematically assess general habitat of this species at a level which can increase understanding of underlying ecological mechanisms, aid in management at various scales, and be extrapolated across time and space. The objectives of this study include one review of past Karner blue conservation efforts and three scientific studies aimed at identifying and evaluating Karner blue habitat and Karner blue habitat selection. The first objective of this study was to review the history of Karner blue conservation in the state of Wisconsin and evaluate where additional tools may be developed to facilitate management. The second objective of this study was to develop and evaluate models across state properties and field-sites within Karner blue recovery areas, to predict Karner blue habitat, evaluate habitat suitability, and predict Karner blue distribution during the primary flight. The third objective of this study was to evaluate Karner blue and lupine locations relative to American bison locations to explore potential relationships. The fourth objective of this study was to relate lupine nutrient characteristics to habitat composition and structure characteristics, and to Karner blue distributions.

This comprehensive evaluation across the range of Wisconsin can provide a baseline of information for generating fine-resolution landscape-scale tools. This synthesis of the 
current state of knowledge on the mechanisms driving Karner blue persistence, as well as the development of fine-scale tools, seeks to generate a standard by which to identify potential habitat, evaluate habitat quality, and focus conservation efforts of these biological communities, leading to the eventual de-listing of this species.

\section{$\underline{\text { References }}$}

Anderson RC, Fralish JS, Baskin JM. 1999. Savannas, barrens, and rock outcrop plant communities of North America. Cambridge University Press, New York.

Awmack CS, Leather SR. 2002. Host plant quality and fecundity in herbivorous insects. Annual Review of Entomology. Vol. 47, pp. 817-844.

Bede JC, McNeil JN, Tobe SS. 2007. The role of neuropeptides in caterpillar nutritional ecology. Peptides. Vol. 28, pp. 185-196.

Boggs, CL. 2009. Understanding insect life histories and senescence through a resource allocation lens. Functional Ecology. Vol. 23, pp. 27-37.

Boyonoski AM. 1992. Factors affecting the establishment and maintenance of Lupinus perennis (wild lupine). M.S. Thesis. University of Guelph. Guelph, Ontario. 
Chandler C, Cheney P, Thomas P, Trabaud L, Williams D. 1983. Fire in Forestry. Vol. 1: Forest Fire Behavior and Effects. John Wiley \& Sons, New York, NY.

Clausen HD, Holbeck HB, Reddersen J. 2001. Factors influencing abundance of butterflies and burnet moths in the uncultivated habitats of organic farm in Denmark. Biological Conservation. Vol. 98, pp. 167-178.

Curtis JT.1959. The vegetation of Wisconsin. Madison, Wisconsin: University of Wisconsin Press.

Dorney JR. 1981. The impact of Native Americans on presettlement vegetation in southeastern Wisconsin. Wisconsin Academy of Sciences. Vol. 69. pp. 26-36.

Dover J, Settele J. 2009. The influences of landscape structure on butterfly distribution and movement: a review. Journal of Insect Conservation. Vol. 13, pp. 3-27.

Feber RE, Brereton TM, Warren MS, Oates M. 2001. The impacts of deer on woodland butterflies: the good, the bad and the complex. Forestry 74:273-276.

Forrester JA, Leopold DJ, Hafner SD. 2005. Maintaining critical habitat in a heavily managed landscape: effects of power line corridor management on Karner blue butterfly (Lycaeides melissa samuelis) habitat. Restoration Ecology. Vol. 13 (3), pp. 488-498. 
Fox TA, Hugenholtz CH, Bender D., and Gates C.C. 2012. Can bison play a role in conserving habitat for endangered sandhills species in Canada? Biodiversity and Conservation. Vol. 21. pp. 1441-1455.

Frelich LE. 2002. Forest dynamics and disturbance regimes: studies from temperate evergreen-deciduous forests. Cambridge University Press Cambridge, UK.

Grundel R, Pavlovic NB, Sulzman CL. 1998a. The effect of canopy cover and seasonal change on host plant quality for the endangered Karner blue butterfly (Lycaeides melissa samuelis). Oecologia. Vol. 114, pp. 243-250.

Grundel Ralph, Pavlovic NB, Sulzman CL. 1998b. Habitat use by the endangered Karner blue butterfly in oak woodlands: the influence of canopy cover. Biological Conservation. Vol. 85, pp. 47-53.

Häring DA, Suter D, Amrehein N, Lüscher A. 2007. Biomass allocation is an important determinant of the tanning concentration in growing plants. Annals of Botany. Vol. 99, pp. 111-120. 
Heinselman, ML. 1981. Fire intensity and frequency as factors in the distribution and structure of northern ecosystems. In Fire Regimes and Ecosystem Properties. U.S. Forest Service General Technical Report. WO-26. pp. 7-57.

Hess AN, Falkowski MJ, Webster CR, Storer AJ, Pocewicz A, Martinuzzi S. 2013. Employing lidar data to identify butterfly habitat characteristics of four contrasting butterfly species across a diverse landscape. Remote Sensing Letters. Vol. 4(4), pp. 354-363.

Hutchinson MD, Olson S, Vogt T. 1986. A survey of the barrens region in Massac and Pope counties, Illinois. Natural Land Institute, Belknap, Illinois. 63 pp.

Hwang SY, Liu CH, Shen TC. 2008. Effects of plant nutrient availability and host plant species on the performance of two Pieris butterflies (Lepidoptera: Pieridae).

Biochemical Systematics and Ecology. Vol. 36, pp. 505-513.

Jager HI. Overton WS. 1993. Explanatory models for ecological response surfaces. Chapter 42, pp. 422-437. In: Environmental Monitoring with GIS. Oxford University Press, New York. 
Knapp, AK, Blair JM, Briggs JM, Collins SL, Hartnett DC, Johnson LC, Towne EG. 1999. The keystone role of bison in North American tallgrass prairie. BioScience. Vol. 49(1). pp. 39-50.

Krauss J, Steffan-Dewenter I, Tscharntke T. 2003. How does landscape context contribute to effects of habitat fragmentation on diversity and population density of butterflies? Journal of Biogeography. Vol. 30, pp. 889-900.

Leitner LA, Dunn CP, Guntenspergen GR, Stearns F, Sharpe DM. 1991. Effects of site, landscape features, and fire regime on vegetation patterns in presettlement southern Wisconsin. Landscape ecology. Vol. 5(4). pp. 203-217.

Lindell CA, Maurer BA. 2010. Patch quality and landscape connectivity effects on patch population size: implications for metapopulation size and studies of landscape value. Evolutionary Ecology Research. Vol. 12, pp. 249-258.

Luoto M, Kuussaari M. 2002. Modeling butterfly distribution based on remote sensing data. Journal of Biogeography. Vol. 29, pp. 1027-1037.

Mazerolle MJ, Villard ma. 1999. Patch characteristics and landscape context as predictors of species presence and abundance: a review. Ecoscience. Vol. 6 (1), pp. 117124. 
McNab HW, Avers PE. 1994. Ecological subregions of the United States: section descriptions. United States Department of Agriculture: Forest Service, Ecosystem Management. Washington, D.C.

O’Brien DM, Fogel ML, Boggs CL. 2002. Renewable and nonrenewable resources: amino acid turnover and allocation to reproduction in Lepidoptera. Proceedings of the National Academy of Sciences of the United States of America. Vol. 99, pp. 4413-4418.

Öckinger E, Smith HG. 2006. Landscape composition and habitat area affects butterfly species richness in semi-natural grasslands. Oecologia. Vol. 149, pp. 526-534.

Pavlovic NB, Grundel R. 2009. Reintroduction of wild lupine (Lupinus perennis L.) Depends on variations in canopy, vegetation, and litter cover. Restoration ecology. Vol. 17(6), pp. 807-817.

Pauler-Fürste R, Kaule G, Settele J. 1996. Aspects of the population vulnerability of the large blue butterfly, Glaucopsyche (Maculinea) arion, in south-west Germany. In: Settele J, Margules C, Poschlod P, Henle K (eds). Species survival in fragmented landscapes. Kluwer, Dordrecht, pp. 275-281. 
Pickens BA, Root KV. 2008. Factors affecting host-plant quality and nectar use for the Karner blue butterfly: implications for oak savanna restoration. Natural Areas Journal. Vol. 28(3), pp. 210-217.

Pickens BA. 2006. The consequences of a management strategy for the endangered Karner blue butterfly. M.S. Dissertation. Bowling Green State University, Bowling Green, OH, USA.

Pivnick KA, McNeil JN. 1987. Puddling in butterflies: sodium affects reproductive success in Thymelicus lineola. Physiological Entomology. Vol. 12, pp. 461-472.

Polley HW and Wallace LL. 1986. The relationship of plant species heterogeneity to soil variation in bison wallows. The Southerwestern Naturalist. Vol. 31(4). pp. 493-501.

Polley HW and Collins SL. 1984. Relationships of vegetation and environment in bison wallows. American Midland Naturalist. Vol. 112(1). pp. 178-186.

Prugh LR, Hodges KE, Sinclair ARE, Brashares JS. 2008. Effect of habitat area and isolation on fragmented animal populations. PNAS 105:20770-20775. 
Radeloff VC, Mladenoff DJ, Boyce MS. 2000. The changing relation of landscape patterns and jack pine budworm populations during an outbreak. Oikos. Vol. 90(3). pp. $417-430$.

Ricketts TH. 2001. The matrix matters: effective isolation in fragmented landscapes. The American Naturalist. Vol. 158, pp. 87-99.

Rosin ZM, Skórka P, Lenda M, Moroń D, Spark TH, Tryjanowski P. 2011. Increasing patch area, proximity of human settlement and larval food plants positively affect the occurrence and local population size of the habitat specialist butterfly Polyommatus coridon (Lepidoptera: Lycaenidae) in fragmented landscapes. European Journal of Entomology. Vol. 108, pp. 99-106.

Schulte LA, Mladenoff DJ. 2005. Severe wind and fire regimes in northern forests: historical variability at the regional scale. Ecology. Vol. 86(2). pp. 431-445.

Schweitzer DF. 1990. The 1990 status of selected Karner blue remnants in Saratoga and Albany counties, New York with a discussion of monitoring methods. Unpublished Report. New York Department of Environmental Conservation, Endangered Species Unit. 
Smallidge PJ, Leopold DJ, Allen CM. 1996. Community characteristics and vegetation management of Karner blue butterfly (Lycaeides melissa samuelis) habitats on rightsof-way in East-Central New York, USA. The Journal of Applied Ecology. Vol. 33 (6), pp. 1405-1419.

Smith MA, Turner MG, Rusch DH. 2002. The effect of military training activity on eastern lupine and the Karner blue butterfly at Fort McCoy, Wisconsin, USA. Environmental Management. Vol. 29 (1), pp. 102-115.

Stanton ML. 1982. Searching in a patchy environment: foodplant selection by Colias $P$. eriphyle butterflies. Ecology. Vol. 63, pp. 839-853.

Steffan-Dewenter I, Tscharntke T. 2000. Butterfly community structure in fragmented habitat. Ecology Letters. Vol. 3, pp. 449-456.

Store R, Kangas J. 2001. Integrating spatial multi-criteria evaluation and expert knowledge for GIS-based habitat suitability modeling. Landscape Urban Planning. Vol. 55, pp. 79-93.

Swengel AB. 1995. Observations of spring larvae of Lycaeides melissa samuelis (Lepidoptera: Lycaenidae) in central Wisconsin. The Great Lakes Entomologist. Vol. 28 (2), pp. 155-170. 
Sun Y, Ge F. 2011. How do aphids respond to elevation $\mathrm{C}^{2}$ ? Journal of Asia-Pacific Entomology. Vol. 14, pp. 217-220.

Thomas JA, Bourn NAD, Clark RT, Stewart KE, Simcoz DJ, Pearman GS, Curtis R, Goodger B. 2001. The quality and isolation of habitat patches both determine where butterflies persist in fragmented landscapes. Proceedings of the Royal Society B: Biological Sciences. Vol. 268, pp. 1791-1796.

Trager MD, Wilson GWT, Hartnett DC. 2004. Concurrent effects of fire regime, grazing and bison wallowing on tallgrass prairie vegetation. American Midland Naturalist. Vol. 152(2). pp. 237-247.

Tyndall RW. 1992. Historical considerations of conifer expansion in Maryland serpentine barrens. Castanea. Vol. 57. pp. 123-131.

Vogl RJ. 1970. Fire and the northern Wisconsin pine barrens. Proceedings of the Annual Tall Timbers Fire Ecology Conference. Vol. 10. pp. 175-209.

Vogl RJ. 1964. Vegetational history of Crex Meadows, a prairie savanna in northwestern Wisconsin. The American Midland Naturalist. Vol. 72(1). pp. 157-175. 
Weiss SB. 1999. Cars, cows, and checkerspot butterflies: nitrogen deposition and management of nutrient-poor grasslands for a threatened species. Conservation Biology. Vol. 13(6), pp. 1476-1486.

Whitford PB, Whitford K. 1971. Savanna in central Wisconsin, USA. Vegetatio. Vol. 23. pp. $77-88$.

Woiwod I, Thomas JA. 1993. The ecology of butterflies and moths at the landscape scale. In: Haines-Young R (ed). Landscape Ecology in Britain. IALE(UK), Preston, pp. $76-92$. 


\section{Chapter 2: Karner Blue Butterfly Habitat Conservation in Wisconsin: A Brief Overview of Historical, Current, and Developing Management.}

\section{$\underline{\text { Abstract }}$}

The federally endangered Karner blue butterfly (Lycaeides melissa samuelis Nabokov) has become a focus for species and habitat conservation and restoration in Wisconsin, where the majority of the remaining globally imperiled oak/pine grassland communities persists. Recovery and conservation efforts for the species began in 1992 when the species was proposed for listing. A large scale conservation and management effort began in 1999 with the implementation of the Wisconsin Statewide Habitat Conservation Plan. The U.S. Fish and Wildlife Service (FWS) published a technical/agency draft recovery plan in 2001 and a final recovery plan for the Karner blue butterfly in 2003. The Wisconsin Statewide Recovery Program began in earnest in 2007. Conservation of this species has evolved to include Federal properties stateowned properties, public agencies and private landowners, as well as significant volunteer efforts. Since the foundation of these conservation and recovery programs, management has been focused at a landscape-scale. Existing remote sensing tools at this scale utilize low resolutions for identifying potential habitat, and there remains a need for high resolution tools capable of crossing the barrier between landscape and fieldlevel analysis. Multiple monitoring techniques have been developed to track and better understand the Karner blue and its habitat. Developing standardized tools for more effectively and efficiently understanding Karner blue habitat selection, identifying specific sites, evaluating habitat quality, and monitoring Karner blue populations will 
help to focus management and recovery efforts and may accelerate the reclassification (from endangered to threatened) and subsequent delisting of this species.

\section{Oak/Pine Grassland Communities and the Karner Blue Butterfly}

\section{Grassland Communities}

Oak/pine barrens, savanna and dry prairie communities were once a dominant feature on the landscape of the Great Lakes Region, but have greatly decreased in number and integrity throughout North America over the past 150 years (Anderson et al. 1999; Nuzzo 1986). While terms for variants of these communities include woodland, barrens, sand savanna, scrub oak savanna and brush prairie (Anderson et al. 1999) among others, they will be referred to as oak/pine grassland communities here.

In Wisconsin variants of oak/pine grassland communities occur along what is referred to as the 'tension zone' that approximately follows the southernmost advance of the last glacial period, and which is defined by the distributional boundary of plant species (Curtis 1959). North of the tension zone is a region of mixed conifer-hardwood vegetation with cool summers and long winters. South of the tension zone is an area of hardwood vegetation and warmer, drier summers with sporadic snow cover in winter (Anderson et al. 1999). Subsequently these communities are associated with lownutrient, drought-prone lacustrine sandy soils resulting from glacial moraines, dune systems located near glacial margins, outwash plains, and sandy glacial lake beds 
(Anderson et al. 1999; McNab and Avers 1994). All oak/pine barrens grassland communities are characterized by varying gradients of scattered oak and jack pine, grasses, shrubs and forbs (WDNR 2001). Today only scattered remnants occur, succeeding to closed-canopy oak woodland (Auclair 1976). Habitat loss and fragmentation through development and forest succession remain the greatest threat to these biological communities (KBBRT 2003). Though once spanning from Minnesota to Maine, today only $0.01 \%$ of these original estimated oak/pine grassland communities persist (Pickens and Root 2008) most of which remains in the state of Wisconsin (approximately 0.02 million ha of an originally estimated 1.7 million ha) (Mossman et al. 1991; Curtis 1959). Oak/pine grassland communities are now among the most threatened ecosystems in North America, and are classified by the Wisconsin Department of Natural Resources as natural communities of great conservation need due to association with threatened and endangered vertebrates (WDNR 2005; King 2003; Breining 1993). Over 50 species of concern and state and federally endangered and threatened species are associated with oak/pine barrens and savanna.

\section{Karner Blue Morphology, Behavior and Habitat Selection}

The Karner blue butterfly (Lycaeides melissa samuelis Nabokov) serves as a flagship species in oak/pine grassland community management and restoration, and can draw public support and aid to a host of species (Guiney and Oberhauser 2008). It is estimated that this species has declined in numbers by 99\% (FWS 1992) as habitat has 
been severely depleted (Figure 2.1). Threats to the species (including habitat loss and fragmentation) and the small and/or declining number of sites range-wide warranted listing of the Karner blue in 1992 as endangered under the protection of the Federal Endangered Species Act, as amended in 1973 (ESA) (FWS 1992). Historically the Karner blue occurred in 12 states and at several sites in the province of Ontario, Canada (FWS 2003). Currently it is likely extant in only six states (New Hampshire, New York, Ohio, Indiana, Michigan, and Wisconsin); Minnesota has likely lost its Karner blues and the Indiana population is at a high risk of extinction; Karner blues are extinct in Ontario (Cathy Carnes, FWS, pers. comm., 2013). Due to these factors, conservation of Karner blues is considered a critical concern in the state of Wisconsin (WDNR 2005; MacNab and Avers 1994).

The Karner blue is a small blue butterfly with a wingspan between 2.2 and $3.2 \mathrm{~cm}$ (Opler and Krizek 1984; Scudder 1889; FWS 1992) (Figure 2.2). Males display a light blue on the upper (dorsal) side of the wings, which also have a black margin and white fringe, The females upper wings range from dull blue to bright purplish blue near the body and central portions of the wings, and the remainder of the wing is a light or dark gray-brown with marginal orange crescents typically restricted to the hind wing. On both sexes, the bottom (ventral) side of the wings is a grayish fawn color and orange crescents are present near the margins of both the hind and forewings (FWS 2003). The Karner blue requires nectar sources for adults, and wild blue lupine (Lupinus perennis) for larvae feeding. 
The Karner blue lifecycle is bivoltine, producing two generations, or broods, each year (Figure 2.3). The second brood overwinters as an egg (Peterson et al. 2006; Swengel and Swengel 2005). Eggs generally hatch about mid-April. First brood of adults generally emerge in late May, lay eggs, and die about mid-to-late June, while the second adult brood emerges early to mid-July, hatching from eggs laid by the first brood, and continues through mid-to-late August.

The Karner blue is dependent on wild lupine, a long-lived perennial legume (Boyonoski 1992; Grigore 1992; Grundel et al.1998) that ranges from Minnesota to Maine, and south along the Atlantic seaboard to the Gulf of Mexico. Lupine normally begins to grow in late March or early April, flowering in May and June, seeding by mid-July, and senescing during late July and August (Dirig 1973; Grigore 1992). In some seasons the lupine will senesce before the second, or primary, Karner blue flight begins, depriving developing larvae of their food source and contributing to Karner blue mortality. Lupine is a disturbance-adapted species occurring in sites that are historically maintained by fire, and grows best in a mosaic of sun and shade (Leach 1993). Karner blue populations most likely existed historically as shifting metapopulations that increased and declined as lupine recolonized areas with recurring disturbance. However, due to decades of effective fire suppression and canopy succession, lupine is not as common as it once was (Shuey 1997). 
Although Karner blue larvae are dependent on lupine, it does not serve as a favored nectar plant for adults (Leach 1993), and is generally not flowering during the secondgeneration flight. The Karner blue is not heavily dependent on a particular suite of nectar plants (FWS 2003), but does exhibit selectivity of nectar plants when options are available, preferring plants with white or yellow flowers (Grundel and Pavlovic 2000) (FWS 2012).

The Karner blues inhabit many types of oak/pine grassland communities (Shuey 1997), including oak/pine grassland remnants, dune complexes, rights-of-way, roadsides, sand pits, trails, fallow fields, and some forest lands (FWS 2003; Martin 1992; Bess 1989). Despite this versatility, the Karner blue has declined significantly across its range.

\section{Development of Karner Blue Conservation Efforts}

When the Karner blue was federally-listed in 1992 federal permits were required to authorize "take" of the Karner blue. Section 9 of the ESA defines "take" as harassing, harming, pursuing, hunting, shooting, wounding, killing, trapping, capturing, or collecting a species. Thus permits are required when managing Karner blue sites, as implementation of management actions (e.g., prescribed burns, herbiciding, mowing) may kill or harm various life stages of the butterfly. Permits issued for management activities required land managers with known Karner blue populations to follow management prescriptions (permit conditions) in order to ensure survival and recovery 
of the species. Surveys for the presence/absence of Karner blues became necessary to determine if the butterfly was present and a permit would be needed to conduct activities within occupied Karner blue habitat. Given the complexity that began to surround the Karner blue and its habitat, several agencies were formed to mitigate take and implement restoration efforts. Figure 2.4 provides a timeline of resulting management events.

\section{Habitat Conservation Plan Partnership}

In 1999, the Wisconsin Department of Natural Resources (WDNR) completed and began to implement the Wisconsin statewide Karner Blue Butterfly Habitat Conservation Plan (HCP) (WDNR 2000). The initial 10 year HCP was extended an additional 10 years in 2010 (WDNR 2010b). Development of the HCP was necessary to obtain an incidental take permit that would allow the HCP partners (industrial and county forestry operations, utility rights-of-way owners/managers, WDNR, Wisconsin Departments of Transportation and Agriculture and other landowners or managers) to conduct otherwise illegal land management operations on sites occupied by the KBB. The WDNR is a major HCP partner and administers the HCP under the FWS incidental take permit \# TE0100064-4 (ITP) and its Implementing Agreement with the FWS.

The HCP has grown from 26 partners in 1999 to 42 partners today (2013). This partnership program allows landowners and organizations to participate as full or 
limited partners. Each HCP partner operates under the terms of a Species and Habitat Conservation Agreement a contractual agreement with the WDNR and must comply with the conservation measures in the HCP and permit.

The HCP also provides blanket permit coverage for landowners in what is termed the "Voluntary Group;" the landowners in this group are encouraged, but can choose not to, conserve the Karner blue. Landowners in the "Voluntary Group" include small private landowners, NGOs, non-commercial forestry and agriculture. The "Voluntary Group" is supported by the concept that more conservation will be realized by landowners in this group if conservation is voluntary rather than mandatory, and by the large HCP partner acreage where conservation and recovery for the KBB occurs.

The HCP partnership helps to conserve the Karner blue butterfly by complying with the conservation measures in the HCP while conducting management actions in occupied species habitat. Conservation measures include surveying for the Karner blue butterfly to determine its presence. On state Karner blue recovery properties, the WDNR is helping to recover the species via habitat management and creation, and habitat and KBB population monitoring.

HCP Partnership maintains Karner blue habitat across the Wisconsin range by avoiding or minimizing "take," by mitigating for permanent take, and by managing the landscape to provide continued suitable habitat for the Karner blue over time by complying with 
HCP management guidelines and protocols. The partners implement a formal method of monitoring (presence/absence monitoring for Karner blues), and provide information regarding new lupine and Karner blue sites in their annual reports (WDNR 2007). The goal of the HCP is "no net loss of habitat". The HCP follows a five-point plan established in 2006: 1) focus HCP implementation on lands near recovery areas 2) streamline processes and redirect resources, 3) improve protocols and guidelines (i.e. monitoring and management of protocols and guidelines), 4) support and assist the recovery effort of the Karner blue in Wisconsin, and 5) extend the term of the ITP (which was done in 2010).

In 2007 the HCP was re-assessed and guidelines and protocols were checked for consistency and integrated into a HCP web-based training module (WDNR 2007). In some cases, new or modified management protocols and guidelines were established generating parameters for landscape vs. metapopulation and land definitions (e.g. management site vs. population site) that allow for management discretion among land managers related to specific ecosystem characteristics (WDNR 2007).

\section{Federal Recovery Program}

Concurrent with the development and implementation of the HCP, a Technical/Agency Draft KBB Recovery Plan was developed (FWS 2001) and a Final recovery plan for the species completed in 2003 (FWS 2003). The recovery program seeks to perpetuate 
viable metapopulations of the Karner blue throughout its range, in order to allow reclassification and ultimately remove the species from the federal listing of "endangered and threatened wildlife and plants". The Karner blue may be considered for reclassification and ultimate delisting when the recovery criteria are met, which is estimated to take at least 20 years, until about 2023.

The Federal recovery plan outlines specific criteria that need to be met in order to reclassify the Karner blue from endangered to threatened and to delist the species (FWS 2003). These criteria require the establishment of viable metapopulations (VPs) and/or large viable metapopulations (LPs) in 13 recovery units across the Karner blue range in the United States. The criteria describe what characteristics each VP and LP should have (e.g. a management and monitoring plan, sufficient number of Karner blue individuals, and connectivity between subpopulations). Reclassification criteria will be satisfied when 27 metapopulations (e.g., containing 19 viable metapopulations with 3,000 butterflies each and 8 large metapopulations with 6,000 butterflies each) are established within at least 13 recovery units and are managed consistently following recovery criteria. Complete delisting will be considered when at least 29 metapopulations (e.g., 13 viable and 16 large viable metapopulations) are established within at least 13 recovery units and are managed consistently following recovery criteria. 
The Stepdown Recovery Outline identifies the following activities necessary to recover the species: 1) protect and manage the Karner blue and associated habitat to perpetuate viable metapopulations 2) evaluate and implement translocation where and when appropriate, 3 ) develop range-wide and regional management guidelines, 4) develop and implement information and educational programs, 5) collect ecological data regarding the Karner blue and associated habitat, and 6) review and track recovery progress that the Federal recovery plan also identifies for each of the recovery sites (metapopulations) (FWS 2003).

\section{Wisconsin Statewide Recovery Program}

In 2007 the state-wide Wisconsin Karner Blue Recovery Program was developed to help recover viable metapopulations of the Karner blue on state recovery properties in Wisconsin as identified in WDNR's HCP Conservation Agreement, and on potentially additional properties with good Karner blue populations. Wisconsin bears the heaviest burden of recovery within the nation because it encompasses most of the remaining Karner blue habitat across the range. As a result, Wisconsin is responsible for 5 of the 13 nationwide recovery units, within which both state and county properties are assigned specific viable and large viable metapopulation goals and requirements.

This program conducts Karner blue population monitoring, conducts habitat management restoration with landowners and property managers, and procures funding 
for habitat restoration efforts. The Wisconsin recovery effort relies on contracted scientific survey groups and volunteer assistance to achieve monitoring activities. These activities include making initial contact with property owners and managers and filing periodic reports to the Wisconsin DNR, federal recovery program, and the statewide HCP (WDNR 2007). State property planning is conducted with the help of the DNR land manager, DNR's master planning staff and the WI Recovery Coordinator and includes measures to recover viable metapopulations of KBBs on state recovery properties

Four of the five original recovery units are managed and monitored for Karner blue's throughout the state of Wisconsin. The number of sites where recovery activities occur has grown from 33 sites on 9 recovery properties, in 2008 to 54 sites on 11 recovery properties, as well as 3 private landowners, in 2013. The Federal recovery plan identifies five recovery units in Wisconsin within which viable metapopulations of Karner blues are to be restored. The recovery units were established to preserve possible geographically associated genetic variation and to buffer against large-scale stochastic variation, such as regional variation in weather or catastrophic disturbance, by providing an adequate number of widely dispersed metapopulation in a wide range of habitat types (FWS 2003). Data collected in recovery units is used to fulfill the requirements of the Federal Karner Blue and HCP programs (i.e. reporting estimated populations and documenting all management and restoration efforts), as well as to adjust management techniques (i.e. adjust management intensity). 
In 2010, the Wisconsin Karner Blue Recovery Program organized a joint meeting of all major participants in Wisconsin Karner blue conservation and lead a comprehensive review of the two conservation programs in Wisconsin. This was done in order to assess the efficacy of current management activities and protocols. This review concluded that the progression of conservation activities up to this point were adequate to maintain habitat, but were not pro-active enough to achieve complete recovery of the species. More quantified habitat information was necessary in order to effectively promote habitat sites for Karner blue habitat and occupancy. In addition, it was apparent that there were many differences between management approaches that had not been compared or analyzed regarding the effect on Karner blue habitat.

The Wisconsin recovery program organized a collaborative research effort with several universities to quantify habitat information across the range, develop a better understanding of Karner blue habitat selection, and develop tools to utilize in conservation efforts. The original project format included the inclusion of climate data to assess how Karner blue butterflies could possibly shift across the landscape with various climate change scenarios, generating a climate-shift model that focused on habitat projection and development. However, due to a lack of funding the project was scaled back to not include climate information. 


\section{Development of Management Policies}

Numerous Karner blue habitat conditions exist in Wisconsin that requires various resource management strategies. Management strategies have developed and evolved since listing of the Karner blue in 1992 and implementation of the HCP (1999) and recovery plan (2003). Karner blues are known to rely on a disturbance-dependent community, and therefore depend on management activities that replicate a steady natural disturbance regime (WDNR 2007). Traditional management of grasslands, such as with prescribed fire, mowing, grazing, and mechanical and chemical applications (Borth 1997; Swengel 1998) have been utilized, adjusted and sometimes discarded.

In 1998, the WDNR completed the Wildlife Management Guidelines for the Karner Blue Butterfly (KBBRT 1998), based on efforts by the Karner Blue Butterfly Technical Team (KBTT). The guidelines included recommending that a management and monitoring plan be established for each metapopulation. This plan would include: 1) monitoring populations, 2) buffering of habitat, 3) maintaining heterogeneous habitat, and 4) establishing management responses for potential Karner blue population decline. Requirements also included circumventing any management treatment that would likely have an adverse impact to Karner blues within the time-frame of two or fewer consecutive generations, as well as separating Karner blue habitat into separate management units to allow for effective reoccupation from adjacent untreated areas 
(WDNR 1998; Lane 1997). The later strategy is termed a "shifting mosaic" management strategy.

Management practices required accounting for the size of the Karner blue population. proximity to other populations, size and context of associated habitat (e.g. habitat surroundings, habitat diversity potential, etc.) $t$, and the potential of the overall site and biodiversity implications such as impacts on rare species. Successful management must also address cost, equipment and personnel availability, landowner's short and longterm objectives, and expected benefits to habitat structure and composition (WDNR 1998).

To implement these guidelines, a variety of management tools and techniques were developed to promote habitat diversity and connectivity within fragmented management units (KBBRT 1998) across different spatial scales. Original management sought to achieve a shifting mosaic of closed and open-canopy habitat and corridors that were essential for maintaining large viable Karner blue populations. This included the use of mechanical and/or chemical management in small sites (i.e. $<5$ acres), with low observed numbers of Karner blues (i.e. $<25$ adults during peak summer flight), with site expansion prior to treatments.

Initial recommendations also included landscape-scale management of metapopulation regimes, including establishing sites that are $0.25 \mathrm{~h}$ or greater in size with 3 to 5 local 
subpopulations of Karner blues. Large viable metapopulations would contain about 260 ha (about 640 acres) of habitat distributed over an about 10 square mile area (FWS 2003). Connectivity between large sites was suggested to be no more than $2 \mathrm{~km}$, and preferably $200 \mathrm{~m}$ (KBBRT 1998). The KBB recovery plan recommends that connectivity between subpopulations be such that the average nearest-neighbor distance between subpopulations is no more than 1 kilometer ( 0.62 miles), and the maximum distance between subpopulations is no greater than 2 kilometers (1.24 miles). Viable metapopulations were suggested to contain at least 3000 adults in the second brood, with 300-600 adults per subpopulation, while large viable metapopulations were suggested to contain at least 6000 adults in the second broods at least 4 of out 5 years (FWS 2003; KBBRT 1998). In all years, a minimum of 1500 adults is required in the first or second brood (FWS 2003).

While many of the recommendations noted above are consistent with the KBB recovery plan (FWS 2003), refer to the recovery plan for further information and discussion on the recommended composition and structure of viable Karner blue metapopulations, especially Appendix E (Spatial Structure of a Minimum Viable Metapopulation), Appendix F (Large Viable Metapopulations), and Appendix G (Management Guidelines).

The Karner blue recovery plan (FWS 2003) identifies 5 landscape-scale recovery units within Wisconsin (refer to Wisconsin Statewide Recovery Program, above). Survey 
sites were established on recovery sites within these recovery units in 2007 , based on HCP monitoring records and knowledge of the WDNR staff members involved in Karner blue recovery work (Hess and Schuurman 2009a). The resulting survey and management sites for Karner blues were based on soil type, historic Karner blue observations and habitat suitability. These sites exist as discrete patches of $<200$ acres, but are more often $<50$ acres (Hess and Schuurman 2009a), due to fragmentation.

\section{Development of Methodologies}

\section{Landscape assessments}

Due to the relative difficulty of surveying an entire landscape, the WDNR explored the development of several statistical and Geographic Information Systems (GIS) models to determine the presence of Karner blues on the landscape.

The High Potential Range Map (HPR), developed by Sickley in 1998, predicts the occurrence of lupine, the Karner blue host plant (WDNR 2007). This model, at $400 \mathrm{~m}$ resolution, is extremely effective in identifying broad-scale potential habitat across the state. This model is used by the HCP for management purposes: any activities that fall within the HPR are required to follow the HCP monitoring guidelines, which includes surveying for lupine. This model eventually became a Karner blue occurrence predictor, and has been continually upgraded and improved with the aid of University of Wisconsin-Madison, Department of Landscape Ecology. 
The Karner Blue Probability Model developed in 2004-2006 was used by the Landscape Ecology Lab to adjust the Karner Blue High Potential Range (HPR) (WDNR 2007), eliminating unoccupied potential habitat that lies more than 10 miles from a documented Karner blue elemental occurrence. The HPR is intended to be updated at five year intervals to include new information on Karner blue locations. The WDNR Division of Forestry continued support of GIS based recovery research, including using the Karner Blue Probability Model to develop phase-1 Biological Recovery Zones, and a Karner Blue Emergence Model for Distance Sampling, which was implemented in 2008. The newly adjusted HPR and the Biological Recovery Zones provided a more efficient focus for HCP implementation efforts. The HCP then shifted focus in 2007 from random effectiveness monitoring using relative abundance indices to more efficient population estimates on identified long-term recovery sites (as coordinated by the Karner Blue Recovery Program). However, the capability to identify specific sites and evaluate habitat quality for the development of comprehensive management schemes across the landscape remains undeveloped.

\section{Population Estimates}

The critical establishment of standardized Karner blue monitoring was developed early in 2008 with the assistance of the FWS and the U.S. Geological Survey. The HCP identified the Distance sampling method (Buckland et al. 2004) as an appropriate 
method for statewide comprehensive Karner blue surveys. USGS staff conducted workshops to teach DNR staff from multiple states how to apply Distance sampling techniques to monitoring programs for the Karner blue.

The first of these comprehensive sampling efforts was conducted on WDNR recovery properties in 2008 using Distance sampling techniques. Population monitoring is now conducted annually by the state-wide Wisconsin Karner Blue Butterfly Recovery Program through the WDNR Bureau of Endangered Resources (BER) (WDNR 2007) with funding assistance from the FWS.

The statewide recovery program developed and established survey designs for each site using parallel sampling transects or random transects that are permanently established and flagged as needed for comparable annual surveys. Due to the varying levels of Karner blue populations per field-site, three types of monitoring are conducted to measure inter-annual Karner blue populations and inter-site variability:

presence/absence, relative abundance based on a modified Pollard's-Yate survey (known as the Level 2+ survey), and the intensive Distance sampling method (WDNR 2010a).

KBB presence/absence surveys are conducted 3 times during the flight season (with at least 2 of the surveys conducted during second flight). This method is conducted at any sites where Karner blues are not known to be present, or where populations are 
extremely low and/or management efforts require continually checking the status of the population. The latter two surveys (Level $2+$ and Distance) are conducted a minimum of three times to establish a significantly accurate population estimate. These two methods are conducted on permanent transects established along the longitudinal axis of a field with a random starting point, at 30,60 , or $90 \mathrm{~m}$ spacing dependent upon the size of the field (generally, fields $<15$ ha require $30 \mathrm{~m}$ spacing, while fields $>15$ ha require $60+\mathrm{m}$ spacing).

Level 2+ relative abundance surveys are conducted at fields with small Karner blue populations ( $<80$ Karner blues counted across all surveys) for the purposes of lowerintensity abundance surveys of lower density Karner blue populations. This method helps to assess whether ongoing habitat restoration and management techniques are "generating substantial improvements in Karner blue abundances", or if Karner blue abundance is declining over time (Hess and Schuurman 2009a). Originally this survey method was conducted once, but has evolved to three surveys over the course of a flight starting within one week of flight emergence. The method utilizes a 2.25 un-demarcated pole and establishes a relative encounter rate based on transects with a fixed width (Hess and Schuurman 2009a).

Distance sampling is conducted only at sites with larger populations ( $>80$ Karner blues counted across all surveys) (Hess and Schuurman 2009a). This method is conducted every 7 days from the beginning to the end of the flight (up to 5 weeks). A demarcated 
pole is used to determine the distance from the observer to the Karner blue, at intervals: 0-0. m, 0.5-1.0m 1.0-1.5m 1.5-2.25m 2.25-3.0m, 3.0-4.0m, and 4.0-5.0m (Figure 2.5). Numbers from transects are totaled and used to generate encounter rates, confidence limits and population estimates for each field (Figure 2.6). Distance sampling and Level $2+$ encounter rates are comparable at $2.25 \mathrm{~m}$.

The HCP survey protocols utilizes a similar method of initial surveys, including: the level 1 lupine presence/absence survey, the level 2 Karner blue presence/absence survey, and the level 3 Karner blue relative abundance survey. A Level 1 survey (lupine survey) is used to determine the abundance of lupine at a site. If lupine is found in sufficient abundance, the observer conducts a Level 2 (Karner blue) survey that establishes presence/absence of KBB only. Information collected during the Karner blue survey includes weather and habitat characteristics, and specific information on the location of the Karner blue and its habitat at the site.

\section{Habitat Assessments}

Habitat assessments (nectar plant and canopy cover visual evaluations) are conducted to assess field-site characteristics. To date no standardized format of habitat assessments has been established between agencies. The statewide recovery program performs habitat assessments that are conducted every five years, or during the second growing season after a restoration project. These are conducted in order to gain information on 
vegetative composition and structure (including lupine, nectar plants, and threats such as invasive species). The assessment method used assesses vegetation within $2.25 \mathrm{~m}$ to either side of the observer, as measured with any pole or stick that is $2.25 \mathrm{~m}$ in length (Hess and Schuurman 2009b). Habitat assessments are conducted along a series of parallel transects identical to the methods described for population estimates. Habitat assessments include noting the abundance of 17 focal nectar plants and 11 invasive species. The survey also assesses other nectar plants according to abundant/common/scarce, canopy cover, and other impressionable features of the site (Hess and Schuurman 2009b).

The HCP lupine and Karner blue survey protocols include habitat assessment. The Level 1 Lupine Presence/Absence survey protocol includes identifying lupine presence, as well as the distribution, number of plants and relative abundance of plants. It also identifies any negative factors (or threats) such as mildew on lupine, browsing and agricultural sprays, and assesses additional associated vegetation. Associated vegetation observations include documenting the relative abundance (abundant/common/scarce) of commonly associated nectar plants during the first and second Karner blue flights. This survey also records information regarding nectar plant seeding and mitigation (WDNR 2007). The Level 2 Karner blue butterfly Presence/Absence survey also assesses the relative abundance of commonly associated nectar plants during the first and second Karner blue flights, in addition to weather conditions at the time of the survey, and any Karner blues observed (WDNR 2007). 


\section{Conclusions: Habitat Management and Monitoring Needs}

The constantly evolving process of Karner blue management has acted as a catalyst for the development of many landscape-scale monitoring and management strategies, many of which are highly effective, others inadequate, and some redundant. Since listing of the Karner blue in 1992, conservation and recovery efforts in Wisconsin have evolved to include Federal recovery efforts (Necedah National Wildlife Refuge, Fort McCoy, Air National Guard Hardwood Range), HCP partners (industrial and county forests, utilities, WDNR, Wisconsin Departments of Transportation and Agriculture, and many county and township highway departments) the efforts of private agencies and landowners, and numerous volunteers.

Although the conservation of Karner blues is federally mandated, insufficient funding has limited the ability to monitor current populations and establish further habitat for Karners blues. In essence, potential habitat exists but remains unrealized. Although several attempts have been made to generate detailed standardized monitoring and management methods, methods have remained variable between agencies and states. To date, progress has been made in states working on recovery of the Karner blue: New York, Michigan and Wisconsin are using Distance sampling methods to assess the size of their recovery populations, estimates which will be comparable between states. 
The landscape-scale methods currently used (i.e. variations of the HPR map) are not capable of identifying specific sites across the landscape that could be developed into habitat. The HPR map, for example, is only capable of identifying general areas greater than $400 \mathrm{~m}$. Furthermore there remains no systematic science-based method for evaluating habitat quality or flight distribution as based on Karner blue habitat selection dynamics. These issues have led to data collection that is repetitive, insufficient for improving management techniques, and almost always underutilized.

Due to robust Karner blue populations, Wisconsin has the opportunity to pioneer monitoring methods and management approaches that could contribute to conservation within other states. It is essential to isolate and understand why Karner blues select habitat both at the landscape-scale and at the field-level, taking into account habitat composition and structure as well as population dynamics. The development of more efficient and effective management tools will aid in identifying potential or existing habitat and applying techniques that establish, promote and sustain healthy barrens and savanna communities by focusing conservation efforts.

A comprehensive review of current management activities and protocols within the state of Wisconsin, conducted in 2010 by the Wisconsin recovery program, concluded that the progression of conservation activities were adequate to maintain habitat, but were not pro-active enough to achieve complete recovery of the species. The major needs included: a quantified comparison of premier and degraded field-sites in order to 
effectively promote habitat sites for Karner blue habitat and occupancy, and the development of fine-resolution tools that could identify potential habitat across the landscape and evaluate the quality of that habitat with limited funding and resources available. These tools would truly improve the efficacy of management practices by identifying why Karner blues select habitat both at the landscape-scale and at the fieldlevel, taking into account habitat composition and structure as well as population dynamics. Such finer-scale tools, in the form of ecological risk models, could build on the existing habitat suitability map (HPR map) and increase understanding of quantified habitat characteristics, comparing premiere habitat sites (with robust Karner blue populations) to degraded habitat sites (barrens in advanced successional stages or sites that do not support Karner populations).

The areas managed and maintained by the Wisconsin Karner Blue Recovery Program in Wisconsin, USA, provide the ideal base for an evaluation of oak/pine grassland biological communities and assessment of the relationships with the Karner blue. Understanding habitat characteristics that contribute to the Karner blue can greatly assist in the conservation of other specialist Lepidopterans. Additionally, establishing sustainable Karner blue habitat can provide much-needed leverage to conserve and improve oak/pine biological communities in a broader sense, contributing to a range of threatened and endangered species that share this habitat. By building on the efforts of the High Potential Range map, fine-scale tools could be used to identify specific fieldsites that can be used to focus management efforts within recovery units. 


\section{$\underline{\text { Acknowledgements }}$}

Hess, Robert J. Karner blue butterfly Recovery Program Coordinator. Wisconsin Department of Natural Resources, Bureau of Endangered Resources, Wisconsin.

Carnes, Catherine. Karner Blue Butterfly Recovery Coordinator. U.S. Fish and Wildlife Service, Ecological Services Field Office, New Franken, Wisconsin.

Schuurman, Gregor. Ph.D. Ecologist, National Park Service Climate Change Response Program, Fort Collins, Colorado. (Formerly: Conservation Biologist, Karner blue butterfly Recovery Program Statistician, Wisconsin Department of Natural Resources, Bureau of Endangered Resources, Madison, Wisconsin). 


\section{$\underline{\text { References }}$}

Anderson RC, Fralish JS, Baskin JM. 1999. Savannas, barrens, and rock outcrop plant communities of North America. Cambridge University Press, New York.

Auclair AN. 1976. Ecological Factors in the Development of Intensive-Management Ecosystems in the Midwestern United States. Ecology. Vol. 57, pp. 431 - 444.

Bess JA.1989. Status of the Karner blue butterfly, Lycaeides melissa samuelis Nabakov, in the Manistee National Forest. Unpublished Report, Michigan Natural Features Inventory, Lansing, MI.

Borth RJ. 1997. Karner blue management implications for some associated Lepidoptera of Wisconsin barrens. Wisconsin GAS: A Wicor Company.

Boyonoski AM. 1992. Factors affecting the establishment and maintenance of Lupinus perennis (wild lupine). M.S. Thesis. University of Guelph. Guelph, Ontario.

Breining G. 1993. The case of the missing ecosystem. Nature Conservancy. November/December, pp. 10-15. 
Buckland ST, Anderson DR, Burnham KP. 2004. Advanced distance sampling. Oxford University Press, New York.

Curtis JT.1959. The vegetation of Wisconsin. Madison, Wisconsin: University of Wisconsin Press.

Dirig R. 1973. The endangered Karner blue. The Conservationist. Vol. 28. pp. 6-47.

FLEL (Forest Landscape Ecology Lab). 2007. Karner blue butterfly high potential range with $40 \%$ and $50 \%$ prob. Thematic Map. University of Wisconsin-Madison.

FWS (U.S. Fish and Wildlife Service). 2012. Karner blue butterfly 5-year review: summary and evaluation. U.S. Fish and Wildlife Service, Ecological Services Field Office, New Franken, Wisconsin.

FWS (U.S. Fish and Wildlife Service). 2003. Final recovery plan for the Karner blue butterfly (Lycaeides melissa samuelis). U.S. Fish and Wildlife Service, Bloomington, MN 273 pp.

FWS (U.S. Fish and Wildlife Service). 1992. Endangered and threatened wildlife and plants; determination of endangered status for the Karner blue butterfly. Final rule. Federal Register 57(240): 59236-59244. 
Grigore M. 1992. The short-term effect of fire on wild lupine (Lupinus perennis L.). M.S. Thesis, University of Toledo. Toledo, Ohio.

Grundel R, Pavlovic NB. 2000. Nectar plant selection by the Karner blue butterfly (Lycaeides melisssa samuelis) at the Indiana Dunes National Lakeshore. The American Midland Naturalist. Vol. 144(1), pp. 1-10.

Guiney MS, Oberhauser KS. 2008. Insects as flagship conservation species. Terrestrial Arthropod Reviews Vol. 1, pp. 111-123.

Haack RA. 1993. The endangered Karner blue butterfly (Lepidoptera: Lycaenidae): biology, management considerations, and data gaps. North Central Forest Experiment Station, USDA Forest Service, Insect Project. $9^{\text {th }}$ Central Hardwood Forest Conference.

Hess RJ, Schuurman G. 2009(a). Distance Sampling Survey Protocol 2010. Wisconsin Department of Natural Resources, Karner blue butterfly Recovery Program.

Hess RJ, Schuurman G. 2009(b). Habitat Assessment Protocol 2010. Wisconsin Department of Natural Resources, Karner blue butterfly Recovery Program. 
Karner Blue Technical Team (KBBRT). 1998. Wildlife management guidelines for the Karner blue butterfly. Prepared by the Wisconsin Department of Natural Resources Karner blue Technical Team.

King RS. 2003. Habitat Management for the Karner blue butterfly (Lycaeides melissa samuelis): evaluating the short-term consequences. Ecological Restoration. Vol. 21(2), pp. 101-106.

Lane CP. 1997. Forest management guidelines: developing management plans compatible with Karner blue butterfly persistence. Wisconsin Department of Natural Resources. Madison, Wisconsin. United States Fish and Wildlife Service. Fort Snelling, Minnesota.

Leach M. 1993. Status and distribution of the Karner blue butterfly at Fort McCoy, Wisconsin: final report on a two-year study. Unpublished Report Prepared for the Natural Resources Management Division, Fort McCoy Military Research Reservation, U.S. Army. The Nature Conservancy, Wisconsin Chapter.

Martin ML. 1992. Karner blue butterfly (Lycaeides melissa samuelis) in Indiana: 1990 Status Report. Unpublished Report. Indiana Department of Natural Resources, Indianapolis. IN. 
McNab HW, Avers PE. 1994. Ecological subregions of the United States: section descriptions. United States Department of Agriculture: Forest Service, Ecosystem Management. Washington, D.C.

Mossman MJ, Epstein E, Hoffman RM. 1991. Birds of Wisconsin Pine and Oak Barrens. Passenger Pigeon. Vol. 53, pp. 137 - 163.

Nuzzo VA. 1986. Extent and status of Midwest oak savanna: presettlement and 1985. Natural Areas Journal. Vol. 6, pp. 6-36.

Opler PA, Krizek GO. 1984 butterflies east of the great plains. Baltimore, MD: John Hopkins University Press, pp. 120-121.

Peterson RKD, Mayer SJ, Wolf AT, Wolt JD, Davis PM. 2006. Genetically engineered plants, endangered species, and risk: a temporal and spatial exposure assessment for Karner blue butterfly larvae and Bt maize pollen. Risk Analysis. Vol. 26(3), pp. 845858.

Pickens BA, Root KV. 2008. Factors affecting host-plant quality and nectar use for the Karner blue butterfly: implications for oak savanna restoration. Natural Areas Journal. Vol. 28(3), pp. 210-217. 
Scudder SH. 1889. The butterflies of Eastern United States and Canada with special reference to New England. Cambridge, MA, pp. 964-969.

Shuey JA. 1997. Dancing with fire: ecosystem dynamics, management, and the Karner blue (Lycaeides melissa samuelis Nabokov) (Lycaenidae). Journal of the Lepidopterists Society. Vol. 51, pp. 263-269.

Swengel AB. 1998. Effects of management on butterfly abundance in tallgrass prairie and pine barrens. Biological Conservation. Vol. 83(1), pp. 77-89.

Swengel AB, Swengel SR. 2005. Long-term population monitoring of the Karner blue (Lepidoptera: Lycaenidae) in Wisconsin 1990-2004. The Great Lakes Entomologist. Vol. 38 (3-4), pp. 107-154.

WDNR (Wisconsin Department of Natural Resources). 2010a. Wisconsin Karner blue butterfly recovery program: 2009 annual report to the U.S. Fish and Wildlife Program. Wisconsin Department of Natural Resources. Endangered Resources.

WDNR (Wisconsin Department of Natural Resources). 2010b. Wisconsin Statewide Habitat Conservation Plan: TE010064-5. PUBL-SS-947. Wisconsin Department of Natural Resources. Division of Forestry. 
WDNR (Wisconsin Department of Natural Resources). 2007. The Wisconsin Karner blue butterfly habitat conservation plan: annual report of activities for calendar year 2007. Wisconsin Department of Natural Resources. Division of Forestry.

WDNR (Wisconsin Department of Natural Resources). 2005. Wisconsin's strategy for wildlife species of greatest conservation need. Wisconsin Wildlife Action Plan. pp. 385394.

WDNR (Wisconsin Department of Natural Resources). 2001. Oak and pine barrens communities. Ecological Landscapes of Wisconsin Handbook, pp. 1-10.

WDNR, 2000. Wisconsin statewide Karner blue butterfly habitat conservation plan and environmental impact statement. PUBL-SS-947-00. Wisconsin Department of Natural Resources. 


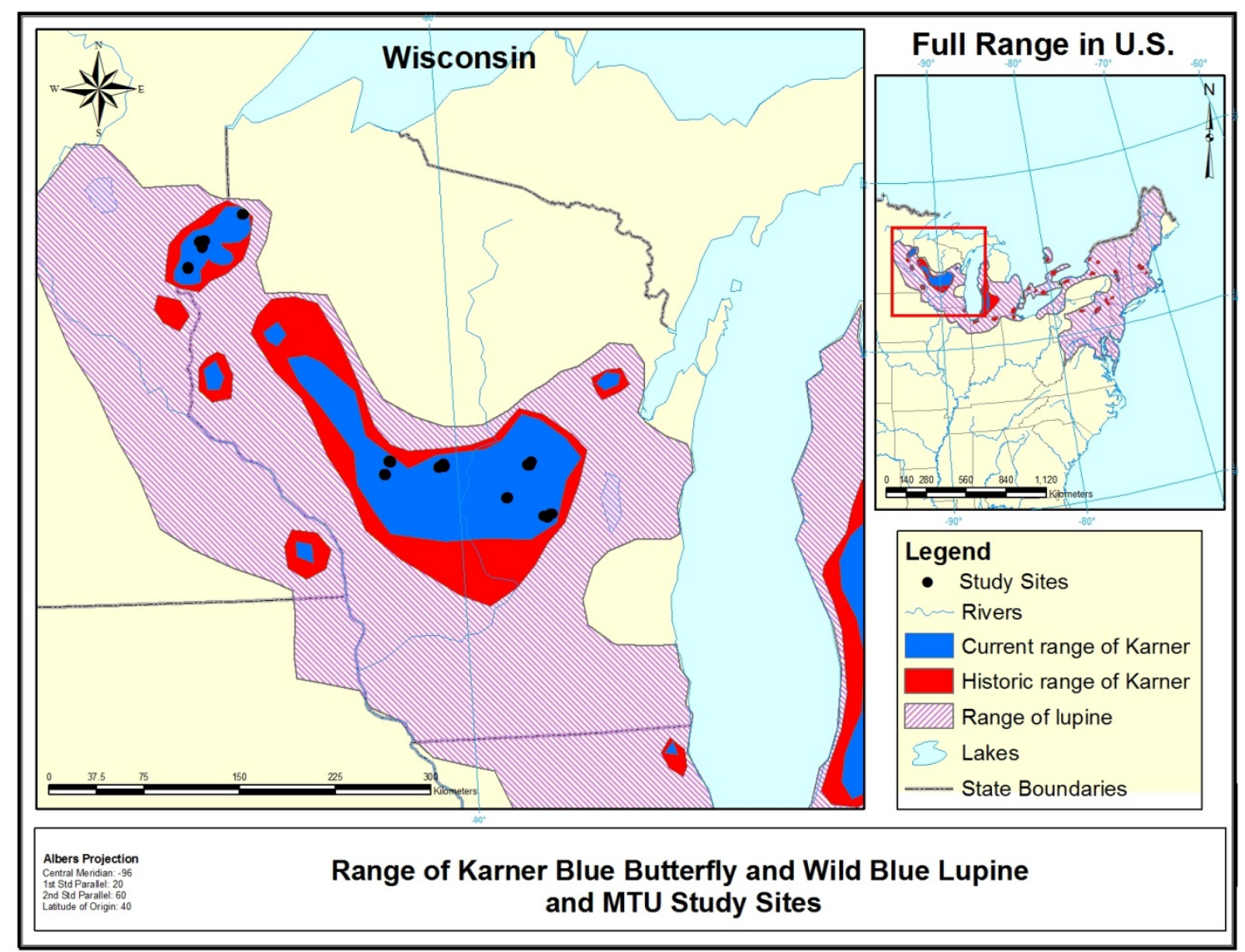

Figure 2.1: Current and historic Karner blue butterfly habitat range and current wild blue lupine range across North America. Information is based on FLEL (2007), and Haack (1993). Range expanse does not necessarily reflect Karner blue presence. Map by A. Hess. 


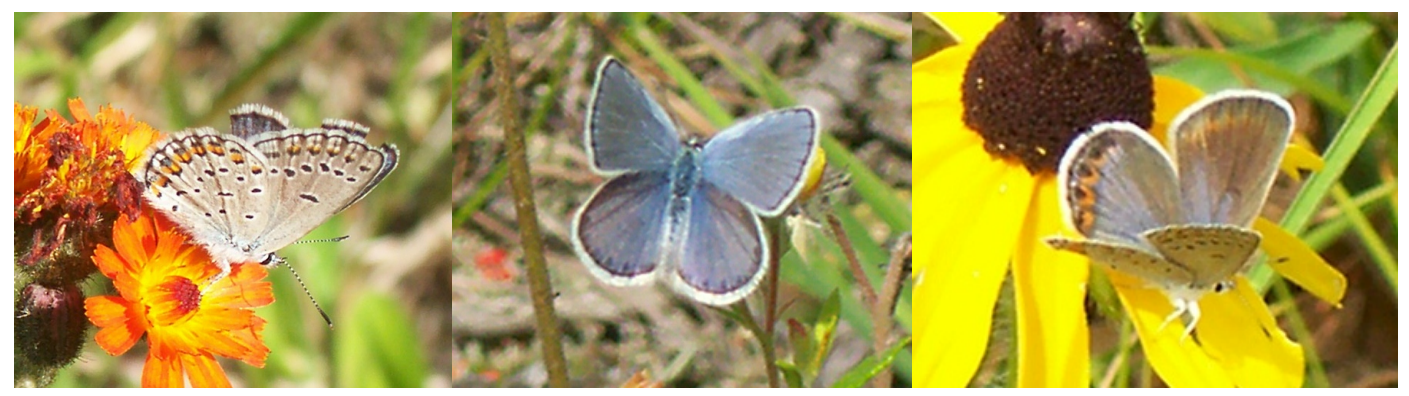

Figure 2.2: Karner blue butterfly underwing, adult male and adult female. Photos by A Hess. 


\section{Karner blue and wild blue lupine lifecycle}

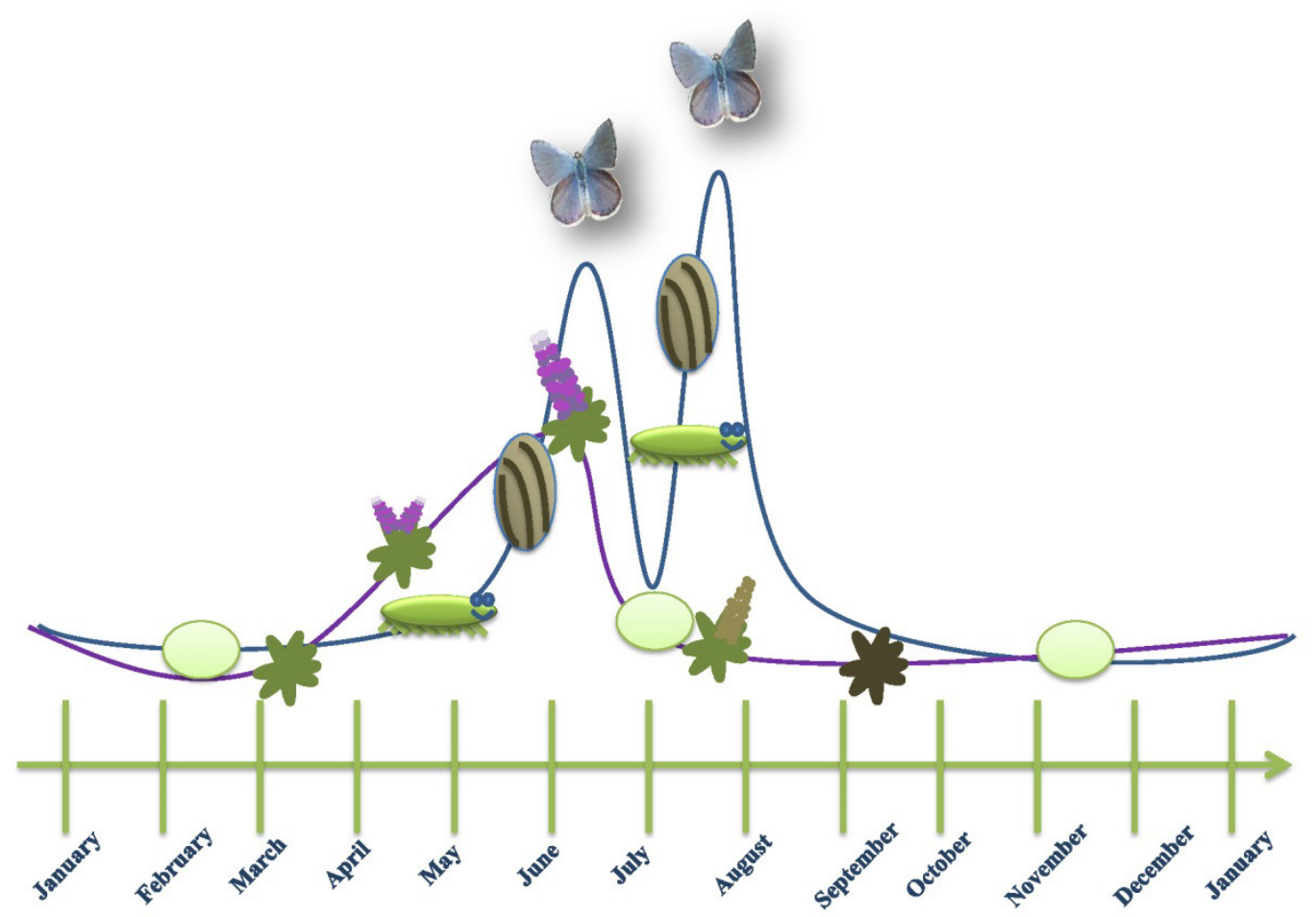

Figure 2.3: Karner blue butterfly lifecycle overlaid with the approximate lifecycle of host plant wild blue lupine. Karner blue butterfly lifecycle is represented by the blue line and egg, larvae and adult images, while wild blue lupine is represented by the purple line and small lupine plant images. Lupine plant images become brown as the lupine senesces in its lifecycle. The second, or primary flight, is shown higher than the first flight due to the primary flight normally having larger populations. Graphic by A. Hess. 


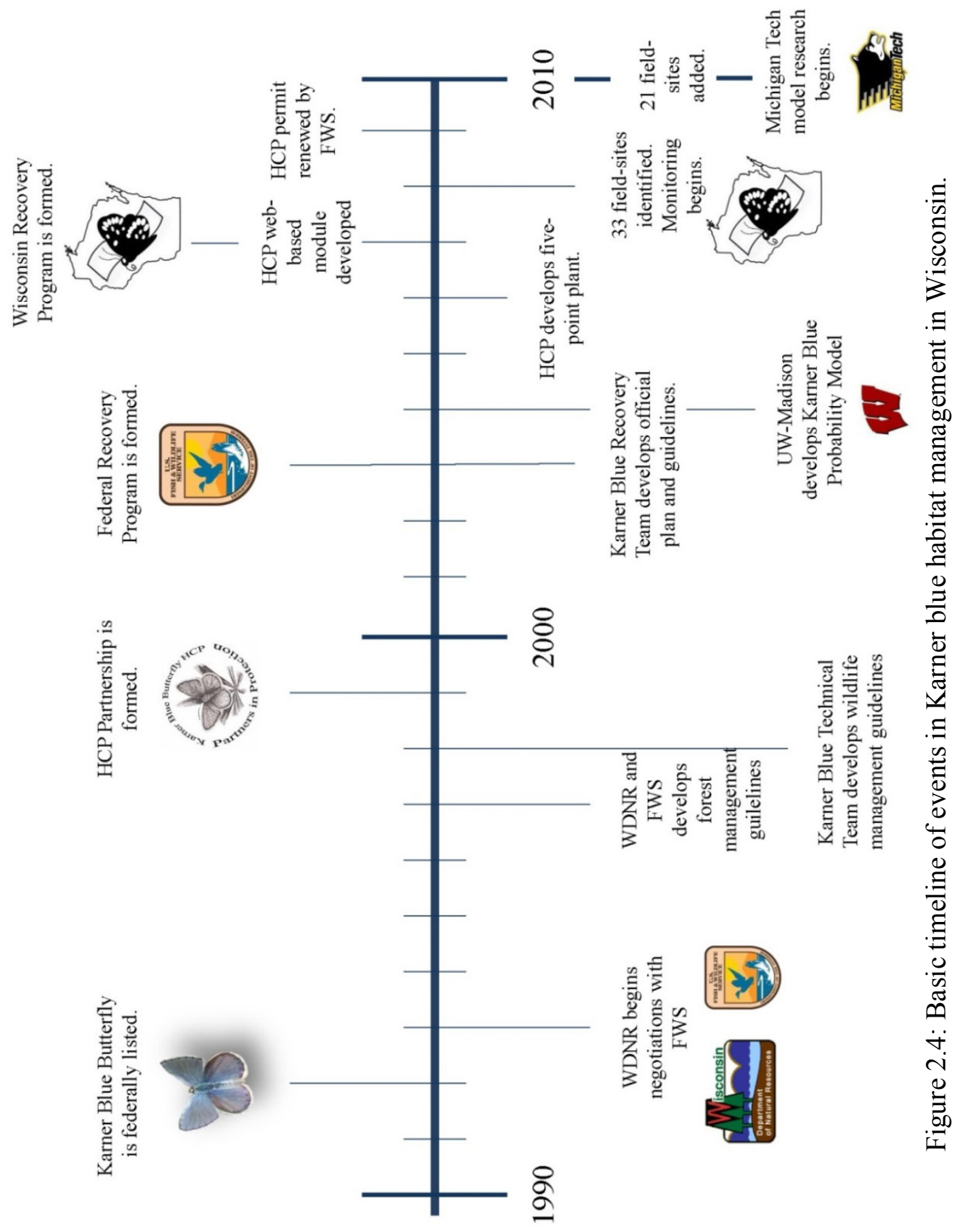




\begin{tabular}{|l|c|c|c|c|c|c|c|}
\hline $\begin{array}{l}\text { Pole } \\
\text { Color }\end{array}$ & Red & Bhue & Orange & Green & White & Yellow & End \\
\hline Inte wal & $0-0.5 \mathrm{~m}$ & $0.5-1 \mathrm{~m}$ & $1-1.5 \mathrm{~m}$ & $1.5-2.25 \mathrm{~m}$ & $2.25-3 \mathrm{~m}$ & $3-4 \mathrm{~m}$ & $4-5 \mathrm{~m}$ \\
\hline
\end{tabular}

Figure 2.5: Demarcations on the Wisconsin statewide recovery program distance sampling pole used for Karner blue butterfly population estimate surveys. Survey pole is $4.5 \mathrm{~m}$ long. Intervals are color-coded as illustrated above. This illustration represents one half of the pole, the other half being a mirror image. Taken from Schuurman (2009a). 


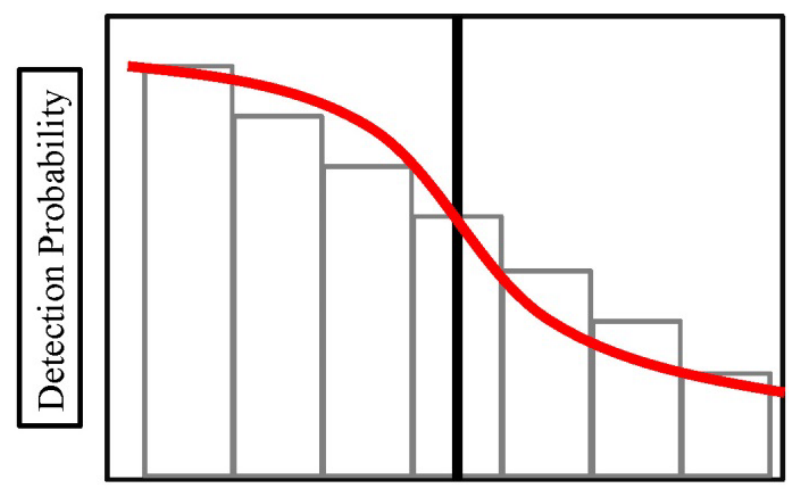

Perpendicular Distance in Meters

Figure 2.6: Illustration of the distance sampling detection function $\mathrm{g}(\mathrm{x})$ used to calculate a total population estimate count. This approach operates under the assumption that as distance from the middle of the transect increases, observations will decreases following a normal curve. The red line represents the formation of the half normal curve as butterflies are detected moving away from the transect center. The black line represents the effective strip width, within which a statistically significant amount of observations will be accounted for. Graphic by A. Hess. 


\section{Chapter 3: Habitat suitability models for the identification and evaluation of Karner blue butterfly habitat using a Multi-Criteria Risk Modeling approach.}

\section{$\underline{\text { Abstract }}$}

Restoration and conservation success is dependent on the ability to efficiently and effectively identify suitable habitat for restoration efforts. GIS based multi-criteria risk models are capable of producing cartographic outputs that illustrate levels of suitable habitat for specific species. Empirical and literature based models were generated across nine state properties in Wisconsin selected for species restoration of the federally endangered specialist Lepidopteran, the Karner blue butterfly. The habitat landscape consists of oak/pine barrens grassland communities scattered across $\sim 34,800$ ha. A Potential Habitat Model was developed using 1m resolution orthophotos and GIS soils layers. This model was tested by assessing 30 field-sites with potential habitat or known Karner blue occupancy, and by assessing randomly selected sample plots. A Relative Habitat Suitability Model was developed for evaluating the quality of potential habitat sites. Stepwise linear regressions were used to select influential habitat variable inputs at the local-scale. These models were applied to each of 13 fields with detectable Karner blue populations, based on ground-data and Global Positioning System locations of Karner blue adults collected during the summer of 2011, and additionally tested using randomly generated point distributions for model validation. The Potential Habitat Model identified known potential habitat at all nine state properties and 
correctly evaluated potential or non-potential habitat at random points. The Relative Habitat Suitability Model identified 50.7-100\% of Karner blue adult locations in the model categories representing areas of high quality habitat where Karner blues are most likely to be found. Lower predictability results were associated with loosely clustered Karner blue locations. Results of this study may help focus restoration efforts by increasing the efficiency and efficacy of identifying potential habitat, managing for groundcover that promotes robust Karner blue populations, and identifying areas within sample areas where Karner blues are most likely to aggregate, improving the ability to monitor populations. This study illustrates the ability of distribution models to predict and evaluate habitat selection of a rare Lepidopteran species.

\section{$\underline{\text { Introduction }}$}

Conservation success relies on selecting appropriate sites to re-establish and promote species or biological communities of concern. This selection of sites is dependent upon an understanding of the areas being considered, the species and communities of focus, and the ability to isolate prominent environmental features. Habitat selection theory outlines the process through which species select resources within their limitations and ability to move and compete (McCarthy and Elith 2002; Rosenzweig 1981). Identifying and visualizing these habitat selection dynamics can be done via a variety of species distribution models, based on species habitat selection and habitat quality, and tested using a number of different means. Correctly selecting variables for modeling a species' 
habitat selection dynamics is dependent on an understanding of how specific geographic and habitat characteristics drive species presence, density and movement. This selection of variables can be successful when using a combination of high quality mediums including remotely sensed data and in situ ground measurements (Hess et al. 2013), or when data is limited, expert knowledge can be used to establish a foundation for data (Store and Kangas 2001). Modeling tools, developed specifically for species of need or as general foundations for habitat evaluation and monitoring, greatly aid the ecological success of restoration efforts (Kuefler et al. 2008).

\section{Modeling Approaches}

Traditional ecological modeling has used statistical relationships resulting in empirical equation models (e.g. Souza Gomes Guarino et al. 2012; Dennis et al. 1991). These models provide quantified information and details on stochastic processes that influence species' population growth and persistence. Ecological niche-modeling incorporates species distributions, and habitat selection and quality based on biotic and abiotic factors (or a combination thereof identifying fundamental or realized niches), to identify specific limitations and predict species' or habitat distribution across the landscape (Peterson 2001). An advantage of ecological niche-modeling is the application of this information to visualize the geographical distribution of species. However, the applicability of modeling approaches depends on the quality of the input information, which can be difficult to allocate for rare species modeling. Even with qualitative 
information, these models can predict species presence across the landscape, gain an understanding of habitat selection at various spatial scales, identify evolutionary branches and development across space and time, and identify specific environmental characteristics such as barriers and geographic factors that may influences species mobility, movement, and persistence on the landscape (Elith and Leathwick 2009; Kearney and Porter 2009; Phillips et al. 2006; Elith et al. 2006; Guisan and Thuiller 2005; Peterson 2001).

Cartographic models have evolved to include spatial modeling of species distributions based on Geographic Information Systems (GIS) layers (Guisan and Thuiller 2005) to produce a visualization of habitat fitness. Different approaches have been used for these models, but common approaches have linked remotely sensed information with biological data for regional conservation planning (Ferrier et al. 2002); used ecological niche modeling based on historical information to predict rare species distributions (Raxworthy et al. 2003); predicted invasive species future distribution based on empirical data and expert knowledge (Shartell et al. 2013), and determined the distribution of rare species (Engler et al. 2004). However; large un-surveyed areas, especially for rare species, produce challenges for regional conservation planning. Using remotely sensed information within a GIS framework helps to select appropriate attributes and extrapolate information across large un-surveyed areas (Eastman et al. 1995) to aid future surveying efforts. 
Remotely-sensed information can be used to generate habitat suitability maps based on species' distribution information (e.g. Guisan and Thuiller 2005). The most successful habitat suitability maps result from incorporating ecological theory, such as habitat selection, to determine direct or indirect environmental predictors. These maps are then used to improve future models. When focusing on habitat selection, model development must involve identifying what abiotic and biotic factors most influence the species, (i.e. what factors the species tolerates), which ultimately lead to an illustration of what influences the distribution and abundance of the species (McCarthy and Elith 2002). Species distribution modeling can also take into account temporal changes such as the degradation or loss of these influential factors, source-sink dynamics due to the habitat fitness and favorability of resources, as well as intraspecific competition (Morris 2003; Rosenzweig 1981). However, it is often difficult to compare or combine separate habitat suitability maps that have been derived from different environmental datasets.

Multi-criteria Risk Models are capable of considering multiple habitat variables, both regional and in situ, thereby incorporating a gradient of values for these variables, and accounting for the geographic organization of these variables. These models generate a detailed map that illustrates an incline of habitat suitability specific to a species' preferences and distribution. Thus, the method is capable of incorporating many characteristics of the models discussed above. By over-laying various geographic information systems (GIS) layers and applying habitat suitability categories to various environmental factors (e.g. soil types), these models can predict the risk, or likelihood, 
of a species to occupy an area (Jager and Overton 1993). Overlaying various environmental within the model generates a single value for a study area within the model output that can be assessed in direct comparison to the species in question (Eastman 1999).

An advantage of Multi-criteria Risk Models includes the ability to quickly adjust model inputs using incoming knowledge and databases, thus improving precision and accuracy of habitat and species' distribution predictions and evaluations. Incorporating or adjusting variables one at a time can also allow researchers to directly observe the influence of variables on species both spatially and temporally (Store and Kangas 2001). In comparison to empirical models, which must be conducted using detailed empirical datasets that are usually unavailable over large areas and are expensive and time-consuming to collect, multi-criteria risk models can be developed using as many or as few layers as are deemed necessary, making them extremely useful in studying dynamics over large areas (Store and Kangas 2001). Thus, the habitat-evaluation modeling approach proposed in this study is valuable to endangered species because 1) extensive empirical studies may not be available across large areas that may span hundreds or thousands of hectares, 2) the map output can be used for the evaluation of habitat quality, 3) the map output is extremely useful in examining species' distributions, 4) and various scales can be incorporated into the method to address different restoration needs and target different ecological questions. 
The value of multi-criteria modeling has been expressed primarily through successful invasive species monitoring (Eastman 1999). Risk modeling, used in this context, can predict the potential for a species to inhabit a space at one point in time or through separate phases, such as the introduction, establishment and spread of garlic mustard (Shartell et al. 2011). Developing such models is difficult for endangered species because generally large datasets of presence and absence data are not available, or sample sizes are low. Several studies have developed or evaluated predictive models for rare and endangered species (e.g. Cianfrani et al. 2010; Le Lay et al. 2010; Engler et al. 2004). Many of these studies have found that using presence data, even in small sample sizes, can produce accurate model predictive capabilities if the environmental characteristics preferred by the species are distinct (Guisan et al. 2006), correctly identified, and tested in an appropriate way such that the model does not miss areas where a species may be able to spread (Cianfrani et al. 2010).

\section{Habitat Quality and Selection}

The condition and geographical distribution of resources (habitat quality) is inherently important to all species and is especially influential to Lepidopterans (Bauerfeind et al. 2009; Hanski 1998; Hanski 1994; Hanski et al. 1994). For example, studies have found that Lepidopteran density and diversity may be influenced by habitat patch structure and connectivity (Dover and Settele 2009; Öckinger and Smith 2006; Krauss et al. 2003; Luoto and Kuussaari 2002; Steffan-Dewenter and Tscharntke 2000) geographical 
barriers (Hanski 1998, 1994; Hanski et al. 1994; Woiwod and Thomas 1993), and the structure and composition of habitat between suitable patches (Ricketts 2001). Understanding the importance, impact, and limitations of these factors is imperative to structuring successful restoration reserves and maintenance activities that will benefit a species and the associated biological communities (Bauerfeind et al. 2009; Dennis et al. 2006). This understanding primarily encompasses the ability to assess habitat patches, or areas of relatively homogeneous habitat structure and composition.

Habitat quality is particularly important to Lepidopterans due to their dependence on specific temperature, humidity and wind regimes, the availability of resources for all life-stages, and in many cases, limited mobility across large distances (Thomas et al. 2001). Butterfly habitat selection theory outlines a minimum of three habitat types necessary for critical life-stages in all butterfly species: habitat for foraging, mating, and oviposition (Wiklund 1977). Foraging habitat is necessary for both larvae and adults (Boggs 2009), and may overlap or be exclusive. Mating habitat is important to male butterflies for the exhibition of displaying, which in many cases takes place along elevational gradients (referred to as hilltopping) (Brown and Alcock 1990; Turner 1990). Oviposition habitat fulfills preferences by female butterflies and differs greatly among species, but is normally closely tied to the resources necessary for healthy larval development (Grundel et al. 1998a; Thomas 1988). 
Assessing the Karner Blue Butterfly

Understanding habitat selection is particularly important for the eventual removal of a species of concern from the endangered species list. The Karner blue butterfly (Lycaeides melissa samuelis Nabokov), hereafter referred to as Karner blue, is one such species. This butterfly was listed as federally endangered in 1992 (FWS 1992) and has received strong public and federal consideration, which has drawn attention to multiple species of concern within its habitat (Guiney and Oberhauser, 2008). The Karner blue has declined an estimated 99\% (FWS 1992); along with its preferred habitat of oak and Jack pine barrens, savanna, and dry prairie (hereafter referred to as oak/pine grassland communities).

Oak/pine grassland communities are established on sandy, lacustrine soils (Anderson et al 1999; McNab and Avers 1994) left behind by the last glacial retreat ( $\sim 12,000$ years ago). These communities once spanned from Minnesota to New York throughout the Great Lakes Region (Anderson et al. 1999) and are now reduced to small pockets of habitat. It is estimated that only $0.01 \%(\sim 0.02$ million ha of the original 1.7 million ha) of the original estimated habitat still exists (Pickens and Root 2008; Curtis 1959). The majority of remaining habitat persists in the tension zone of Wisconsin, a transition zone of deciduous to boreal forests trending Northwest to South-Central across the state (Curtis 1959). 
Canopy cover plays a critical role in the structure of this habitat. Referred to as openforest complexes, these areas generally display $0-50 \%$ canopy cover. These communities maintain open canopy through regular disturbance activities. Historically the open-canopy structure of oak/pine grassland communities was maintained by fire (Szeicz and MacDonald 1991; Nuzzo 1986; Shuey 1997) and megaherbivore activity. Today, fire and mechanical maintenance are used to setback succession and maintain the open-canopy conditions. The loss of habitat is attributed primarily to forest succession.

The Karner blue is primarily dependent on the presence and relative abundance of wild blue lupine (Lupinus perennis) (Shuey 1997), hereafter referred to as lupine, which serves as the only food source for the Karner blue caterpillar. This disturbancedependent legume prefers partial shade, with moderate to low ground litter and surrounding groundcover (Grundel and Pavlovic 2007; Swengel 1995). Lupine grows abundantly in a variety of areas; however, loss of habitat has reduced overall lupine persistence on the landscape (Shuey 1997).

The Karner blue is observed mostly in areas with low canopy cover (e.g. $<10 \%)$ but can be found in semi-closed canopy conditions (Lane 1997; Leach 1993; Grundel et al 1998b). These butterflies exhibit preferences for habitat with tall grass and other herbaceous vegetative cover ranging from 19-90\% (Lane 1997), presumably because 
these areas produce shade cover. The Karner blue adult is a generalist that feeds on many plants but displays selectivity towards specific species when available (Savanick 2005; Grundel and Pavlovic 2000). When lupine is present, these butterflies are able to inhabit an assortment of habitats such as oak/pine openings, dune complexes and dry sand prairies (Bess 1989; Martin 1992), disturbed right-of-ways, sand pits, trails and fallow patches (Forrester et al. 2005; Haack 1993), military bases (Smith et al. 2002), and a variety of barrens, savanna and brush prairie (Anderson et al. 1999).

Previous habitat management efforts have included the development of Karner Blue High Potential Range Model, which identifies approximate areas of potential habitat at $400 \mathrm{~m}$ resolution (WDNR 2007). This model identifies potential habitat range of lupine and Karner blue based on soil types and elemental occurrences of Karner blues. However, the High Potential Range Model depicts potential habitat using 400m resolution, which is too large of a scale to be useful to site managers attempting to identify and evaluate habitat quality of specific habitat patches. To better understand overall habitat selection dynamics, and extrapolate that information across multiple habitat patches, tools must be developed that can identify small-scale areas within a large-scale framework, and evaluate the quality of those small-scale areas.

The main objective of this study was to generate two habitat suitability models via a Multi-Criteria Risk Modeling approach: a large-scale model that will improve identification of potential lupine and Karner blue habitat across large areas of more than 
$\sim 10,000$ hectares ( model that will improve the ability to evaluate habitat quality across delineated sample areas in order to predict where Karner blues are most likely to aggregate if present. These models will 1) identify habitat across large areas such as state properties, using canopy cover estimates within oak/pine communities that will aid large-scale land management efforts; 2) improve small-scale habitat restoration efforts by isolating habitat factors that Karner blues find favorable; 3) improve monitoring by identifying areas at the small-scale where Karner blues are most likely to aggregate. In essence, these models will produce tools for improving habitat identification and species monitoring.

We hypothesized that: 1) Lupine and Karner blue habitat can be identified across large areas such as state properties (ranging from $\sim 100-10,000+$ ha at a time, $\sim 130$ to $\sim$ 27,500 ha within this study) using basic soil types and canopy cover, and 2) the suitability and quality of Karner blue habitat at the small-scale can be predicted by isolating in situ groundcover variables significant to Karner blue life stages.

\section{$\underline{\text { Methods }}$}

Study Area

The study area consisted of oak/pine barrens grassland habitat areas previously identified by the Federal Karner Blue Recovery Program for species restoration sites. 
Wisconsin supports the largest and most widespread Karner blue populations due to the availability of quality habitat (Peterson et al. 2006). The network of nine state properties are part of the Wisconsin Department of Natural Resources Karner Blue Butterfly Recovery Program (Figure 3.1, Table 3.1) and include: Crex Meadows Wildlife Area, Fish Lake Wildlife Area, Black River State Forest, Bauer Brockway Barrens State Natural Area, Sandhill Wildlife Area, Emmons Creek Fishery Area, Hartman Creek State Park, Greenwood Wildlife Area, and White River Marsh Wildlife Area. Biological communities found within these state properties include Jack pine barrens, scrub oak barrens, mixed Jack pine/scrub oak barrens, scrub oak savanna, and dry prairie. These areas have historical Karner blue populations at varying population levels (currently absent to 'recovered'). Within these larger state property areas, which range from $\sim 130$ to $\sim 27,500$ ha, 30 sample areas totaling $\sim 307$ ha were monitored annually for Karner blue populations (Table 3.1). Hereafter, state properties refer to large-scale areas evaluated mainly in the Potential Habitat Model, while sample areas refers to smallscale areas of habitat located within the state properties that are the focus of Karner blue habitat sampling. Sample areas are both used as the focus of the Relative Habitat Suitability Model, and are used to validate the Potential Habitat Model.

\section{Field Data Collection}

\section{Karner Blue Population Information}

Karner blue adult population information was collected using relative abundance and distance sampling methods (Buckland et al. 2004; Schuurman 2009) to estimate density 
and collect spatial information within each of the 30 sample areas. This information was collected by WDNR technicians and affiliated scientific survey groups during the summers of 2010-2012. Karner blue adult populations were estimated during the second, or primary, flight (generation) from approximately mid-to-late July to mid-tolate August. Evenly spaced, permanent transects were established within each sample area using a random starting point. Transects were set perpendicular to the longitudinal axis of a sample area, with spacing either 30 or $60 \mathrm{~m}$ apart based on field size (Schuurman 2009). Populations were estimated using two methods: distance sampling (Buckland et al. 2004) and a relative abundance survey (Schuurman 2009).

In high density locations, distance sampling was conducted to calculate an encounter rate for Karner blues that could be used to estimate population density per sample area, and to collect Karner blue GPS points within high density sample areas. Distance sampling was conducted at least three times with seven days between surveys to avoid counting adults more than once, resulting in over-estimating density. A minimum of 80 observations was required to produce a population estimate for a sample area based on a half-normal curve. The distance sampling method was conducted by walking a transect with a demarcated pole with intervals: $0-0.5 \mathrm{~m}, 0.5-1.0 \mathrm{~m}, 1.0-1.5 \mathrm{~m}, 1.5-2.25 \mathrm{~m}, 2.25-$ 3.0 m, 3.0-4.0 m, and 4.0-5.0 m, and counting Karner blues that cross each interval. This method produced a sample area population estimate and an encounter rate, or the number of observations per linear meter of transect. Distance sampling was used at 13 sample areas throughout Wisconsin. Global Positioning Satellite location points were 
taken at the location of each butterfly using a Trimble GeoXT unit or Trimble Nomad unit. Population data were analyzed using Distance software (Thomas et al. 2010).

In low density locations, a relative abundance survey was conducted to calculate an encounter rate for Karner blue population density per sample area. This sampling method (referred to as relative abundance) is used in lower density sample areas $(<80$ observations over at least three surveys spaced seven days apart), and produces an encounter rate at $2.25 \mathrm{~m}$ comparable to the distance sampling $2.25 \mathrm{~m}$ encounter rate. Thus, sample areas using the two aforementioned methods can be compared even though density sampling is conducted differently. This method involved walking along the length of a transect with a $2.25 \mathrm{~m}$ pole, and counting each Karner blue that intersects the pole.

\section{Vegetation Sample Plots}

Vegetation sample plots were established within the 30 sample areas in order to collect in situ groundcover information. As stated above, sample areas were selected according to areas currently surveyed within state properties. Sample plots were established within each sample area according to a strategic systematic sampling design with a random starting point (staggered grid pattern), placed along the Karner blue survey transects used for estimating Karner blue adult populations (Figure 3.2). Sample plots were evenly spaced along transects to achieve 2 sample plots per hectare with a minimum of 10 sample plots per sample area. This resulted in a total of 691 sample plots across a 
total of 307 ha within 30 sample areas, ranging from 10-132 sample plots per sample area.

\section{Vegetation Groundcover Data}

Vegetation groundcover data was collected using a standard line-intercept method (Elzinga et al. 1998) to determine which in situ variables were most influential to presence and density of Karner blue adults. This line-intercept method consisted of measuring the length that groundcover classes intercepted the transect, at a minimum of 1 centimeter. Line-intercept transects were 10 meters in length and set perpendicular to the existing transect. The percent of eight groundcover classes based on Smith et al. (2002), Grundel and Pavlovic (2000), and LeBare et al. (2000) were measured including: bareground, ground litter, moss, grass, nectar plant, lupine plant, fern, and shrub/tree. Stand composition and structure information was recorded at each sample point and included: tree height, diameter at breast height, and canopy cover. A convex densiometer was used to estimate canopy cover. Focal nectar plant stem count abundance was recorded within a $1 / 800$ ha circular quadrat located at the center of each sample plot. Stem counts were collected for 16 focal nectar plants species (based on Savanick 2005). Focal nectar plants included: lead-plant (Amorpha canascens), dotted horsemint (Monarda punctata), butterfly weed (Asclepias tuberose), old-field cinquefoil (Potentilla simplex), cinquefoil (Potentilla recta), prairie coreopsis (Coreopsis palmata), woodland sunflower (Helianthus divaricatus), western sunflower (Helianthus occidentalis), black-eyed susan (Rudbeckia hirta), common dewberry (Rubus 
flagellaris), common blackberry (Rubus allegheniensis), flowering spurge (Euphorbia corollata), whorled milkweed (Asclepias vertifillata), new jersey tea (Ceanothus americanus), annual fleabane (Erigon annuus) and sand cress (Arabis lyrata). Additionally, stem counts were conducted for host plant, wild blue lupine (Lupinus perennis).

\section{Habitat Modeling Approach}

Two separate habitat suitability models were generated using ArcMap 10.0 (Environmental Systems Research Institute (ESRI), Inc., Redlands, CA, USA) via the Model Builder extension. Vegetation groundcover information and additional habitat variables including soils layers and remotely sensed information were overlaid using a multi-criteria evaluation method (Carver, 1991), allowing for the overlay of multiple datasets and the adjustment of habitat suitability categories with expert knowledge or additionally gained empirical data (Store and Kangas 2001).

The approach consisted of the development of two separate, unique models:

1) A Potential Habitat Model was developed as a large-scale model capable of: identifying potential habitat on state properties at $1 \mathrm{~m}$ resolution including small areas $\left(>1 \mathrm{~m}^{2}\right)$ and potential areas of connectivity; capable of calculating general canopy cover within delineated areas, specific values of which are imperative to 
the persistence of the Karner blue. This model was developed by overlaying derived canopy cover from $1 \mathrm{~m}$ resolution NAIP (National Agriculture Imagery Program) 2010 county-based orthophotos with Wisconsin Department of Natural Resources GIS SSURGO soil data (converted from vector to $1 \mathrm{~m}$ resolution raster format to maintain the integrity of the original vector dataset). This model was applied to the extent of nine state properties and validated by evaluating sample areas and geographically separated random points within each state property, and by ground-truthing canopy cover calculations at 691 sample plots across a total of 30 sample areas.

2) A Relative Habitat Suitability Model was developed as a separate small-scale model capable of: evaluating potential habitat quality and identifying areas of high Karner blue density at the small-scale for the purposes of restoration management and for improving surveying and monitoring efforts. This model was developed by collecting influential in situ groundcover information at each of 30 sample areas with varying Karner blue populations $(0-500+)$, incorporating this data into a GIS setting, interpolating the data across sample areas, applying model values, and overlaying the layers into a single model output. This model was applied to 13 sample areas where intense Karner blue population estimates (and GPS locations of adults) were conducted. The model was validated by using sample areas where GPS locations were statistically clustered, and intercepting the GPS locations in model output (map) categories. 
The number of GPS locations intercepted within good model (map) categories was compared to the number of random points intercepted within good model (map) categories.

\section{Potential Habitat Model}

The Potential Habitat Model (Figure 3.3) was used to identify potential Karner blue habitat where lupine is likely to persist and subsequently Karner blue populations may persist. This model was developed and applied at the large-scale to each of nine state properties (approximately a total of $\sim 34,800$ ha). Soil types and canopy cover were selected to use in this model as influential habitat variables based on literature that indicates the most suitable habitat is located on high sand-content soils (Anderson et al 1999; McNab and Avers 1994) where canopy cover plays a critical role.

Habitat suitability categories were assigned according to estimated Karner blue habitat favorability, with 1 being favorable and 9 being unfavorable. These habitat suitability categories were separated into three groups: a) 1-3, high favorable habitat, b) 4-6, moderately favorable habitat, and c) 7-9, low unfavorable habitat.

Soils were derived from Wisconsin Department of Natural Resources GIS SSURGO soil data $(\sim 1: 20,000)$ (NRCS 2006). Musym codes (codes for soil type) were organized according to dominant soil texture using NRCS databases per county. Soils were then assigned a habitat suitability category of 1 through 9: sandy soils were assigned a 
habitat suitability category of 1 (habitat favorable to the Karner blue) and habitat suitability categories increased as sand content decreased (e.g. loamy sand was assigned a habitat suitability category of 2) (Table 3.2). Soils of peat/muck were assigned a habitat suitability category of 8 , and areas dominated by water were assigned a habitat suitability category of 9 .

Canopy cover was derived from National Agriculture Imagery Program (NAIP) 2010, 1-m resolution county-based orthophotos using ArcMap 10.0. Generating this canopy cover layer is necessary to produce a large-scale layer of habitat structure critical to lupine and the Karner blue, which can be extrapolated across large un-surveyed or surveyed areas of $>10,000$ ha at a time, and is capable of identifying habitat within delineated areas of interest. This resolution size was selected for four primary reasons: 1) $1 \mathrm{~m}$ resolution allows for the general calculation of canopy cover within delineated areas of interest due to the ability to identify single trees or clumps of trees (note that canopy cover is a critical part of habitat structure for the Karner blue and being able to estimate canopy cover is necessary for determining habitat potential), 2) $1 \mathrm{~m}$ resolution allows for the identification of habitat patches ( $<1$ hectare) and areas of connectivity between patches across large areas $(>10,000 \mathrm{ha})$ that may otherwise be difficult to detect or be over-looked given a larger resolution 3) the original NAIP orthophotos are $1 \mathrm{~m}$ resolution and maintaining this resolution in the model output preserves the structure of the original NAIP image and allows for comparison between the NAIP orthophoto and the model output (providing further aerial photograph interpretation), 4) 
the $1 \mathrm{~m}$ resolution model output can be generally compared to models with larger resolution output. Orthophotos were delineated according to state property boundaries and separated into fifteen pixel categories using iso-cluster unsupervised classification. Various cover types (e.g. water, canopy cover, grass cover) were identified and pooled into 2 basic habitat suitability categories (1-7 derived as open space, 8-15 derived as canopy cover or water). Open spaces were assigned a habitat suitability category of 1 , reflecting favorable habitat, while canopy cover and water were assigned were assigned a habitat suitability category of 9, reflecting unfavorable habitat to the Karner blue (Table 3.2).

Areas that were identified as canopy cover using NAIP orthophotos were groundtruthed using stand composition and structure data collected at valid sample plots $(\mathrm{n}=$ 470). Sample plots with $>30 \%$ difference between densiometer readings and in situ shrub/tree percent cover measurements collected during field surveys were eliminated from the ground-truthing analyses due to inconsistencies in data collection. A simple linear regression was used to compare the percent of shrub/tree percent cover calculated along the $10 \mathrm{~m}$ line intercept transect located at each sample plot, and the canopy cover delineated along the $10 \mathrm{~m}$ line intercept using remote sensing of the NAIP orthophotos.

Soils and canopy cover habitat suitability categories were overlaid using the weighted overlay tool in ArcMap 10.0 to produce a map of 1-m resolution across each of the nine state properties. Habitat suitability categories of 1 were considered favorable habitat 
(sandy soils, open canopy), while habitat suitability categories of 9 were considered extremely poor habitat (water or peat/muck).

Model validation used both surveyed Karner blue sample areas, and random points. The Potential Habitat Model was validated using 30 sample areas with potential habitat or with known Karner blue habitat, and using random points generated within state properties. The area of the existing 30 sample areas that fell within high, moderate or low habitat suitability categories were compared using a Kruskal-Wallis ANOVA ( $p \leq$ 0.05). Analyses were conducted in Statistix8 (Analytical Software 2008).

Random plots were generated within state properties and evaluated to further validate the accuracy of the model. Among three and fifteen random points were generated and evaluated within each property depending on size. This was done by generating randomly placed 40 -acre plots. Plots that overlapped were randomly removed. Plots were also not allowed to overlap with existing sample areas (of the 30 sample areas referred to earlier). The centroid of each plot was used as a random point. If the random points fell into water, these points were located as closely as possible on the shoreline. At each random point location, habitat was visually evaluated for habitat suitability by documenting general soil type, estimated canopy cover, lupine presence or absence, signs of Karner larval feeding activity when lupine was present, the presence of water bodies, and the presence of appropriate foliage (i.e. little bluestem, blueberries, lupine), 
or inappropriate foliage (i.e. aspen regrowth, wool grass), following methods similar to Shartell et al. (2013).

\section{Relative Habitat Suitability Model}

The Relative Habitat Suitability Model (small-scale) (Figure 3.4) was trained and validated using 13 sample areas in which Karner blue GPS locations had been collected. The model was trained using 6 sample areas with Karner blue GPS locations that were not highly statistically clustered, and tested using 7 sample areas that were statistically clustered in order to generate an accurate comparison against randomly generated points within each sample area, and to determine the ability of the model to identify areas that are favorable to Karner blues as well as areas where Karner blues are likely to aggregate. Separate habitat suitability categories were developed for sandy vs. loamysand dominated sites due to the differences in vegetation cover preferred by the Karner blue.

The Karner blue GPS locations were tested for statistical clustering using a multidistance spatial cluster analyses (Ripley’s K Function, Ripley 1977) via the Spatial Statistics tool in ArcMap 10.0. This resulted in 6 sample areas used for model training, and 7 sample areas used for model validation.

The in situ groundcover data (described above and collected at 30 sample areas) were selected for potential model inputs. Pearson's correlation was used via a cross- 
correlation table to test for multicollinearity among groundcover variables. Correlations with $p \leq 0.05$ and $\mathrm{R}^{2}>0.8$ were considered significant. A stepwise linear regression (backwards) ( $p$-value $\leq 0.05)$ was applied to explain the density of Karner blues per field based on influential environmental variables. Environmental variables isolated using the regression models were used for model input. All analyses were conducted in Statistix8 (Analytical Software 2008).

Influential habitat variables were interpolated across each sample area using Inverse Distance Habitat (IDW) in ArcMap 10.0 to generate isolines of percent groundcover classes. These interpolations were based on the 691 sample plots. Habitat variable values were divided into eight percent cover increments $(0-1,1-5,5-10,10-20,20-33$, 33-50, 50-75, 75-100) based on the Domin-Krajina cover abundance scale. Model habitat suitability categories (weights) were established by examining the location of Karner blue GPS points in relation to cover types across the 6 selected model training sample areas. Habitat suitability categories were assigned according to Karner blue habitat favorability, with 1 being favorable and 9 being unfavorable.

The resulting habitat suitability categories (Table 3.3 and 3.4) were overlaid and used to develop 1-m resolution model maps on the 7 sample areas used for model validation. The model was tested on those sample areas with statistically clustered Karner blue GPS points in order to generate an accurate comparison against randomly generated points within each sample area. The resulting models were assessed for accuracy, or the 
presence of points correctly predicted. Karner blue GPS locations for 2011 and 2012 and random points (comparable to the Karner blue GPS counts) were used to validate the model. These points were intercepted with the percent cover increments per habitat variable. This results in the percentage of points located within each of the habitat variable categories.

\section{$\underline{\text { Results }}$}

The Potential Habitat Model and Relative Habitat Suitability Model successfully produced model outputs that 1) identified potential lupine and Karner blue habitat across state properties, 2) were capable of calculating general canopy cover, 3) evaluated small-scale relative habitat suitability (i.e. sample area), and 4) predicted where Karner blues are likely to aggregate within a sample area (see Appendix 1 and Appendix 2 for detailed map outputs).

\section{Potential Habitat Model}

Potential Habitat Models produced an overlay of derived canopy cover and soils layers to highlight habitat areas that would be most favorable to Karner blue butterflies and lupine (Figure 3.5). Evaluation of randomly generated points and data from 30 surveyed sample areas within each state property (surveyed sample areas evaluated in detail below) revealed that the model correctly identified habitat suitability ranging from 
favorable to unfavorable, including water bodies, marshes, soil types and general canopy cover observed at each sample plot. Accuracy of NAIP orthophoto derived canopy cover was comparable to in situ groundcover information $(\mathrm{R}=0.82, p \leq 0.05, \mathrm{n}$ $=469, \mathrm{~s}=0.02 \%$ cover, simple linear regression analyses) (Figure 3.6), allowing for the general calculation of canopy cover across state properties and at the small-scale.

The area (hectares) of 30 sample areas with known potential or existing habitat and present or historical Karner blue populations varied between high favorable and low favorable habitat suitability categories. The area of these 30 sample areas was significantly different $(p \leq 0.05)$ between habitat suitability categories (Figure 3.7, 3.8). Overall, the sample areas were an average of $79.2 \%$ within the high favorable habitat suitability categories (Figure 3.7,3.8). Sites with a measurable encounter rate of $0.01 \mathrm{~m}$ fell $>70 \%$ within the high favorable habitat suitability categories (1-3, prime to good habitat) (Figure 3.8). Sites with lower encounter rates or absence of Karner blues varied between $31.8-96.8 \%$ within the high favorable habitat suitability categories. This difference depended on the degree of shrub/tree percent cover at each sample area. In some cases sample areas with high canopy-cover also had relatively suitable encounter rates, although these sample areas were not considered recovered.

\section{Relative Habitat Suitability Model}

The stepwise linear regression model procedure identified three habitat variables influential to Karner blue density for use in Relative Habitat Suitability Models 
including: greater percent lupine cover $(p<0.0001)$, lower percent shrub/tree percent cover $(p<0.0001)$ and greater focal nectar plant stem counts $(p<0.0001)$. Regressions were re-run without lupine to evaluate the significance of other variables. Significant variables resulting from this regression analyses included shrub/tree percent cover $(p<$ $0.0001)$ and focal nectar plant stem counts $(p<0.0001)$. Lupine and shrub/tree percent cover and focal nectar plant stem counts were used as inputs in the Relative Habitat Suitability Model. Because the $p$-values for these variables were equally influential, these habitat variables were given equal influence within the model parameters. Note that 'influence' and 'weights' are two different measurements of application within the weighted overlay function used to generate a model output.

The Relative Habitat Suitability Model application of four sandy and three loamy-sand validation sample areas (Figure 3.9) predicted 50.63-96.5\% of Karner blue occurrences within the high favorable habitat suitability categories (top two habitat suitability categories within model output) (Figures 3.10, 3.11). Within the sandy validation sample areas, $50.63-96.5 \%$ of Karner blue occurrences were correctly identified, while $97.8-100 \%$ of Karner blue occurrences were identified at loamy-sand validation sample areas. Low GPS point interception occurred in sample areas where Karner blue GPS points were not as highly statistically clustered as other sample areas (Figures 3.10, $3.11)$. 
Random points occupied fewer high potential habitat suitability categories and lower potential habitat suitability categories than actual Karner blue GPS points and consistently occupied different habitat suitability categories (Figures 3.10, 3.11).

\section{Discussion}

\section{Potential Habitat Model}

The Potential Habitat Model was designed to identify potential lupine and Karner blue habitat across state properties, as well as to calculate general canopy cover within delineated areas, which is a critical habitat feature. There are many advantages to this model, including: the identification of favorable soil types, the calculation of general canopy cover, and the comparison of sample areas with no existing Karner blue populations to areas with known Karner blue populations. This model is most useful for a comparison of general canopy cover between sites, and for identifying sites where lupine is most likely to occur and propagate, and subsequently support Karner blue populations. The evaluation of such models is difficult, as many butterfly species occupy only small areas of known suitable habitat (New 2007); however, we provide an argument for the utility of this model based on its ability to identify potential habitat and contribute to future ecological investigations.

Habitat Aspects 
The overall accuracy of percent canopy cover enables the model user to make general calculations of canopy cover within areas of interest. The ability to do this within areas of interest, or across large expanses of habitat, is critical in evaluating habitat potential. Because no updated layers such as this existed for this rare species within the areas of interest, the layer had to be generated in order to implement the model design. Karner blues are known to favor areas of low canopy cover $(<10 \%)$ as well as semi-closed canopy of up to 50\% canopy cover (Grundel et al. 1998b; Lane 1997; Leach 1993). Thus, the ability to estimate canopy cover or changes in cover across large expanses of state properties could greatly contribute to the identification of potential habitat areas. This model cannot replicate with exactness the accuracy of a ground-survey, but it is accurate enough to produce general calculations to act as a first step in identifying areas of interest. Inaccuracies in canopy cover may be due to inaccurate GPS point locations at the time in situ groundcover information was collected, inaccuracies in the measurement of groundcover, or due to inherit inaccuracies in the derived canopy cover process.

Other models that evaluate the influence of habitat structure and composition on Lepidopteran populations have also integrated the use of habitat networking (connectivity, size, and distance) (Bauerfeind et al. 2009; Hanski 1998). Habitat networking is inherently important to Lepidopterans as it influences the movement of individuals, populations, or metapopulations across the landscape in relation to resources (Bauerfeind et al. 2009; Hanski et al. 1994). These studies have found that 
these variables are influential to Lepidopteran occupancy and movement, but is highly dependent on the species in question (Bauerfeind et al. 2009; Haddad and Tewksbury 2005; Thomas et al. 2001).

Due to the fine resolution of the Potential Habitat Model, it provides the user with the basic ability to identify open areas that could serve as potential areas of connectivity between sample areas, though it is uncertain how necessary this is for the persistence of Karner blue populations. The Karner blue is capable of traveling distance up to 1.22 km, through closed canopy, highly unfavorable conditions (Dunn 2008; Shillinglaw and Shillinglaw 2008). Other butterflies are also able to cross $1 \mathrm{~km}$ of nonsuitable habitat (Pauler-Fürste et al. 1996). The Karner blue can decrease in population size when highly isolated and lacking connectivity (Fuller 2008). However, the ultimate requirements of the Karner blue in relation to connectivity are relatively unknown, making it difficult to incorporate the information directly into the structure of ecological models without making spurious assumptions (e.g. New 2007). The $1 \mathrm{~m}$ resolution of this model may allow conservationists to make future observations on the relationships that the Karner blue may have among and within populations across the landscape. The ability to identify potential corridor areas between existing and potential sample areas could greatly increase the ability to restore successful, self-sustaining populations across the landscape. 
Theoretically, increasingly suitable habitat sites should contain increasingly favorable habitat to unfavorable habitat. However, this is determined at several scales, based on increasingly specific resources that are influential to species (New 2007; Dennis et al. 2006). For example, strictly open or non-open habitat does not make suitable habitat alone, but can affect the overall success of associated species, such as insects and butterflies (Feber et al. 2001). Several sample areas evaluated in this study did not contain Karner blue populations at all, but contained favorable habitat characteristics according to the literature. These sites generally displayed higher canopy cover. This would influence the ability of lupine or nectar plants to establish themselves within these sample areas due to factors such as unfavorable shade levels or elevated groundlitter conditions (Grundel et al. 1998a; Grundel and Pavlovic 2007). Conversely, highly open areas may contain high amounts of grass cover which competes with lupine. These conditions could have been maintained historically through fires (Leach 1993; Schulte and Mladenoff 2005), or insect infestations (Radeloff et al. 2000) to maintain the favorable habitat conditions. Though the Potential Habitat Model is extremely useful for identifying potential habitat, a ground survey must still be completed in order to assess the quality of the habitat (as outlined in the Relative Habitat Suitability Model).

Vegetation important to the Karner blue also varies between soil types. The Potential Habitat Model was designed to indicate a relative difference between the suitability of the sandy and loamy-sand sites. Increasingly sandy soils are required for the successful 
establishment of oak/pine barrens grassland habitat (e.g. Anderson et al. 1999; Curtis 1959). The model habitat suitability categories decreased in potential as the soils became less sandy. Validation of the Potential Habitat Model using 30 surveyed sample areas revealed that the loamy-sand sample areas and sandy sample areas are both successful (measured by the occurrence of Karner blues) though differences still exist. For example, sandy sites displayed a wider range of canopy cover conditions, and less percent cover of nectar plants and host plant. This observation led to the establishment of two separate groups, sandy and loamy-sand sites, for the Relative Habitat Suitability Model

\section{Technical Aspects}

Multi-criteria approaches have been used to improve habitat suitability evaluations for invasive species predictions. Adjusting these techniques can produce habitat suitability models that predict potential habitat for endangered species. Modeling the distribution of rare species can be highly accurate even with small species occurrence datasets, and increase in predictive potential if species display specific preferences for environmental characteristics or small geographic ranges (Hernandez et al. 2006). The use of presence only data in model development and validation has been found to increase the ability of a habitat suitability model to identify areas where a species may be able to colonize, whereas the use of presence-absence data prevents the model from identifying these areas if the species is not already present (Cianfrani et al. 2010; Phillips et al. 2006). The Potential Habitat Model utilizes presence data to validate model predictability and 
to identify potential habitat areas where the Karner blue may not yet be present. In the case of the Karner blue, which are found most commonly in a small range of canopy cover values (generally $0-40 \%$ ) and only on specific soil types, identifying these areas across state properties allows the model to identify potential habitat, and increase the ability predict locations of even small Karner blue populations (e.g. $<10$ adults; Hernandez et al. 2006).

Other ecological models, and the Potential Habitat Model evaluated in this study, are designed to identify potential habitat based on the most basic habitat variables reflecting the needs of the species in question (in this case, soils and canopy cover) (i.e. Store and Kangas 2001). Other studies (Shartell et al. 2013) have successfully predicted the occurrence of earth invasion at $58 \%$ of plots in the Huron Mountains and $64 \%$ of plots in the Seney National Wildlife Refuge, using basic requirements of earthworms. This particular model was further tested for sensitivity by removing dynamic variables including roadways, which resulted in a decrease in accuracy of the model outputs. The resulting static models predicted the potential distribution of the species in question, similar to the Potential Habitat Model. Similarly the sensitivity of the Potential Habitat Model was assessed by attempting to use 24K hydrology layer (WDNR 2005), as well as 10,20 , and $30 \mathrm{~m}$ buffers surrounding these layers, and a $30-\mathrm{m}$ resolution wiscland landcover data (WDNR 1998). However, these variables greatly reduced the accuracy of the model due to limitations in the spatial datasets including resolution size and 
relative age of the information (2005 and 1998, respectively), and were removed from the final model product.

Spatial resolution has been found to be important in the development of successful habitat suitability modeling (Engler et al. 2004). Finer-resolution models are capable of identifying and including more variation in variables important to species, while coarser resolution models display higher prediction error (Gillingham et al. 2012). The Potential Habitat Model used a spatial output resolution of $1 \mathrm{~m}$. This is finer than comparable models intended for the prediction of invasive species occupancy, including the prediction of exotic earthworm distributions (Shartell et al. 2013), garlic mustard (Shartell et al. 2011), and other invasive plant species (e.g. Latsch 2011). These models used $10-30 \mathrm{~m}$ resolution because the available datasets were developed at that resolution. Shartell et al. (2011) compared two model spatial resolutions at 30m and $10 \mathrm{~m}$ to account for finer-scale data when it was available in natural areas. Similarly, the Potential Habitat Model was produced at a fine-scale resolution due to the advanced capabilities of ArcGIS, allowing for the calculation of general canopy cover which determines habitat suitability for lupine propagation as well as the persistence of Karner blues. This comparison suggests that size may not matter, and that effectiveness relies on the overall resolution. This finer-scale resolution also allows for the identification of finer-scale habitat pockets such as roadway and utility corridors (Haddad and Tewksbury 2005; Forrester et al. 2005; Smallidge et al. 1996; Haack 1993), and very fine-resolution pockets of habitat where Karner blues are known to persist (Lane 1993). 
In this way, the smaller resolution of the model better represents the ecological processes driving Karner blue occurrence and abundance.

This Potential Habitat Model is useful for identifying potential habitat sites, identifying potential habitat adjacent to existing habitat, for the identification of potential habitat connectivity, and for the calculation of general canopy cover before the need to conduct ground surveys. This will enable land managers or researchers to better focus ground survey efforts by choosing the most suitable habitat areas ahead of time. This model may also be useful for further studying the dynamics of populations in relatively isolated sample areas, in relation to adjacent sample areas, or in relation to movement among sample areas.

\section{Relative Habitat Suitability Model}

The Relative Habitat Suitability Model was developed specifically to evaluate suitable habitat for an endangered species across small-scale sample areas, and to generate an example on which to base similar habitat suitability models (Store and Kangas 2001, Jager and Overton 1993). This model used more specific habitat variables that influence Karner blue persistence than used in the Potential Habitat Model. This model simultaneously overlays and evaluates the importance of both resource condition (habitat suitability) and resource organization (the spatial configuration of the habitat variables across a habitat patch) within the patch setting, thereby generating an 
illustration of habitat quality (Bauerfeind 2009) in relation to preferences of the Karner blue. Thus, the model generates an approach for researchers that wish to observe the spatial dynamics of a species in relation to multiple in situ variables influencing habitat composition and structure.

\section{Habitat Aspects}

Identifying habitat quality was the focus of this model, as habitat patch quality may be more important to the overall success of Lepidopterans than configuration factors such as patch size and isolation (Lindell and Maurer 2010; Thomas et al. 2001). This is especially important to butterfly species such as the Karner blue which depend on the presence of wild blue lupine and are influenced by specific canopy cover levels as well as nectar plant abundance. Patch quality, including within-patch structure and composition that may provide areas of unsuitable habitat, should be considered in order to manage for a particular species, and to avoid creating sub-optimal habitat for associated species (Dover and Settele 2009; Prugh et al. 2008; Mazerolle and Villard 1999).

The Relative Habitat Suitability Model was applied separately to sandy and loamy-sand sites due to large differences in vegetative groundcover and canopy cover levels, as well as differing preferences displayed by the Karner blue. These differences were not surprising, as soil types produce soil variables that generate different levels of nectar plant availability and lupine availability. For example, excessive xeric conditions 
resulting from sandy soils cause lupine to senesce more quickly and is known to decrease the development success of Karner blue larvae, while soils with higher moisture content or increased shade allow lupine to senesce more slowly (Lawrence 1994). Multiple habitat variables were measured at the ground level in this study; however, lupine cover, focal nectar abundance and shrub/tree percent cover were consistently the most significant variables measured and differed between the sandy and loamy-sand soil types. These variables may influence or be influenced by the remaining measured habitat variables, including ground litter, which can positively influence host plant cover as well as influence the moisture content of soil (e.g. Pavlovic and Grundel 2009; Grundel and Pavlovic 2007). Future investigations of these habitat variables may improve model performance.

Canopy cover, or the percent cover of shrubs/trees, was consistently significant to the Karner blue throughout analyses. Many butterfly species are influenced by canopy cover and variations in forest structure, even when compared to important variables such as host plants and nectaring abundance (Hess et al. 2013; Pocewicz et al. 2009; Haddad and Tewksbury 2005). The Karner blue most likely existed historically in patches of mixed canopy cover resulting from fire disturbance (Schweitzer 1990), in areas with low canopy cover (e.g. $<10 \%$ ) but also in semi-closed canopy conditions (Grundel et al 1998b ; Lane 1997; Leach 1993; Maxwell and Givnish 1993). Karner blue occurrences generally increased as shrub/tree percent cover decreased. However Karner blues displayed a much higher preference for canopy cover (10-20\%) in sandy 
sites, and displayed a steady increase with decreasing shrub/tree percent cover in loamy-sand sites, dominating areas with $0 \%$ cover. This is most likely due to the dynamics of shade-forb tolerance on soil types and Karner blue preferences given groundcover options. At loamy-sand sites, where Karner blue occurrences steadily decreased with shrub/tree percent cover increase, herbaceous groundcover can serve as shade/protection for Karners and for lupine. Within these areas, increasing shrub/tree percent cover will reduce lupine growth while decreasing cover will cause early senescence (Grundel and Pavlovic 2007). Sandy sites with no grass or shrub/tree cover will not produce comparable nectar plant or host plant cover for Karner blues due to edaphic conditions and increased thermal extremes (Lawrence 1994). Thus, the model incorporated a difference in shrub/tree cover to account for the varying preferences of Karner blues within the different soil types.

Nectar plant diversity and abundance is as influential to butterfly abundance and dispersal as host plant abundance and geographical distribution of habitat (Matter and Roland 2002; Pywell 2004; Kuussaari et al. 1996). For example, L. helle populations were strongly influenced by increasingly abundant nectar plants in comparison to several other structural and compositional characteristics of suitable habitat (Bauerfeind et al. 2009). The availability of nectar plants was measured two different ways during the development of the Relative Habitat Suitability Model: as overall percent cover of forbs that had the potential to flower, and as stem counts for focal nectar plants as identified by Savanick (2005). The focal nectar plant abundance variable was more 
significantly related to Karner blue encounter rates than the overall nectar plant cover variable during the development of regression models. This suggests that a focus on specific nectar plants, or a variety of nectar plants, may be favorable over the application of relative nectar plant cover (i.e. if a forb flowers during its lifecycle it will serve as nectar plant availability). Karner blues display generalist behavior when nectaring options are available (Savanick 2005; Grundel and Pavlovic 2000), and higher stem counts will provide more options among species (depending on diversity) and among specific species. Within the context of the model, it was determined that the Karner blues would favor any small areas $(\sim 1 / 800$ ha plot $)$ with $>10$ focal nectar plants, and that areas below this simply did not provide suitable habitat.

Several modeling studies have found that the cover of host plants is significant to some Lepidopteran species but not to others, affecting the overall applicability of host plants in habitat suitability models. Modeling evaluations of habitat quality in relation to Co. tullia suggest that this species is not highly influenced by its own host plant, but is highly related to the shrub-like host plants of Ce ladon which shade out favorable nectaring sources (Hess et al. 2013; Dennis and Eales 1997). P. smintheus is influenced by both abundance of its host plant and abundance of nectar flowers (Matter and Roland 2002). V. cardui, and Cu. amyntula, in comparison, are not highly influenced by host plants, whether theirs or that of another species, in comparison to other habitat quality features (Hess et al. 2013). However, many butterfly species are highly influenced by their host plants (e.g. Pywell 2004); even if these variables may not be identified during 
statistical analyses due to autocorrelation with other habitat variables (Dover 1996). In the case of the Karner blue and other specialist Lepidopterans, the inclusion of the host plant is critical to the success of the model performance. Although a great deal of lupine cover is not necessary for the persistence of the species, the presence of lupine is required (Hermes 1996); thus, lupine was given almost equal habitat suitability values across the model spectrum. All areas with lupine present were considered favorable habitat, however Karner blue occurrences decreased as lupine cover increased to $100 \%$ because this amount of lupine cover appears to prevent the growth of nectar plants.

\section{Technical Aspects}

This Relative Habitat Suitability Model is useful in two main ways: to evaluate the most suitable and unsuitable portions of a sample area, and to predict where Karner blues are most likely to aggregate within that sample area. Similar to other models, this evaluation of habitat quality at the small-scale accounts for several life stages of the species in question, including larval habitat, adult foraging and mating, and oviposition habitat suitability (e.g. Matter and Roland 2002; Wiklund 1977). Latsch (2011) generated risk models to predict the spread of several invasive species across Pictured Rocks National Lakeshore, and evaluated habitat variables that the invasive plants in question were most dependent on during their life cycle, including introduction, establishment and spread phases. In comparison, the Relative Habitat Suitability Model developed during this study combines the habitat variables needed during phases of a species lifecycle into an overall evaluation of habitat variables that best reflect the needs 
of the species. This overlay of variables accounts for the presence of the host plant and abundance of forage as well as influential habitat structure (the cover of shrubs/trees) that are known to determine the suitability of habitat for insects throughout all life stages (Boggs 2009; Pickens and Root 2008; Awmack and Leather 2002; Moilanen and Hanski 1998). In the case of the Karner blue, this includes favorable conditions for oviposition (30-60\% canopy cover) (Grundel et al. 1998a), increased nectar plant density for foraging (Pickens and Root 2008), as well as open areas where Karner blue males generally forage and display (Grundel et al. 1998a).

Traditional modeling methods use random sampling designs for site selection. Selecting sample areas for model development or rare species can be problematic because a random sampling of sites may fail to select areas where the species is present at all, or where the species is displaying specific habitat preferences that are measurable in a model setting (Guisan et al. 2006). Directing the selection of sample areas for model evaluation to increase the probability of sampling a rare species is appropriate to validate model accuracy as well as facilitate more efficient surveying practices (Le Lay et al. 2010; Guisan et al. 2006). In the case of the Relative Habitat Suitability Model, sample areas were selected based on known Karner blue populations with variation in population levels, and then evaluated based on the predictability of the model to identify the majority of the population in comparison to random points per sample area. 
Validating the overall accuracy of this model is difficult because of the mobility of the species in question (a Lepidopteran) and also because it is used in sample areas that have measurable Karner blue populations (i.e. greater than 80 observations recorded over the course of the primary flight due to the parameters of the population estimate method used in the sample areas). However, a great deal of variability was still present among sample areas, ranging from $\sim 80$ to $\sim 500$ observations over the course of a survey period. The Relative Habitat Suitability Model identified 50-100\% of Karner blue locations in the highest ranking habitat suitability categories at $1 \mathrm{~m}$ resolution, the lowest model accuracies being associated with poorly clustered Karner blue populations (highly dispersed, difficult to predict). In comparison, Latsch (2011) accurately identified $70-100 \%$ of relatively sedentary invasive species using risk models at $30 \mathrm{~m}$ resolution. A future test of the accuracy of this model would be to develop suitable habitat based on the model parameters and evaluate an increase, if at all, of Karner blue populations over a period of many years.

Overall, the Relative Habitat Suitability Model provides a detailed comparison the percent cover of shrubs/trees among the Karner blue occupied sample areas, as well as the cover of nectar plants, and filters out areas where the host plant is simply not present. This is ultimately useful in identifying the highest quality areas of a sample area, provides a comparison with which to restore unsuitable areas of a sample area, and allows land managers to target areas within a sample area where Karner blues are most likely to aggregate, for use in monitoring. 


\section{Conclusions and Recommendations}

The success of conservation and restoration efforts relies on selecting sites that are appropriate for re-establishing biological communities and promoting associated species. To do this, conservationists must understand the geographic area under consideration, the species and community in question, and also be able to isolate influential habitat characteristics. This also relies on the integration of high quality habitat data and expert knowledge. GIS settings are ideal for overlaying multiple habitat variables that are influential to a specific species and for developing reliable models of suitable habitat and potential habitat. The success to mapping species distribution in relation to habitat quality involves gaining a better understanding of how a species selects habitat at various spatial scales, how specific habitat characteristics influence species distribution at various spatial scales, and how this distribution across the landscape can be assessed within protected areas.

This study produced two models with the purpose of identifying potential Karner blue and lupine habitat and illustrating the relative habitat suitability based on ground measurements. Though this study most likely did not account for all variables that could potentially influence the Karner blue, and it would be very difficult to do so, it does provide a base for estimating potential habitat and for evaluating habitat quality for an endangered species. Building on this information and incorporating additional sites will produce increasingly superior model results, allowing for the successful illustration of 
habitat suitability for this and other species. The chief advantage to the development of these models is an increased ability to identify potential habitat across large expanses of land, and the ability to identify areas within sample areas where habitat quality is highest, and where Karner blue populations are most likely to aggregate. This allows for land managers to most successfully monitor existing populations, to use high quality areas as a reference in habitat restoration, and to target areas most in need of habitat restoration. Furthermore this study illustrates that habitat selection for a rare species and for Lepidopterans, can be successfully predicted and evaluated using a limited number of influential habitat variables, and that this information can be used to predict the spatial distribution of a rare species. We recommend that these models be used to identify potential habitat across state properties, and especially in the use of identifying potential sample areas nearby existing sites that are currently monitored for the Karner blue. We also recommend that these models be used to evaluate the overall habitat suitability of sample areas by using basic ground measurements (i.e. lupine, nectar plant, and shrub/tree percent cover). The results of this study will allow land managers to focus efforts on geographic areas most suitable for habitat development, implement practices that more effectively isolate habitat characteristics that influence species success, and monitor species of concern more efficiently.

\section{$\underline{\text { Acknowledgements }}$}

Data collection for this research was partially funded by the Wisconsin Department of Natural Resources-Karner Blue Butterfly Recovery Program, the United States Fish and 
Wildlife Federal Recovery Program, and Michigan Technological University. Butterfly population information and habitat information was collected by the Wisconsin DNR and associated scientific survey groups including the University of Wisconsin-Stevens Point group led by Dr. Michael Demchik, and Endangered Resources Services, LLC. WDNR Bureau of Science Services and Dr. Gregor Schuurman provided analyses of population data. This data is part of the WDNR Natural Heritage Inventory. Permits to conduct study include: Natural Heritage Inventory LA157, Wisconsin Endangered and Threatened Species Permit \#687, and State of Wisconsin Department of Administration Volunteer Agreement. Additional data for this study was collected with the help of Robert J. Hess, Joy L.M. Hess, Julie A. Hess, Jennifer Resch, Jessica Kempke-Lewis, Kris Poncek, Michael J. Falkowski, Linda C. Lyons, Julius Dewald, Jill Utrup, Jodi Shaw, and with the permission and help of the state property staff including Wayne Hall, Paul Samerdyke, Pete Engman, Steve Hoffman, James Holzwart, Raymond Paisley, Brandon Stefanski, James Tomasko, Nancy Christel, Peter Bakken, and Armund Bartz.

\section{$\underline{\text { References }}$}

Analytical Software. 2008. Statistix 8. Analytical Software: Tallahassee, FL.

Anderson RC, Fralish JS, Baskin JM. 1999. Savannas, barrens, and rock outcrop plant communities of North America. Cambridge University Press, New York. 
Awmack CS, Leather SR. 2002. Host plant quality and fecundity in herbivorous insects. Annual Review of Entomology. Vol. 47, pp. 817-844.

Bauerfeind SS, Theisen A, Fischer K. 2009. Patch occupancy in the endangered butterfly Lycaena helle in a fragmented landscape: effects of habitat quality, patch size and isolation. Vol. 12, pp. 271-277.

Bess JA.1989.Status of the Karner blue butterfly, Lycaeides melissa samuelis Nabakov, in the Manistee National Forest. Unpublished Report, Michigan Natural Features Inventory, Lansing, MI.

Boggs, CL. 2009. Understanding insect life histories and senescence through a resource allocation lens. Functional Ecology. Vol. 23, pp. 27-37.

Buckland ST, Anderson DR, Burnham KP. 2004. Advanced distance sampling. Oxford University Press, New York.

Brown W.D., Alcock J. 1990. Hilltopping by the Red Admiral Butterfly: mate searching alongside congeners. Journal of Research of the Lepidoptera. Vol. 29(1-2). pp. 1-10. 
Carver SJ. 1991. Integrating multicriteria evaluation with Geographical Information Systems. International Journal of Geographic Information Systems. Vol. 5(3), pp. 321339.

Cianfrani C, Le Lay G, Hirzel AH, Loy A. 2010. Do habitat suitability models reliably predict the recovery areas of threatened species? Journal of Applied Ecology. Vol. 47(2), pp. 421-430.

Curtis JT.1959. The vegetation of Wisconsin. Madison, Wisconsin: University of Wisconsin Press.

Dennis RLH, Shreeve TG, van Dyck H. 2006. Habitats and resources: the need for a resource-based definition to conserve butterflies. Biodiversity and Conservation. Vol. 15, pp. 1943-1966.

Dennis RLH, Eales HT. 1997. Patch occupancy in Coenonympha tullia (Müller, 1974). (Lepidoptera: Satyrinae): habitat quality matters as much as patch size and isolation. Journal of Insect Conservation. Vol. 1, pp. 167-176.

Dennis B, Munholland PL, Scott JM. 1991. Estimation of growth and extinction parameters for endangered species. Ecological Monographs. Vol. 61(2), pp. 115-143. 
Dover JW, Settele J. 2009. The influences of landscape structure on butterfly distribution and movement: a review. Journal of Insect Conservation. Vol. 13, pp. 3-27.

Dover JW. 1996. Factors affecting the distribution of satyrid butterflies on arable farmland. Journal of Applied Ecology. Vol. 33, pp. 723-734.

Dunn JP. 2008. Investigations of adult dispersal, habitat quality analysis, and the development of monitoring techniques for the Karner blue butterfly within the Muskegon Recovery Unit. Final Report to MI DNR. 40 pp.

Eastman JR. 1999. Multi-criteria evaluation and GIS. In: Longley P, Goodchild MF, Maguir DJ, Rhind DW (editors). Geographical Information Systems: Principles and Technical Issues. Wiley, New York.

Eastman JR, Weigen J, Kyem PAK, Toledano J. 1995. Raster procedures for multicriteria/multi-objective decisions. Photogrammetric Engineering and Remote Sensing. Vol. 61(5), pp. 539-547.

Eastman JR. 1999. Multi-criteria evaluation and GIS. In: Longley PA, Goodchild MF, Maguire DJ, Rhind DW (Eds.). 1999. Geographical Information Systems. Wiley, New York. 
Elith J, Leathwick JR. 2009. Species distribution models: ecological explanation and prediction across space and time. Annual Review of Ecological, Evolution, and Systematics. Vol. 40, pp. 677-697.

Elith J, Graham CH, Anderson RP, Dudy’k M, Ferrir S, Guisan A, Hijmans RJ, Huettmann F, Leathwick JR, Lehmann A, Li J, Lohmann LG, Loiselle BA, Manion G, Moritz C, Nakamura M, Makazawa Y, Overton JM, Peterson AT, Phillips SJ, Richardson K, Scachetti-Pereira R, Schapire RE, Sobero'n J, Williams S, Wisz MS, Zimmerman NE. 2006. Novel methods improve prediction of species' distributions from occurrence data. Ecography. Vol. 29, pp. 129-151.

Elzinga CL, Salzer DW, Willoughby JWL. 1998. Measuring and monitoring plant populations. U.S. Department of the Interior. Bureau of Land Management. The Nature Conservancy. BLM Technical Reference $1730-1$.

Engler R, Guisan A, Rechsteiner L. 2004. An improved approach for predicting the distribution of rare and endangered species from occurrence and pseudo-absence data. Journal of Applied Ecology. Vol. 41, pp. 263-274.

Feber RE, Brereton TM, Warren MS, Oates M. 2001. The impacts of deer on woodland butterflies: the good, the bad and the complex. Forestry 74:273-276. 
Ferrier S, Drielsma M, Manion G, Watson G. 2002. Extended statistical approaches to modeling spatial pattern in biodiversity in northeast New South Wales. II. Communitylevel modeling. Biodiversity and Conservation. Vol. 11, pp. 2309-2338.

Forrester JA, Leopold DJ, Hafner SD. 2005. Maintaining critical habitat in a heavily managed landscape: effects of power line corridor management on Karner blue butterfly (Lycaeides melissa samuelis) habitat. Restoration Ecology. Vol. 13 (3), pp. 488-498.

Fuller SG. 2008. Population dynamics of the endangered Karner blue butterfly (Lycaeides melissa samuelis Nabakov). Doctoral Thesis. State University of New York. College of Environmental Science and Forestry. Syracuse, New York.

FWS (U.S. Fish and Wildlife Service). 1992. Endangered and threatened wildlife and plants; determination of endangered status for the Karner blue butterfly. Federal Register. December 14, 1992. Vol. 57 (240), pp. 59236-59244.

Gillingham PK, Huntley B, Kunin WE, Thomas CD. 2012. The effect of spatial resolution on projected responses to climate warming. Diversity and Distributions. Vol. 18(10), pp. 990-1000. 
Grundel R, Pavlovic NB. 2007. Resource availability, matrix quality, microclimate, and spatial pattern as predictors of patch use by the Karner blue butterfly. Biological Conservation. Vol. 135, pp. 135-144.

Grundel R, Pavlovic NB. 2000. Nectar plant selection by the Karner blue butterfly (Lycaeides melisssa samuelis) at the Indiana Dunes National Lakeshore. The American Midland Naturalist. Vol. 144(1), pp. 1-10.

Grundel R, Pavlovic NB, Sulzman CL. 1998a. The effect of canopy cover and seasonal change on host plant quality for the endangered Karner blue butterfly (Lycaeides melissa samuelis). Oecologia. Vol. 114, pp. 243-250.

Grundel Ralph, Pavlovic NB, Sulzman CL. 1998b. Habitat use by the endangered Karner blue butterfly in oak woodlands: the influence of canopy cover. Biological Conservation. Vol. 85, pp. 47-53.

Guiney MS, Oberhauser KS. 2008. Insects as flagship conservation species. Terrestrial Arthropod Reviews Vol. 1, pp. 111-123.

Guisan A, Broennimann O, Engler R, Vust M, Yoccoz NG, Lehmann A, Zimmerman NE. 2006. Using niche-based models to improve the sampling of rare species. Conservation Biology. Vol. 20(5), pp. 501-511. 
Guisan A, Thuiller W. 2005. Predicting species distribution: offering more than simple habitat models. Ecology Letters. Vol. 8, pp. 993-1009.

Haack RA. 1993. The endangered Karner blue butterfly (Lepidoptera: Lycaenidae): biology, management considerations, and data gaps. North Central Forest Experiment Station, USDA Forest Service, Insect Project. $9^{\text {th }}$ Central Hardwood Forest Conference.

Haddad NM, Tewksbury JJ. 2005. Low-quality habitat corridors as movement conduits for two butterfly species. Ecological Applications. Vol. 15(1), pp. 250-257.

Hanski I. 1998. Metapopulation ecology. Oxford University Press, Oxford.

Hanski I. 1994. Patch-occupancy dynamics in fragmented landscapes. Trends in Ecology and Evolution. Vol. 9, pp. 131-135.

Hanski I, Kuussaari M, Nieminen M. 1994. Metapopulation structure and migration in the butterfly Melitaea cinxia. Ecology. Vol. 75(3), pp. 747-762.

Hermes CP. 1996. The Endangered Karner blue butterfly (Lepidoptera: Lycaenidae) in Michigan: Habitat Suitability, Potential Impacts of Gypsy Moth (Lepidoptera: 
Lymanitriidae) Suppression, and Laboratory Rearing. Master of Science Thesis. Michigan State University. Department of Entomology.

Hernandez PA, Graham CH, Master LL, Albert DL. 2006. The effect of sample size and species characteristics on performance of different species distribution modeling methods. Ecography. Vol. 29, pp. 773-785.

Hess AN, Falkowski MJ, Webster CR, Storer AJ, Pocewicz A, Martinuzzi S. 2013. Employing lidar data to identify butterfly habitat characteristics of four contrasting butterfly species across a diverse landscape. Remote Sensing Letters. Vol. 4(4), pp. 354-363.

Jager HI. Overton WS. 1993. Explanatory models for ecological response surfaces. Chapter 42, pp. 422-437. In: Environmental Monitoring with GIS. Oxford University Press, New York.

Kearney M, Porter W. 2009. Mechanistic niche modeling: combining physiological and spatial data to predict species' ranges. Ecology Letters. Vol. 12, pp. 1-17.

Krauss J, Steffan-Dewenter I, Tscharntke T. 2003. How does landscape context contribute to effects of habitat fragmentation on diversity and population density of butterflies? Journal of Biogeography. Vol. 30, pp. 889-900. 
Kuefler D, Haddad NM, Hall S, Hudgens B, Bartel B, Hoffman E. 2008. Distribution, population structure and habitat use of the endangered Saint Francis Satyr butterfly, Neonympha mitchellii francisci. American Midland Naturalist. Vol. 159(2), pp. 298320.

Kuussaari M, NIeminen M, Hanski I. 1996. An experimental study of migration in the Glanville fritillary butterfly Melitaea cinxia. Journal of Animal Ecology. Vol. 65, pp.791-801.

Lane CP. 1997. Forest management guidelines: developing management plans compatible with Karner blue butterfly persistence. Wisconsin Department of Natural Resources. Madison, Wisconsin. United States Fish and Wildlife Service. Fort Snelling, Minnesota.

Latsch, ME. 2011. Effects of management on native and exotic plant communities in Pictured Rocks National Lakeshore in the Upper Peninsula of Michigan. Dissertation. Michigan Technological University.

Lawrence WS. 1994. Karner blue butterfly populations in the Allegan State Game Area, Michigan. In: Andow DA, Baker RJ, Lane CP (editors). Karner blue butterfly: a symbol 
of a vanishing landscape. Minnesota Agricultural Experiment Station, University of Minnesota, St Paul, pp. 53-62.

Leach M. 1993. Status and distribution of the Karner blue butterfly at Fort McCoy, Wisconsin: final report on a two-year study. Unpublished Report Prepared for the Natural Resources Management Division, Fort McCoy Military Research Reservation, U.S. Army. The Nature Conservancy, Wisconsin Chapter.

LeBare KM, Broyles SB, Klotz RL. 2000. Exploring nectar biology to learn about pollinators. The American Biology Teacher. Vol. 62 (4), pp. 292-296.

Le Lay G, Engler R, Franc E, Guisan A. 2010. Prospective sampling based on model ensembles improves the detection of rare species. Ecography. Vol. 33(6), pp. 10151027.

Lindell CA, Maurer BA. 2010. Patch quality and landscape connectivity effects on patch population size: implications for metapopulation size and studies of landscape value. Evolutionary Ecology Research. Vol. 12, pp. 249-258.

Luoto M, Kuussaari M. 2002. Modeling butterfly distribution based on remote sensing data. Journal of Biogeography. Vol. 29, pp. 1027-1037. 
Martin M.L. 1992. Karner blue butterfly (Lycaeides melissa samuelis) in Indiana: 1990

Status Report. Unpublished Report. Indiana Department of Natural Resources, Indianapolis. IN.

Matter SF, Roland J. 2002. An experimental examination of the effects of habitat quality on the dispersal and local abundance of the butterfly Parnassius smintheus. Ecological Entomology. Vol. 27, pp. 308-316.

Maxwell JS, Givnish T. 1993. Research on the Karner blue butterfly at Fort McCoy, Wisconsin: Progress Report for the 1993 Field Season.

Mazerolle MJ, Villard ma. 1999. Patch characteristics and landscape context as predictors of species presence and abundance: a review. Ecoscience. Vol. 6 (1), pp. 117 124.

McCarthy MA, Elith J. 2002. Species mapping for conservation. Gap Analysis Bulletin, 2. United States Geological Survey. Vol. 11, pp. 50-57.

McNab HW, Avers PE. 1994. Ecological subregions of the United States: section descriptions. United States Department of Agriculture: Forest Service, Ecosystem Management. Washington, D.C. 
Moilanan A, Hanski J. 1998. Metapopulation dynamics: effects of habitat quality and landscape structure. Ecology. Vol. 79, pp. 2503-2515.

Morris DW. 2003. How can we apply theories of habitat selection to wildlife conservation and management? Wildlife Research. Vol. 30, pp. 303-319.

Natural Resources Conservation Service (NRCS). 2006. Soil Survey geographic (SSURGO) database. http://soildatamart.nrcs.usda.gov

New TR. 2007. Understanding the requirements of the insects we seek to conserve. Journal of Insect Conservation. Vol. 11, pp. 95-97.

Nuzzo VA. 1986. Extent and status of Midwest oak savanna: presettelement and 1985. Natural Areas Journal. Vol. 6, pp. 6-36.

Öckinger E, Smith HG. 2006. Landscape composition and habitat area affects butterfly species richness in semi-natural grasslands. Oecologia. Vol. 149, pp. 526-534.

Pauler-Fürste R, Kaule G, Settele J. 1996. Aspects of the population vulnerability of the large blue butterfly, Glaucopsyche (Maculinea) arion, in south-west Germany. In: Settele J, Margules C, Poschlod P, Henle K (eds). Species survival in fragmented landscapes. Kluwer, Dordrecht, pp. 275-281. 
Pavlovic NB, Grundel R. 2009. Reintroduction of wild lupine (Lupinus perennis L.) Depends on variations in canopy, vegetation, and litter cover. Restoration ecology. Vol. 17(6), pp. 807-817.

Peterson RKD, Mayer SJ, Wolf AT, Wolt JD, Davis PM. 2006. Genetically engineered plants, endangered species, and risk: a temporal and spatial exposure assessment for Karner blue butterfly larvae and Bt maize pollen. Risk Analysis. Vol. 26 (3), pp. 845858.

Peterson AT. 2001. Predicting species' geographic distributions based on ecological niche modeling. The Condor. Vol. 103, pp. 599-605.

Phillips SJ, Anderson RP, Schapire re. 2006. Maximum entropy modeling of species geographic distributions. Ecological Modeling. Vol. 190 (3-4), pp. 231-259.

Pickens BA, Root KV. 2008. Factors affecting host-plant quality and nectar use for the Karner blue butterfly: implications for oak savanna restoration. Natural Areas Journal. Vol. 28(3), pp. 210-217. 
Pocewicz, Amy, Penelope Morgan and Sandford D. Eigenbrode. 2009. Local and landscape effects on butterfly density in northern Idaho grasslands and forests. Journal of Insect Conservation. Vol. 13, pp. 593-601.

Prugh LR, Hodges KE, Sinclair ARE, Brashares JS. 2008. Effect of habitat area and isolation on fragmented animal populations. PNAS 105:20770-20775.

Pywell RF, Warman EA, Sparks TH, Greatorex-Davies JN, Walker KH, Meek WR, Carvell C, Petit S, Firbank LG. 2004. Assessing habitat quality for butterflies on intensively managed arable farmland. Biological Conservation. Vol. 118, pp. 313-325.

Radeloff VC, Mladenoff DJ, Boyce MS (2000) The changing relation of landscape patterns and jack pine budworm populations during an outbreak. Oikos. Vol. 90(3), pp. 417-430.

Raxworthy CJ, Martinex-Meyer E, Horning N, Nussbaum RA, Schneider GE, OrtegaHuerta MA, Peterson AT. 2003. Predicting distributions of known and unknown reptiles species in Madagascar. Nature. Vol. 426, pp. 837-841.

Ricketts TH. 2001. The matrix matters: effective isolation in fragmented landscapes. The American Naturalist. Vol. 158, pp. 87-99. 
Ripley BD. 1977. Modeling spatial patterns. Journal of the Royal Statistical Society Series B - Methodological. Vol. 39, pp. 172-212.

Rosenzweig MI. 1981. A theory of habitat selection. Ecology. Vol. 62(2), pp. 327-335.

Savanick MA. 2005. Population dynamics and nectar preference of the Karner blue butterfly, Lycaeides melissa samuelis (Nabokov) [Lepidoptera: Lycaenidae]. Master's Degree Thesis. University of Minnesota.

Schulte LA, Mladenoff DJ (2005) Severe wind and fire regimes in northern forests: historical variability at the regional scale. Ecology. Vol. 86(2), pp. 431-445.

Schuurman G. 2009. Distance sampling survey protocol. Wisconsin Department of Natural Resources: Wisconsin Karner Blue Butterfly Recovery Program.

Schweitzer DF. 1990. The 1990 status of selected Karner blue remnants in Saratoga and Albany counties, New York with a discussion of monitoring methods. Unpublished Report. New York Department of Environmental Conservation, Endangered Species Unit.

Shartell LM, Lilleskov EA, Storer AJ. 2013. Predicting exotic earthworm distribution in the northern Great Lakes region. Biological Invasions. Vol 15(8), pp. 1665-1675. 
Shartell LM, Nagel LM, Storer AJ. 2011. Multi-criteria risk model for garlic mustard (Alliaria petiolata) in Michigan's Upper Peninsula. The American Midland Naturalist. Vol. 165, pp. 116-127.

Shillinglaw J, Shillinglaw C. 2008. Movement of Karner blue butterflies into and between prairie restorations; implications for establishing a viable metapopulation. Unpublished document. Karner Blue Butterfly Recovery.

Shuey JA. 1997. Dancing with fire: ecosystem dynamics, management, and the Karner blue (Lycaeides melissa samuelis Nabokov) (Lycaenidae). Journal of the Lepidopterists Society. Vol. 51, pp. 263-269.

Smallidge PJ, Leopold DJ, Allen CM. 1996. Community characteristics and vegetation management of Karner blue butterfly (Lycaeides melissa samuelis) habitats on rightsof-way in East-Central New York, USA. The Journal of Applied Ecology. Vol. 33(6), pp. 1405-1419.

Smith MA, Turner MG, Rusch DH. 2002. The effect of military training activity on eastern lupine and the Karner blue butterfly at Fort McCoy, Wisconsin, USA. Environmental Management. Vol. 29 (1), pp. 102-115. 
Souza Gomes Guarino E, Barbosa AM, Waechter JL. 2012. Occurrence and abundance models of threatened plant species: applications to mitigate the impact of hydroelectric power dams. Ecological Modeling. Vol. 230, pp. 22-33.

Steffan-Dewenter I, Tscharntke T. 2000. Butterfly community structure in fragmented habitat. Ecology Letters. Vol. 3, pp. 449-456.

Store R, Kangas J. 2001. Integrating spatial multi-criteria evaluation and expert knowledge for GIS-based habitat suitability modeling. Landscape Urban Planning. Vol. 55 , pp. 79-93.

Swengel AB. 1995. Observations of spring larvae of Lycaeides melissa samuelis (Lepidoptera: Lycaenidae) in central Wisconsin. The Great Lakes Entomologist. Vol. 28(2), pp. 155-170.

Szeicz JM, MacDonald GM. 1991. Postglacial vegetation history of oak savanna in Southern Ontario (Canada). Canadian Journal of Botany. Vol. 69, pp. 1507-1519.

Thomas L, Buckland ST, Rexstad EA, Laake JL, Strindberg S, Hedley SL, Bishop JRB, Marques TA, Burnham KP. 2010. Distance software: design and analysis of distance sampling surveys for estimating population size. Journal of Applied Ecology Vol. 47, pp. 5-14. 
Thomas JA, Bourn NAD, Clark RT, Stewart KE, Simcoz DJ, Pearman GS, Curtis R, Goodger B. 2001. The quality and isolation of habitat patches both determine where butterflies persist in fragmented landscapes. Proceedings of the Royal Society B: Biological Sciences. Vol. 268, pp. 1791-1796.

Thomas JN. 1988. Evolutionary ecology of the relationship between oviposition preference and performance of offspring in phytophagous insects. Entomologica Experimentalis et Applicata. Vol. 47, pp. 3-14.

Turner J.D. 1990. Vertical stratification of hilltopping behavior in swallowtail butterflies (Papilionidae). Journal of the Lepidopterists' Society. Vol. 44(3). pp. 174179.

WDNR (Wisconsin Department of Natural Resources). 2007. The Wisconsin Karner blue butterfly habitat conservation plan: annual report of activities for calendar year 2007. Wisconsin Department of Natural Resources. Division of Forestry.

WDNR (Wisconsin Department of Natural Resources). 2005. Hydrography. Madison, WI. 
WDNR (Wisconsin Department of Natural Resources). 1998. Wisconsin Land Cover Image. Madison, WI.

Wiklund C. 1977. Oviposition, feeding and spatial separation of breeding and foraging habitats in a population of Leptidea sinapsis (Lepidoptera). Oikos. Vol. 28, pp. 56-68.

Woiwod I, Thomas JA. 1993. The ecology of butterflies and moths at the landscape scale. In: Haines-Young R (ed). Landscape Ecology in Britain. IALE(UK), Preston, pp. $76-92$. 
Table 3.1: Comparison of 30 sample areas used in model development and validation throughout the study.

\begin{tabular}{|c|c|c|}
\hline Recovery Unit & $\begin{array}{l}\text { Sample } \\
\text { Area } \\
\text { Code }\end{array}$ & $\begin{array}{l}\text { Area } \\
\text { (ha) }\end{array}$ \\
\hline \multirow{3}{*}{ Sandhill Wildlife Area } & SBP & 67.91 \\
\hline & SNE & 33.65 \\
\hline & SW & 6.05 \\
\hline \multirow{5}{*}{ Black River State Forest } & BBB & 15.80 \\
\hline & $\mathrm{C} 11$ & 3.76 \\
\hline & $\mathrm{C} 35$ & 14.94 \\
\hline & $\mathrm{C} 38$ & 12.27 \\
\hline & $\mathrm{C} 16$ & 15.17 \\
\hline \multirow{11}{*}{ Emmons Creek Fishery Area } & EC2 & 6.33 \\
\hline & EC3 & 1.82 \\
\hline & $\mathrm{EC} 3 \mathrm{~A}$ & 3.62 \\
\hline & EC4 & 8.29 \\
\hline & EC5 & 1.75 \\
\hline & EC67 & 4.03 \\
\hline & EC8 & 4.89 \\
\hline & ECF1 & 10.94 \\
\hline & ECF2 & 10.47 \\
\hline & ECFL & 4.38 \\
\hline & ECL & 1.16 \\
\hline Hartman Creek State Park & $\mathrm{CR}$ & 4.10 \\
\hline \multirow{4}{*}{ White River Marsh State Wildlife Area } & $\mathrm{K}$ & 1.63 \\
\hline & $\mathrm{PE}$ & 3.46 \\
\hline & $\mathrm{TN}$ & 3.01 \\
\hline & $\mathrm{W}$ & 4.17 \\
\hline Greenwood Wildlife Area & $\mathrm{G} 2$ & 12.80 \\
\hline \multirow{5}{*}{$\begin{array}{l}\text { Crex Meadows and Fish Lake Wildlife } \\
\text { Area }\end{array}$} & BU52 & 10.15 \\
\hline & RL & 18.76 \\
\hline & SS & 5.45 \\
\hline & $\mathrm{TH}$ & 6.45 \\
\hline & SRFB & 9.88 \\
\hline
\end{tabular}


Table 3.2: Habitat suitability categories applied to Potential Habitat Model across all used Karner blue butterfly sample areas in Wisconsin.

\begin{tabular}{lc}
\hline \multicolumn{1}{c}{ Variable } & $\begin{array}{c}\text { Habitat suitability } \\
\text { categories }\end{array}$ \\
\hline \hline Sand & 1 \\
Loamy-sand & 2 \\
Bedrock & 2 \\
Sandy-loam & 3 \\
Loam & 4 \\
Clay-loam & 5 \\
Sandy-clay-loam & 5 \\
Sandy silt-loam & 6 \\
Sandy-clay & 6 \\
Silt-loam & 7 \\
Silty-clay-loam & 7 \\
Silt & 8 \\
Clay-loam & 8 \\
Silty-clay & 8 \\
Peat & 8 \\
Muck & 9 \\
Water & 9 \\
VAR & 9 \\
Shrub/tree percent cover & 9 \\
Open Area & 1 \\
\hline \hline
\end{tabular}


Table 3.3: Habitat suitability categories applied to Relative Habitat Suitability Model percent groundcover categories at Karner blue butterfly sandy sample areas in Wisconsin.

\begin{tabular}{|c|c|c|c|}
\hline \multicolumn{4}{|c|}{ Sandy Sites } \\
\hline & Shrub/Tree & $\begin{array}{c}\text { Focal } \\
\text { Nectar }\end{array}$ & Lupine \\
\hline $\begin{array}{c}\text { Groundcover } \\
\text { Categories }\end{array}$ & & $\begin{array}{c}\text { Habitat } \\
\text { suitability } \\
\text { categories }\end{array}$ & \\
\hline 0---1 & 5 & 8 & 1 \\
\hline $1---5$ & 3 & 7 & 1 \\
\hline 5---10 & 2 & 3 & 1 \\
\hline $10---20$ & 1 & 3 & 1 \\
\hline $20---33$ & 2 & 3 & 1 \\
\hline $33---50$ & 3 & 2 & 1 \\
\hline 50---75 & 6 & 1 & 1 \\
\hline 75---100 & 7 & 1 & 2 \\
\hline
\end{tabular}


Table 3.4: Habitat suitability categories applied to Relative Habitat Suitability Model percent groundcover categories at Karner blue butterfly loamy-sand sample areas in Wisconsin.

\begin{tabular}{|c|c|c|c|}
\hline \multicolumn{4}{|c|}{ Loamy-Sand Sites } \\
\hline & Shrub/Tree & $\begin{array}{l}\text { Focal } \\
\text { Nectar }\end{array}$ & Lupine \\
\hline $\begin{array}{c}\text { Groundcover } \\
\text { Categories }\end{array}$ & & $\begin{array}{c}\text { Habitat } \\
\text { suitability } \\
\text { categories }\end{array}$ & \\
\hline 0---1 & 1 & 8 & 1 \\
\hline $1---5$ & 1 & 7 & 1 \\
\hline 5---10 & 2 & 3 & 1 \\
\hline $10---20$ & 3 & 3 & 1 \\
\hline $25---33$ & 5 & 3 & 1 \\
\hline $33---50$ & 6 & 2 & 1 \\
\hline $50---75$ & 7 & 1 & 1 \\
\hline 75---100 & 8 & 1 & 2 \\
\hline
\end{tabular}




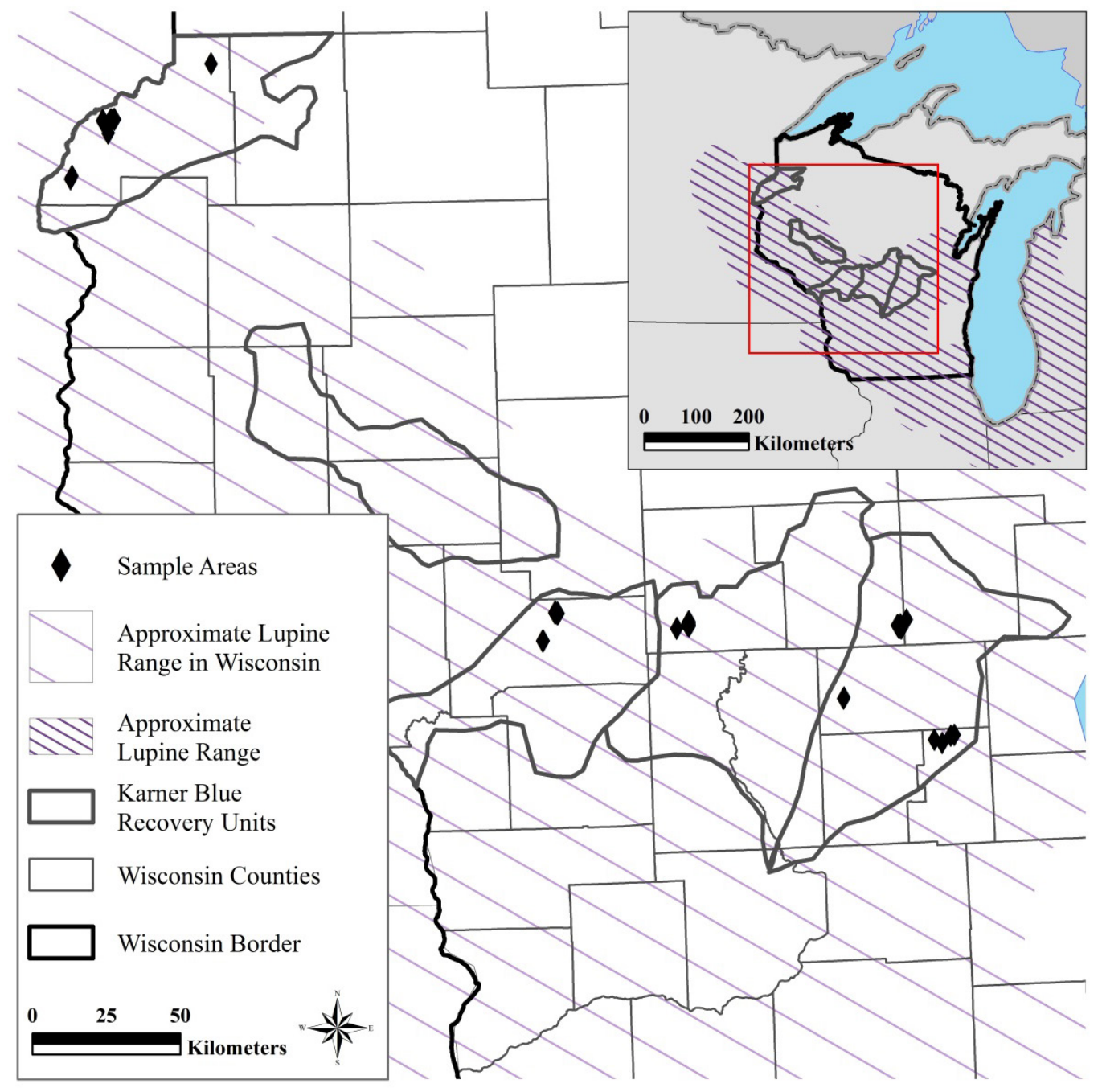

Figure 3.1: Study sites across the Karner blue butterfly range and demarcated Karner blue butterfly recovery zones in Wisconsin. Map by A. Hess. 


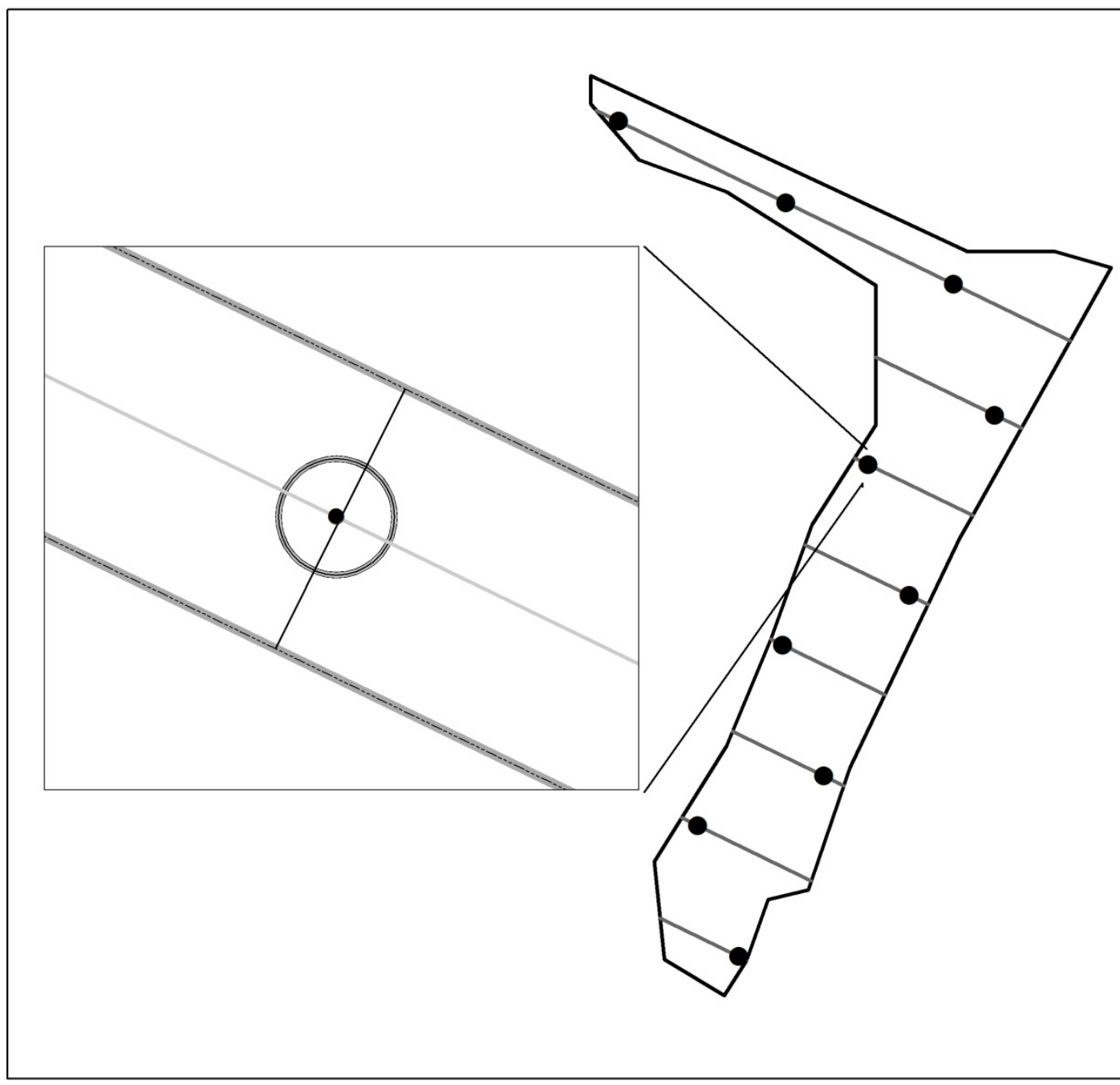

\section{Sample Plot Features}

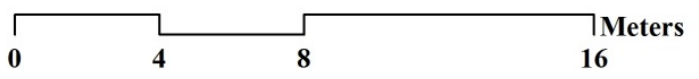

- $\quad$ Sample Point

- $5 \mathrm{~m}$ Line Intercept Transect

Karner Blue Population Estimate Transect (permanent transect)

$\square \quad 1 / 800$ ha Plot (for focal nectar plant stem counts)

$5 \mathrm{~m}$ Buffer (Represents full width of population estimate transect)

Sample Area Boundary

Figure 3.2: Example of the sample design used across small-scale sample areas to collect ground measurements at Michigan Tech research sample areas. 


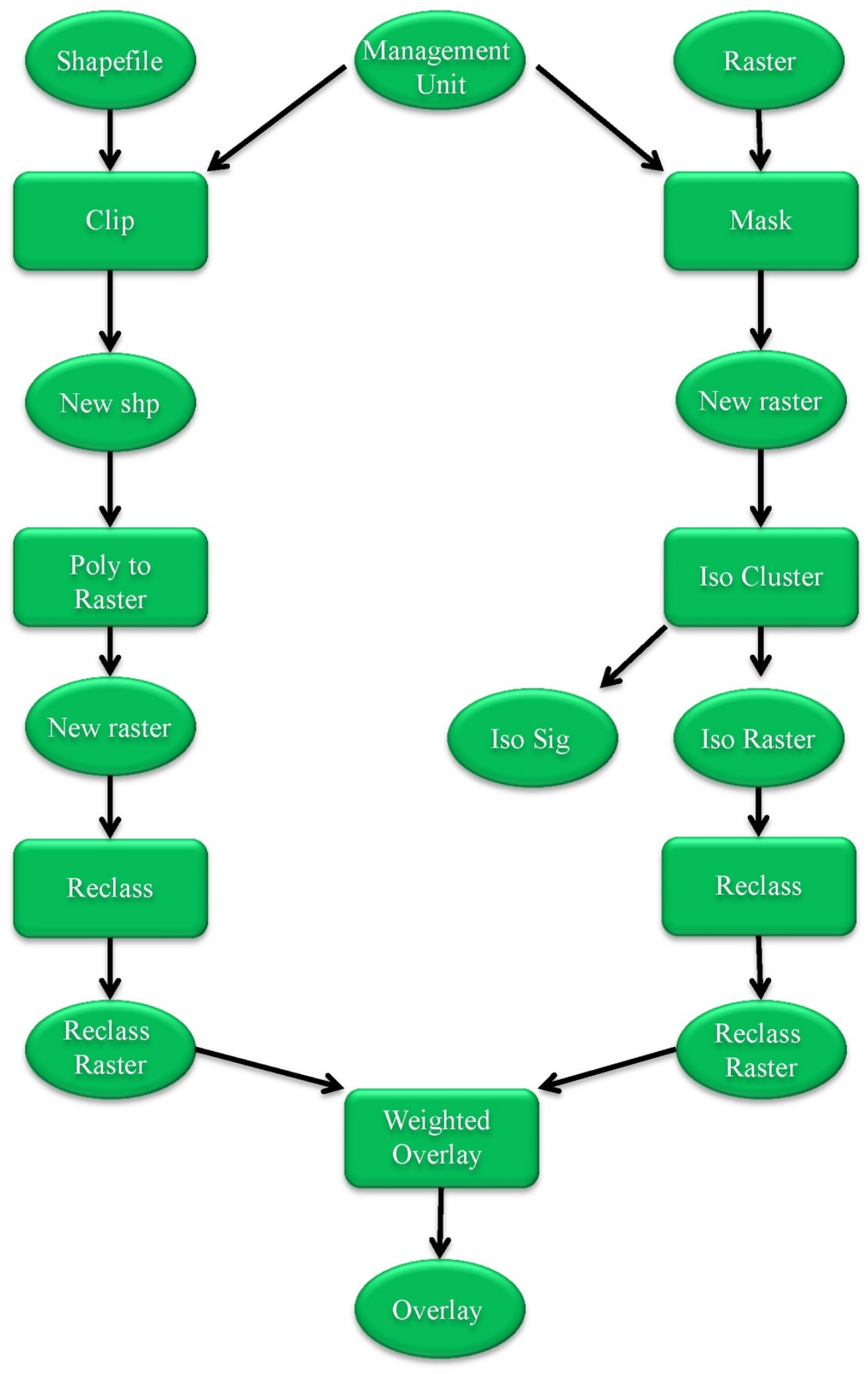

Figure 3.3: Flow-chart representing the basic steps of producing the Potential Habitat Model. Graphic by A. Hess. 


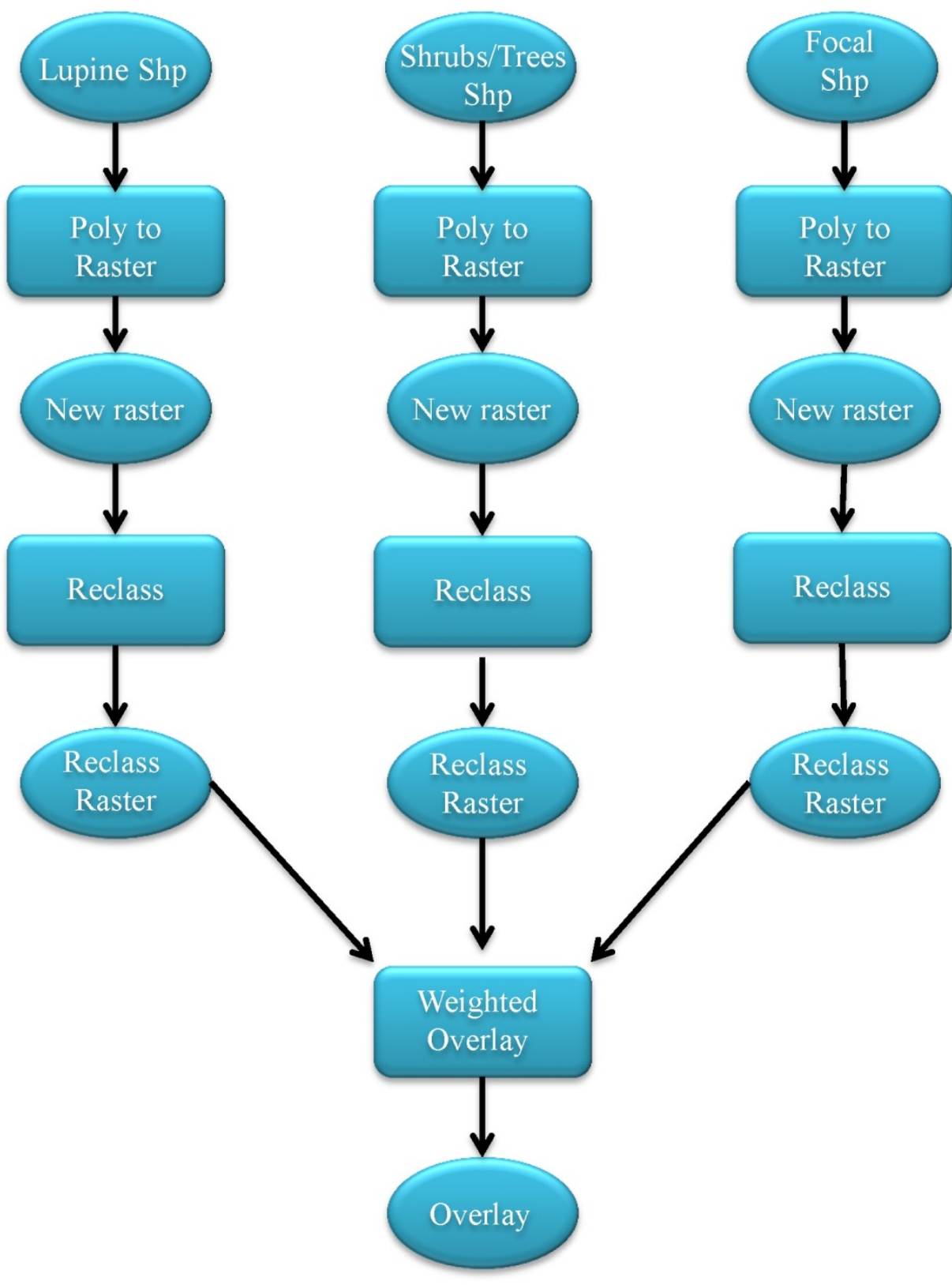

Figure 3.4: Flow-chart representing the basic steps of producing the Relative Habitat Suitability Model. Graphic by A. Hess. 


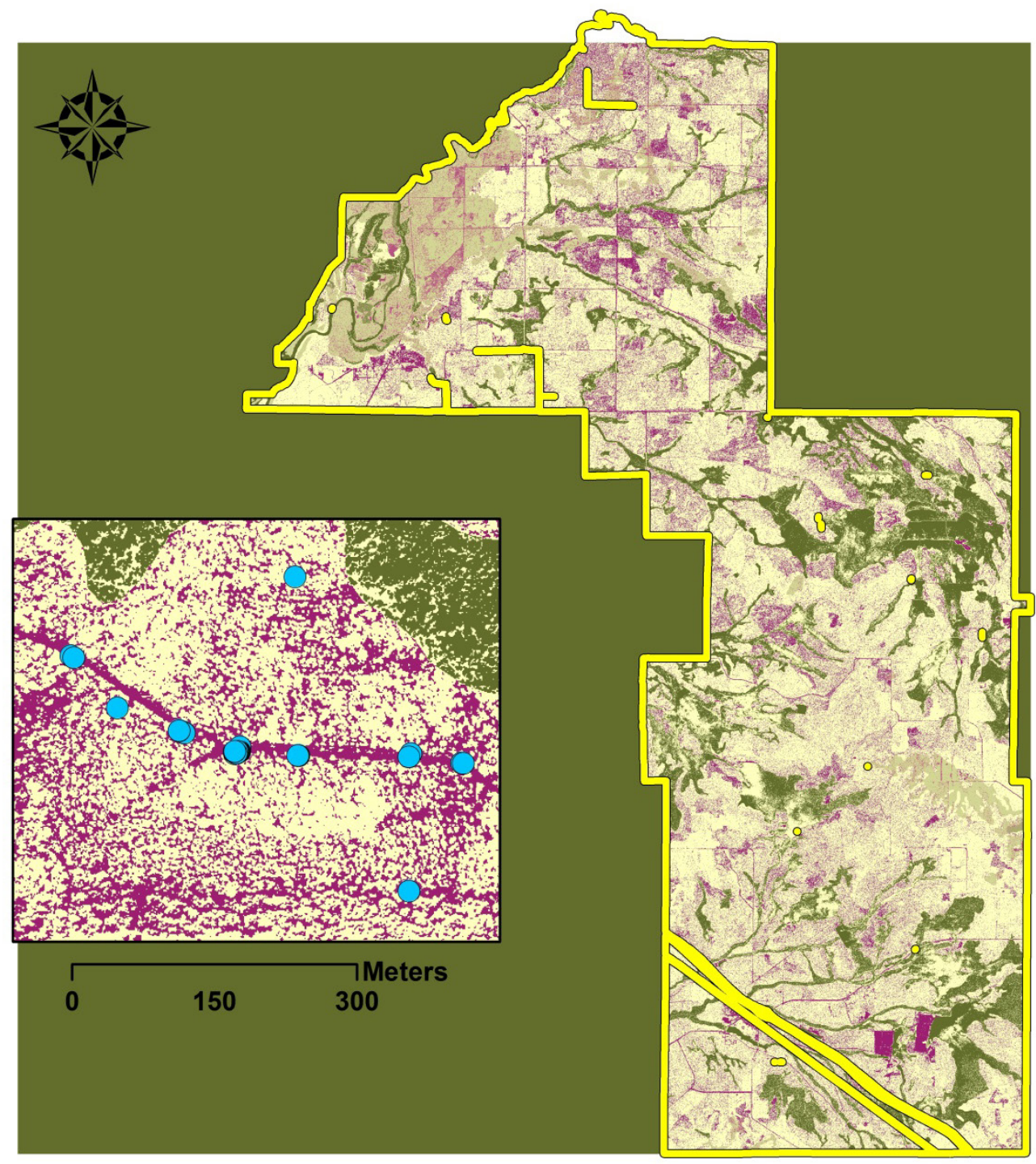

\section{Potential Habitat}

\begin{tabular}{cc} 
High & Moderate \\
$\square$ & $\square$ \\
\hline & \\
\hline & \\
\hline
\end{tabular}

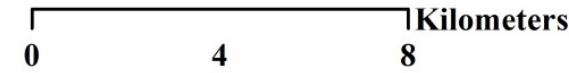

Karner Blue GPS Points

State Property Boundary

Map by Anna N Hess

Figure 3.5: Example of the Potential Habitat Model output for identifying Karner blue butterfly habitat within a state property in the Karner blue range in Wisconsin. $1 \mathrm{~m}$ resolution of the model allows for identification of fine-scale habitat structural characteristics such as corridors, pictured above, that are favorable to Karner blues. Black River State Forest, Wisconsin. 


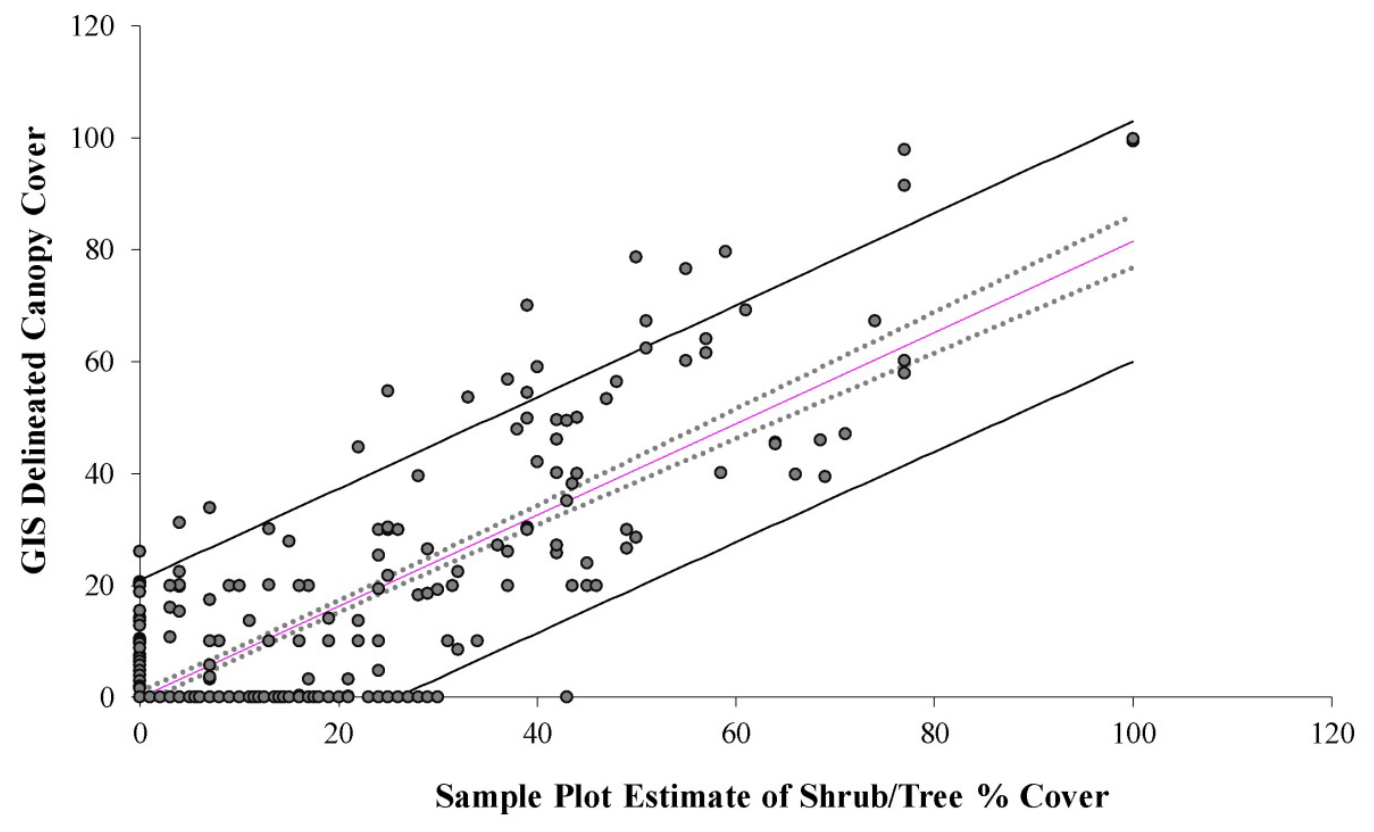

- Data

$\longrightarrow \mathrm{Y}=-3.50042 \mathrm{E}-02+0.81523 * \mathrm{X}$

— $95 \%$ Confidence (Data)

..... 95\% Confidence (Line)

Figure 3.6: Ground-validation of derived canopy cover from 2010 NAIP orthophotos. 470 plots were used to compare $\%$ shrub/tree percent cover along a $10 \mathrm{~m}$ line intercept transect derived from orthophotos, and using in situ groundcover information. $\mathrm{R}=0.8$ at $p \leq 0.05$. 


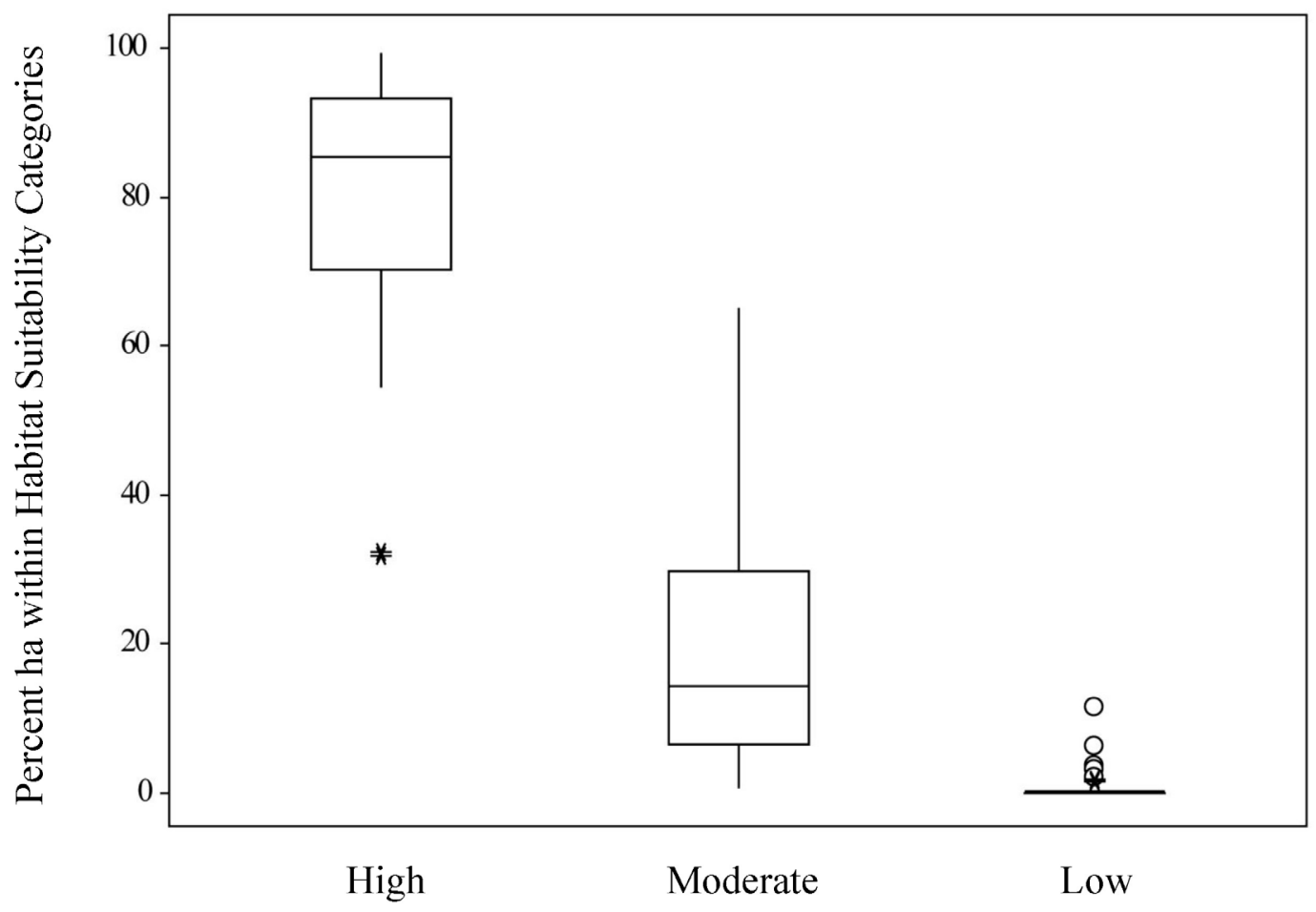

Habitat Suitability Categories

Figure 3.7: Comparison of the area for 30 sample areas in Potential Habitat Model suitability categories. Habitat suitability categories are categorized in three groups: a) habitat suitability categories 1-3, high favorable habitat, b) habitat suitability categories 4-6, moderately favorable habitat, and c) habitat suitability categories 7-9, low unfavorable habitat. Groups a-c were significantly different using a Kruskal-Wallis ANOVA, $p \leq 0.05$. Box encloses median (bar line) and $25^{\text {th }}$ and $75^{\text {th }}$ percentiles, vertical lines represent 1.5 Interquartile Range (IQR), outliers (*) and extreme outliers at 3 IQR (o). 


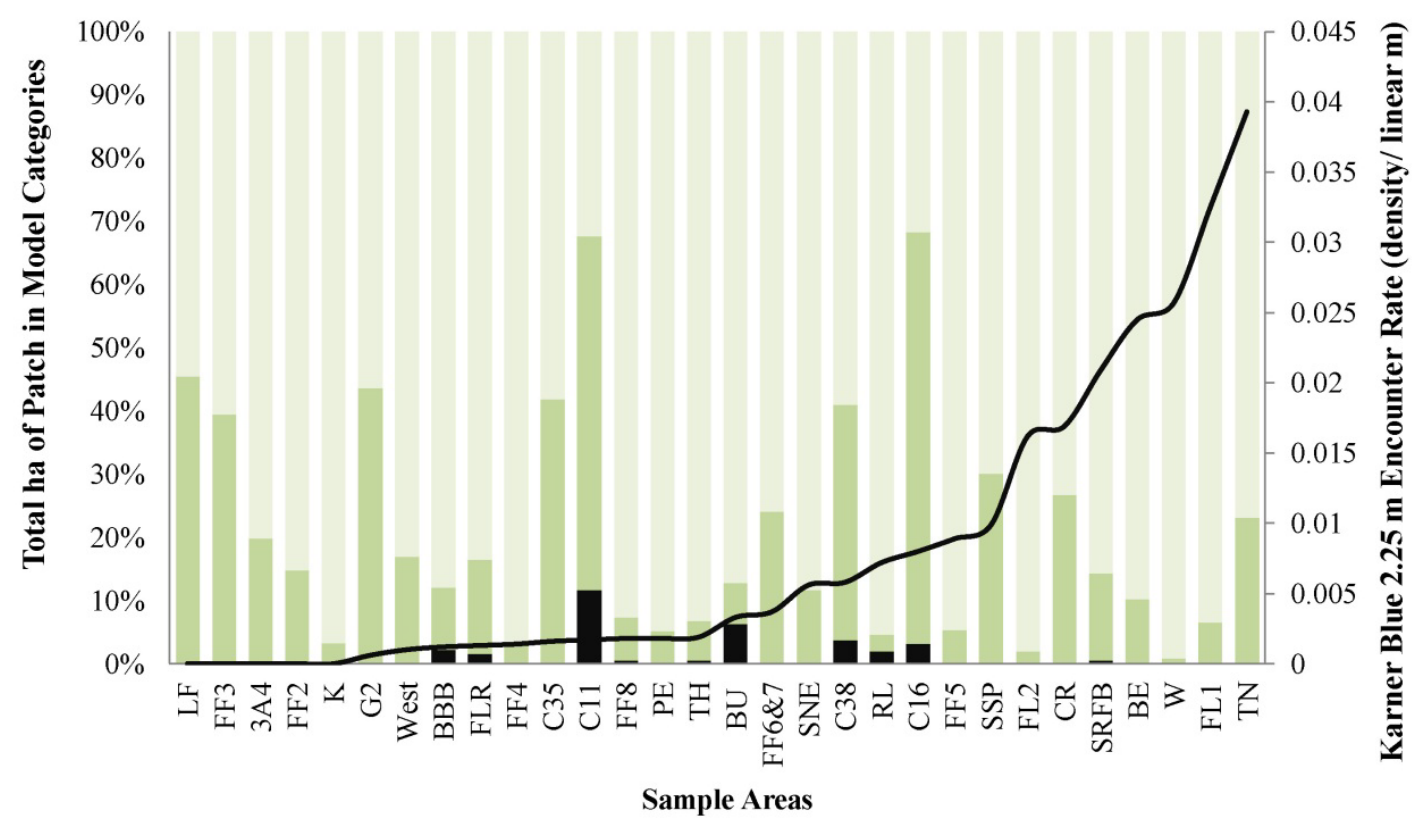

a) Habitat Suitability Categories 1-3 (High, Favorable Habitat)

b) Habitat Suitability Categories 4-6 (Moderate, Favorable Habitat)

c) Habitat Suitability Categories 7-9 (Low, Unfavorable Habitat)

-2.25 m Encounter Rate

Figure 3.8: Comparison of the area for 30 sample areas in Potential Habitat Model suitability categories to the Karner blue encounter rate per sample area for $2.25 \mathrm{~m}$. Habitat suitability categories are categorized in three groups: a) 1-3, high favorable habitat, b) 4-6, moderately favorable habitat, and c) 7-9, low unfavorable habitat. Data is arranged according to increasing encounter rate from left to right. 
Site BU52
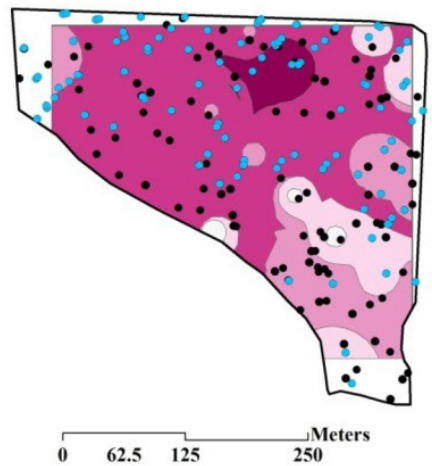

Site BBB

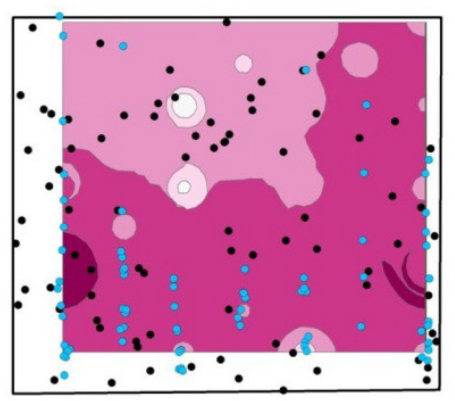

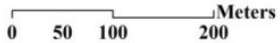

Site W
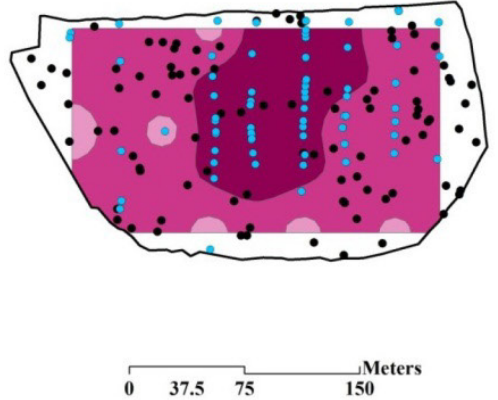
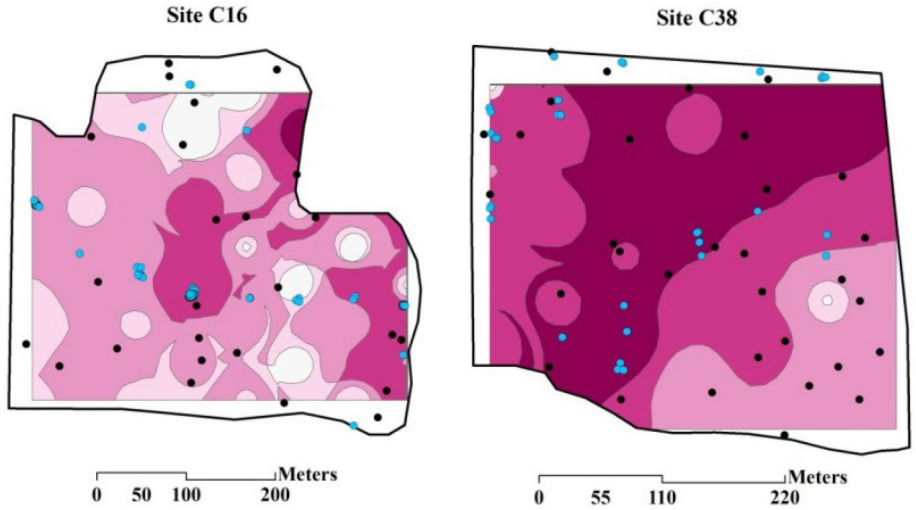

Site TN
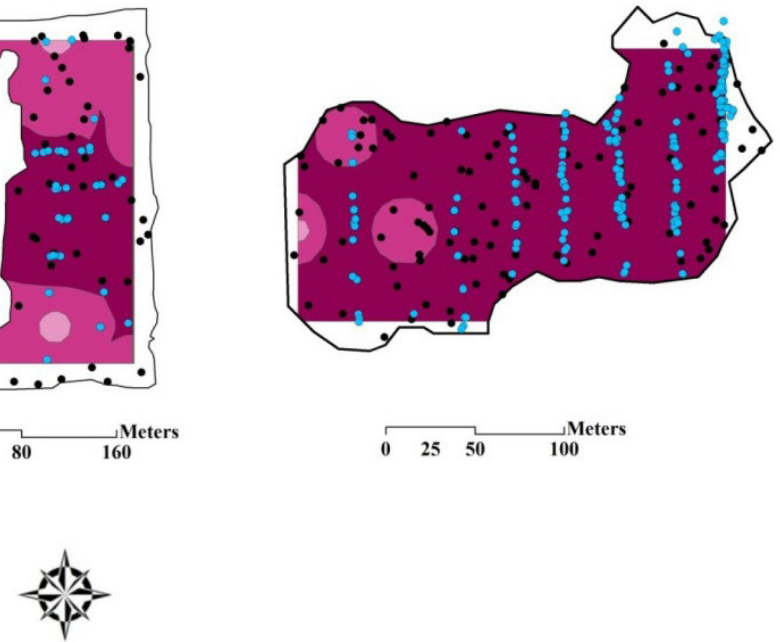

Relative Habitat Quality High Moderate Low

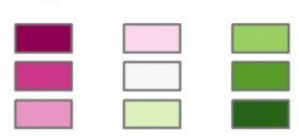

Karner Blue Field Site

Karner Blue GPS Points

- Random Points

Map by Anna N Hess

Figure 3.9: Relative Habitat Suitability Model output for seven validation sample areas, evaluating Karner blue butterfly habitat suitability in Wisconsin. Note that sites with high Karner blue populations will contain higher model categories, while sites with low populations will contain lower model categories. 

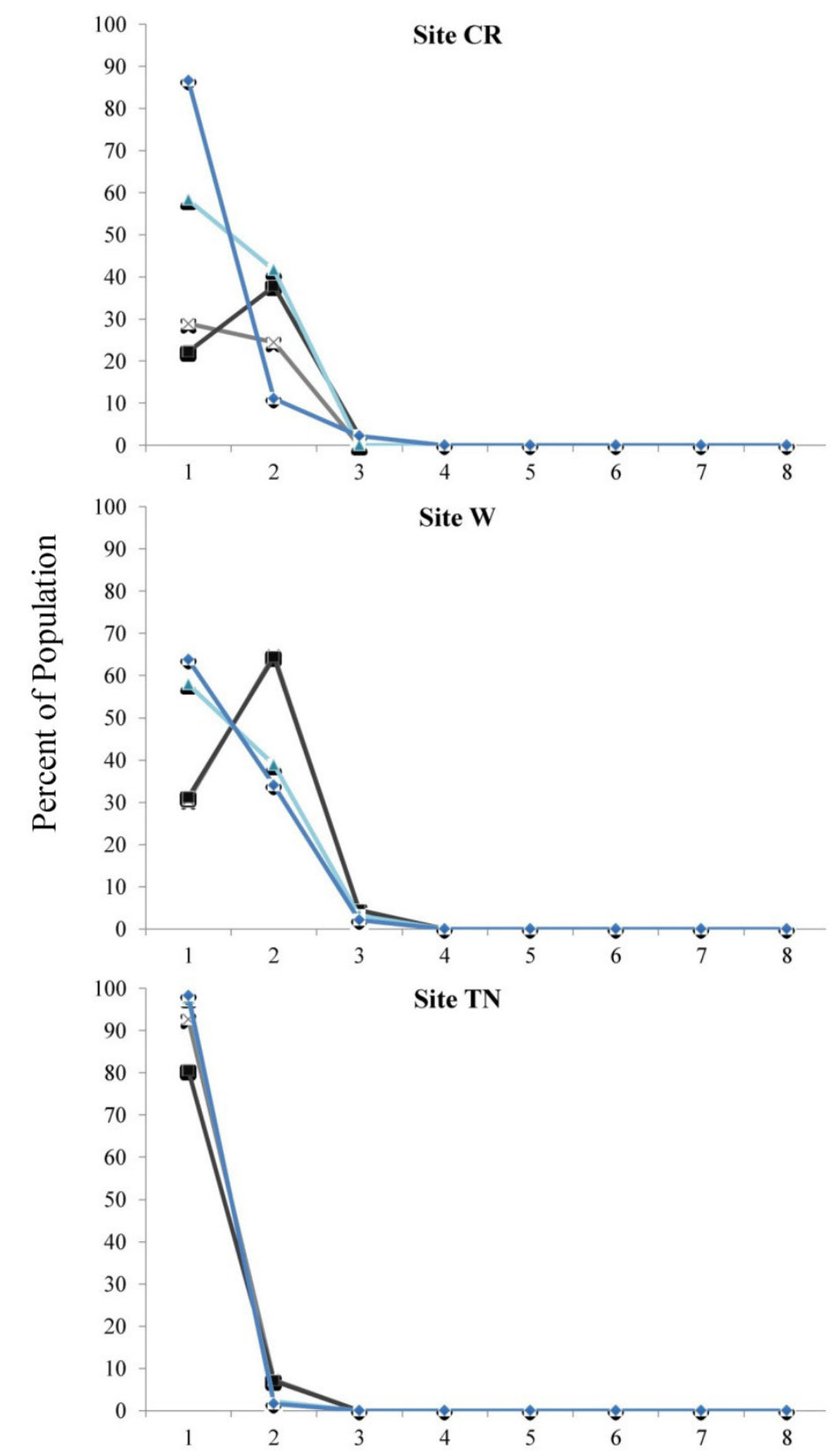

Model Categories $(1=$ Good Habitat, $8=$ Poor Habitat $)$

$\begin{array}{ll}-2011 \% \text { Karner Blues } & -2011 \% \text { Random Points } \\ -\Delta-2012 \% \text { Karner Blues } & =2012 \% \text { Random Points }\end{array}$

Figure 3.10: Percent of Karner blue populations and random points identified in the Relative Habitat Suitability Model in loamy-sand sample areas. Populations within sample areas BU52 were not highly statistically clustered. 


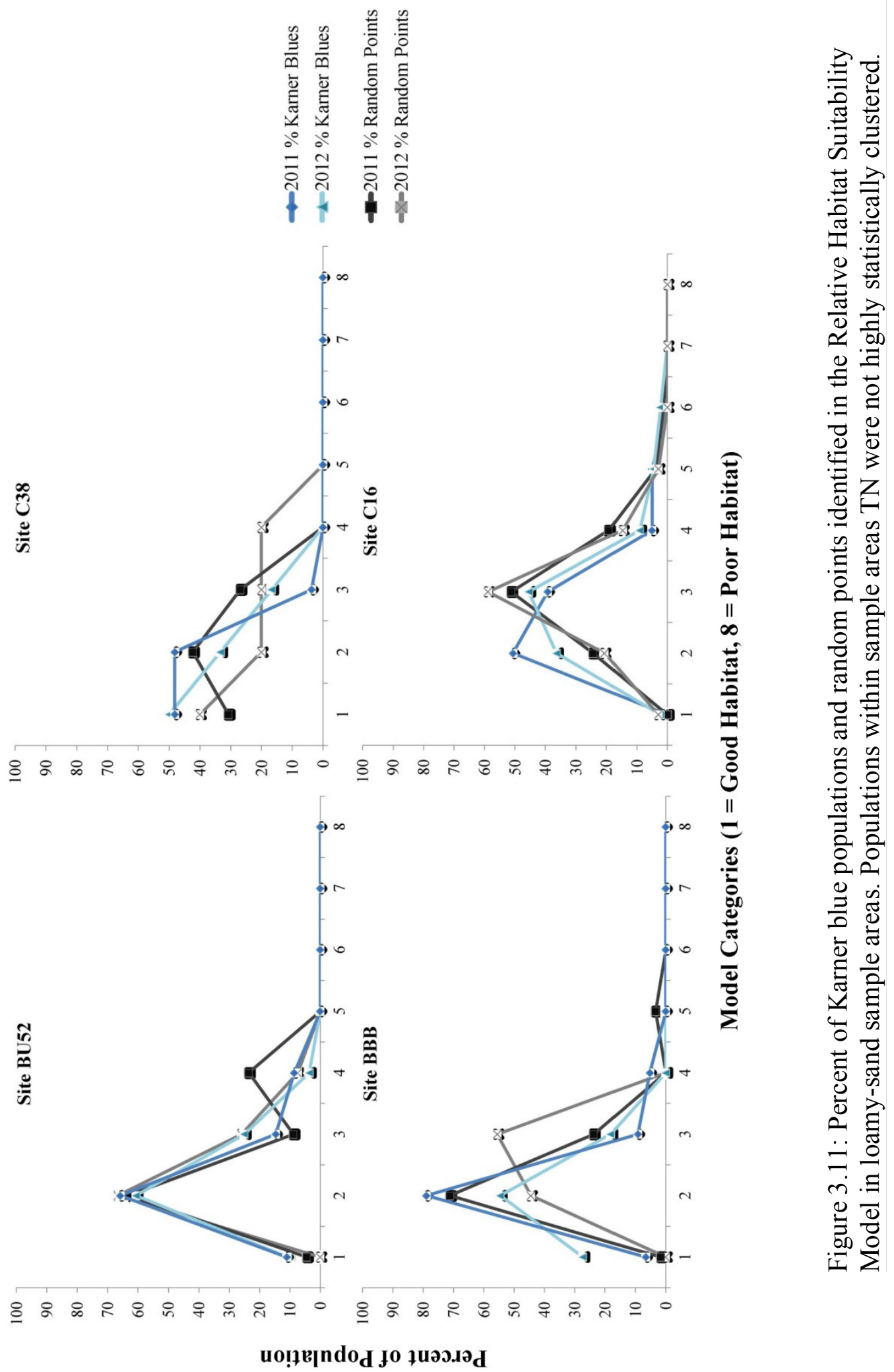




\section{Chapter 4: Do American bison influence distribution of a specialist Lepidopteran and its host plant?}

\section{$\underline{\text { Abstract }}$}

The activities of megaherbivores once provided an important source of mineral-soil disturbance and biomass production across grassland areas. We assessed how American bison influence the distribution of Karner blue butterfly populations and the distribution of host plant wild blue lupine at the Sandhill Wildlife Area, Wisconsin. Of the 78 sample plots examined, Karner blues and lupine were present in areas that experience low to high disturbance levels but were most likely to occur in areas of low level (presumably aged) disturbance. When Karner blues were present in areas undergoing moderate to combined moderate/high levels of disturbance, occurrence was most frequent where bison had recently been present (indicated by presence of bison chips). Similarly, lupine was most likely to occur in areas of combined moderate/high disturbance when bison had recently been present. The results of this correlative study suggest a lagged effect between the presence of bison and the growth of lupine, as well as a relationship between the recent presence of bison and Karner blue and lupine occupancy. Further investigations may reveal cause and effect of these relationships and define underlying mechanisms. The Sandhill Wildlife Area bison pasture provides a rare opportunity to observe a natural biological community that is virtually non-existent across its original range. 


\section{Introduction}

Historically, the activities of American bison (Bison bison) and other ungulates played an important role in maintaining open-canopy grassland areas such as barrens and savanna by browsing on vegetation, creating mineral-soil disturbance, and influencing vegetation structure and composition (Fox et al. 2012; Schulte and Mladenoff 2005; Trager et al. 2004; Knapp et al. 1999). Today these open-forest complexes are highly endangered ecosystems, decreased mainly due to habitat degradation through forest succession (Leach and Givnish 1999). American bison browsing, wallowing, and rubbing activities affect nutrient cycling and the number of ecosystem processes by increasing nitrogen availability and gas exchange between the soil and the aboveground growth (Knapp et al. 1999). Bison grazing increases plant species richness and habitat diversity (Trager et al. 2004; Polley and Wallace 1986), while wallowing, horning and the use of trails create mineral-soil disturbance and instability that slow or retard succession and create a shifting mosaic of disturbance effects (Fox et al. 2012; Trager et al. 2004; Knapp et al. 1999).

Due to the severity of wallowing disturbance, edaphic conditions, and compaction of soil, the vegetation diversity and composition differ in and between areas of high mineral-soil disturbance (Polley and Wallace 1986; Barkley and Smith 1934). Areas of constant disturbance, such as frequently used wallows, generally contain fewer and ruderal species, while those areas that have been allowed to recover from frequent and 
high magnitude disturbance activities contain perennial plants (Polley and Wallace 1986; Polley and Collins 1984).

Bison generally prefer foraging on graminoids, more so than cattle, (Knapp et al. 1999), allowing woody vegetation to grow. However, horning and rubbing activities will kill or damage small trees and shrubs limiting the distribution and structure of woody vegetation (Copperidge and Shaw 1997; England and DeVos 1969), while trampling and wallowing will prevent the growth of large forbs (Polley and Wallace 1986). The constant clipping of grasses through grazing increases gas exchange and biomass production, promoting the growth of forbs (Knapp et al. 1999). Overall, bison activities generate reduced graminoid cover, increased forb abundance and increased species diversity (Knapp et al. 1999; Collins and Adams 1983).

Many butterfly species are known to rely on grazing activities of large herbivores to maintain open-canopy complexes (Feber et al. 2001). This depends on the overall disturbance mechanism and butterfly species in question. Butterfly abundance of specialist species in tallgrass prairies increase with single occasional wildfires, rather than regular rotational burning, and with mechanical cutting more so than grazing. However, this appears to differ among species (Swengel 1998). For example, butterfly species composition (diversity) is greatly reduced in areas where non-woody and young woody vegetation were grazed by elk and deer (Kleintjes Neff et al. 2007; Baines et al. 
1994), and general insect abundance (overall population size) increases in un-grazed areas (Rambo and Faeth 1999).

Disturbance of the federally endangered Karner blue butterfly (Lycaeides melissa samuelis Nabokov) host plant, wild blue lupine (Lupinus perennis), is required for continual propagation (Swengel 1998). Lupine establishes itself most robustly in a mosaic of sun and shade (Leach 1993) and in areas of frequent but low intensity disturbance (Smallidge et al. 1996). However lupine will occupy areas of high intensity disturbance where disturbance is still active, and after disturbance activities cease (Forrester et al. 2005; Smith et al. 2002). Both Karner blue abundance and wild blue lupine density increases in frequently disturbed management units, including small pockets of oak/pine grassland communities habitat (Pickens 2006), powerline corridors (Forrester et al. 2005; Smallidge et al. 1996), and military establishments (Smith et al. 2002). These species reside primarily in the remaining small pockets of disturbancedependent oak (Quercus spp.) and jack pine (Pinus banksiana) barrens, oak savanna, and dry prairie (oak/pine grassland communities) across the Great Lakes Region (Anderson et al. 1999).

Though bison once helped to maintain oak/pine grassland communities, they have been virtually eliminated from the landscape. The removal of these megaherbivores and associated activities has made the importance of their natural roles in habitat dynamics difficult to evaluate (Collins and Adams, 1983). The Sandhill Wildlife Area of Central 
Wisconsin provides a rare glimpse at the interactions between bison activities and the surrounding habitat structure. Though it appears that the American bison herd at the Sandhill Wildlife Area helps to maintain the oak savanna that is critical to the persistence of the Karner blue, the underlying relationships remain un-evaluated.

Because American bison are known to encourage the growth of perennial species, and the Karner blue host plant, lupine, is a disturbance dependent species, we hypothesize that American bison at the Sandhill Wildlife Area may have some influence on the persistence of Karner blues. Furthermore, this site hosts the largest Karner blue population surveyed in the state of Wisconsin. Specifically, we hypothesized that Karner blue butterfly occurrences would increase with increasing mineral-soil disturbance, and that host plant wild blue lupine occurrence would increase after disturbance activities have taken place.

\section{$\underline{\text { Methods }}$}

Study Area

This study was conducted at the Sandhill Wildlife Area, a research facility located in Central Wisconsin (Figure 4.1). This wildlife area contains $\sim 3,700$ ha of rolling sand ridges, marshland, mixed-deciduous forest and large expanses of oak barrens and savanna. The property features a permanent herd of American bison contained within a $\sim 85$ ha pasture. This herd appears to help maintain the open oak community, which 
serves as habitat for numerous endangered and threatened species, among them the federally endangered Karner blue butterfly. The Wisconsin Karner Blue Recovery Program monitors this site annually for Karner blue populations as it is persistently the largest population of Karner blues population surveyed within the state $(\sim 3800-22,300$ adults annually, 2008-2013). A 12-foot welded-fence with barbed-wire encloses the entire facility, while an additional, 7-foot welded-fence encloses the bison pasture, preventing the movement of large mammals in and out of the facility. Due to this we can be certain that the levels of mineral-soil disturbance are primarily due to bison.

\section{Field Work and Remote Sensing}

Karner blue adult population information was collected by the Wisconsin recovery program and affiliated research groups during the summers of 2011 and 2012. Karner blue populations were estimated using a distance sampling method (Buckland et al. 2004) during the primary (second) Karner blue flight (generation). At least three surveys were conducted, seven days apart. This method involves walking along a transect with a pole demarcated: $0-0.5 \mathrm{~m}, 0.5-1.0 \mathrm{~m}, 1.0-1.5 \mathrm{~m}, 1.5-2.25 \mathrm{~m}, 2.25-3.0 \mathrm{~m}$, 3.0-4.0 m, and 4.0-5.0 m, and counting each Karner blue that intercepts the pole intervals. Distance sampling produces a total population estimate and an encounter rate (occurrences per linear m). Global Positioning Satellite (GPS) points were taken at the location of each Karner blue observation using a Trimble GeoXT unit. Permanent 
transects with a random starting point were established perpendicular to the longitudinal axis of a field, with 60m spacing (Schuurman 2010).

Areas of mineral-soil disturbance (heavy grazing, wallowing, and congregating) were identified and delineated on National Agriculture Imagery Program (NAIP) 2010 orthophotos using Arcmap 10.0 (Environmental Systems Research Institute (ESRI), Inc., Redlands, CA, USA). These areas were identified based on visible bareground which is discernible from surrounding vegetation. These areas were visually compared to areas of high Karner blue density, or 'hot spots', identified by generating kernel density isopleths based on Karner GPS locations in Arcmap 10.0 using the Spatial Analyst kernel density function. Isopleths were generated for each of four surveys conducted during the Karner blue flight period of 2011 and three surveys in 2012. Isopleths were categorized according to $0.5-1$, and $>1$ Karner blue adults per hectare.

Sample plots used to collect in situ field data were $5 \mathrm{~m}$ in diameter, surrounding a central point generated based on the locations of Karner blue adults in 2011 (Figure 4.2). A $15 \mathrm{~m}$ buffer was generated around each 2011 Karner blue GPS occurrence location. Each $15 \mathrm{~m}$ buffered area was considered a high-potential area for detecting a Karner blue adult. This $15 \mathrm{~m}$ distance is half the distance assumed for conducting independent surveys ( $30 \mathrm{~m}$ is the minimum distance required between Karner blue population estimate transects to ensure independence of observations). A total of 80 plots were randomly generated within the buffered area with a $30 \mathrm{~m}$ minimum distance 
between sample plots. An additional 40 plots were generated outside of these buffers in the low-potential area for detecting a Karner blue adult with a 30m minimum distance between sample plots. This difference in sample plots is due to an original sampling design which separated plots into three categories: 40 high potential, 40 moderate potential, and 40 low potential. The high and moderate potential plots were combined. Overlapping plots of the resulting 80 high potential and 40 low potential plots were eliminating by selected one of the pair at random to discard. Random selection was done using two random number generators representing a left side and a right side. The plot corresponding with the higher random number was selected and discarded. This resulted in 52 high-potential and 24 low-potential plots. These plots were used to collect ground information, detailed below. Each sample plot centroid located using a Trimble GeoXT unit.

Ground information was collected during early July of 2012, at the start of the Karner blue primary flight, immediately after the bison were removed from the pasture. Percent cover of lupine was visually estimated within each $5 \mathrm{~m}$ plot using a percent cover estimate guide based on the Braun-Blanquet cover abundance scale (Braun-Blanquet 1964, 1932). This method uses generalized images of percent cover to help visually estimate plant abundance within a designated area. The number of bison chips was totaled within each plot. The presence/absence and level of mineral-soil disturbance within each plot was visually estimated according to categories: low (disturbance is aged, grass displays regeneration, and hummocks are visible), moderate (grass displays 
thinning due to grazing, bareground visible), and high (extremely thin grass and bareground due to wallow, trail, and heavy grazing is obvious). Percent cover of dominant groundcover per sample plot was recorded including: ferns, forbs (not including lupine), lupine, grasses, shrub/tree cover, and bareground. Fern cover was combined with forb cover due to low levels of dominance. Bareground and lupine was removed from analyses due to a lack of dominance at any plots.

\section{Data Analysis}

The consistency of Karner blue high density areas were compared between consecutive years to ensure that sample plot placement in high and low potential areas was relevant. This was done by comparing both 2011 locations to 2012 locations to selected sample plots. Karner blue locations for 2011 and 2012 were calculated within 5 and $15 \mathrm{~m}$ buffers in high and low potential sample plots. We then visually compared areas of high Karner blue density to areas of bison-caused mineral-soil disturbance that were delineated on aerial photographs. These comparisons were made for Karner blue flights during 2011 and 2012 to check for consistency of Karner blue locations in relation to bison-caused mineral-soil disturbance between years. Isopleths were categorized according to: $0.5-1$, and $>1$ Karners per hectare.

Spatial autocorrelation of bison chips was tested to determine whether the plot selection method using random selection was unbiased. Spatial autocorrelation was calculated 
using Moran's I in the Spatial Statistix toolbox in ArcMap 10.1. Spatial relationships were conceptualized using the zone of indifference option which reduces the influence of neighbors as distance increases. Distances were calculated using Euclidean distance. Calculations were standardized to reduce bias within the transect sampling design. Using this test, the null hypothesis states that the spatial distribution of the bison chips is due to complete spatial randomness. Sample plots were also tested for statistical clustering using the nearest neighbor function in the Spatial Statistix toolbox in ArcMap 10.1. Relationships $p \leq 0.05$ were considered significant.

Hierarchical log-linear analyses (Zar, 1984) were used to isolate relationships between Karner blue and lupine presence/absence and the interactions of disturbance presence/absence, level of disturbance, dominant groundcover, and presence/absence of bison, similar to methods used in Storer et al. (1998). Storer et al. (1998) used hierarchical log-linear analyses to breakdown potential relationships of pitch canker disease of Fusarium subglutinans f. sp. pini among different locations, three types of pine branch, and two treatments. Hierarchical analyses followed the breakdown: Disturbance level ( 0 - low, 1 - moderate, 2 - high), Dominant groundcover ( 0 - grass cover, 1 - forb cover, 2 - shrub/tree cover), presence/absence of bison chips ( 0 - absent, 1 - present). Areas of high disturbance were combined with moderate disturbance due to a low number of plots where high disturbance was present. $G$-tests were utilized for final analyses of Karner blue, lupine, and bison presence/absence based on the resulting isolated relationships of the log-linear models. Models evaluated using $G$-tests include: 
Disturbance_level Dominant_cover*ChipsP/A and Disturbance_level ChipsP/A.

Relationships with $p$-value $\leq 0.1$ were considered significant. $P$-value $\leq 0.1$ was used to generate a less conservative dataset. All analyses were conducted in Statistix8 (Analytical Software 2008).

\section{$\underline{\text { Results }}$}

Karner blue 'hot spots' were often nearby areas where mineral-soil disturbance was apparent on orthophotos (Figure 4.3). These areas of mineral-soil disturbance included areas of heavy grazing, wallows, and trails. Obvious trail systems were often located along fence lines, near gates, and surrounding an elevated, standing observation tour within the bison pasture. Wallows were located more frequently along the east-central part of the pasture. The Karner blue 'hot spots' are located most heavily around two gate entrances, and surrounding an observation tour. Karner blues were not aggregated around wallows.

A total of 254 Karner blue occurrences were observed in 2011 compared to 98 occurrences observed in 2012. A high percentage of 2011 and 2012 Karner blue locations fell within $15 \mathrm{~m}$ of the high potential sample plots (Figure 4.4). Approximately $55 \%$ of the total 2011 Karner blue population and 35\% of the 2012 Karner blue population fell within $15 \mathrm{~m}$ of sample plots. In comparison, $2 \%$ of 2011 Karner blue locations and $0 \%$ of 2012 Karner blue locations fell within $15 \mathrm{~m}$ of the low-potential 
sample plots. From these results we can assume that high-potential sites represent relative Karner blue presence while low-potential sites represent relative Karner blue absence for 2012 .

Bison chips within the original dataset of 80 high potential and 40 low potential sample plots were significantly spatially autocorrelated (zscore $=2.68, p \leq 0.05$ ). Bison chips within the randomly selected plots were not spatially autocorrelated (zscore $=1.07, p=$ 0.29). This indicates that the spatial distribution of the bison chips in the selected sample plots is the result of a random spatial process. Original and selected sample plots were not statistically clustered $(p>0.05)$. This indicates that the original and selected sample plots were randomly dispersed across the bison pasture within low and high potential plots.

Hierarchical log-linear models found significant relationships within interactions among levels of disturbance, dominant groundcover, and presence or absence of bison chips for Karner blue and lupine presence/absence. Significant relationships exist among the levels of disturbance (low/moderate/high) and the presence/absence of bison chips (indicative of the recent presence of bison at the sample plot) (Figures 4.5, 4.6). Karner blue and lupine occupancy differed significantly based on level of disturbance as well as the presence/absence of bison chips. Karner blues were more likely to occur in areas of low disturbance than in areas of moderate, high, or combined moderate/high disturbance $(p \leq 0.1)$. Karner blues were more likely to occur in areas of moderate or 
combined moderate/high mineral-soil disturbance when bison chips were present ( $p \leq$ $0.1)$. Lupine was significantly more likely $(p \leq 0.1)$ to occur in areas of low disturbance. When lupine occurred in areas of combined moderate/high disturbance areas it was more likely to occur where bison were recently present $(p \leq 0.1)$.

\section{$\underline{\text { Discussion }}$}

The bison pasture at the Sandhill Wildlife Area consistently produces the largest population of Karner blues surveyed in Wisconsin (based on observations of five consecutive years by the Karner Recovery Program). These butterflies reside primarily within the bison pasture, producing numbers so low outside of the bison enclosure that only rudimentary surveys (i.e. presence/absence) can be used to estimate the populations.

Sample plots for this study were based upon 2011 GPS points collected at Karner blue observations. An evaluation of buffers around these plots indicates that the Karner blues are almost completely absent from 2012 low-potential plots. This suggests that the high potential sample plots were placed within or nearby the Karner blue hot spots across the

field-site. Fewer Karner blues were present around the high-potential plots in 2012 than 2011, which may be due to several factors: 1) Karner blue populations were significantly lower, 2) individuals may have moved into different areas of the bison pasture in search of resources (i.e. Dunn 2008, Shillinglaw and Shillinglaw 2008), 3) 
this may be an artifact of the sampling method. Despite the low population count in 2012, Karner blues were present within 15m of high potential plots and were not present within $15 \mathrm{~m}$ of low potential plots. This suggest that the Karner blue populations remained relatively consistent between the two years.

Original observations of Karner blue kernel density 'hot spots' suggested that these areas were nearby areas that are frequently used by bison. This suggested a relationship between areas of bison-caused mineral-soil disturbance and Karner blue clustering. However, according to this study Karner blues were more abundant in areas of low mineral-soil disturbance. The lack of overlap may have been due to the low number of sample plots located within overlapping areas that are apparent on the aerial photographs, or due to the inherent mobility of the Karners relative to the GPS points taken during surveys.

Although Karner blues and lupine did occur in areas of moderate and moderate/high disturbance, they were consistently more frequent in areas of low disturbance. The mineral-soil disturbance caused by the bison may generate a long-term effect that provides disturbance for the lupine and other perennial nectar plants (e.g. Fox et al. 2012; Trager et al. 2004; Knapp et al. 1999), expanding lupine and nectar plant growth and thereby improving Karner blue habitat and the potential for detecting an adult Karner blue. Lupine and other nectaring forbs may occupy these areas after a period of time has passed and mineral-soil disturbance has recovered to the point that perennial 
species can establish themselves (e.g. Polley and Wallace 1986; Polley and Collins 1984). The high levels of mineral-soil disturbance generated by American bison promote the growth of perennial species only after a period of time has passed and those areas have been able to recover (Polley and Wallace 1986; Polley and Collins 1984; Barkley and Smith 1934).

Similar to the lagged effect that may be present in this study, areas of heavily managed powerline corridors using mechanical and herbicide treatments at 4 to 8 year intervals produced higher lupine and Karner blue populations (Forrester et al. 2005). Lupine abundance and nectar plant abundance and species richness increased following disturbance activities and decreased with eventual woody encroachment (Forrester et al. 2005; Smallidge et al. 1996). Disturbance activities at Fort McCoy, Wisconsin, produced a higher proportion of lupine and nectar plant stems in immediately disturbed areas, such as maintenance equipment ruts from tank activity, due to reduced competition of other plants (Smith et al. 2002). Disturbance caused by heavy equipment may be able to mimic the activities of megaherbivores and could potentially be used to improve habitat maintenance.

When Karner blues occurred in areas of moderate to high disturbance they were more likely to occur when bison were recently present (bison chips present), suggesting that they are seeking out areas that bison have recently utilized. This tendency to occupy areas where bison chips are abundant may be due to several factors. An immediate 
result may be that butterflies in general are known to feed on decaying matter or animal scat for the purposes of acquiring readily available minerals, nutrients, and especially moisture. Karner blues specifically have been observed on bison, horse, coyote and wolf scat piles, when scat piles were freshly deposited, as well as on dead and decaying squirrels and grass snakes (personal observations, Bob Welch, Anna Hess, Joy Hess and Robert Hess).

Lupine was also more frequent in low disturbance areas, but when present in higher disturbance areas occurred more frequently where bison had recently been present (bison chips were present). This may be due to a more recent turnover of mineral-soil caused by bison wallowing and heavy grazing activities, which would generate mineralsoil disturbance that opens open canopy, benefitting many butterfly species (Feber et al. 2001). This combined combination of high disturbance and recent presence of bison may produce exceedingly low levels of plant competition for the disturbance dependent lupine plant. Bison grazing and wallowing will also increase nitrogen availability and gas exchange between the soil and the aboveground growth, promoting the growth of forbs (Knapp et al. 1999).

Although dominant groundcover (forbs, grasses, shrubs/trees) did not significantly influence the presence/absence of Karner blue adults or of lupine at the sample plots evaluated in this study, the Karners and lupine appeared to favor open areas of grass and forbs. High potential plots were very seldom, although not significantly, dominated by 
shrub/tree cover. Lupine was also greater in areas dominated by grasses than in areas dominated by forbs, or in areas of shrub/tree cover. These areas of grasses and forbs that Karner blues and lupine are associated with may be due to the mineral-soil disturbance and open-canopy generated by the bison.

\section{$\underline{\text { Conclusions }}$}

Large ungulate and other megaherbivore activities are known to influence biological communities by slowing succession, changing edaphic conditions and affecting vegetation diversity and composition. However these activities have been almost entirely removed from grassland ecosystems. We found correlations between the presence of bison and Karner blue and host plant wild blue lupine occupancy through different mechanisms. Karner blues and lupine were similarly more likely to occur in areas of low level disturbance, but when occurring in areas of high disturbance were more likely to occur where bison were recently present. In the case of lupine this suggests a lapse in time between the presence of bison and the growth of lupine, or low levels of initial disturbance (e.g. areas of low-intensity grazing). Perennial species such as the lupine may benefit from this constant rotation of mineral-soil disturbance that allows for a turnover of species and creates the low level of mineral-soil disturbance associated with lupine presence. Furthermore the Karner blue appears to favor areas where bison are active. The presence of large mega-herbivores such as bison could provide, in addition to favorable habitat conditions, nutrients and minerals that are 
otherwise more difficult to allocate. We suggest further studies that examine larger areas for comparison between habitat composition and structure and do not limit themselves to $30 \mathrm{~m}$ buffer areas in which habitat composition and structure as well as bison activities may not overly differ. We believe that the Sandhill Wildlife Area bison pasture provides a rare opportunity to observe these and other natural biological processes that once existed across a much larger range.

\section{$\underline{\text { Acknowledgements }}$}

Data collection for this research was partially funded by the Wisconsin Department of Natural Resources-Karner Blue Butterfly Recovery Program and Michigan Technological University. Butterfly population information and habitat information was collected by the Wisconsin DNR and associated scientific survey groups including the University of Wisconsin-Stevens Point group led by Dr. Michael Demchik. WDNR Bureau of Science Services and Dr. Gregor Schuurman provided analyses of population data. This data is part of the WDNR Natural Heritage Inventory. Permits to conduct study include: Natural Heritage Inventory LA157, Wisconsin Endangered and Threatened Species Permit \#687, and State of Wisconsin Department of Administration Volunteer Agreement. Additional data for this study was collected with the help of Robert J. Hess, Joy L.M. Hess, Julie A. Hess, Beverly S Paulan, and with the aid of Sandhill Wildlife Refuge Wildlife Biologist, Wayne H. Hall Jr. 


\section{$\underline{\text { References }}$}

Analytical Software. 2008. Statistix 8. Analytical Software: Tallahassee, FL.

Anderson RC, Fralish JS, Baskin JM. 1999. Savannas, barrens, and rock outcrop plant communities of North America. Cambridge University Press, New York.

Baines D, Safe RB, Baines MM. 1994. The implications of red deer grazing to ground vegetation and invertebrate communities of Scottish native pinewoods. Journal of Applied Ecology. Vol. 31, pp. 776-783.

Barkley FA, Smith CC. 1934. A preliminary study of bison wallows in the vicinity of Norman Oklahoma. Proceedings of the Oklahoma Academy of Science. Vol. 14, pp. 47-52.

Buckland ST, Anderson DR, Burnham KP. 2004. Advanced distance sampling. Oxford University Press, New York.

Braun-Blanquet J. 1964. Pflanzensociologie: Grundzuge der Vegetationskunde. 3te aufl. Springer-Verlag, Wein. 965 pp. 
Braun-Blanquet J. 1932. Plant sociology. (Translated by Fuller GD, Conrad HS). McGraw-Hill, New York. 539 pp.

Collins SL, and Adams DE. 1983. Succession in grasslands: thirty-two years of change in a central Oklahoma tallgrass prairie. Vegetation. Vol. 51, pp. 181-190.

Copperidge BR and Shaw JH. 1997. Effects of horning and rubbing behavior by bison (Bison bison) on woody vegetation in a tallgrass prairie landscape. American Midland Naturalist. Vol. 138(1), pp. 189-196.

Dunn JP. 2008. Investigations of adult dispersal, habitat quality analysis, and the development of monitoring techniques for the Karner blue butterfly within the Muskegon Recovery Unit. Final Report to MI DNR. 40 pp.

England RE, DeVos A. 1969. Influence of animals on pristine conditions on the Canadian grasslands. Journal of Range Management. Vol. 22, pp. 629-644.

Feber RE, Brereton TM, Warren MS, Oates M. 2001. The impacts of deer on woodland butterflies: the good, the bad and the complex. Forestry. Vol. 74, pp. 273-276. 
Forrester JA, Leopold DJ, Hafner SD. 2005. Maintaining critical habitat in a heavily managed landscape: effects of power line corridor management on Karner blue butterfly (Lycaeides melissa samuelis) habitat. Restoration Ecology. Vol. 13 (3), pp. 488-498.

Fox TA, Hugenholtz CH, Bender D., and Gates C.C. 2012. Can bison play a role in conserving habitat for endangered sandhills species in Canada? Biodiversity and Conservation. Vol. 21, pp. 1441-1455.

Kleintjes Neff PK, Fettig SM, Van Overbeke DR. 2007. Variable response of butterflies and vegetation to elk herbivory: An exclosure experiment in ponderosa pine and aspenmixed conifer forests. The Southwestern Naturalist. Vol. 52(1), pp. 1-14.

Knapp, AK, Blair JM, Briggs JM, Collins SL, Hartnett DC, Johnson LC, Towne EG. 1999. The keystone role of bison in North American tallgrass prairie. BioScience. Vol. 49(1), pp. 39-50.

Leach MK, Givnish TJ. 1999. Gradients in the composition, structure, and diversity of remnant oak savannas in southern Wisconsin. Ecological Monographs. Vol. 69(3), pp. $353-374$.

Leach M. 1993. Status and distribution of the Karner blue butterfly at Fort McCoy, Wisconsin: final report on a two-year study. Unpublished Report Prepared for the 
Natural Resources Management Division, Fort McCoy Military Research Reservation, U.S. Army. The Nature Conservancy, Wisconsin Chapter.

Pickens BA. 2006. The consequences of a management strategy for the endangered Karner blue butterfly. M.S. Dissertation. Bowling Green State University, Bowling Green, OH, USA.

Polley HW and Wallace LL. 1986. The relationship of plant species heterogeneity to soil variation in bison wallows. The Southerwestern Naturalist. Vol. 31(4), pp. 493-501.

Polley HW and Collins SL. 1984. Relationships of vegetation and environment in bison wallows. American Midland Naturalist. Vol. 112(1), pp. 178-186.

Rambo JL, Faeth SH. 1999. Effect of vertebrate grazing on plant and insect community structure. Conservation Biology. Vol. 13, pp. 1947-1954.

Schulte LA, Mladenoff DJ. 2005. Severe wind and fire regimes in northern forests: historical variability at the regional scale. Ecology. Vol. 86(2). pp. 431-445.

Schuurman G. 2010. Distance sampling survey protocol. Wisconsin Department of Natural Resources: Wisconsin Karner Blue Butterfly Recovery Program. 
Shillinglaw J, Shillinglaw C. 2008. Movement of Karner blue butterflies into and between prairie restorations; implications for establishing a viable metapopulation. Unpublished document. Karner Blue Butterfly Recovery.

Smallidge PJ, Leopold DJ, Allen CM. 1996. Community characteristics and vegetation management of Karner blue butterfly (Lycaeides melissa samuelis) habitats on rightsof-way in East-Central New York, USA. The Journal of Applied Ecology. Vol. 33 (6), pp. 1405-1419.

Smith MA, Turner MG, Rusch DH. 2002. The effect of military training activity on eastern lupine and the Karner blue butterfly at Fort McCoy, Wisconsin, USA. Environmental Management. Vol. 29 (1), pp. 102-115.

Storer AJ, Gordon TR, Clark SL. 1998. Association of the pitch canker fungus, Fusarium subglutinans f.sp. pini with Monterey pine seeds, and seedlings in California. Plant Pathology. Vol. 47, pp. 649-656.

Swengel, Ann B. 1998. Effects of management on butterfly abundance in tallgrass prairie and pine barrens. Biological Conservation. Vol. 83 (1), pp. 77-89. 
Trager MD, Wilson GWT, Hartnett DC. 2004. Concurrent effects of fire regime, grazing and bison wallowing on tallgrass prairie vegetation. American Midland Naturalist. Vol. 152(2), pp. 237-247.

Zar JH. 1984. Biostatistical Analysis. Engelwood Cliffs, New Jersey, USA. PrenticeHall. 


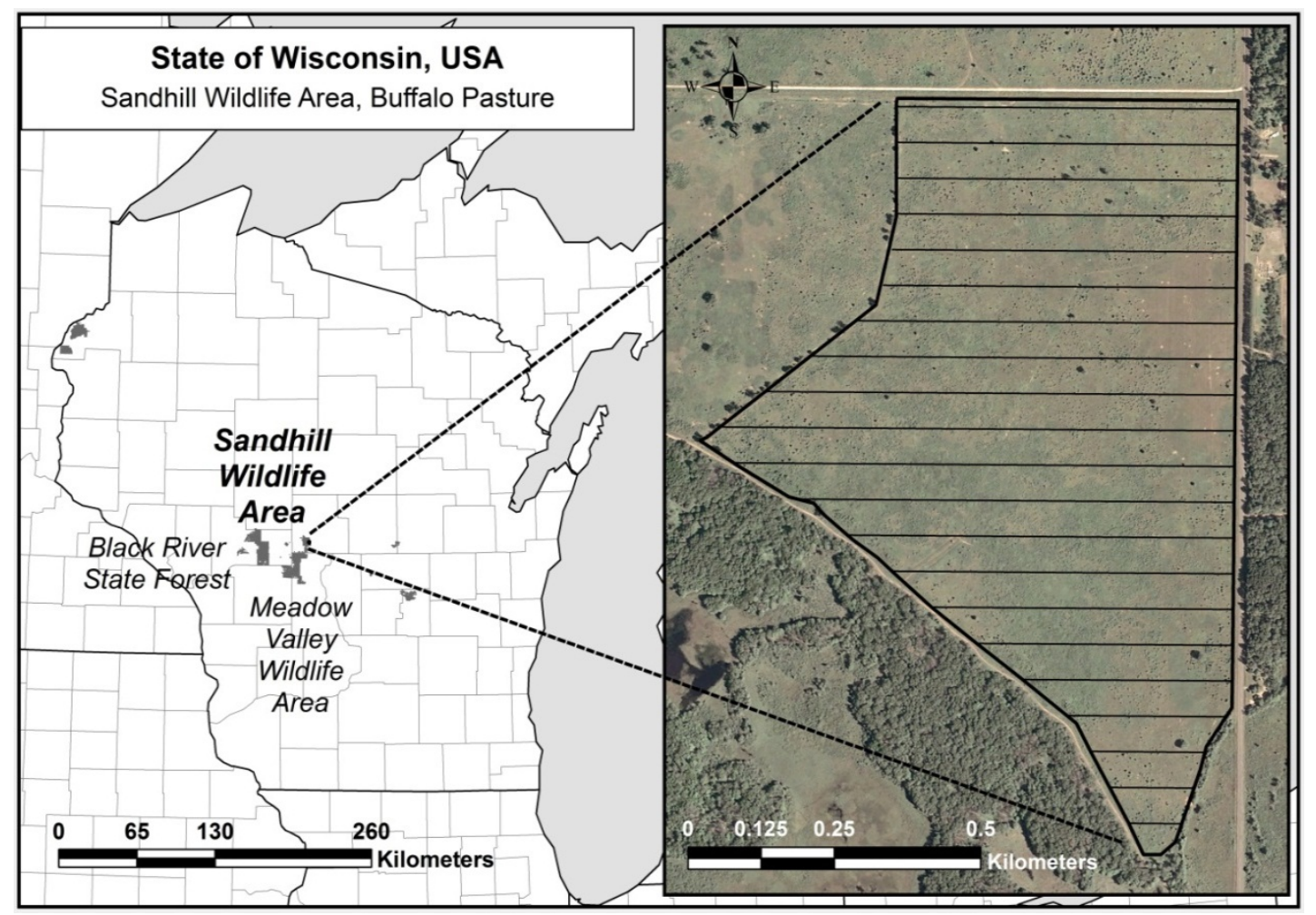

Figure 4.1: The Sandhill Wildlife Area, Wisconsin, interior bison pasture and study site. Transects used for estimating Karner blue butterfly populations and establishing sample plots are represented by black lines. 

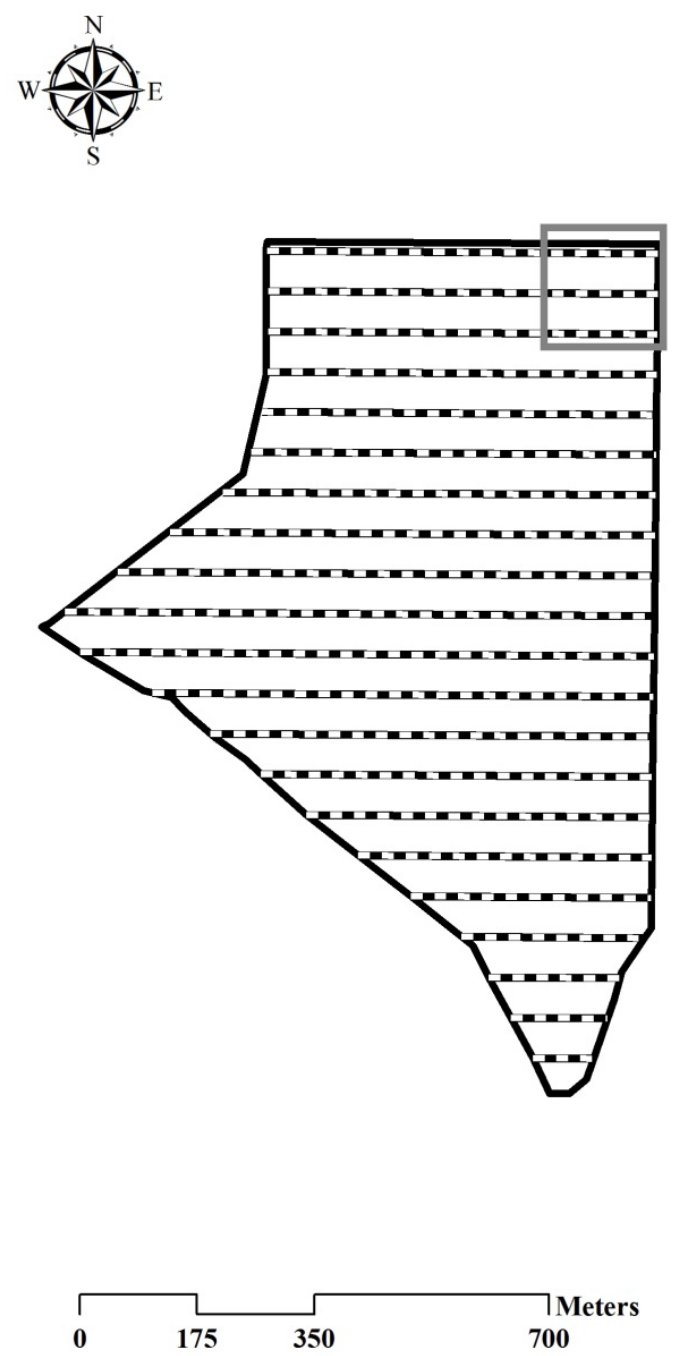

A Karner Blue 2011 Locations

○ High-Potential Sample Point

- Low-Potential Sample Point

Karner Blue Population Estimate Transects
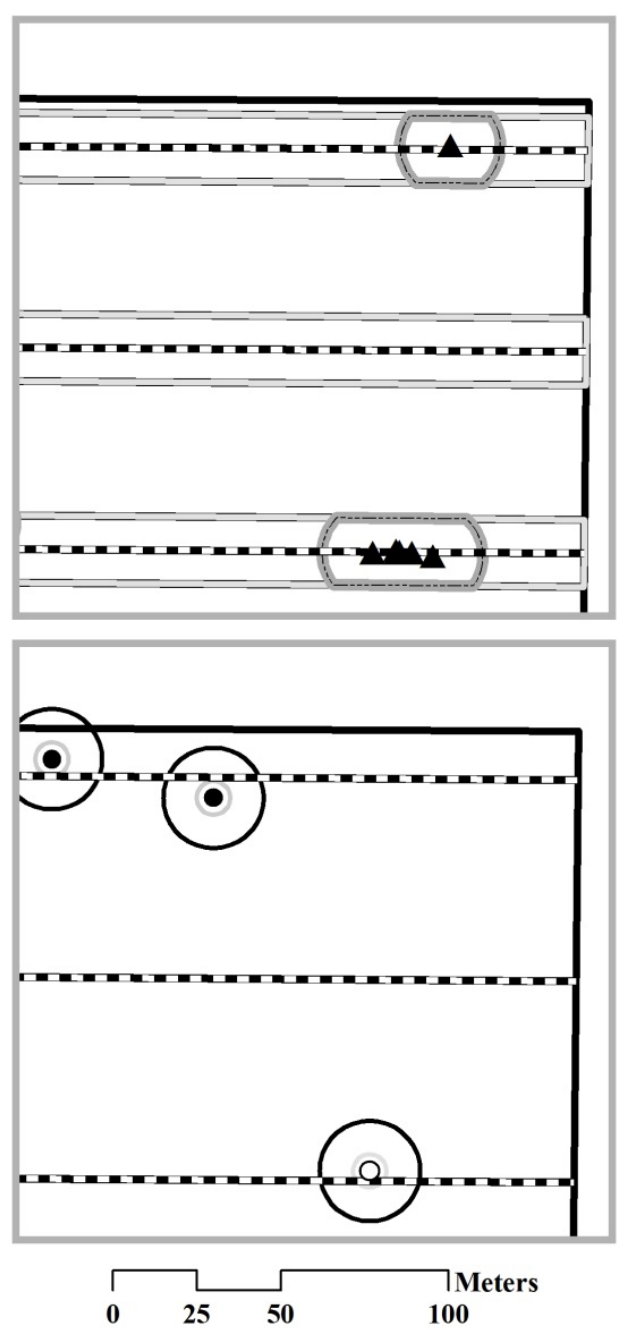

High-Potential Buffer (15m Buffer Around 2011 Karner Blue Locations)

Low-Potential Buffer (Area Outside of High-Potential Buffer)

$5 \mathrm{~m}$ Sample Plot

15m Sample Point Buffer

Buffalo Pasture Boundary 


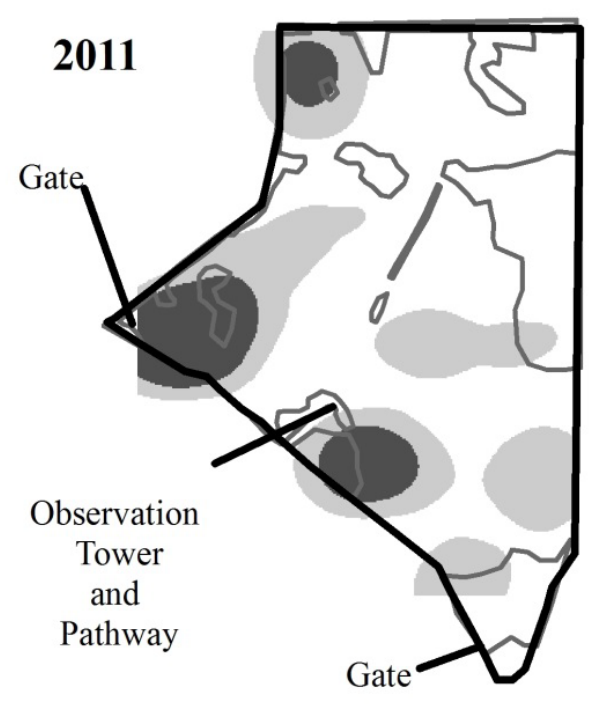

Mineral-Soil Disturbance

$\square$ Bison Pasture Boundary

Karner blues per km2
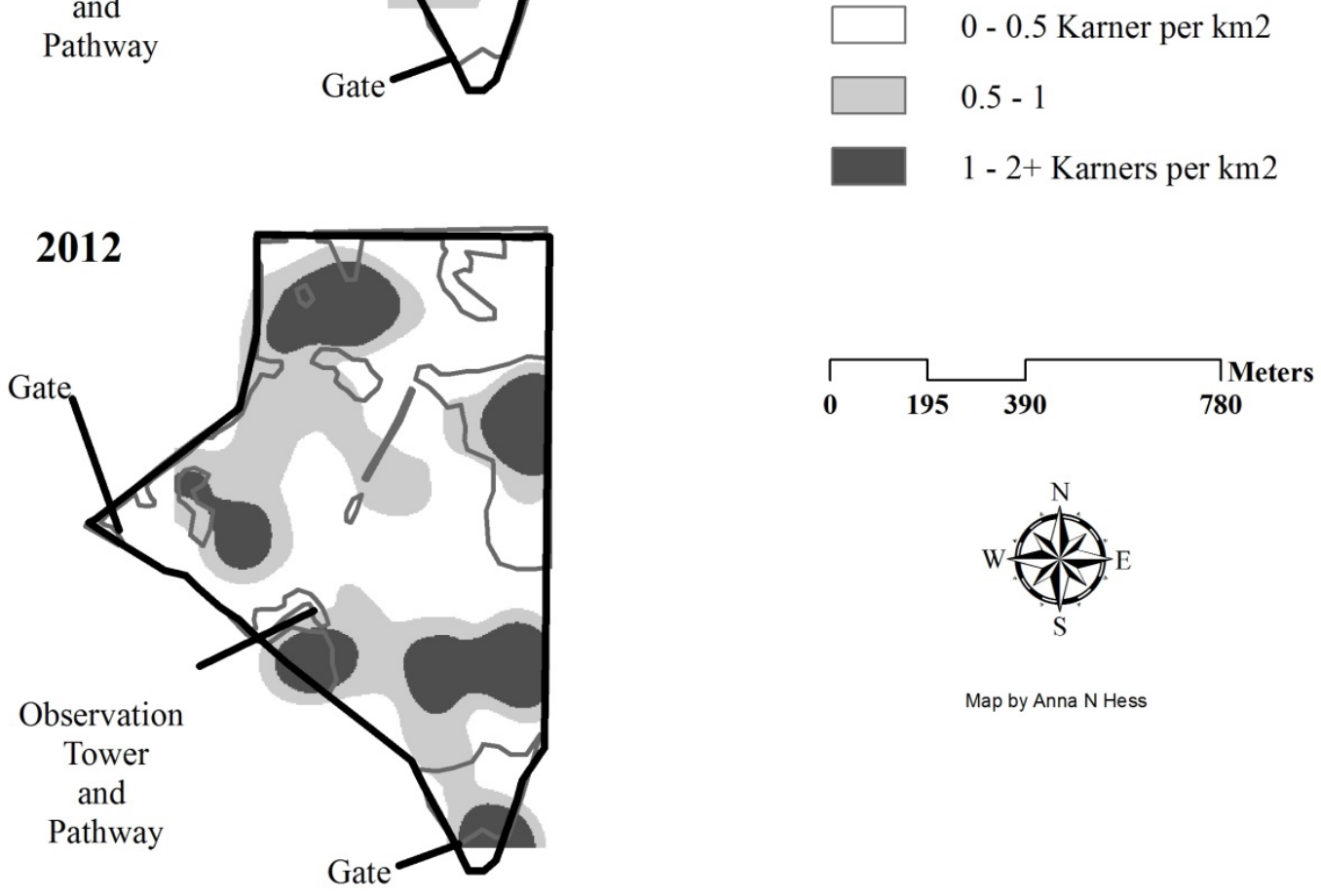

Map by Anna $\mathrm{N}$ Hess

Figure 4.3: Karner blue 'hot spots' of the peak of the Karner blue flight in relation to areas of bison-caused mineral-soil disturbance at the bison pasture, Sandhill Wildlife Area, Wisconsin. 


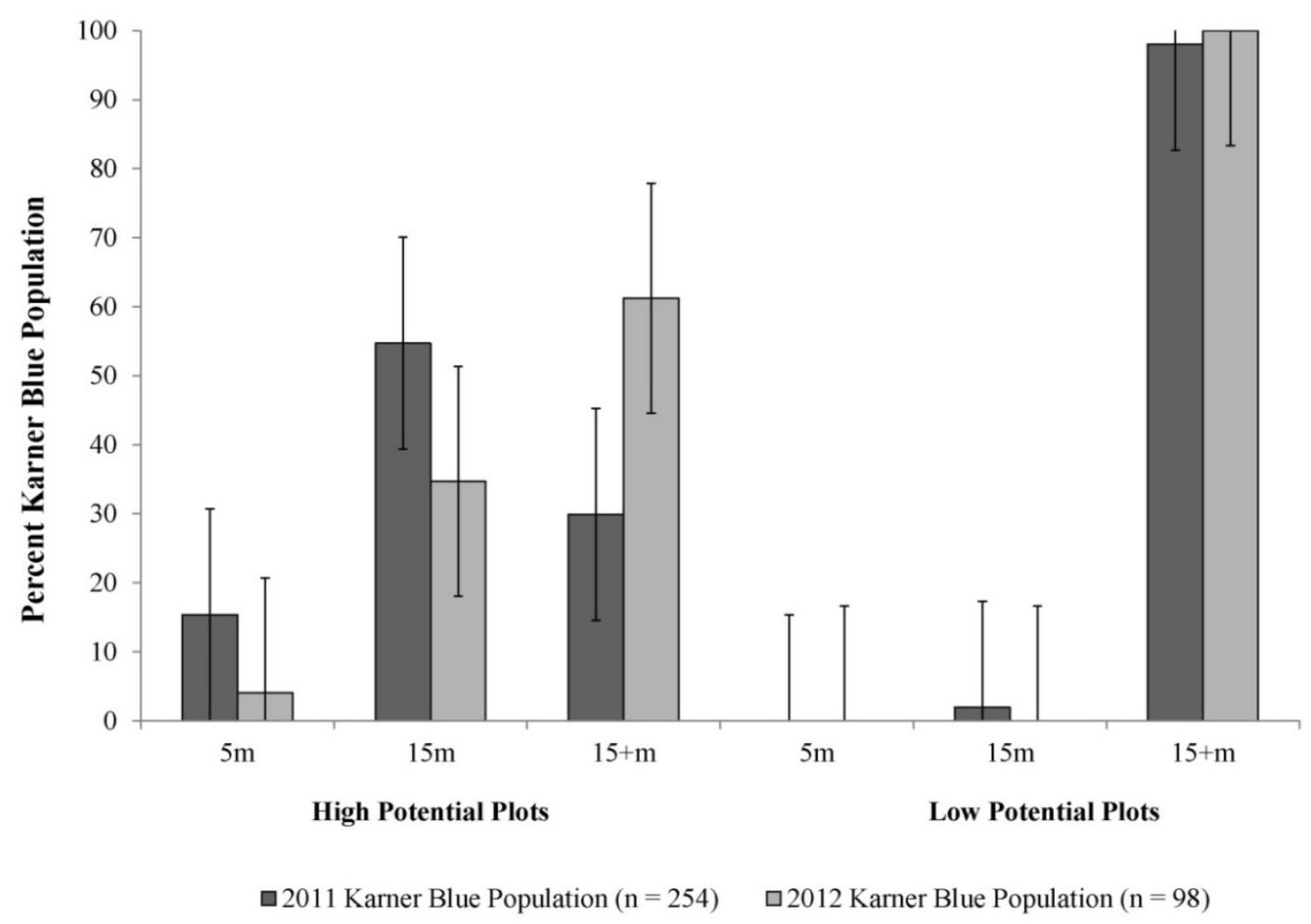

Figure 4.4: Comparison of the 2011 and 2012 Karner blue populations within 5, 15, and $15+\mathrm{m}$ of designated High and Low potential sample plots in the bison pasture at the Sandhill Wildlife Area, Wisconsin. Error bars represent standard error. 


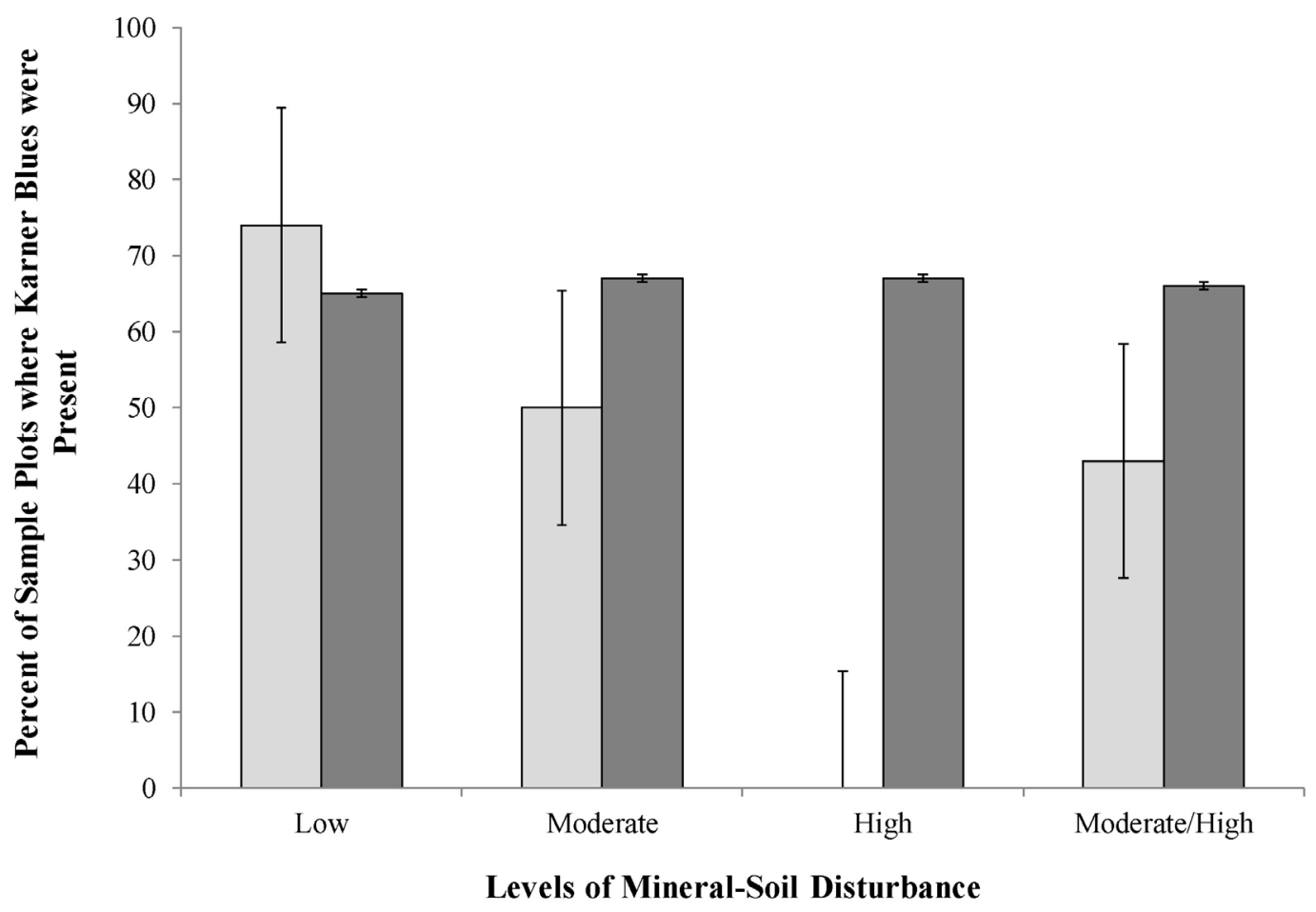

$\square$ Bison Chips Absent $\quad \square$ Bison Chips Present

Figure 4.5: Percent of sample plots where Karner blues were present in relation to habitat variables at Sandhill Wildlife Area, Wisconsin. Error bars represent standard error. 


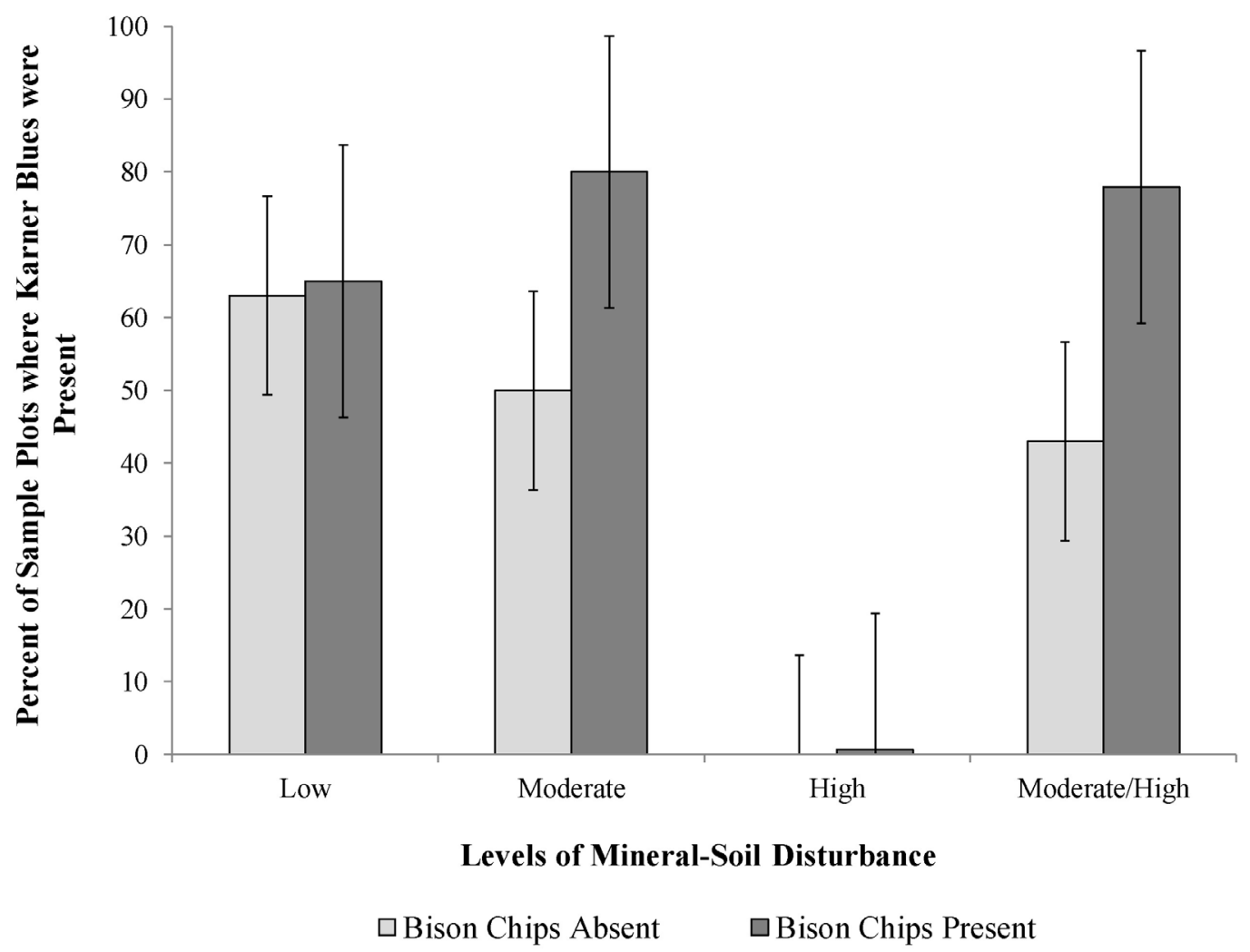

Figure 4.6: Percent of sample plots where lupine was present in relation to habitat variables at Sandhill Wildlife Area, Wisconsin. Error bars represent standard error. 


\section{Chapter 5: Analyses of $\mathrm{C}: \mathrm{N}$ ratio, nitrogen and phenolic content in host plant wild blue lupine (Lupinus perennis) relative to habitat for a specialist Lepidopteran.}

\section{$\underline{\text { Abstract }}$}

Habitat composition and structure greatly influences the overall quality of host plants which are imperative to the success of specialist species, and especially Lepidopterans. This study evaluated relationships among habitat variables and the $\mathrm{C}: \mathrm{N}$ ratio, nitrogen content, and phenolic content of the legume wild blue lupine, which serves as the sole host plant for the federally endangered Karner blue butterfly. Lupine foliage samples and in situ habitat composition and structure were collected over $\sim 307$ ha of oak and pine grasslands that are currently the focus of Karner blue habitat restoration efforts within the state of Wisconsin. Lupine foliage was tested for carbon, nitrogen, and phenolic content. These nutrient and defensive compounds were related to in situ habitat characteristics and Karner blue adult observations, both within-patch and assessed across the sampling range. Lupine $\mathrm{C}: \mathrm{N}$ ratio and nitrogen displayed large variation across all sample plots (9.1:1 - 16:1, and $2.4-5.3 \%$ dry weight, respectively), sample plots where Karner blues were present (9.1:1 - 16:1, and 2.4-5.0\% dry weight, respectively), and sample plots where Karner blues were absent (9.2:1 - 12.7:1, and 3.3$5.2 \%$ dry weight, respectively). Lupine $\mathrm{C}: \mathrm{N}$ ratio decreased in relation to ground litter cover and increased in relation to shrub/tree cover and focal nectar plant abundance. In comparison, nitrogen content increased in relation to ground litter cover and decreased in relation to cover of shrub/tree and focal nectar plant abundance. Phenolics were not 
significantly related to any candidate habitat variables. Karner blue density increased in relation to lupine $\mathrm{C}: \mathrm{N}$ ratio and decreased relative to nitrogen content, but was not related to phenolic content. Management that generates a mix of canopy-cover conditions (10-25\%), decreases ground litter $(\sim 10 \%)$ and increases focal nectar plant abundance (>10 stems per 1/800 ha) can influence nutrient levels and produce more favorable conditions for Karner blue populations at all life-stages.

\section{$\underline{\text { Introduction }}$}

Forage quality for organisms varies spatially across geographical areas and temporally as plants grow and age (Knox 2010). This quality is of the utmost importance to organisms as it determines the overall nutrient and energy availability for basic metabolic functions, and is one important factor determining how an organism will select habitat (Van der Wal et al. 2000). Organisms will ultimately select habitat based on these qualities and the ability to draw fiber and nitrogen, among other nutrients, from available resources (Van der Wal and Loonen 1998; Post and Klein 1996). Despite the quality of food, the amount of resources available also influences the way organisms select habitat; areas with more resources generally increase life span and body size of organisms and subsequently help populations to persist (Post and Klein 1996; Geist 1987). The classic tradeoff of quality vs. quantity forces organisms to choose between expending energy to select habitat with low quality (generally higher biomass) or high quality (generally more necessary nutrients) food sources. 
The composition and structure of surrounding habitat directly influences the overall quality of forage. Influential factors include abiotic factors such as geology and soil types (Craine et al. 2009; Lawrence 1994), disturbance and grazing (Weiss et al. 1988), fertilizer applications (Hwang et al. 2008), and climatic conditions, while biotic factors include surrounding vegetation types and canopy cover (Sun and Ge 2011). Growing conditions that allow rapid growth generally produce more easily digestible forage with lower defensive compound levels and lower levels of fiber and lignin, whereas the inverse makes food more difficult to digest (Van der Wal et al. 2000).

Habitat selection theory proposes that Lepidopterans require a minimum of three habitat types to satisfy all stages of a lifecycle including habitat for foraging and nectaring, habitat for mating, and habitat for oviposition (Wiklund 1977). These habitats can overlap or be exclusive, depending on butterfly species. Female butterflies will select specific areas for the purpose of oviposition (Grundel et al. 1998a), while male butterflies will exhibit 'hilltopping', or displaying atop an elevational gradient (Brown and Alcock 1990; Turner 1990). Nectaring habitat will provide suitable carbohydrates required by adults (Boggs 2009) while foraging habitat will provide nutrients necessary for larval survival. The selection of habitat during oviposition will ultimately select the general area where larvae will forage and ultimately determine the success of larval development. Female butterflies will theoretically select host plants that will support accelerated larval development and increased larval survival (Thomas 1988). Insect 
larval food in general is critical during development, as these resources determine the stored reserves carried from the larvae to the adult and are subsequently utilized for reproduction and other activities (Boggs 2009). Thus, habitat suitability, including forage availability as well as quality, is critical at all life stages.

The significance of host plant quality is a growing area of importance in the evaluation of butterfly abundance (Pickens and Root 2008). The quality and distribution of host plants are affected by habitat structure (e.g. Grundel et al. 1998b; Stanton 1982), which in turn can affect larval growth (Grossmueller and Lederhouse 1985), adult reproduction and longevity (Sun and Ge 2011). How habitat structure affects habitat suitability is especially important for oviposition by Lepidopteran adults, and by association larval foraging, through the influence of host plant abundance and distribution (Grundel et al. 1998b; Stanton 1982). Many researchers theorize that the presence of a host plant and abundance of forage does not solely determine the suitability of habitat for the persistence of an insect (Pickens and Root 2008; Moilanen and Hanski 1998). Essentially, a sub-optimal diet resulting from unfavorable habitat conditions can be detrimental to Lepidopteran growth, reproduction, and overall survival (Boggs, 2009; Awmack and Leather 2002). Thus, identifying habitat characteristics that may influence host plants and subsequently how adults select host plants for oviposition and larval forage, is imperative for successful management of sustainable butterfly populations (Grundel et al. 1998b). 
Habitat conditions can alter the availability of nutrients and resources, with consequences for the nutrient content of plants. For example, the relative ability of a plant to photosynthesize will determine carbon availability while placement within nitrogen-rich soils will increase nitrogen availability. Lepidopteran larvae require a diet composed of carbohydrates (composed of carbon, hydrogen and oxygen) that are important in growth and development, such as fueling energy-intensive flights and in the development of eggs (Merkx-Jacques et al. 2008; O’Brien et al. 2004; Pivnick and McNeil 1987). Carbohydrate intake must be balanced with protein intake (composed of amino acids formed mainly from nitrogen, carbon, oxygen and hydrogen) for energy as well as egg production (Boggs 2009, O’Brien et al. 2002). This balance of carbohydrates and proteins is not easy to classify and depend on the species in question as well as the life stage of the insect (Boggs 2009). This also depends on the ability of host plants to produce optimal nutritional sources for larvae, which occurs through photosynthesis (carbohydrate formation) and nitrogen uptake. The $\mathrm{C}: \mathrm{N}$ ratio (carbon: nitrogen) in host plants is indicative of the availability of these resources to herbivorous insects. These factors may cause compensatory foraging based on a nutritional rail (compensating for a lack of nutrients by moving to new resources), affecting the development of larvae and increasing larval exposure to predators (Boggs 2009; Hwang et al. 2008; Bede et al. 2007).

The availability of resources during plant growth also influences the allocation of defensive compounds (Hemming and Lindroth, 1999; Bryant et al., 1983), or adaptive 
secondary metabolites, such as phenolics, against fungal growth and insect herbivory (Lattanzio et al. 2006). According to the Carbon Nutrient Balance (CNB) hypothesis, this pattern of allocation to defensive compounds will increase carbon-based defensive compounds such as phenolics with increasing photosynthesis, and increase nitrogenbased defensive compounds with decreasing photosynthesis (Ralphs et al. 1998; Fajer et al. 1992; Bryant et al. 1983). Based on this theory, insect herbivores that feed on host plants with elevated $\mathrm{C}: \mathrm{N}$ ratios will develop more slowly due to an increase in carbon defenses (Coviella et al. 2002). Phenolics, specifically, are synthesized primarily via the shikimic acid pathway and are composed of carbon rings bonded to a hydroxyl group (Mazid et al. 2011). These chemical defenses repel insect herbivory by generating tough plant material that is indigestible, by generating a strong astringent flavor that generally make plant tissues unpalatable, and by acting as an antimicrobial chemical that disrupts digestion (Mazid et al. 2011).

Habitat suitability and the resulting influence on host plant quality is of particular important to specialist Lepidopterans such as the Karner blue butterfly (Lycaeides melissa samuelis Nabokov), a, federally endangered butterfly whose larvae is dependent on wild blue lupine (Lupinus perennis). These two species reside in oak and pine barrens/savanna and grasslands across the Great Lakes region to the eastern seaboard, characterized by oak and jack pine trees which intermittently shade grassy areas of low shrubs and flowering grassland plants (Anderson et al. 1999; Curtis 1959). Karner blue 
larvae forage exclusively on the leaves of lupine, a disturbance-dependent, long-lived, perennial legume (Swengel 1995; Boyonoski 1992; Grigore 1992; Grundel et al.1998a).

Habitat composition and structure greatly influence the quality of herbaceous vegetation, as well as host plants that Lepidopterans rely on. Because Karner blue adults almost exclusively use lupine for oviposition while larvae require the host plant for foraging, habitat suitability is of the utmost importance to Karner blue adults. This study asks four broad questions: 1) what is the variation in lupine $\mathrm{C}: \mathrm{N}$, nitrogen content, and phenolic content within Karner blue habitat; 2) do potentially influential habitat characteristics differ significantly between areas where lupine and Karners blues are abundant and areas where they are not; 3 ) are lupine $\mathrm{C}: \mathrm{N}$ ratio, nitrogen content, and phenolic content levels related to and possibly influenced by surrounding habitat characteristics; 4) do these nutrient and defensive compound levels influence Karner blue adult populations, which are indicative of the overall success of all Karner blue life stages?

We hypothesized that 1) lupine $\mathrm{C}: \mathrm{N}$, nitrogen, and phenolic levels would be related to habitat characteristics, and 2) candidate habitat variables would differ significantly between areas where lupine and Karner blues were present or absent, 3) Karner blue adult populations would be related to $\mathrm{C}: \mathrm{N}$, nitrogen and phenolic levels. 


\section{$\underline{\text { Methods }}$}

\section{Study Area}

The study areas were located on oak/pine grassland community sites that are currently part of the Wisconsin Department of Natural Resources Karner Blue Butterfly Recovery Program (Figure 5.1). These areas include the Crex Meadows Wildlife Area, Fish Lake Wildlife Area, Black River State Forest, Bauer Brockway Barrens State Natural Area, Sandhill Wildlife Area, Emmons Creek Fishery Area, Hartman Creek State Park, Greenwood Wildlife Area, and White River Marsh Wildlife Area. The Namekagon Barrens Wildlife Area was also included as it contains healthy oak barrens, but it is outside of the recovery program. These areas comprise 31 sites over 307 ha across the tension zone of Wisconsin.

\section{Field Data Collection}

Karner blue adult population surveys were conducted during the summer of 2010 using a modified distance sampling method (Buckland et al. 2004), analyzed using Distance software (Thomas et al. 2010). Transects used to estimate populations were established in each field site with a random starting point, perpendicular to the long axis of the field, and spaced 30 or $60 \mathrm{~m}$ apart based on field size (Schuurman 2010). This modified distance sampling method involves an observer walking the length of a transect while holding a $2.25 \mathrm{~m}$ pole perpendicular to the transect and intercepting all Karner blues 
within the length of the pole. This method produces a population encounter rate at 2.25 $\mathrm{m}$. This survey is conducted three times per primary flight with a minimum of 7 days in between each survey.

Sample plots were established within each of 31 field sites (Figure 5.1) according to a strategic systematic sampling design along pre-existing transects used for estimating Karner blue adult populations (Schuurman 2010) (Figure 5.2). Sample plots were evenly spaced along transects using a density of 2 sample plots per hectare with a minimum of 10 sample plots per field resulting in a total of 691 data points across 307 hectares.

A standard line-intercept method was used at each sample point to collect vegetation groundcover information, following methods described by Elzinga et al. (1998) and categorized into eight groundcover classes based on Smith et al. (2002), Grundel and Pavlovic (2000), and LeBare et al. (2000). These groundcover classes were percent cover of bareground, leaf litter, moss, grass, nectar plant, lupine plant, fern, and shrub/tree. Stem counts of host plant wild blue lupine and 16 focal nectar plant species were recorded within a 1/800 ha circular plot at each sample plot. Focal nectar plant species were selected based on Savanick (2005) and included lead-plant (Amorpha canascens), dotted horsemint (Monarda punctata), butterfly weed (Asclepias tuberose), old-field cinquefoil (Potentilla simplex), cinquefoil (Potentilla recta), prairie coreopsis (Coreopsis palmata), woodland sunflower (Helianthus divaricatus), western sunflower 
(Helianthus occidentalis), black-eyed susan (Rudbeckia hirta), common dewberry (Rubus flagellaris) and common blackberry (Rubus allegheniensis) grouped together into Rubus, flowering spurge (Euphorbia corollata), whorled milkweed (Asclepias vertifillata), new jersey tea (Ceanothus americanus), annual fleabane (Erigon annuиs), sand cress (Arabis lyrata), and wild blue lupine (Lupinus perennis). Focal nectar plants counts were totaled and used as a groundcover category in data analyses.

\section{Lupine Collection and Analysis}

Wild blue lupine samples (minimum of six full, palmate leaves) were collected where lupine was present within $5 \mathrm{~m}$ of the plot centerpoint (322 of the 691 total plots) in June of 2010 (Figure 5.2). Selected leaves were young and without signs of senescence. Selected leaves were dehydrated at approximately $160^{\circ} \mathrm{C}$ and tested for total carbon, nitrogen, and phenolic content. Carbon and nitrogen content were analyzed using a Flash EA 1112 Carbon/Nitrogen Analyzer ${ }^{\mathrm{TM}}$ (Thermo Electron Corporation, CE

Elantech, Lakewood, NJ, USA). Phenolics were analyzed using an Alpkem ${ }^{\mathrm{TM}} 305 \mathrm{~A}$ Rapid Flow Analyzer (Astoria Pacific International, Clackamas, OR, USA). Phenolic sample concentrations are expressed based on calibration using Quebracho tannin (L.H. Lincoln \& Son, Inc. Coudersport, PA, 16915) due to a lack of purified lupine tannin for standardization. These sample concentrations are relative to each other (based on a Quebracho baseline) and do not represent true lupine phenolic levels but can be used to evaluate relationships in phenolics among lupine plants in our study area. 


\section{Data analysis}

\section{Variation}

Variation across lupine $\mathrm{C}: \mathrm{N}$, nitrogen and phenolic content was examined across three groups of lupine samples: all sample plots, sample plots where Karner blues were

present, sample plots where Karner blues were not present. Lupine C:N and nitrogen content was compared visually to average C:N levels for Crimson Clover (Trifolium incarnatum L. ), Alfalfa (Medicago sativa L.) and Hairy Vetch (Vicia villosa L. Roth) (Somda et al. 1991) for purposes of general comparison. Lupine phenolics could not be compared to other legume values because the lupine analyses resulted in relative phenolic levels based on a Quebracho tannin baseline. Variation was examined using standard descriptive statistics. Variance (square of standard deviation) was used as a measure of spread in order to account for both deviations of data from the mean as well as frequency of deviations.

\section{Identifying influential habitat variables}

Standard stepwise regressions (backward selection) were used to model the influence of habitat composition variables on $\mathrm{C}: \mathrm{N}$, nitrogen, and phenolic levels of lupine across the Karner blue range. Potentially influential variables included percent cover of: bareground, ferns, ground litter, grass, moss, nectar plants, shrub/tree; and focal nectar plant abundance (stem counts). Habitat variables with $\mathrm{p} \leq 0.05$ were considered significant. Multicollinearity between candidate variables was evaluated using a 
correlation table. Due to low model predictability, relationships among candidate habitat variables and nutrient and defensive compounds were further assessed using a Spearman Rank Correlation analyses $\left(\mathrm{r}_{\mathrm{s}}\right)$. This nonparametric method ranks groups according to the mean and calculates a parametric Pearson's Correlation Coefficient based on the ranks. Difference of $r_{s}>0.2$ and $p \leq 0.05$ were considered significant.

\section{Comparison of lupine and Karner blue presencelabsence}

In order to assess how habitat quality influences the overall presence and persistence of lupine at sites, all sample plots were divided into four groups based on the presence and absence of lupine, and the presence and absence of Karner blues. This serves as a preliminary evaluation of how habitat quality influences lupine and subsequently Karner blue presence and absence. These groups included: lupine absent/Karner blues present, lupine absent/Karner blues absent, lupine present/Karner blues present, and lupine present/Karner blues absent. Karner blue presence was based on presence at the field-level, while lupine presence was based on presence at individual sample plots. This was done because all field sites had lupine present at some level (ranging from 2$100 \%$ of sample plots), thus not every sample plot at every field contained lupine. A Kruskal-Wallis non- parametric ANOVA was used to assess differences among groups. This nonparametric method associated ranks with each group mean and applies a parametric ANOVA to the ranks. Differences of $p \leq 0.05$ were considered significant. 
Relating candidate habitat variables to nutrient and defensive compound levels Lupine C:N, nitrogen and phenolic content were related to candidate habitat variables across all sample plots, and among five seemingly high quality field sites with high density of lupine. High-quality field sites were selected based on the presence of lupine at every sample plot or with few sample plot gaps. Levels of C:N, nitrogen and phenolic content of lupine were related to candidate habitat variables among sites using a Spearman Rank correlation $\left(\mathrm{r}_{\mathrm{s}}\right)$ analysis. Difference of $\mathrm{r}_{\mathrm{s}}>0.2$ and $\mathrm{p} \leq 0.05$ were considered significant.

\section{Karner blue populations}

Karner blue adult populations were related to lupine C:N, nitrogen and phenolic content across all sample plots, and among the five high quality field sites identified above. $\mathrm{C}: \mathrm{N}$, nitrogen and phenolic content were related to Karner blue density per field via a Spearman Rank correlation $\left(\mathrm{r}_{\mathrm{s}}\right)$ analysis. Difference of $\mathrm{r}_{\mathrm{s}}>0.2$ and $\mathrm{p} \leq 0.05$ were considered significant. Analyses were conducted in Statistix8 (Analytical Software 2008).

\section{$\underline{\text { Results }}$}

\section{Variation}

Lupine C:N across all sample plots ranged from 9.1-16, averaged 11.8 and varied 1.63 (Figure 5.3) (variance represents the sum of all data points, squared, and divided by 
sample size; or the square of the standard deviation). In comparison, lupine C:N only across plots where Karner blues were present ranged from 9.1-16, averaged 11.8, and varied 1.7 (Figure 5.3), while sample plots where Karner blues were absent ranged from 9.2-12.7, averaged 11.6, and varied 0.82 across plots. Overall, lupine C:N was much lower than for crimson clover, but averaged nearly the same as Alfalfa and higher than Hairy Vetch (USDA 2011; Ketterings et al. 2011; Somda et al. 1991).

Lupine nitrogen content across all sample plots ranged from $2.4-5.3 \%$ dry weight, averaged $3.7 \%$, and varied $0.24 \%$ (Figure 5.4). In comparison, lupine nitrogen content across plots where Karner blues were present ranged from $2.4-5.0 \%$ dry weight, average $3.7 \%$, and varied $0.24 \%$, while those plots where Karner blues were not present ranged from $3.3-5.2 \%$ dry weight, average $3.8 \%$, and varied $0.18 \%$. Overall, lupine nitrogen content was much lower than Hairy Vetch, approximately the same average as alfalfa, and higher than crimson clover (USDA 2011; Ketterings et al. 2011; Somda et al. 1991).

Lupine phenolic content displayed little variation across the range (Figure 5.5). Lupine phenolic content ranged from $0.0017-0.0324 \%$ dry weight, average $0.0163 \%$, and varied $0.0018 \%$. In comparison, lupine phenolic content at sample plots where Karner blues were present ranged from $0.0017-0.0324 \%$ dry weight, average $0.0163 \%$, and varied $0.0018 \%$, while sample plots where Karner blues were absent ranged from $0.0118-0.0317 \%$ dry weight, average $0.0167 \%$, and varied $0.0018 \%$. 


\section{Identifying influential habitat variables}

The regression model procedure identified between two and three habitat variables for each nutrient and defensive compound (Table 5.1). Resulting models weakly explained between 3 and $12 \%$ of variation across the dataset.

\section{Comparison of lupine and Karner blue presence/absence}

Percent cover of candidate habitat variables including shrub/tree and focal nectar plant stem counts were significantly different among groups of lupine and Karner blue presence/absence (Figures 5.6). Percent cover of ground litter did not significantly differ among these groups. Percent cover of shrub/tree was significantly higher where lupine and Karner blues were absent, and significantly lower where Karner blues were present, or lupine was present and Karner blues were not. Focal nectar plant stem counts were significantly higher in areas where lupine and Karner blues were both present.

Relating candidate habitat variables to nutrient and defensive compound levels Spearman rank correlations between candidate habitat variables and lupine nutrient content illustrated weak relationships for all sample plots across Wisconsin (Figure 5.7). Lupine C:N displayed an inverse relationship with ground litter $\left(\mathrm{r}_{\mathrm{s}}=-0.22,<p=0.001\right)$ and positive relationship with the percent cover of shrub/tree $\left(\mathrm{r}_{\mathrm{s}}=0.25, p=0.001\right)$ and focal nectar plants $\left(\mathrm{r}_{\mathrm{s}}=0.33,<p=0.001\right)$. Nitrogen content displayed a positive relationship with ground litter $\left(\mathrm{r}_{\mathrm{s}}=0.23<p=0.001\right)$ and decreased with increasing 
cover of shrub/tree $\left(\mathrm{r}_{\mathrm{s}}=-0.27,<p=0.001\right)$ and focal nectar plants $\left(\mathrm{r}_{\mathrm{s}}=-0.32,<p=\right.$ 0.001). Phenolic content was not significantly related to any habitat variables $\left(\mathrm{r}_{\mathrm{s}}>0.2, \mathrm{p}\right.$ $\leq 0.05)$

Spearman Rank Correlations between candidate habitat variables and nutrient content of lupine at the 5 sites with high densities of lupine illustrated similar weak relationships as that of all combined sample plots (Figure 5.8). Percent cover of ground litter and focal nectar plant stem counts were related to levels of $\mathrm{C}: \mathrm{N}$, nitrogen content and phenolic content. Lupine $\mathrm{C}: \mathrm{N}$ ratio was negatively related to percent cover of ground litter $\left(\mathrm{r}_{\mathrm{s}}=-0.27, p=0.002\right)$ and positively related to focal nectar plant stem counts $\left(\mathrm{r}_{\mathrm{s}}=\right.$ $0.25, p=0.003)$. Nitrogen content was positively related to ground litter $\left(\mathrm{r}_{\mathrm{s}}=0.27, p=\right.$ $0.001)$ and negatively related to nitrogen content $\left(r_{s}=-0.22, p=0.009\right)$. Percent cover of shrub/tree was not related to $\mathrm{C}: \mathrm{N}$ or nitrogen content among these five fields, and phenolic content was not significantly related to any habitat variables (Figure 5.8) ( $p \leq$ $0.05)$.

\section{Karner blue populations}

Karner blue density (observations/linear m) was significantly related to lupine nitrogen content across all sample plots (Figure 5.9). Karner blue density was positively related to lupine nitrogen content $\left(\mathrm{r}_{\mathrm{s}}=0.2, p=<0.0012\right)$. Karner blue density was not significantly related to lupine $\mathrm{C}: \mathrm{N}$ or phenolic content across these sample plots. 
Karner blue density (observations/linear m) were significantly related to lupine C:N ratio and nitrogen content among five high density lupine field sites (Figure 5.10). Karner blue density was positively related to lupine $\mathrm{C}: \mathrm{N}$ ratio $\left(\mathrm{r}_{\mathrm{s}}=0.3, p=<0.001\right)$ and negatively related to nitrogen content $\left(\mathrm{r}_{\mathrm{s}}=-0.32, p=<0.001\right)$. Phenolic content was not related to Karner blue density among these five field sites.

\section{$\underline{\text { Discussion }}$}

The results of this study suggest that habitat characteristics including the percent cover of shrub/tree and ground litter, as well as the abundance of focal nectar plants, are interrelated with lupine $\mathrm{C}: \mathrm{N}$ ratio and nitrogen content, and Karner blue density. Overall, it appears that Karner blues during the second flight are associated with habitat parameters that produce robust lupine leaves with increasing $\mathrm{C}: \mathrm{N}$ ratios, primarily related to moderate shade cover (10-25\%), an abundance of focal nectar plants $(>10$ stems per $1 / 800$ plot, preferably $30-60+$ stems), and a low amount of ground litter $(\sim 10 \%)$, resulting in a wide range of $\mathrm{C}: \mathrm{N}$ and nitrogen content.

\section{Lupine Variability}

Lupine $\mathrm{C}: \mathrm{N}$ ratio range varied considerably across all sample plots in Wisconsin, from values of about 11:1 to $13: 1$ average overall, but ranging from 9:1 to $16: 1$. The overall range of lupine $\mathrm{C}: \mathrm{N}$ was far greater in areas where Karner blues were present than in areas where Karner blues were not present (C:N ratio of approximately 9 to 13$)$. In 
comparison to common cover crops including crimson clover, alfalfa and hairy vetch, all of which are used to help residue decomposition following a high C:N ratio crop, lupine ranked on average with alfalfa $\mathrm{C}: \mathrm{N}$ values, and much lower than crimson clover (USDA 2011). The function of legume crops in agriculture are to maintain a balance of carbon and nitrogen content in the soil such that soil microorganisms can maintain their own body C:N balance (generally 8:1), and requiring a constant rotation of approximately 24:1 in order to maintain physiological functions and continue decomposing crop residues (USDA 2011; Ketterings et al. 2011; Somda et al. 1991). It should also be noted that the average $\mathrm{C}: \mathrm{N}$ ratio of these legume cover crops, or any cover crop, differs significantly with age; a young alfalfa crop will average a $\mathrm{C}: \mathrm{N}$ ratio of 13:1, while a mature crop will average $25: 1$. Alfalfa, to which lupine was very similar, is commonly used as a hay crop due to its value as both high quality (high protein content and digestible fiber) and high quantity forage, and serves as a host plant for many Lepidopterans, including the family Pieridae (commonly referred to as sulfurs), suggesting that these $\mathrm{C}: \mathrm{N}$ values around 13:1 are preferable for Lepidopteran forage.

Similarly, the variation of lupine nitrogen content was much smaller in areas where Karners were absent than where Karners were present ( $\sim 3-4 \%$ nitrogen dry weight vs. $\sim 2.5-4.75 \%$, respectively). Again, the lupine nitrogen content was similar to an alfalfa cover crop. The nitrogen content in this study may also reflect lupine age. Younger lupine plants may display higher nitrogen content than older plants (Schroeder 1986). 
The samples collected in this study were gathered just before the peak flight of the Karner blues, a week before or during the foraging of the peak flight Karner blue larvae, approximately halfway through the overall lifecycle of lupine. Lupine in similar studies (e.g. Pickens and Root 2008; Grundel et al. 1998b) displayed higher nitrogen levels, but were collected earlier in the season, which may be contributing to higher overall reports on nitrogen levels. The lower range of nitrogen levels in areas where Karner blues are not present at all may also reflect lower soil quality on already low-nutrient, xeric soils, which subsequently influences lupine and focal nectar plant growth making habitat completely unsuitable (De Deyn et al. 2011; Grundel et al. 1998b; Lawrence 1994).

These findings suggest that Karner blues may be more successful in areas where there is a greater range of lupine $\mathrm{C}: \mathrm{N}$ and nitrogen content, and where larvae or ovipositing females have more selection of preferable to non-preferable plants. Habitat composition and structure (quality) most likely explains this range of values in lupine and apparent preferences of the Karner blue and are discussed further below.

\section{Habitat Parameters}

Habitat suitability and quality is based on more than the presence of host plants and forage for Lepidopterans (Pickens and Root 2008; Moilanen and Hanski 1998). Overall shade appears to influence the quality of lupine more than other habitat variables when evaluated across the range in Wisconsin, increasing lupine $\mathrm{C}: \mathrm{N}$ with increased shrub/tree cover as well as the cover of robust prairie plants. Shrub/tree cover was higher in areas where lupine and Karner blues were absent than in areas where lupine 
was present. Though lupine does grow in areas of up to $75 \%$ canopy, it grows most robustly in areas of moderate canopy cover.

According to this study, areas with a variation above $45 \%$ canopy cover prohibit the growth of lupine altogether, while $10-25 \%$ was preferable for both lupine and Karner blue presence. The lack of a significant relationship to shrub/tree cover among the five high density lupine field sites is most likely due to the lack of canopy variation among these particular sites. According to the CNB hypothesis, lupine $\mathrm{C}: \mathrm{N}$ ratio should increase as photosynthesis increases (given increased availability of sunlight). However, the lupine $\mathrm{C}: \mathrm{N}$ appears to be increasing with increasing shade. Lupine is known to grow preferentially in partially shaded areas (Grundel et al. 1998b; Lawrence 1994), due to extreme edaphic and thermal conditions on sandy soils which force lupine to senesce earlier given a lack of suitable canopy cover or shade provided by robust prairie plants (Pavlovic and Grundel 2009; Lawrence 1994).

It should also be noted that this study was conducted during the second, or primary, Karner blue flight, and that summer conditions in Wisconsin from July to August tend to be extremely hot and humid and Karner blues may have been seeking more shaded areas where the lupine was senescing less quickly rather than based on plant nutritional quality. 
Focal nectar plant abundance was significantly higher in areas where both lupine and Karner blues were present (30-60+ stems per 1/800 plot), and areas $<10$ stems lacked lupine and Karner blues altogether. Herbaceous vegetation density such as robust native grassland plants increases butterfly density (Ellis 2003), and provides shade for lupine without displacing it (Pickens and Root 2008) while also providing an abundant food source (Mevi-Schutz et al. 2003). The focal nectar plants evaluated in this study may also contribute to the increasing $\mathrm{C}: \mathrm{N}$ ratio and decreasing nitrogen content by immobilizing the available nitrogen in the area. Many of the plants evaluated are not legumes but are adapted to sandy substrates. These plants would likely consume nitrogen rather than releasing it in the already nutrient poor sandy soils, contributing rather to the immobilization of lupine rather than mineralization (De Deyn et al. 2011; USDA 2011; Ketterings et al. 2011; Grundel et al. 1998a; Folgarait and Davidson 1995; Somda et al. 1991). Because these plants would provide shade for lupine, these results may further support the theory that lupine requires a mix of closed and open-canopy areas to propagate most successfully (i.e. Grundel et al. 1998a; Grundel et al. 1998b; Boyonoski 1992).

Ground litter also appears to play a significant role in the persistence of lupine. Earlier studies debated whether lupine, a nitrogen-fixing plant, would be influenced at all by the absence or presence of organic material in the soil due to its adaptability to poor nutrient, sandy substrates (Grundel et al. 1998a). Increasing ground litter on these sandy substrates is known to negatively affect the propagation and survival of lupine seedlings 
(Pavlovic and Grundel 2009). Supporting this, the percent cover of ground litter observed in this study is associated with a decrease in lupine $\mathrm{C}: \mathrm{N}$, increasing nitrogen content, and is preferable to both lupine and Karner blue presence at $\sim 10 \%$ cover. Percent cover of ground litter also appears to discourages lupine and Karner persistence at levels above $70 \%$, or if ground litter is absent altogether. Ground litter cover may increase the overall nitrogen content of lupine by increasing microbial decomposition activities in the soil (De Deyn et al. 2011; USDA 2011; Ketterings et al. 2011; Somda et al. 1991). Lupine may also be taking up nitrogen from the soil, or relying on recently fixed nitrogen in the soil; unfortunately we cannot know for certain while relying on the analyses in this study.

Nitrogen mineralization may occur at a greater rate in areas of higher ground litter, and in particular in areas where focal nectar plant abundance is low and excess nitrogen is not being used. This could lead to a possible nitrogen surplus that can be detrimental to microbial and plant health, but could also contribute to an overall improvement in soil quality leading to an increase in herbaceous cover that may compete with lupine (De Deyn et al. 2011; Hwang et al. 2008; Weiss et al. 1988). A delicate balance may exist in which ground litter protects lupine from senescence, reduces competition from herbaceous plants and allows lupine to grow and develop nitrogen content favorable to host species. This balance may have been more readily maintained through natural disturbance regimes such as fire which maintained minimum ground litter levels and aided in nutrient cycling (Curtis 1959). 
The decrease of nitrogen content with increasing shrub/tree cover and focal nectar plant cover disagrees with studies that reported increased nitrogen content in lupine growing in shaded areas (Pickens and Root 2008). This may be because lupine for this analysis was collected in mid-to-late June and at higher latitude (Wisconsin), whereas Pickens and Root (2008) collected lupine in mid-May and late-June at lower latitude (Ohio) where lupine would senesce later (nitrogen content would decrease with leaf maturity, Schroeder 1986). Pickens and Root (2008) reported nitrogen levels of average $\sim 4.75 \%$ nitrogen content (May) and average $\sim 4.2 \%$ nitrogen content (June), marking a decrease in nitrogen content as the summer progressed. In comparison the nitrogen content in this analyses averaged $\sim 3.7 \%$ weight. However, nitrogen in this study was negatively related to overall Karner blue populations across all sample plots, possibly suggesting that the lower nitrogen rates observed in this study may be related to the overall success of the larger Karner blue populations in the state of Wisconsin as opposed to neighboring states which have significantly lower populations.

\section{Karner Blue Populations}

The importance of the derived habitat quality parameters in this study is ultimately how it reflects on the persistence and success of the biological community inhabitants and in particular the Karner blue populations that reside within these habitat areas. Karner blues populations overall increased in relation to lupine $\mathrm{C}: \mathrm{N}$, suggesting that preferable habitat contains lupine that provides more favorable forage than protein-providing high 
nitrogen content (Van der Wal et al. 2000). This reflects on the habitat composition and structure as well, suggesting that cover of shrub/tree in moderation (10-25\%) may produce higher quality habitat and higher quality lupine for the Karner blue, which oviposit more frequently in shade, and which also produces higher water content in lupine leaves which in turn provides better forage quality for larvae (i.e. Grundel et al. 1998a). This is advantageous to many Lepidopterans due to delayed senescence of host plants and prolonged growth, as well as increased availability of nectar plants (Weiss et al. 1988; Cappuccino and Kareiva 1985). However, lupine is less likely to occur in canopy settings above $25 \%$, and especially $>45 \%$.

The development of moderate shade (10-25\%) conditions and low ground litter $(\sim 10 \%)$ for Karner blue habitat may also moderate nitrogen content of lupine leaves. Generally, higher quality forage is associated with nitrogen content because it provides protein concentrations and energy resources (Van der Wal et al. 2000; Van der Wal and Loonen 1998). However, during the second flight (observed in this study), increased nitrogen stores that are allocated in larval form may constrain overall fecundity of the adult insect (Boggs 2009). This may be because larval intake of carbohydrates, which is required for the production of eggs, must be balanced with nitrogen intake, and an imbalance in these may inhibit egg production at later life stages (Merkx-Jacques et al. 2008; O’Brien et al. 2004; Pivnick and McNeil 1987). 
The decreasing relationship between Karner blue populations and nitrogen content during the primary (second) flight may also be due to the relative age of the lupine and the lifecycle of the overall Karner blue population (first flight vs. second flight). Increased nitrogen intake during the first Karner blue generation may increase the ability of the first generation to mature more quickly and reproduce faster (Pickens and Root 2008). Nitrogen content has been found to increase larval size and survival within a laboratory setting (Grundel et al. 1998a). This is similar to other Lepidopterans, including Malacosoma americanum and Hyalophora cecropia, which display increased forage of host plant leaves well as larval survival and shortened growth duration with increased nitrogen content. This increased nitrogen content resulted from being fed early-season foliage with higher nitrogen content (which decreased as leaves matured) (Schroeder 1986). Faster development would be necessary during the first flight in order for Karner blues to mature and lay eggs for the second flight. Faster larval development is theoretically advantageous, resulting in increased avoidance of senesced lupine plants late in the second Karner blue generation (Dirig 1994), and avoidance of predators or other insects that inhibit Karner blue behavior (Swanson and Kleintjes Neff 2007). Larvae that consume higher nitrogen content earlier in the season and experience accelerated growth development, such as the first generation, would theoretically be more successful in producing a second generation. 


\section{Phenolic Content}

Phenolic content was not related to candidate habitat variables or to the density of Karner blues. This could also be due to several reasons, including the decrease of nitrogen availability in lupine as the second flight takes place (Pickens and Root 2008), as well as the possible ability of Karner blues to tolerate carbon-based deterrents that would theoretically increase with C:N ratio (Coviella et al. 2002; Van der Wal et al. 2000; Dudt and Shure 1994). This study did observe Karner blues increasing in relation to lupine $C: N$, suggesting that Karner blues select these areas for higher forage quality. The Karner blue may, instead, show intolerance for nitrogen-based deterrents.

This is in agreement with several studies that dispute the theory that increased carbon intake will increase carbon-based defensive compounds (i.e. Hamilton et al. 2008) and especially that this will inhibit insect performance. Increased herbivory on foliage in open areas has been observed through insect herbivory on Cardamine cordifolia (Louda and Rodman 1996), and Diplacus aurantiacus (Lincoln and Mooney 1984). Plants produce toxins for a variety of reasons, generally to help defend plants from phytophagous insects and pathogens, (Barbehenn and Constabel 2011); however, many insects are capable of tolerating these compounds (Barbehenn and Constabel 2011). Insects develop both biochemical and physical defenses and may be so tolerant of the compounds that they are not inhibited (Barbehenn and Constabel 2011). The Karner blue may have developed sufficient stomach $\mathrm{pH}$ levels and antioxidant production to combat these toxic deterrents. Likewise, the phenolic deterrents may not have been 
measurably high due to the time period during which lupine was collect (June as opposed to later in the season). Chemical defenses such as phenolics will increase with foliage maturity (Folgarait and Davidson 1995) and may not have been completely developed in the lupine leaves.

\section{$\underline{\text { Conclusions }}$}

Habitat quality can influence overall host plant forage quality, which in turn influences the success of dependent invertebrate species such as Lepidopterans. Overall the findings of this study suggest that habitat composition and structure (quality) may influence the presence and absence of species as well as nutrient content of plants. This study provides insight into the potential impacts of basic habitat manipulation (e.g. canopy cover, ground litter control) on overall carbon and nitrogen mechanisms in herbaceous plant cover. Namely, that variations in shade, whether from shrubs, trees, or large robust herbaceous plants, and ground litter may influence C:N and nitrogen content within a native legume, which may have implications for restoration practices within other settings. We suggest through this study that habitat features and nutrient content are inter-related, and that increases in shade may increase a legume $\mathrm{C}: \mathrm{N}$ ratio while increasing ground litter may decrease the $\mathrm{C}: \mathrm{N}$ ratio and increase nitrogen content. Also we demonstrated that a mix of shade conditions is preferable to extremes of lows or highs in a sandy, grassland setting. 
The field sites evaluated in this study displayed a variety of habitat characteristics and Karner blue populations. Karner blues, like other butterflies, utilize a range of habitat characteristics throughout their lifecycle and appeared to favor habitat areas that display a mix of shrub/tree cover and an abundance of focal nectar plants, as well as the presence of the host plant, lupine.

There is no easy solution to successfully manage what was once a highly dynamic, shifting mosaic habitat regime when the natural mechanisms that once maintained the habitat are highly regulated today. In the context of management it is apparent that the presence of lupine alone does not determine the suitability of habitat for the persistence of Karner blues and that other habitat features must be taken into account. Manipulation of these field-level habitat characteristics influence host plant quality, producing more favorable conditions for Karner blue populations as well as species that share the habitat. Manipulation of must take into consideration the needs of the various life stages of the Karner blues: males prefer open areas, females prefer partial shading for oviposition, and larvae prefer larger, more robust lupine plants that typically grow in shaded areas though lupine grows more abundantly in the sunlight. Based on this study and the findings of related studies, management efforts should focus on generating heterogeneous canopy cover conditions, lupine presence across a variety of canopy conditions, and a high abundance of focal nectar plants suitable for both generations of Karner blues. This mix of canopy cover is especially important on hot, sandy soils (i.e. Grundel et al. 1998b; Lawrence 1995). Specifically management efforts should generate 
a mix of canopy-cover conditions (10-25\%), decrease ground litter cover $(\sim 10 \%)$ and especially increase focal nectar plant abundance (preferably $30-60+$ stems per $1 / 800$ ha plot). The findings of this study may inspire new research in this area. Most importantly, this study evaluates host-plant quality in a natural setting, a condition that is rarely quantified (Pickens and Root 2008).

\section{$\underline{\text { Acknowledgements }}$}

Data collection for this research was partially funded by the Wisconsin Department of Natural Resources-Karner Blue Butterfly Recovery Program, the United States Fish and Wildlife Federal Recovery Program, and Michigan Technological University. Butterfly population information and habitat information was collected by the Wisconsin DNR and associated scientific survey groups including the University of Wisconsin-Stevens Point group led by Dr. Michael Demchik, and Endangered Resources Services, LLC. WDNR Bureau of Science Services and Dr. Gregor Schuurman provided analyses of population data. Nutrient analyses were conducted by the USFS Northern Research Laboratory in Rhinelander, Wisconsin. This data is part of the WDNR Natural Heritage Inventory. Permits to conduct study include: Natural Heritage Inventory LA157, Wisconsin Endangered and Threatened Species Permit \#687, and State of Wisconsin Department of Administration Volunteer Agreement. Additional data for this study was collected with the help of Robert J. Hess, Joy L.M. Hess, Jennifer Resch, Jessica

Kempke-Lewis, Kris Poncek, Michael J. Falkowski, Linda C. Lyons, Julius Dewald, Jill 
Utrup, Jodi Shaw, and with the permission and help of the state property staff including Wayne Hall, Paul Samerdyke, Pete Engman, Steve Hoffman, James Holzwart, Raymond Paisley, Brandon Stefanski, James Tomasko, Nancy Christel, Peter Bakken, and Armund Bartz.

\section{$\underline{\text { References }}$}

Analytical Software. 2008. Statistix 8. Analytical Software: Tallahassee, FL.

Anderson RC, Fralish JS, Baskin JM. 1999. Savannas, barrens, and rock outcrop plant communities of North America. Cambridge University Press, New York.

Awmack CS, Leather SR. 2002. Host plant quality and fecundity in herbivorous insects. Annual Review of Entomology. Vol. 47, pp. 817-844.

Barbehenn RB, Constabel CP. 2011. Tannins in plant-herbivore interactions. Phytochemistry. Vol. 72(13), pp. 1551-1565.

Bede JC, McNeil JN, Tobe SS. 2007. The role of neuropeptides in caterpillar nutritional ecology. Peptides. Vol. 28, pp. 185-196. 
Boggs CL. 2009. Understanding insect life histories and senescence through a resource allocation lens. Functional Ecology. Vol. 23, pp. 27-37.

Boyonoski AM. 1992. Factors affecting the establishment and maintenance of Lupinus perennis (wild lupine). M.S. Thesis. University of Guelph. Guelph, Ontario.

Brown WD, Alcock J. 1990. Hilltopping by the Red Admiral Butterfly: mate searching alongside congeners. Journal of Research of the Lepidoptera. Vol. 29(1-2). pp. 1-10.

Bryant JP, Chapin III FS, Klein DR. 1983. C:N nutrient balance of boreal plants in relation to vertebrate herbivory. Oikos. Vol. 40, pp. 357-368.

Buckland ST, Anderson DR, Burnham KP. 2004. Advanced distance sampling. Oxford University Press, New York.

Cappuccino N, Kareiva P. 1985. Coping with a capricious environment: a population study of a rare Pierid butterfly. Ecology. Vol. 66, pp. 152-151.

Coviella CE, Stipanovic RD, Trumble JT. 2002. Plant allocation to defensive compounds: interactions between elevated $\mathrm{CO}_{2}$ and nitrogen in transgenic cotton plants. Journal of Experimental Botany. Vol. 53(367), pp. 323-331. 
Craine JM, Balentyne F, Peel M, Cambatis N, Morrow C, Stock WD. 2009. Grazing and landscape controls on nitrogen availability across 330 South African savanna sites. Austral Ecology. Vol. 34(7), pp. 731-740.

Curtis JT.1959. The vegetation of Wisconsin. Madison, Wisconsin: University of Wisconsin Press.

De Deyn GB, Shiel RS, Ostle NJ, McNamara NP, Oakley S, Young I, Freeman C, Fenner N, Quirk H, Bardgett RD. 2011. Additional carbon sequestration benefits of grassland diversity restoration. Journal of Applied Ecology. Vol. 48, pp. 600-608.

Dirig R. 1994. Historical notes of wild lupine and the Karner blue butterfly at the Albany Pine Bush, New York. In: Andow DA, Baker RJ, Lane Cynthia P, EDS. Karner blue butterfly: a symbol of a vanishing landscape. Miscellaneous Publication 84-1994. St. Paul, MN: University of Minnesota, Minnesota Agricultural Experiment Station: 2326. [63142]

Dudt JF, Shure DJ. 1994. The influence of light and nutrients on foliar phenolics and insect herbivory. Ecology. Vol. 75, pp. 86-98. 
Ellis S. 2003. Habitat quality and management for the northern brown argus butterfly Aricia artaxerxes (Lepidoptera: Lycaenidae) in North East England. Biological Conservation. Vol. 111, pp. 285-294.

Elzinga CL, Salzer DW, Willoughby JWL. 1998. Measuring and monitoring plant populations. U.S. Department of the Interior. Bureau of Land Management. The Nature Conservancy. BLM Technical Reference $1730-1$.

Fajer ED, Bowers MD, Bazzaz FA. 1992. The effects of nutrients and enriched $\mathrm{CO}_{2}$ environments on production of carbon-based allelochemical in Plantago - a test of the carbon nutrient balance hypothesis. The American Naturalist. Vol. 140(4), pp. 707-723.

Folgarait PJ, Davidson DW. 1995. Myrmecophytic cecropia: anti-herbivore defenses under different nutrient treatments. Oecologia. Vol. 104, pp. 189-206.

Geist V. 1987. Bergmann's rule is invalid. Canadian Journal of Zoology. Vol. 65, pp. 1035-1038.

Grigore M. 1992. The short-term effect of fire on wild lupine (Lupinus perennis L.). M.S. Thesis, University of Toledo. Toledo, Ohio. 
Grossmueller DW, Lederhouse RC. 1985. Oviposition site selection: an aid to rapid growth and development in the tiger swallowtail butterfly, Papilio glaucus. Oecologia. Vol. 66, pp. 68-73.

Grundel R, Pavlovic NB. 2000. Nectar plant selection by the Karner blue butterfly (Lycaeides melissa samuelis) at the Indiana Dunes National Lakeshore. The American Midland Naturalist. Vol. 144(1), pp. 1-10.

Grundel R, Pavlovic NB, Sulzman CL. 1998a. The effect of canopy cover and seasonal change on host plant quality for the endangered Karner blue butterfly (Lycaeides melissa samuelis). Oecologia. Vol. 114, pp. 243-250.

Grundel R, Pavlovic NB, Sulzman CL. 1998b. Habitat use by the endangered Karner blue butterfly in oak woodlands: the influence of canopy cover. Biological Conservation. Vol. 85, pp. 47-53.

Hamilton JG, Zangerl AR, DeLucia EH, Berenbaum MR. 2008. The carbon-nutrient balance hypothesis: its rise and fall. Ecology Letters. Vol. 4(1), pp. 86-95.

Hemming JDC, Lindroth RL. 1999. Effects of light and nutrient availability on aspen: growth, phytochemistry and insect performance. Journal of Chemical Ecology. Vol. 25, pp. 1687-1714. 
Hwang SY, Liu CH, Shen TC. 2008. Effects of plant nutrient availability and host plant species on the performance of two Pieris butterflies (Lepidoptera: Pieridae).

Biochemical Systematics and Ecology. Vol. 36, pp. 505-513.

Ketterings QM, Kingston J, McIlvennie S, Long E, Godwin G, Gami S, Stanyard M, Czymmek K. 2011. Cover crop carbon and nitrogen content: fall of 2010 sampling. What's Cropping Up? Vol. 21 (3), pp. 1-4.

Knox NM. 2010. Observing temporal and spatial variability of forage quality. Dissertation. University of Twente, Johannesburg, South Africa.

Lattanzio V, Lattanzio VMT, Cardinali A. 2006. Role of phenolics in the resistance mechanisms of plants against fungal pathogens and insects. Phytochemistry: Advances in Research. pp. 23-67.

Lawrence WS. 1994. Karner blue butterfly populations in the Allegan State Game Area, Michigan. In: Andow DA, Baker RJ, Lane CP (eds.). Karner blue butterfly: a symbol of a vanishing landscape. Minnesota Agricultural Experiment Station, University of Minnesota, St Paul, pp. 53-62. 
LeBare KM, Broyles SB, Klotz RL. 2000. Exploring nectar biology to learn about pollinators. The American Biology Teacher. Vol. 62 (4), pp. 292-296.

Lincoln DE, Mooney HA. 1984. Herbivory on Diplacus aurantiacus shrubs in sun and shade. Oecologia. Vol. 64, pp. 173-176.

Louda SM, Rodman JE. 1996. Insect herbivory as a major factor in the shade distribution of a native crucifer (Cardamine cordifolia A. Gray, bittercress). Journal of Ecology. Vol. 84, pp. 229-237.

Mazid M, Khan TA, Mohammad F. 2011. Role of secondary metabolites in defense mechanisms of plants. Biology and Medicine. Vol. 2(3), pp. 232-249.

Mevi-Schütz J, Goverde M, Erhardt A. 2003. Effects of fertilization and elevated $\mathrm{CO}_{2}$ on larval food and butterfly nectar amino acid preference in Coenonympha pamphilus L. Behavioral Ecology and Sociobiology. Vol. 54, pp. 36-43.

Merkx-Jacques M, Despland E, Bede JC. 2008. Nutrient utilization by caterpillars of the generalist beet armyworm, Spodoptera exigua. Physiological Entomology. Vol. 33, pp. $51-61$. 
Moilanan A, Hanski J. 1998. Metapopulation dynamics: effects of habitat quality and landscape structure. Ecology. Vol. 79, pp. 2503-2515.

O’Brien DM, Boggs CL, Fogel ML. 2004. Making eggs from nectar: connection between butterfly life history and the importance of nectar carbon in reproduction. Oikos. Vol. 105, pp. 279-291.

O'Brien DM, Fogel ML, Boggs CL. 2002. Renewable and nonrenewable resources: amino acid turnover and allocation to reproduction in Lepidoptera. Proceedings of the National Academy of Sciences of the United States of America. Vol. 99, pp. 4413-4418.

Pavlovic NB, Grundel R. 2009. Reintroduction of wild lupine (Lupinus perennis L.) Depends on variations in canopy, vegetation, and litter cover. Restoration ecology. Vol. 17(6), pp. 807-817.

Pickens BA, Root KV. 2008. Factors affecting host-plant quality and nectar use for the Karner Blue butterfly: implications for oak savanna restoration. Natural Areas Journal. Vol. 28(3), pp. 210-217.

Pivnick KA, McNeil JN. 1987. Puddling in butterflies: sodium affects reproductive success in Thymelicus lineola. Physiological Entomology. Vol. 12, pp. 461-472. 
Post ES, Klein DR. 1996. Relationships between graminoid growth form and levels of grazing by caribou (Rangifer tarandus) in Alaska. Oecologia. Vol. 107, pp. 364-372.

Ralphs MH, Manners GD, Gardner DR. 1998. Influence of light and photosynthesis on alkaloid concentration in larkspur. Journal of Chemical Ecology. Vol. 24, pp. 167-182.

Savanick MA. 2005. Population dynamics and nectar preference of the Karner blue butterfly, Lycaeides melissa samuelis (Nabokov) (Lepidoptera: Lycaenidae). Master's Degree Thesis. University of Minnesota.

Schuurman G. 2010. Distance sampling survey protocol. Wisconsin Department of Natural Resources: Wisconsin Karner Blue Butterfly Recovery Program.

Schroeder LA. 1986. Changes in tree leaf quality and growth performance of Lepidopteran larvae. Ecology. Vol. 67(6), pp. 1628-1636.

Smith, MA, Turner MG, Rusch DH. 2002. The effect of military training activity on eastern lupine and the Karner blue butterfly at Fort McCoy, Wisconsin, USA. Environmental Management. Vol. 29(1), pp. 102-115.

Somda ZC, Ford PB, Hargrove WL. 1991. Decomposition and nitrogen recycling of cover crops and crop residues. pp. 103-105. In. Hargrove WL (ed.) Cover crops for 
clean water. Proceedings of the International Conference, Jackson TN. 9-11 April, 1991. Soil and Water Conservation Society, Ankeny, IA.

Stanton ML. 1982. Searching in a patchy environment: foodplant selection by Colias $P$. eriphyle butterflies. Ecology. Vol. 63, pp. 839-853.

Swanson JAI, Kleintjes Neff PK. 2007. Lycaeides melissa samuelis (Lepidoptera: Lycaenidae) response to an aggregation of Lytta Sayi Coleoptera: Meloidae) on Lupinus perennis (Fabacea). The Great Lakes Entomologist. Vol. 40(1-2), pp. 69-79.

Swengel AB. 1995. Observations of spring larvae of Lycaeides melissa samuelis (Lepidoptera: Lycaenidae) in central Wisconsin. The Great Lakes Entomologist. Vol. $28(2)$, pp. $155-170$.

Sun Y, Ge F. 2011. How do aphids respond to elevation $\mathrm{CO}_{2}$ ? Journal of Asia-Pacific Entomology. Vol. 14, pp. 217-220.

Thomas L, Buckland ST, Rexstad EA, Laake JL, Strindberg S, Hedley SL, Bishop JRB, Marques TA, Burnham KP. 2010. Distance software: design and analysis of distance sampling surveys for estimating population size. Journal of Applied Ecology. Vol. 47, pp. $5-14$. 
Thomas JN. 1988. Evolutionary ecology of the relationship between oviposition preference and performance of offspring in phytophagous insects. Entomologica Experimentalis et Applicata. Vol. 47, pp. 3-14.

Turner JD. 1990. Vertical stratification of hilltopping behavior in swallowtail butterflies (Papilionidae). Journal of the Lepidopterists' Society. Vol. 44(3). pp. 174-179.

United States Department of Agriculture Nature Resources Conservation Service (USDA). 2011. Carbon to nitrogen ratios in cropping systems. USDA NRCS East National Technology Support Center, Greesnboro, NC.

Van der Wal R, Madan N, van Lieshout S, Dormann C, Langvatn R, Albon SD. 2000. Trading forage quality for quantity? Plant phenology and patch choice by Svalbard reindeer. Oecologia. Vol. 123, pp. 108-115.

Van der Wal R, Loonen MJJE. 1998. Goose droppings as food for reindeer. Canadian Journal of Zoology. Vol. 76, pp. 1117-1122.

Weiss SB, Murphy DD, White RR. 1988. Sun, slope, and butterflies: topography determinants of habitat quality for Euphydryas editha. Ecology. Vol. 69, pp. 1486-1496. 
Wiklund C. 1977. Oviposition, feeding and spatial separation of breeding and foraging habitats in a population of Leptidea sinapsis (Lepidoptera). Oikos. Vol. 28, pp. 56-68. 
Table 5.1: Best-fit regression model results for $\mathrm{C}: \mathrm{N}$, nitrogen content and phenolic content for all lupine sample plots in Wisconsin.

\begin{tabular}{cccccccc} 
& & \multicolumn{5}{c}{ Best Fit Regression Model } \\
\cline { 2 - 8 } $\begin{array}{c}\text { Nutrient or } \\
\text { Defensive } \\
\text { compound }\end{array}$ & & Constant & $\begin{array}{c}\text { Fround- } \\
\text { litter } \\
\text { Cover }\end{array}$ & $\begin{array}{c}\text { Focal } \\
\text { Shrub/tree } \\
\text { Cover }\end{array}$ & $\begin{array}{c}\text { Nectar } \\
\text { Plant } \\
\text { Stem } \\
\text { Counts }\end{array}$ & $R^{2}$ & $\begin{array}{c}\text { Adj. } \\
R^{2}\end{array}$ \\
\hline C:N Ratio & $p$-value & $<\mathbf{0 . 0 0 1}$ & $\mathbf{0 . 0 2 2}$ & $\mathbf{0 . 0 0 2}$ & $<\mathbf{0 . 0 0 1}$ & 0.12 & 0.11 \\
df=321 & SE & 0.041 & 0.002 & 0.003 & 0.001 & & \\
Nitrogen & $p$-value & $<\mathbf{0 . 0 0 1}$ & 0.016 & $<\mathbf{0 . 0 0 1}$ & $<\mathbf{0 . 0 0 1}$ & 0.13 & 0.12 \\
df=322 & SE & 0.041 & 0.002 & $<0.001$ & $<0.001$ & & \\
Phenolic & $p$-value & $<\mathbf{0 . 0 0 1}$ & & $\mathbf{0 . 0 0 3}$ & $\mathbf{0 . 0 4 2}$ & 0.04 & 0.03 \\
df=321 & SE & 0.017 & & $<0.001$ & $<0.001$ & & \\
\hline \hline
\end{tabular}




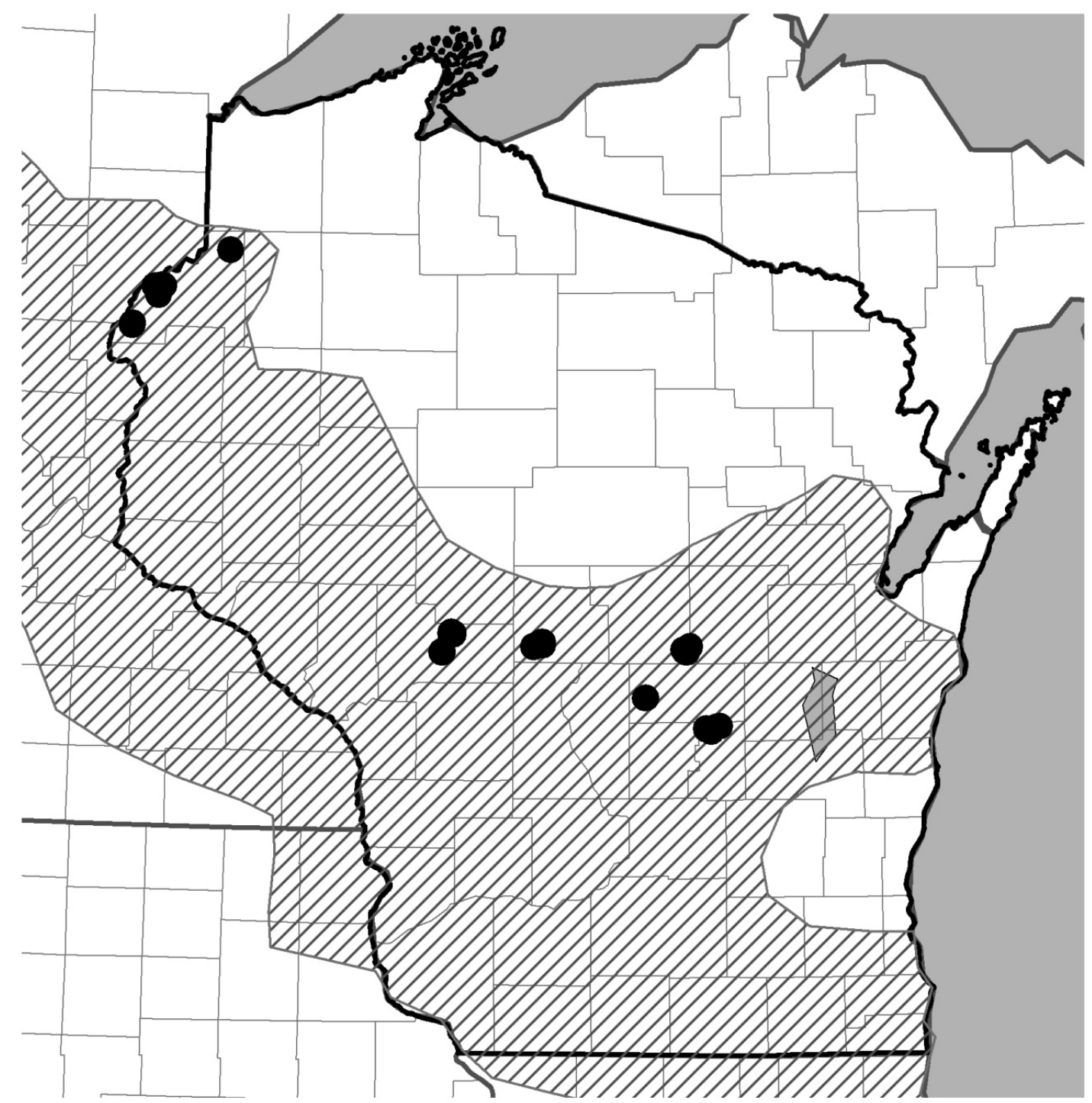

Sampling Locations

DIA Range of Lupine

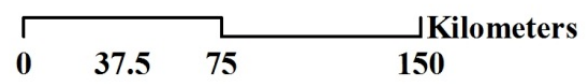

$\square$ Wisconsin Border

$\square$ U.S. State Borders

County Borders

Major Lakes

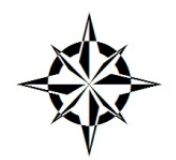

Map by Anna N Hess

Figure 5.1: Locations of field sites in relation to the approximate range of Lupine perennis in Wisconsin. Lupine range is derived from Wisconsin DNR Natural Heritage Inventory data. 


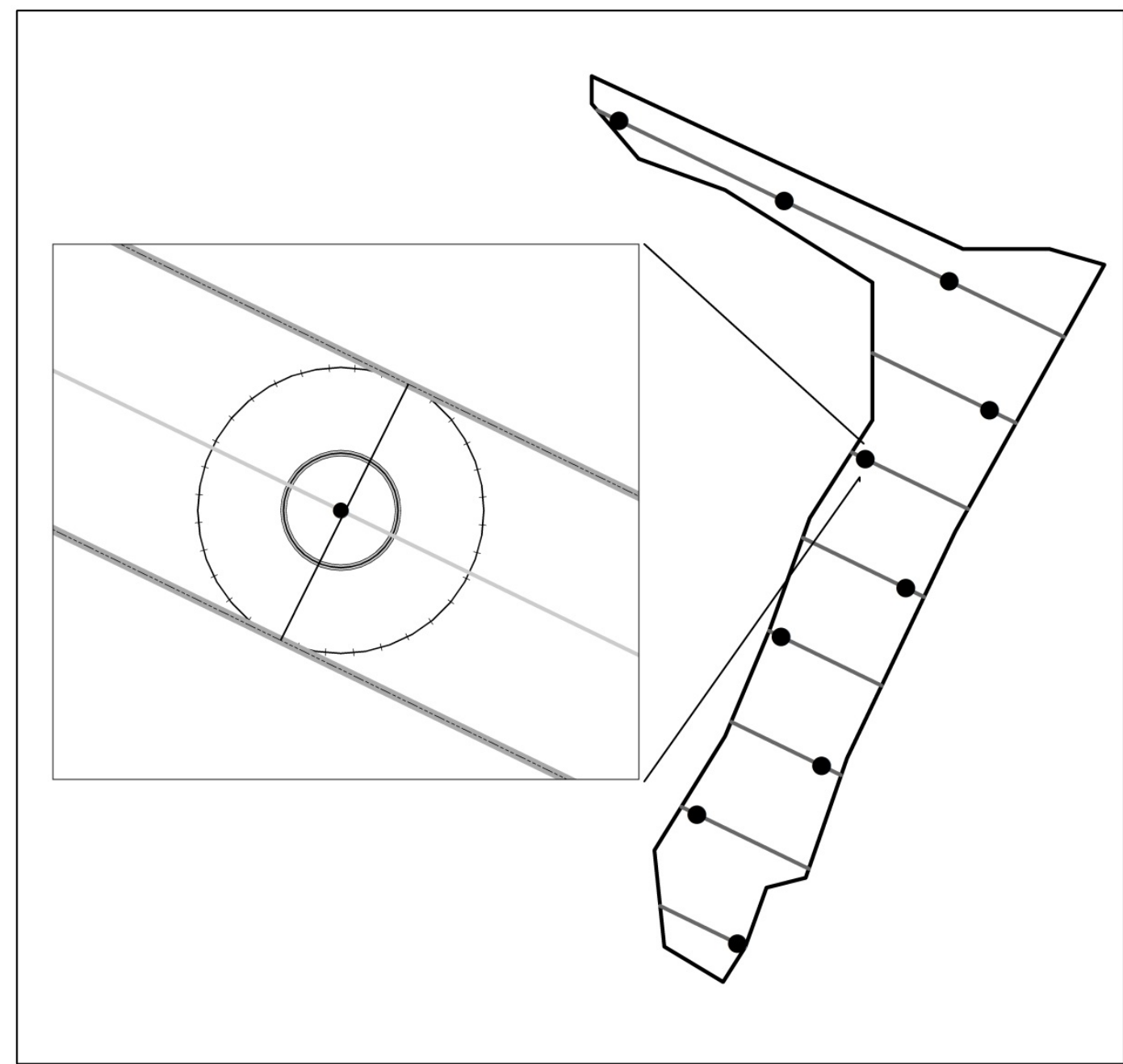

\section{Sample Plot Features}

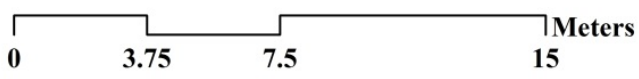

- $\quad$ Sample Point

- $5 \mathrm{~m}$ Line Intercept Transect

Karner Blue Population Estimate Transect (permanent transect)
$1 / 800$ ha Plot (for focal nectar plant stem counts)
Lupine Sample Plot ( $5 \mathrm{~m}$ buffer)
$5 \mathrm{~m}$ Buffer (Represents full width of population estimate transect)
Sample Area Boundary

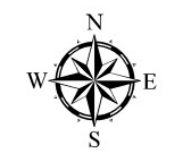

Map by Anna N Hess

Figure 5.2: Illustration of the strategic systematic sampling design for selecting lupine foliage at field sites in Wisconsin. 


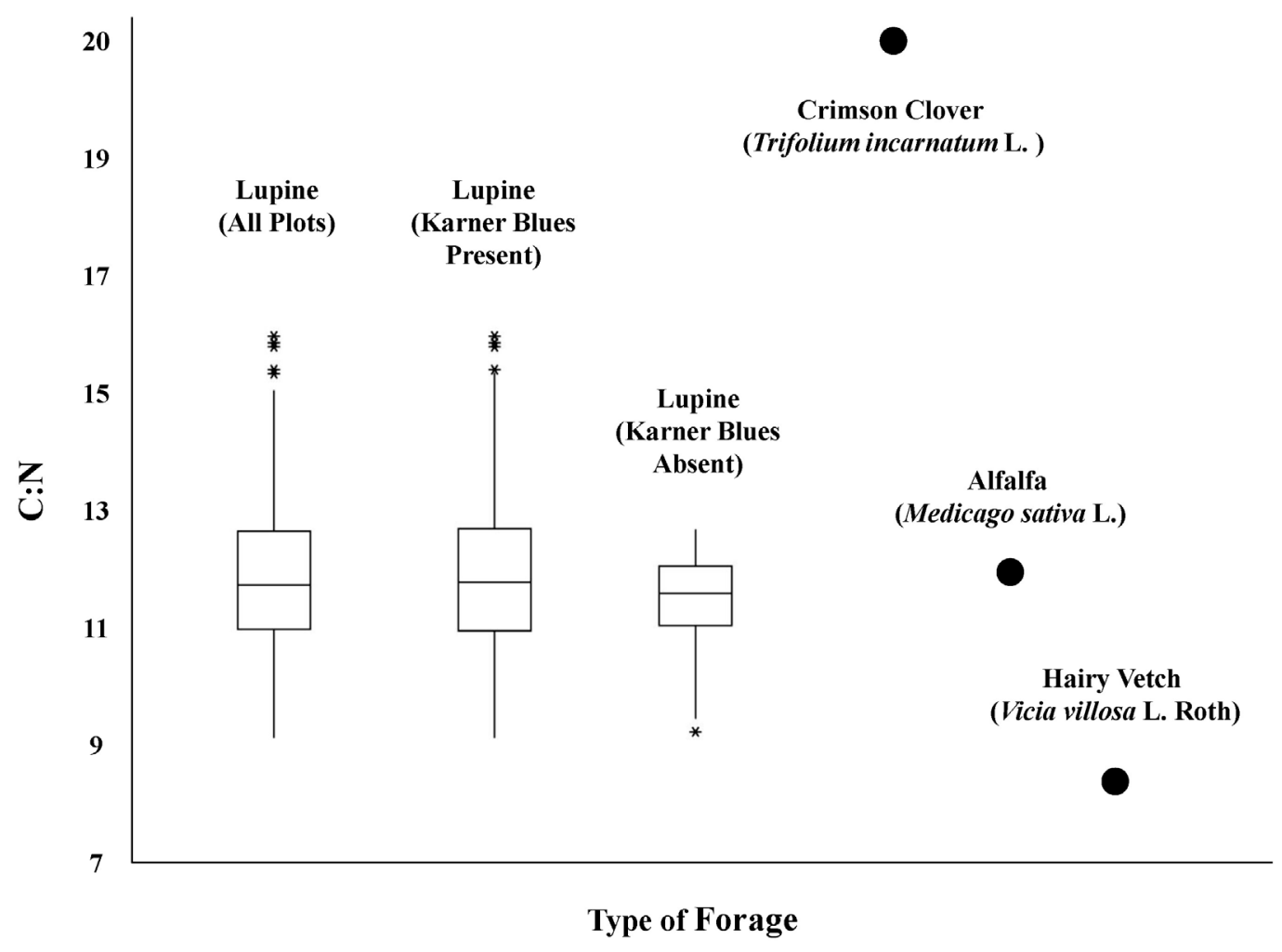

Figure 5.3: Comparison of variation in C:N in lupine across all sample plots, plots where Karner blues were absent or present, and common legume cover crops. Cover crop values derived from USDA (2011), Ketterings et al. (2011), Somda et al. (1991). Box encloses median (bar line) and $25^{\text {th }}$ and $75^{\text {th }}$ percentiles, vertical lines represent 1.5 Interquartile Range (IQR), outliers (*) and extreme outliers at 3 IQR (o). 


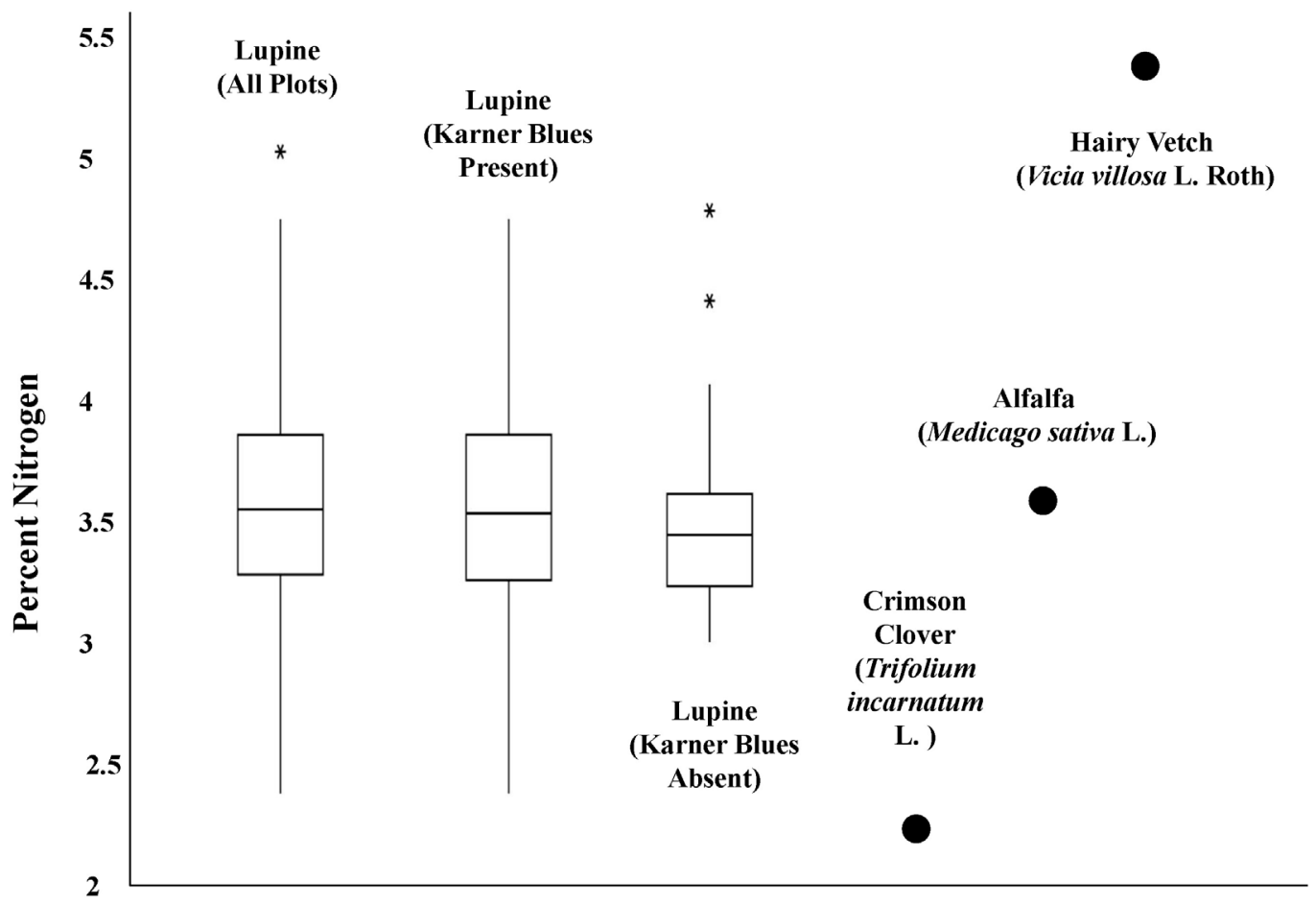

Type of Forage

Figure 5.4: Comparison of variation in percent nitrogen in lupine across all sample plots, plots where Karners were absent or present, and common legume cover crops. Cover crop values derived from USDA (2011), Ketterings et al. (2011), Somda et al. (1991). Box encloses median (bar line) and $25^{\text {th }}$ and $75^{\text {th }}$ percentiles, vertical lines represent 1.5 Interquartile Range (IQR), outliers (*) and extreme outliers at 3 IQR (o). 


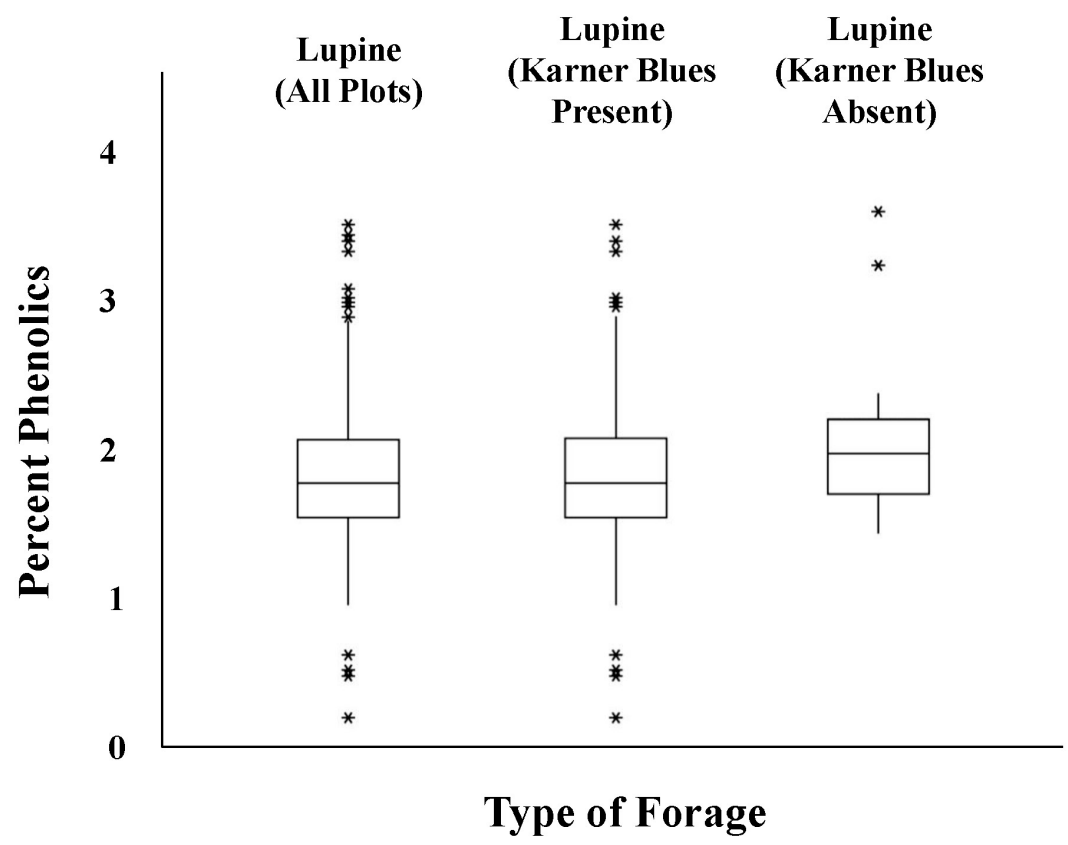

Figure 5.5: Comparison of variation in percent Phenolics in lupine across all sample plots, plots where Karners were absent or present. Box encloses median (bar line) and $25^{\text {th }}$ and $75^{\text {th }}$ percentiles, vertical lines represent 1.5 Interquartile Range (IQR), outliers (*) and extreme outliers at 3 IQR (o). 
A

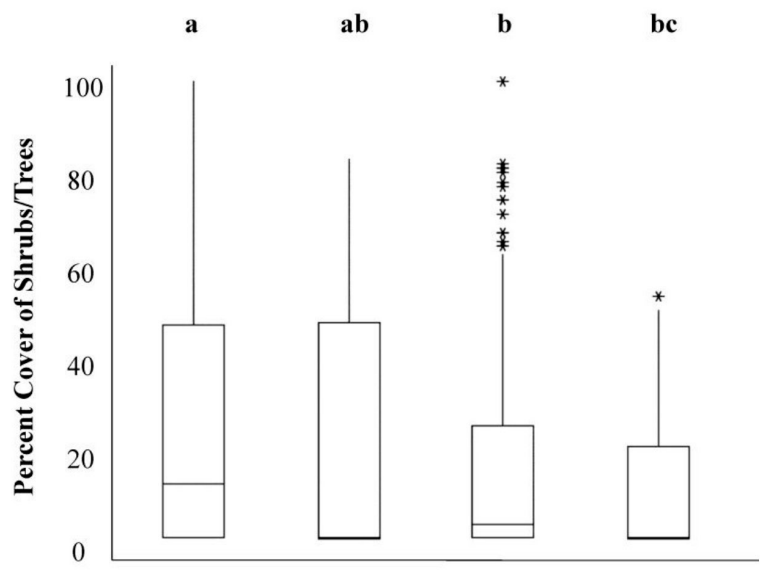

B

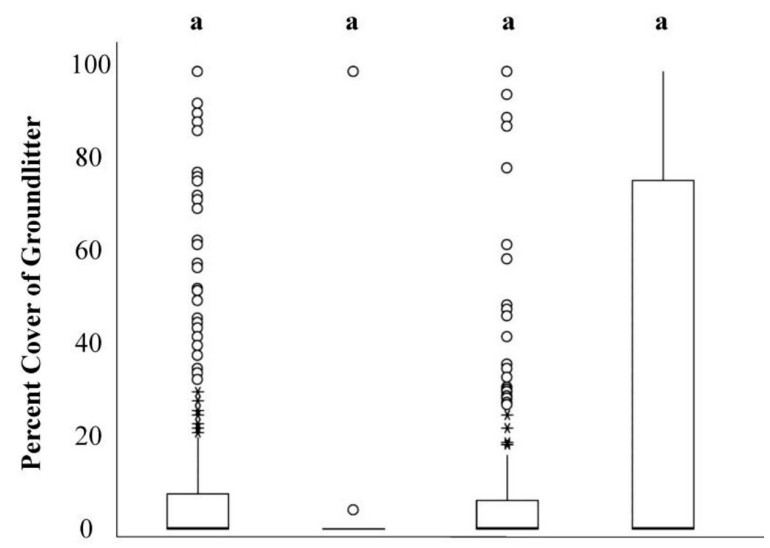

C

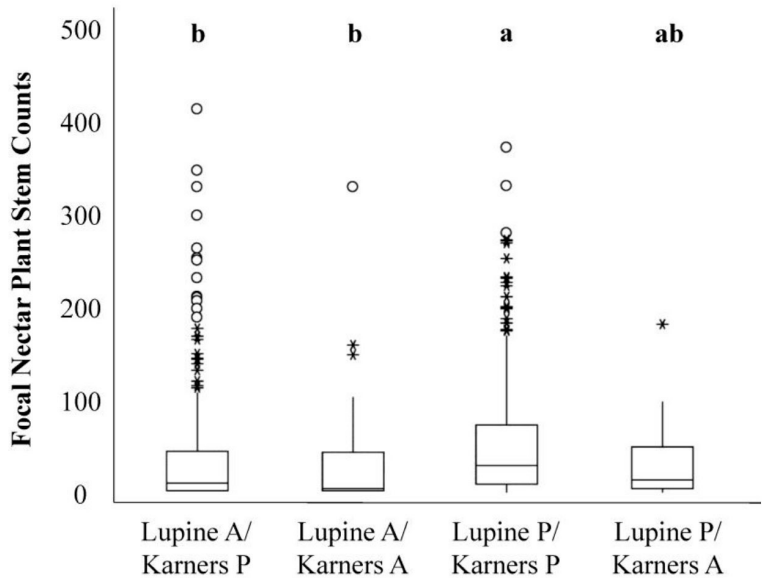

Figure 5.6: Kruskal-Wallis ANOVA pairwise comparisons of four groups of sample plots according to \% cover of shrub/tree and ground litter, and focal nectar plant abundance. Pairwise comparisons are listed across the top of associated field-site. Box encloses median (bar line) and $25^{\text {th }}$ and $75^{\text {th }}$ percentiles, vertical lines represent 1.5 Interquartile Range (IQR), outliers (*) and extreme outliers at 3 IQR (o). 

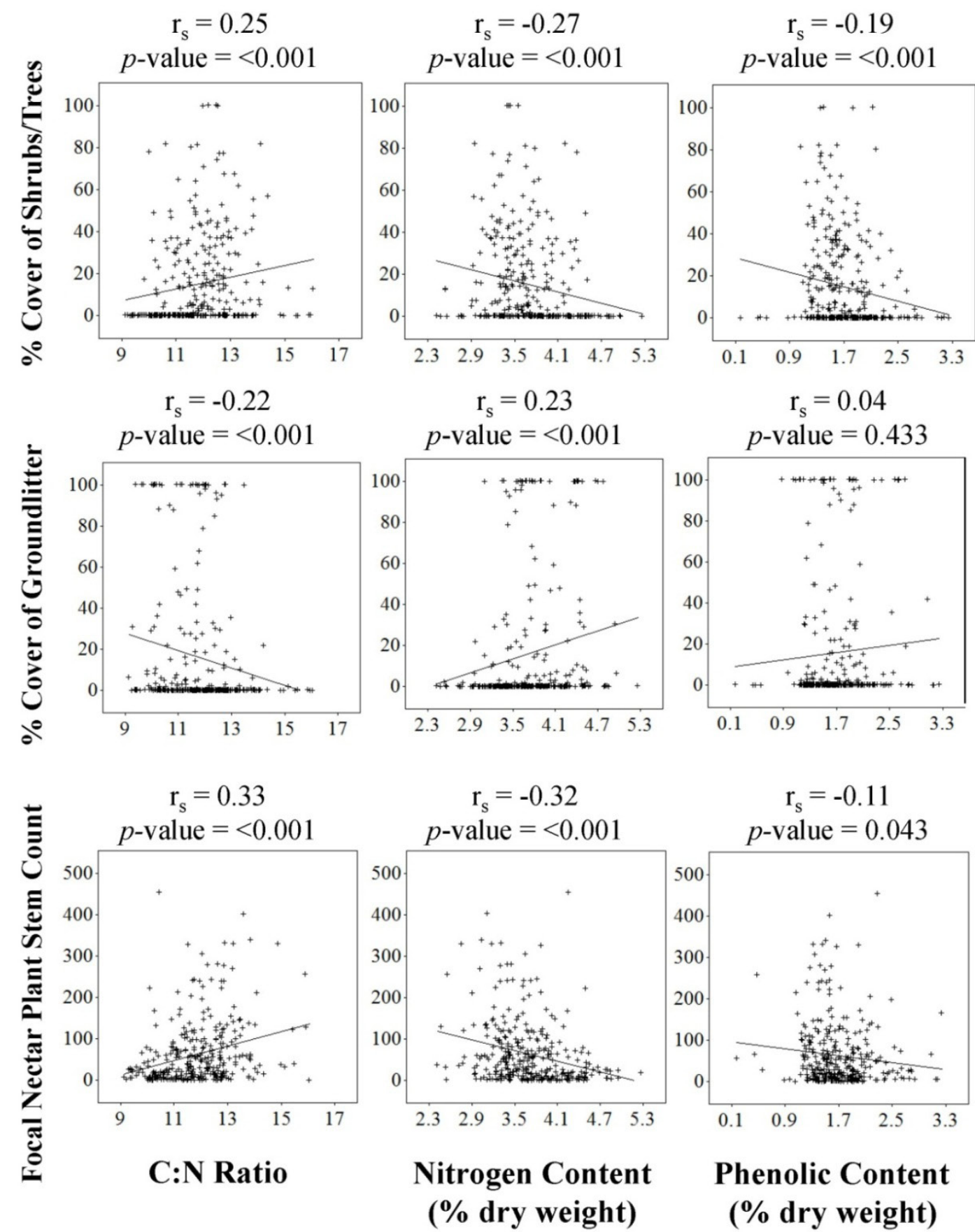

Figure 5.7: Scatter-plot representations of lupine nutrients and defense compounds in relation to percent cover of shrub/tree, percent cover of ground litter, and focal nectar plant abundance for all sample plots across Wisconsin. Spearman rank correlations $\left(\mathrm{r}_{\mathrm{s}}\right)$ and associated $p$-value are above each plot. 

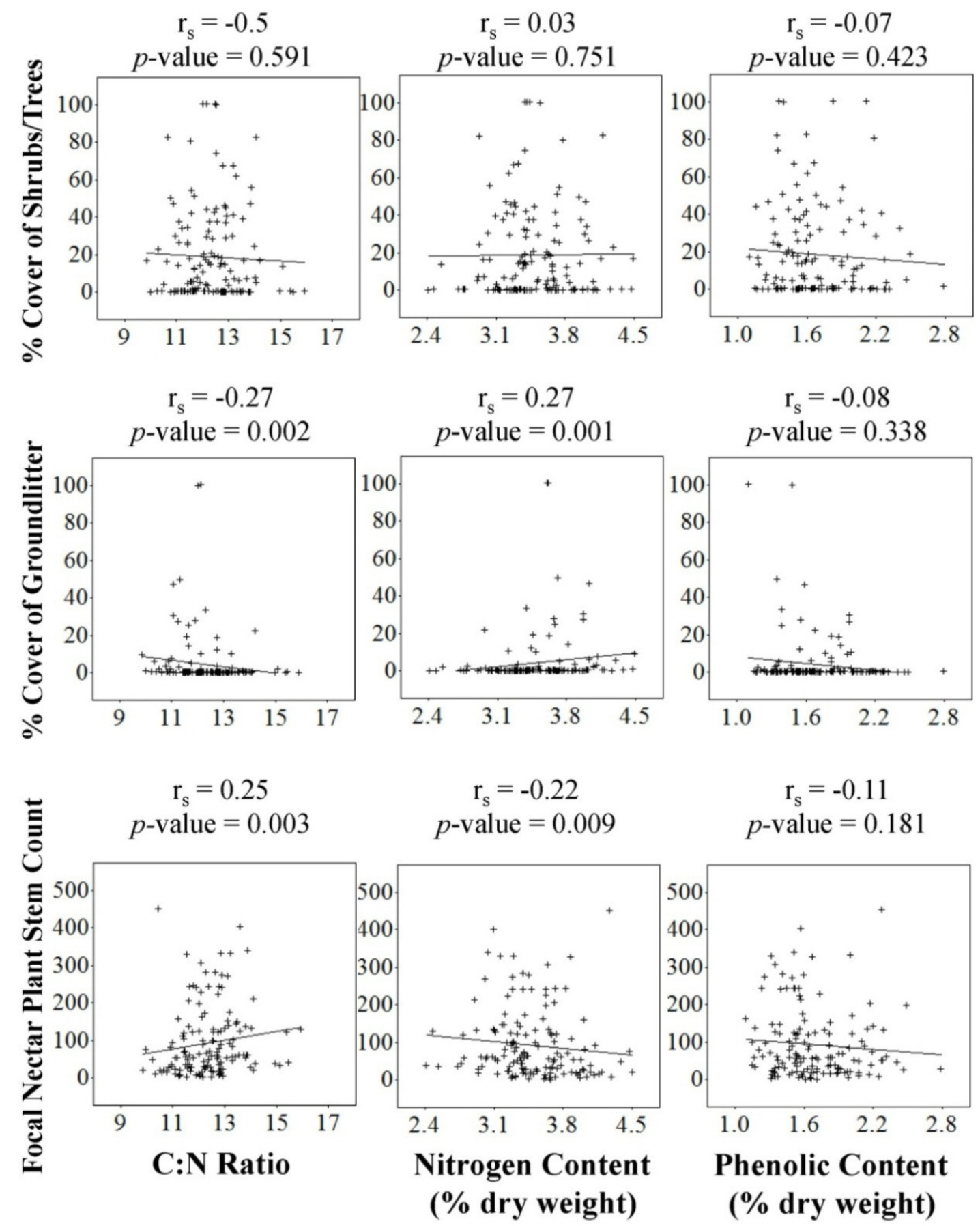

Figure 5.8: Scatter-plot representations of lupine nutrients and defense compounds in relation to percent cover of shrub/tree, percent cover of ground litter, and focal nectar plant abundance for five high density lupine field sites in Wisconsin. Spearman rank correlations $\left(\mathrm{r}_{\mathrm{s}}\right)$ and associated $p$-value are listed above each plot. 


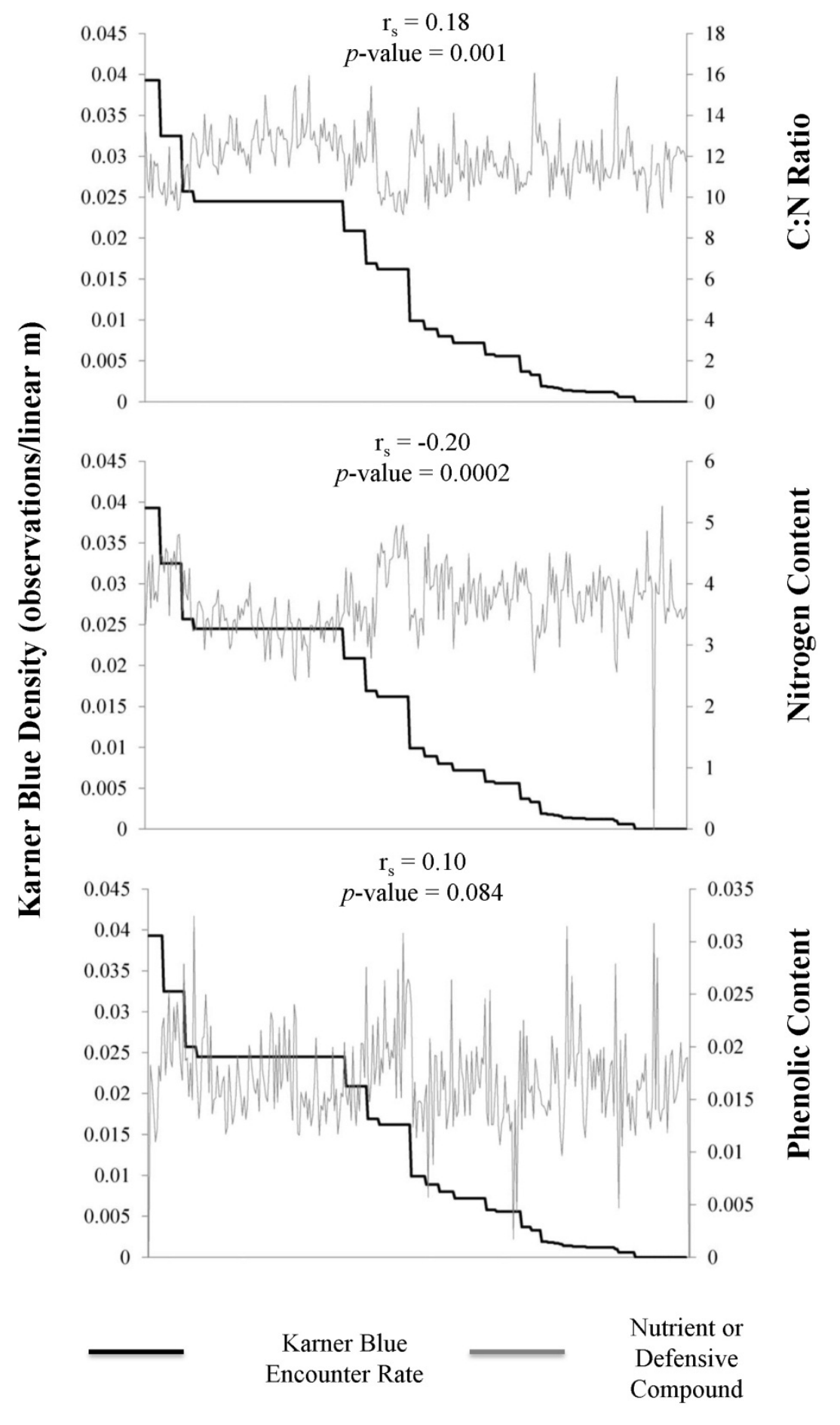

Figure 5.9: Comparison of Karner blue encounter rates (observations/linear $\mathrm{m}$ ) to nutrient or defensive compounds across all sample plots in Wisconsin (322 plots). Field sites are arranged in increasing order according to Karner blue encounter rate. Spearman rank correlations $\left(\mathrm{r}_{\mathrm{s}}\right)$ and associated $p$-value are listed above each plot. 


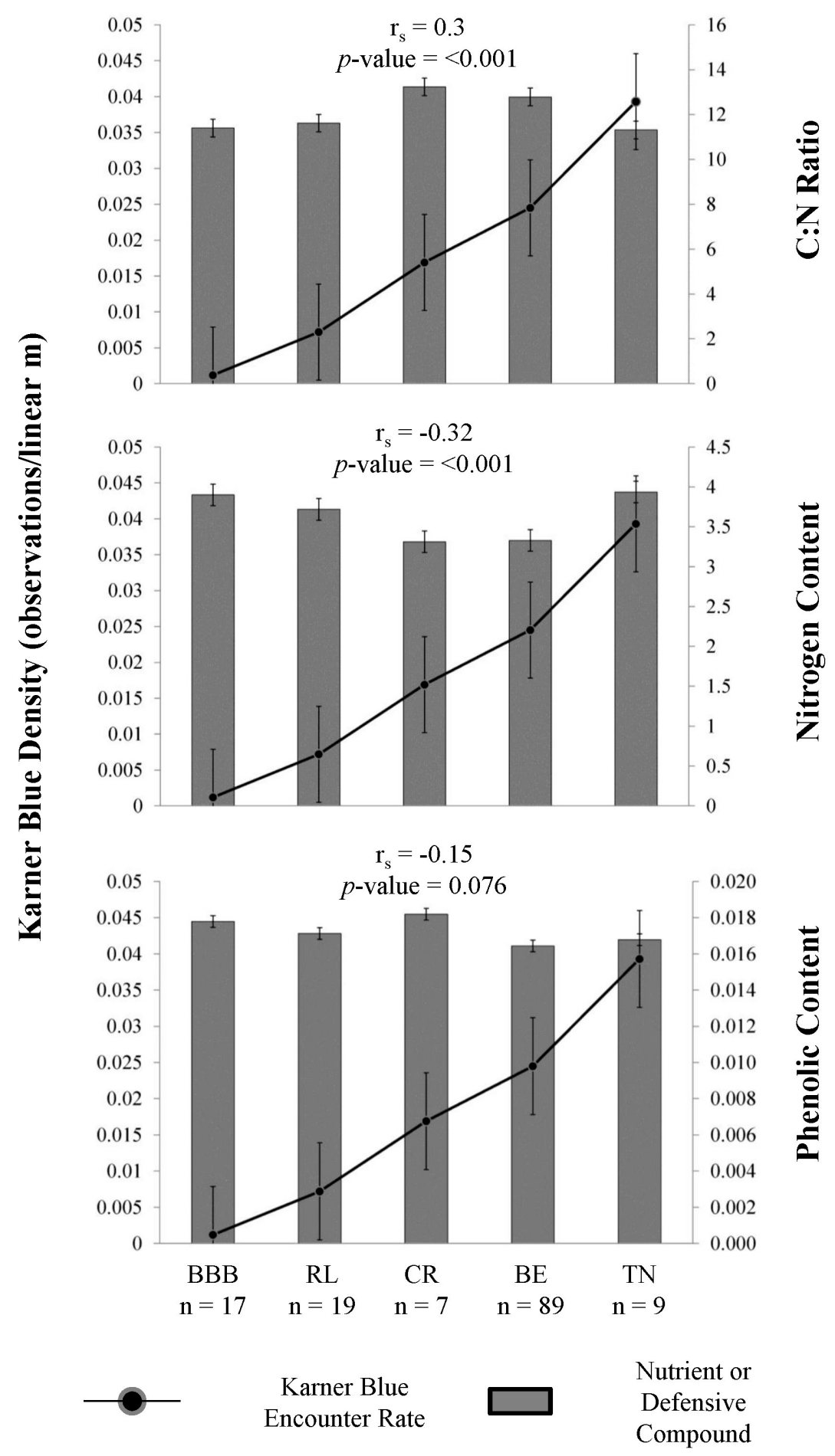

Figure 5.10: Comparison of Karner blue encounter rates (observations/linear m) to nutrient or defensive compounds for five high density lupine field sites in Wisconsin. Error bars represent standard error. Spearman rank correlations $\left(\mathrm{r}_{\mathrm{s}}\right)$ and associated $p$ value are listed above each plot. 


\section{Chapter 6: Summary}

\section{$\underline{\text { Introduction }}$}

The Karner blue butterfly (Lycaeides melissa samuelis Nabokov) lives in a variety of habitat conditions among several grassland biological communities, across a vast range. Despite this, the Karner blue persists in select pockets of habitat. Key factors exist that determine where this species will thrive on the landscape.

\section{$\underline{\text { Karner Blue Management }}$}

Conservation of this species has led to several overarching management policies, all of which are focused at a landscape-scale. The Karner Blue Butterfly Statewide Habitat Conservation Plan Partnership (HCP) allows partners of the HCP to conduct activities in areas where Karner blues persist, while avoiding, minimizing, or mitigating for "take" (killing, injuring, harming, etc.) (as defined by the Federal Endangered Species Act as amended in 1973) of the species. These partners are required to conduct surveys prior to management actions or to permanent take of the species that include surveys for wild blue lupine presence/absence and abundance, and if present in sufficient quantity, then presence/absence surveys for the Karner blue. The Wisconsin DNR also conducts abundance surveys on state recovery properties as funding allows. This information is in turn used to manage for Karner blues and its habitat. The Federal Recovery Plan for 
the Karner blue establishes recovery goals and overall management guidelines for all states within the Karner blue range (FWS 2003). These goals include recovering viable populations of the Karner blue in 13 recovery units located in 6 states across the species range. Recovery criteria include establishing viable metapopulations of at least 3,000 butterflies and large viable metapopulations of at least 6,000 butterflies. For reclassification (down-listing of the species from endangered to threatened) the goal is to establish at least 27 metapopulations and for de-listing (removing the species from the Federal list of Threatened and Endangered Species) a least 29 metapopulations. The recovery program also recommends distance sampling as the overall method of use for estimating Karner blue populations.

The Wisconsin Karner Blue Recovery program includes recovering the butterfly on nine state properties in Wisconsin; these properties are monitored annually for Karner blue population trends as well as habitat quality as funding allows. Through the Wisconsin recovery program, management tools have been developed that can predict Karner blue habitat across the landscape at low-resolutions, as well as predict Karner blue flight emergence across the range of Wisconsin.

However, despite the development of these remarkable tools, there remains a need for high resolution tools that are capable of identifying potential habitat at the landscape and field-level, as well as the evaluation of habitat quality and Karner blue distribution, in order to better facilitate management. These tools must be able to cross the barrier 
between the landscape and field-level and be based on systematic, science-based observations of Karner blue habitat selection dynamics. At the same time, a better understanding of the natural mechanisms driving Karner blue persistence, such as natural disturbance regimes, and the effects that overall habitat quality have on host plant quality, are necessary to better implement management efforts. The state of Wisconsin, with its robust Karner blue populations and availability of natural and restored habitat regimes, is a prime location to develop such observations and tools.

\section{$\underline{\text { Study Contributions }}$}

This study evaluated these management needs through three distinct studies, and generated two unique habitat suitability models for identifying Karner blue habitat across management units and for evaluating Karner blue habitat at the field-level. This study also evaluated and identified relationships resulting from natural mineral-soil disturbance caused by American bison among Karner blue and host plant occupancy and distribution. Lastly, this study evaluated the relationships between habitat characteristics and the Karner blue host plant wild blue lupine, and the potential relationships of host plant quality with Karner blue distribution based on C:N ratio, nitrogen content, and phenolic content.

The development of the large-scale Potential Habitat Model followed literature stating that Karner blue habitat selection at the landscape-scale is driven primarily by soil 
texture (Anderson et al. 1999; Curtis 1959) and canopy cover (e.g. Pavlovic and Grundel 2009; Grundel and Pavlovic 2007). The Potential Habitat Model successfully predicted known Karner blue sites, as well as correctly identified randomly selected sites within each resulting model weight category.

It was noted that Karner blues exist in areas with both sandy and loamy-sand soil types - however those soil types with sandy soils generate lower but more persistent populations, while loamy-sand sites generate more robust but flashier populations. This is most likely due to edaphic and canopy cover conditions. The host plant and nectaring plants required by the Karner blues are not generally competitive with vigorous prairie plant species and can persist longer without disturbance levels in sandier sites that naturally inhibit the growth of most plants (Hutchinson et al. 1986; Whitford and Whitford 1971). However in loamy-sand sites these plants grow more prolifically and therefore compete more with lupine and other nectaring plants. Due to this, Karner blues will exist in both sites, but require more maintenance in loamy-sand sites. Additionally, when sandy soil is available in a loamy-sand dominated region or field, the Karner blues will inhabit these areas more prolifically.

The development of a Relative Habitat Suitability Model that evaluates habitat-quality at the field-level revealed that Karner blues inhabit different habitat characteristics between sandy and loamy-sand dominated sites. The most significant variables between both soil texture types included lupine cover, shrub/tree cover (e.g. Pavlovic and 
Grundel 2009; Smith et al. 2002) and focal nectar plant abundance (e.g. Savanick 2005).

Most significantly: Karner blues inhabit moderate (10-20\%) canopy cover areas in sand sites and low (0-10\%) canopy cover areas in loamy-sand sites. This is most likely due to edaphic conditions: sandy soils are difficult for most plants to live in, and Karner blues are known to seek out areas of shade (Grundel et al. 1998a; Grundel et al. 1998b; Lane 1997). Sandy soil areas with little or no canopy cover will inhibit the growth of nectaring plants and host plants and will provide no shade for Karner adults. However, shaded areas in sandy soils will provide favorable conditions for both plants and Karner blues. In comparison, loamy-sand soils display more robust vegetation that provides shade for Karner blues without the need for canopy cover.

Because conservation success relies so heavily on the selection of appropriate sites to promote a species, land managers must establish a firm understanding of the overall dynamics of a species as well as the specific area being considered, and local prominent habitat features. Based on the outcome of these habitat suitability models, incorporating additional sites will produce increasingly accurate model results, allowing for more successful evaluations of habitat distribution and quality.

The second paper within this study evaluated the direct relationships between megaherbivore activities and Karner blue/lupine distribution and abundance. 
Megaherbivores such as American bison (Bison bison) provided a natural source of mineral-soil disturbance and biomass production across the grasslands of North America (Fox et al. 2012; Shultz and Mladenoff 2005). The disturbance caused by these megaherbivores generates favorable conditions for many butterfly species (Feber et al. 2001). Our paper evaluated what is possibly the only remaining pocket of this natural habitat in the oak savanna bison-pasture at the Sandhill Wildlife Area, Wisconsin. We found that Karner blue presence was more likely to occur in areas of low-level disturbance (disturbance is aged, grass displays regeneration, hummocks are visible), but would also occur in areas of moderate disturbance (grass displays thinning due to grazing, bareground visible), and rarely occurred in high disturbance (extremely thin grass and bareground due to wallow, trail, and heavy grazing is obvious).

Karner blues were distributed almost uniformly in areas of low disturbance where bison had been recently present (as represented by presence of bison chips) and areas where bison had not been present. When Karner blues were in areas of combined moderate/high disturbance, occurrence was higher where bison had recently been present (indicated by presence of bison chips). Lupine occurrence followed this same pattern. Karner blues and lupine alike tended to increase with decreasing levels of disturbance. These results suggest that Karner blues and lupine prefer to occupy areas where disturbance has recovered from moderate to high levels of mineral-soil instability caused by, in the case of American bison, grazing, trails and wallows. 
These species may favor areas where bison were most recently present for separate reasons: lupine may occupy these areas because the competition from other plants is most likely lower (Feber et al. 2001; Pickens 2006), while Karner blues are most likely seeking out the mineral and nutrient rich bison chips. Karner blue populations could benefit overall from megaherbivore activities or activities that mimic the resulting mineral-soil instability and turnover. These findings are in agreement with literature and results within the model paper. Lupine grows in areas after a disturbance event has occurred (Pickens 2006; Forrester et al. 2005; Smith et al. 2002; Smallidge et al. 1996).

Lepidopterans in general prefer areas of low-intensity maintenance (Borth 1997; Swengel 1998; Lawrence and Cook 1989; Panzer 1988). Karner blues tend to aggregate where disturbance-dependent lupine is present during the beginning and end of each flight (Pickens and Root 2008; Grundel et al. 1998a). However, though it is apparent that Karner blues may be indirectly related to levels of disturbance and the lupine groundcover resulting from this disturbance, within the study Karners were not found to significantly prefer one type of dominant cover over another. Despite the lack of a significant relationship, lupine and Karners both tended to occupy areas of forb and grass dominance over the course of this specific study.

The results of this correlative study suggest a lagged effect between the presence of bison and the growth of lupine. These results also suggest a relationship between the recent presence of bison and Karner blue and lupine occupancy. Further, possibly 
experimental investigations could examine cause and effect of these relationships and possibly define underlying mechanisms.

The third and final paper of this study evaluated various nutrient and defense compound levels that were thought to be influential to Karner blue populations. Various nutrient and defense compounds are known to be influential to Lepidopteran populations: nitrogen content aids in growth development (Boggs 2009), carbon content aids in egg development (O’Brien et al. 2004; Pivnick and McNeil 1987), and defense compounds stored as secondary metabolites can inhibit larval growth altogether (Boggs 2009; Hwang et al. 2008; Bede et al. 2007; Lattanzio et al. 2006). These nutrients and defensive compounds are particularly important in larval development because the allocation of these resources will influence growth throughout the life cycle of an insect.

This paper evaluated lupine $\mathrm{C}: \mathrm{N}$ ratio, nitrogen content and phenolic content relative to habitat variables and to Karner blue populations. The most significant variables were shrub/tree cover, focal nectar plant abundance and cover of groundlitter.

Lupine $\mathrm{C}: \mathrm{N}$ ratio generally increased in relation to the cover of shrubs/trees and focal nectar plant cover, while decreasing relative to groundlitter. Nitrogen content, inversely, decreased in relation to shrubs/trees and focal nectar plants and increased with groundlitter. Phenolics, however, were not significantly related to any candidate habitat variables. The increase of $\mathrm{C}: \mathrm{N}$ is most likely due to the lupine preferentially growing in 
moderately shaded areas, while focal nectar plant abundance would act as a beneficial herbaceous plant cover that would shade lupine without displacing it (Pickens and Root 2008; Grundel et al. 1998a, 1998b). Karner blues increased relative to lupine C:N ratio and decreased relative to nitrogen content, but were not related to phenolic content.

When examining these candidate habitat variables among sites where lupine and Karners blues were present or absent, results indicated that excessive cover of shrubs/trees (> 45\%) inhibited the growth of lupine altogether. Focal nectar plant abundance was significantly higher in areas where Karners blues and lupine were both present. Groundlitter cover did not differ significantly among these areas; however, the relationships among groundlitter cover, the lupine $\mathrm{C}: \mathrm{N}$ ratio, nitrogen content and Karner blues suggest that excessive groundlitter may be detrimental to lupine, and thus Karner blue, persistence.

Overall, these results suggest that lupine, and subsequently Karner blues, seek out areas of partial shade throughout all sites, and that habitat characteristics may influence nutrient and defensive compound levels that produce favorable or unfavorable lupine quality. Karners blues appear to favor different vegetative types between areas dominated by different soil textures (sandy vs. loamy-sand), suggesting that these areas cannot be managed using the same techniques. Furthermore, these findings suggest that natural disturbance mechanisms such as bison wallowing and grazing do directly influence both lupine and Karner blue abundance and distribution, suggesting that 
management techniques should try to mimic these mechanisms for the production of favorable habitat.

Lastly, these findings suggest that the manipulation of field-level locations in relation to habitat characteristics could directly influence nutrient and defense compound levels (such as $\mathrm{C}: \mathrm{N}$ and phenolic levels) and subsequently produce less or more favorable conditions for Karner blue populations at all life stages. Better understanding these mechanisms, as well as developing standardized tools for monitoring and management, will lead to more effectively and efficiently understanding Karner blue habitat selection, focus management efforts, and accelerate the de-listing of this species.

\section{$\underline{\text { Summary }}$}

The most successful sites evaluated were those that provided a mix of sandy and loamysand textures, and displayed a mix of canopy cover, host plants, groundlitter and focal nectar plants. Specific management recommendations include: cover of shrubs/trees (10-45\%, ranging from $10-45 \%$ in sandy soils and $0-10 \%$ in loamy sand soils), the presence of host plant cover $(>5 \%$ overall), low to moderate groundlitter cover $(\sim 10$ $40 \%$ ) and an abundance of nectar plant cover (based on a minimum of 10 stems per $1 / 800$ ha found in this study). Specific management techniques should also focus on nectar species that are preferential to Karner blues, such as those in Savanick (2005). 
This comprehensive evaluation of Karner blue habitat across the range of Wisconsin can serve as a baseline of information for evaluating qualitative habitat characteristics, as well as generating improved or more advanced high-resolution tools for identifying, monitoring, and evaluating habitat and Karner blue populations. This study sought to provide a synthesis of the current state of knowledge on the underlying mechanisms driving Karner blue habitat dynamics and Karner blue population persistence. It is our hope that these chapters can contribute to future studies evaluating oak/pine grassland communities, as well as contribute to the successful restoration efforts for this species and other endangered species.

\section{$\underline{\text { References }}$}

Anderson RC, Fralish JS, Baskin JM. 1999. Savannas, barrens, and rock outcrop plant communities of North America. Cambridge University Press, New York.

Bede JC, McNeil JN, Tobe SS. 2007. The role of neuropeptides in caterpillar nutritional ecology. Peptides. Vol. 28, pp. 185-196.

Boggs, CL. 2009. Understanding insect life histories and senescence through a resource allocation lens. Functional Ecology. Vol. 23, pp. 27-37.

Borth RJ. 1997. Karner blue management implications for some associated Lepidoptera of Wisconsin barrens. Wisconsin GAS: A Wicor Company. 
Curtis JT.1959. The vegetation of Wisconsin. Madison, Wisconsin: University of Wisconsin Press.

Feber RE, Brereton TM, Warren MS, Oates M. 2001. The impacts of deer on woodland butterflies: the good, the bad and the complex. Forestry. Vol. 7, pp. 273-276.

Forrester JA, Leopold DJ, Hafner SD. 2005. Maintaining critical habitat in a heavily managed landscape: effects of power line corridor management on Karner blue butterfly (Lycaeides melissa samuelis) habitat. Restoration Ecology. Vol. 13 (3), pp. 488-498.

Fox TA, Hugenholtz CH, Bender D., and Gates C.C. 2012. Can bison play a role in conserving habitat for endangered sandhills species in Canada? Biodiversity and Conservation. Vol. 21, pp. 1441-1455.

FWS (U.S. Fish and Wildlife Service). 2003. Final recovery plan for the Karner blue butterfly (Lycaeides melissa samuelis). U.S. Fish and wildlife Service, Fort Snelling, Minnesota. $273 \mathrm{pp}$.

Grundel R, Pavlovic NB. 2007. Resource availability, matrix quality, microclimate, and spatial pattern as predictors of patch use by the Karner blue butterfly. Biological Conservation. Vol. 135, pp. 135-144. 
Grundel R, Pavlovic NB, Sulzman CL. 1998a. The effect of canopy cover and seasonal change on host plant quality for the endangered Karner blue butterfly (Lycaeides melissa samuelis). Oecologia. Vol. 114, pp. 243-250.

Grundel Ralph, Pavlovic NB, Sulzman CL. 1998b. Habitat use by the endangered Karner blue butterfly in oak woodlands: the influence of canopy cover. Biological Conservation. Vol. 85, pp. 47-53.

Hutchinson MD, Olson S, Vogt T. 1986. A survey of the barrens region in Massac and Pope counties, Illinois. Natural Land Institute, Belknap, Illinois. 63 pp.

Hwang SY, Liu CH, Shen TC. 2008. Effects of plant nutrient availability and host plant species on the performance of two Pieris butterflies (Lepidoptera: Pieridae).

Biochemical Systematics and Ecology. Vol. 36, pp. 505-513.

Lane CP. 1997. Forest management guidelines: developing management plans compatible with Karner blue butterfly persistence. Wisconsin Department of Natural Resources. Madison, Wisconsin. United States Fish and Wildlife Service. Fort Snelling, Minnesota. 
Lattanzio V, Lattanzio VMT, Cardinali A. 2006. Role of phenolics in the resistance mechanisms of plants against fungal pathogens and insects. Phytochemistry: Advances in Research. pp. 23-67.

Lawrence WS, Cook AC. 1989. The status and management of Karner blue (Lycaeides melissa samuelis) populations in the Allegany State Game Area, Michigan. Unpublished report. Nature Conservancy. Michigan Field Office, East Lansing, MI.

O’Brien DM, Fogel ML, Boggs CL. 2002. Renewable and nonrenewable resources: amino acid turnover and allocation to reproduction in Lepidoptera. Proceedings of the National Academy of Sciences of the United States of America. Vol. 99, pp. 4413-4418.

Panzer R.1988.Managing Prairie Remnants for Insect Conservation. Natural Areas Journal. Vol. 6, pp. 6-36.

Pavlovic NB, Grundel R. 2009. Reintroduction of wild lupine (Lupinus perennis L.) Depends on variations in canopy, vegetation, and litter cover. Restoration ecology. Vol. 17(6), pp. 807-817.

Pickens BA, Root KV. 2008. Factors affecting host-plant quality and nectar use for the Karner blue butterfly: implications for oak savanna restoration. Natural Areas Journal. Vol. 28(3), pp. 210-217. 
Pickens BA. 2006. The consequences of a management strategy for the endangered Karner blue butterfly. M.S. Dissertation. Bowling Green State University, Bowling Green, OH, USA.

Pivnick KA, McNeil JN. 1987. Puddling in butterflies: sodium affects reproductive success in Thymelicus lineola. Physiological Entomology. Vol. 12, pp. 461-472.

Savanick MA. 2005. Population dynamics and nectar preference of the Karner blue butterfly, Lycaeides melissa samuelis (Nabokov) [Lepidoptera: Lycaenidae]. Master's Degree Thesis. University of Minnesota.

Schulte LA, Mladenoff DJ. 2005. Severe wind and fire regimes in northern forests: historical variability at the regional scale. Ecology. Vol. 86(2), pp. 431-445.

Smallidge PJ, Leopold DJ, Allen CM. 1996. Community characteristics and vegetation management of Karner blue butterfly (Lycaeides melissa samuelis) habitats on rightsof-way in East-Central New York, USA. The Journal of Applied Ecology. Vol. 33 (6), pp. 1405-1419. 
Smith MA, Turner MG, Rusch DH. 2002. The effect of military training activity on eastern lupine and the Karner blue butterfly at Fort McCoy, Wisconsin, USA. Environmental Management. Vol. 29 (1), pp. 102-115.

Swengel AB. 1998. Effects of management on butterfly abundance in tallgrass prairie and pine barrens. Biological Conservation. Vol. 83(1), pp. 77-89.

Whitford PB, Whitford K. 1971. Savanna in central Wisconsin, USA. Vegetatio. Vol. 23. pp. $77-88$. 
Appendix 1: Potential Habitat Model Outputs 


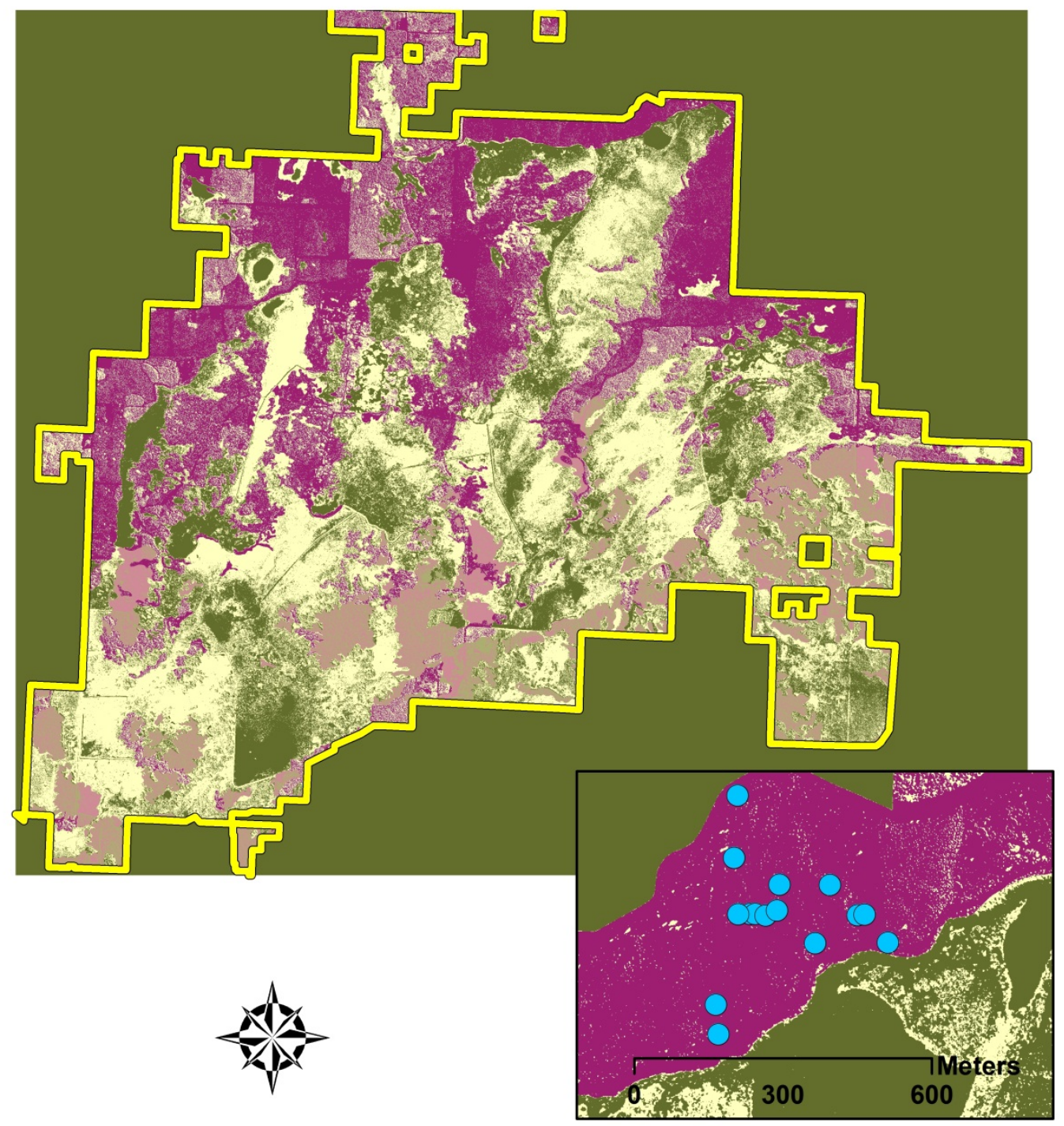

Potential Habitat

\begin{tabular}{cc} 
High & Moderate \\
$\square$ & $\square$ \\
\hline & \\
\hline
\end{tabular}

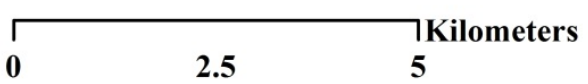

Karner Blue GPS Points

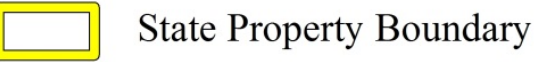

Map by Anna N Hess

Figure A1.1: Potential Habitat Model for Crex Meadows Wildlife Area. 


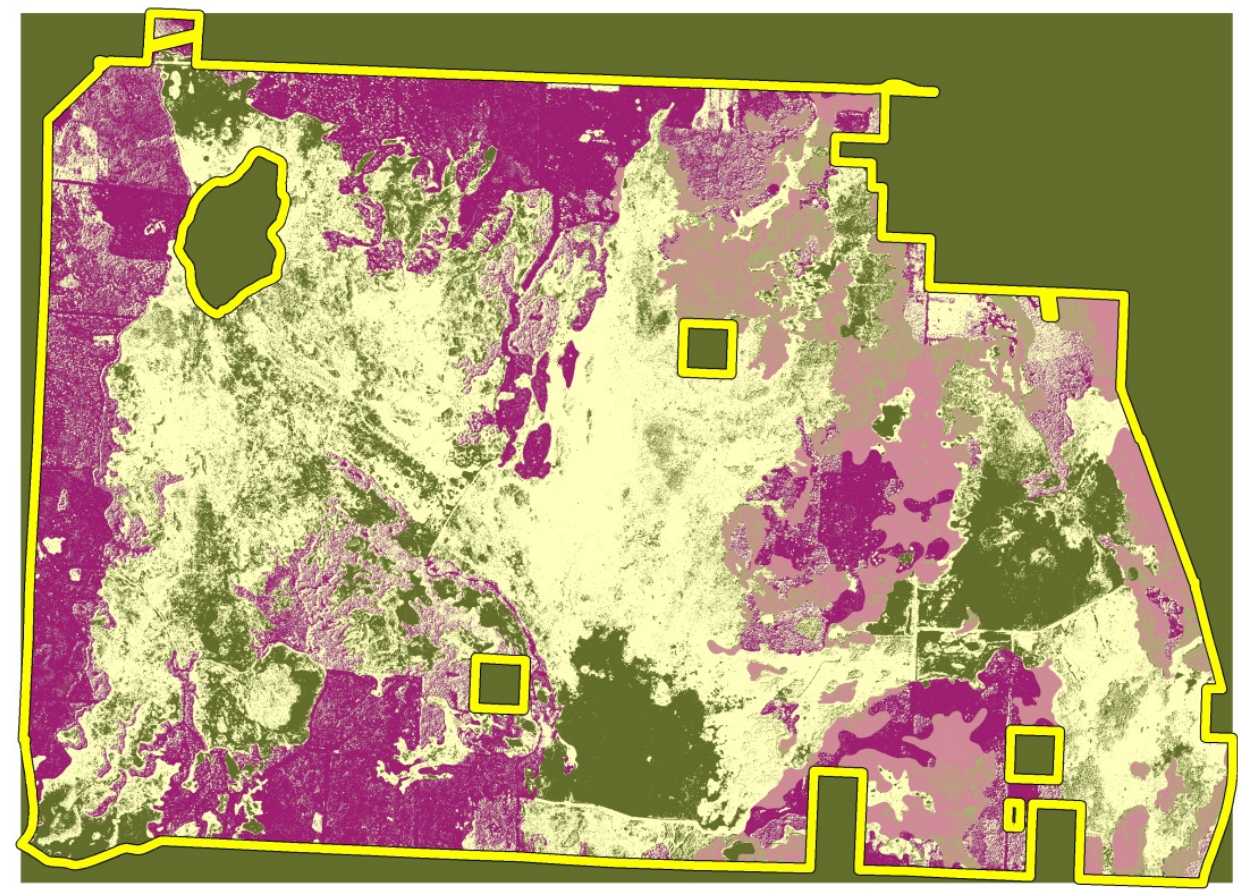

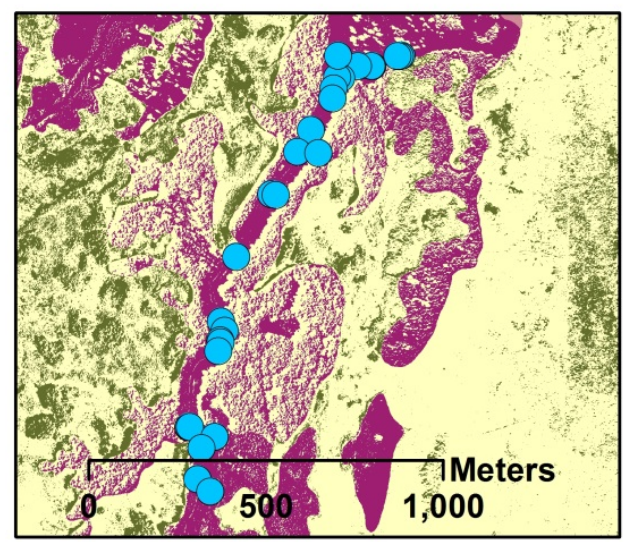

Potential Habitat

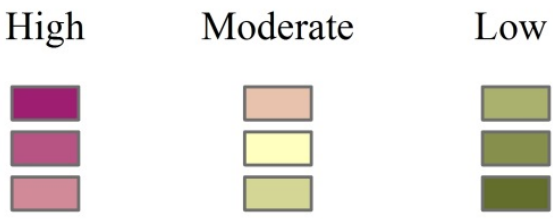

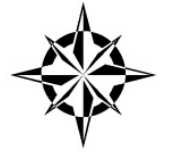

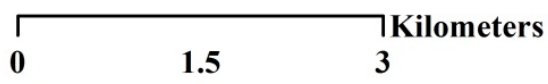

Karner Blue GPS Points

State Property Boundary

Map by Anna N Hess

Figure A1.2: Potential Habitat Model for Fish Lake Wildlife Area. 


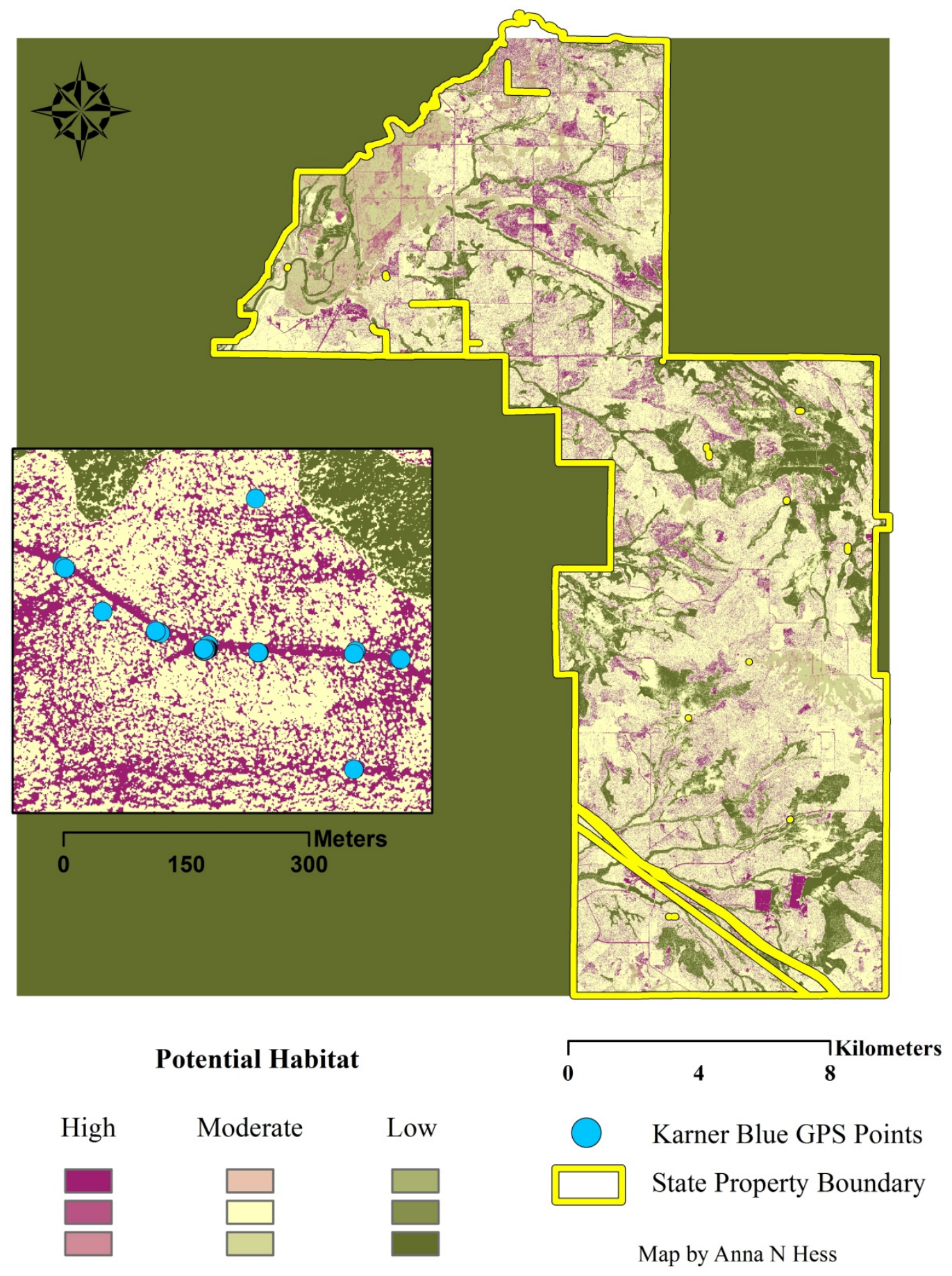

Figure A1.3: Potential Habitat Model for the Black River State Forest. 


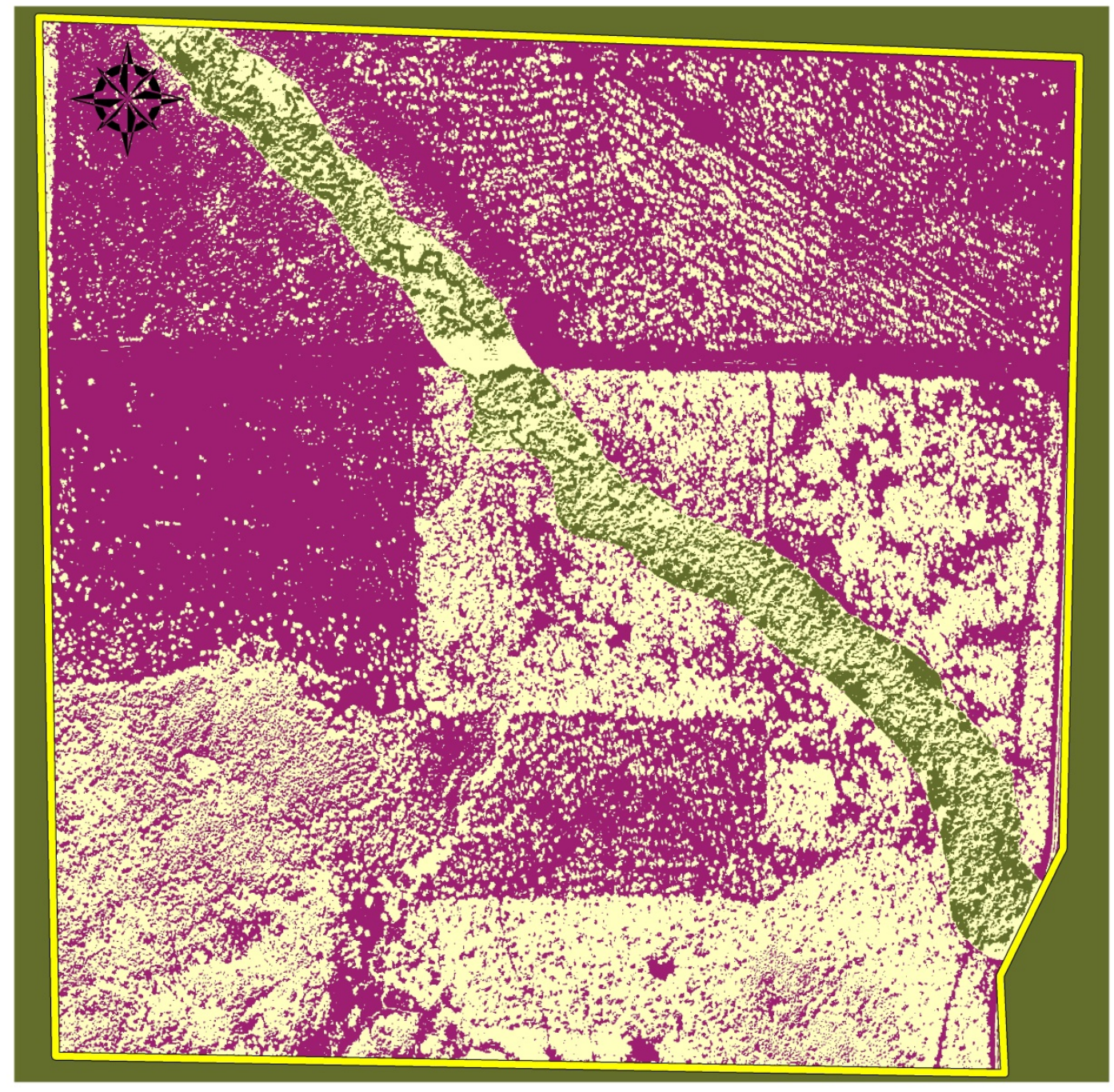

Potential Habitat

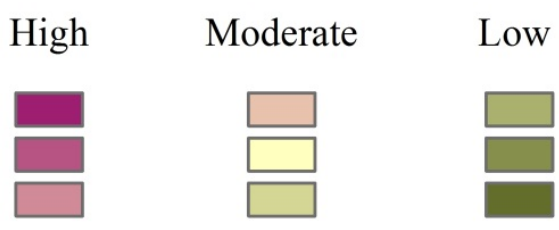

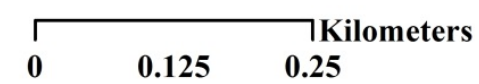

Karner Blue GPS Points

State Property Boundary

Map by Anna N Hess

Figure A1.4: Potential Habitat Model for Bauer Brockway Barrens State Natural Area. 


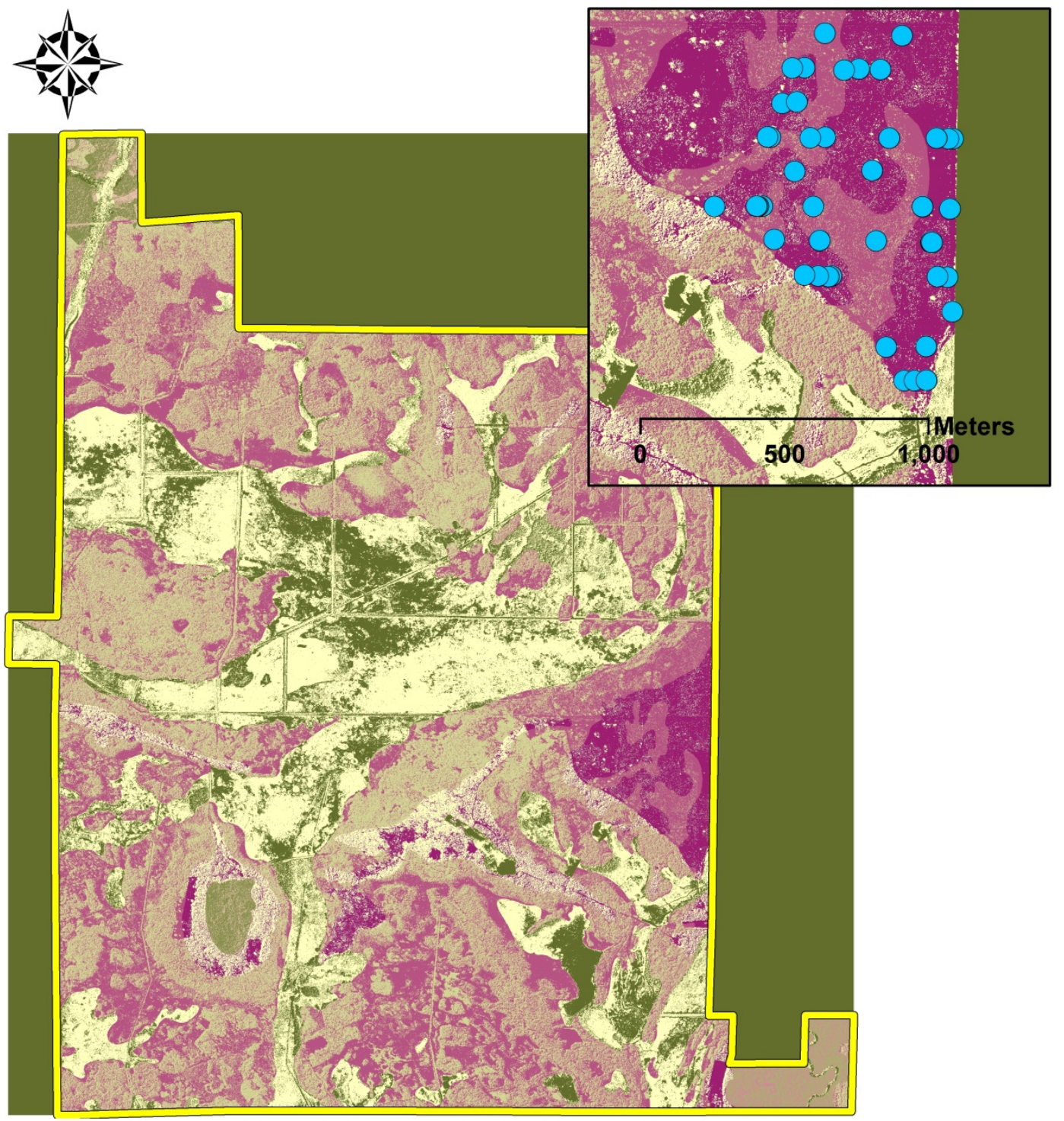

Potential Habitat

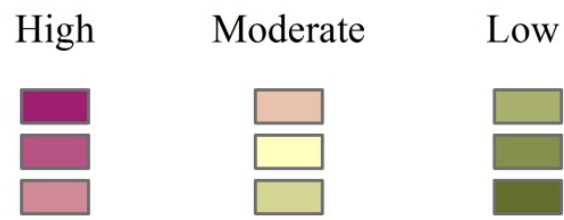

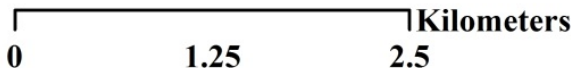

Karner Blue GPS Points

State Property Boundary

Map by Anna N Hess

Figure A1.5: Potential Habitat Model for the Sandhill Wildlife Area. 


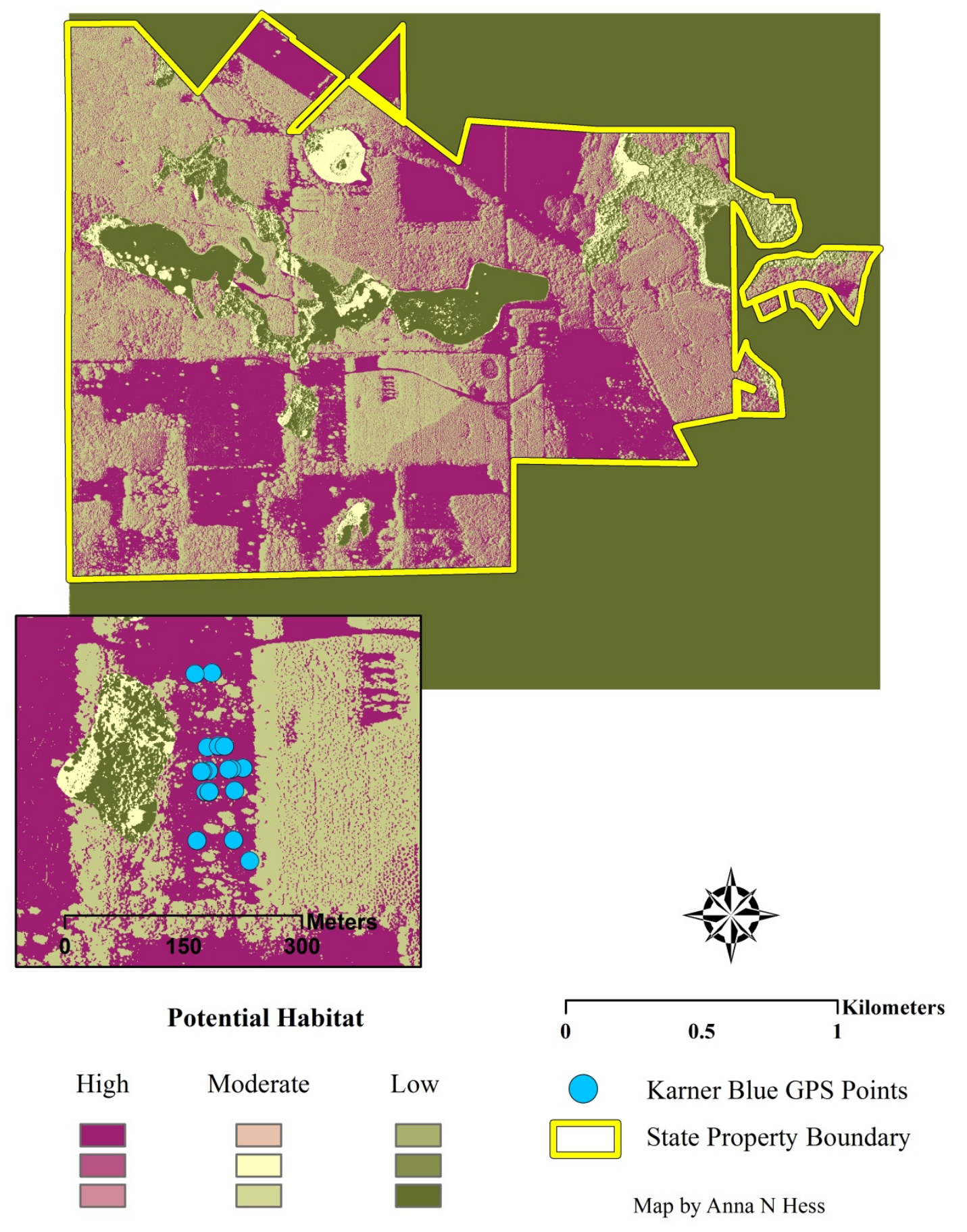

Figure A1.6: Potential Habitat Model for Hartman Creek State Park. 


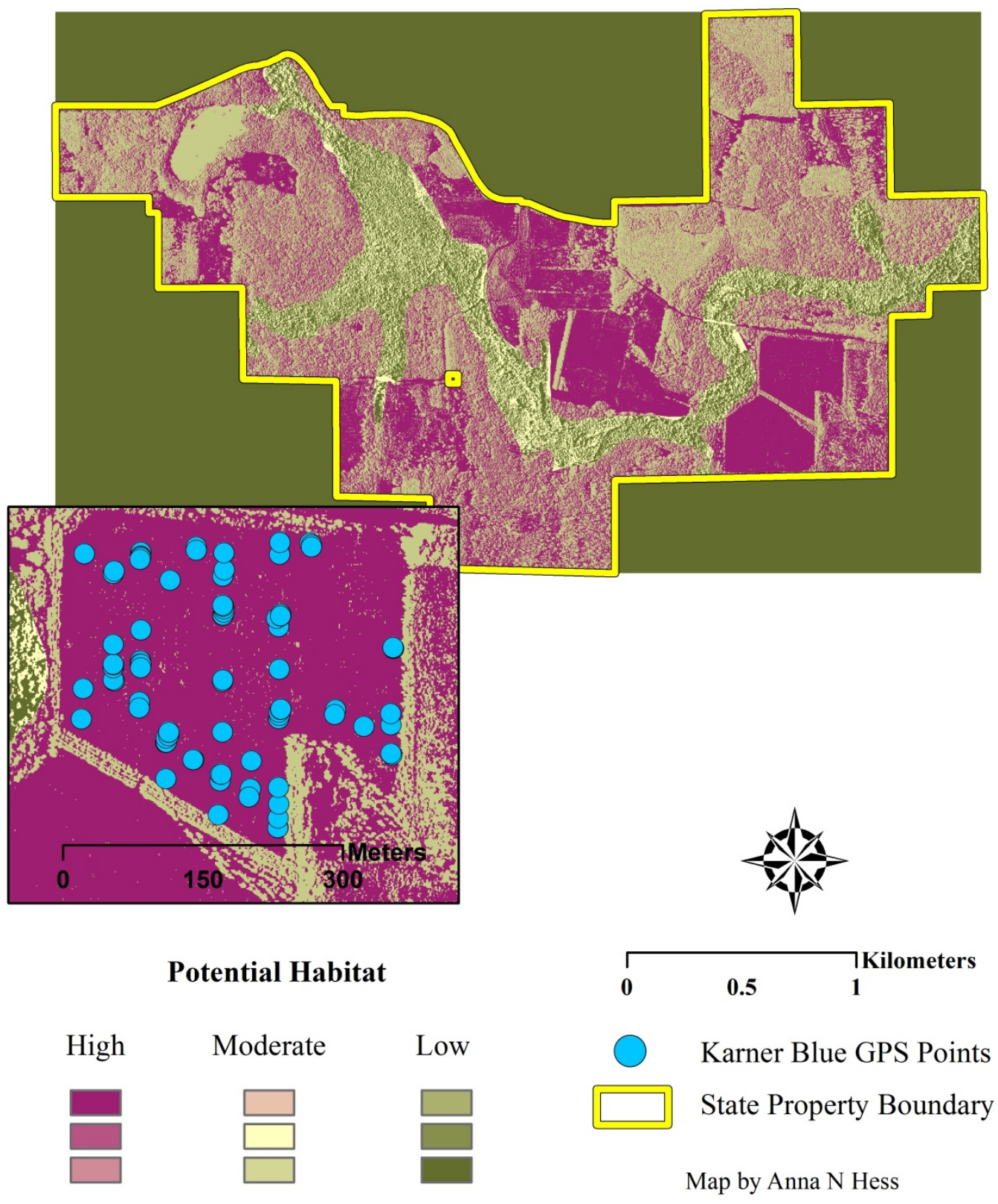

Figure A1.7: Potential Habitat Model for Emmons Creek Fishery Area. 


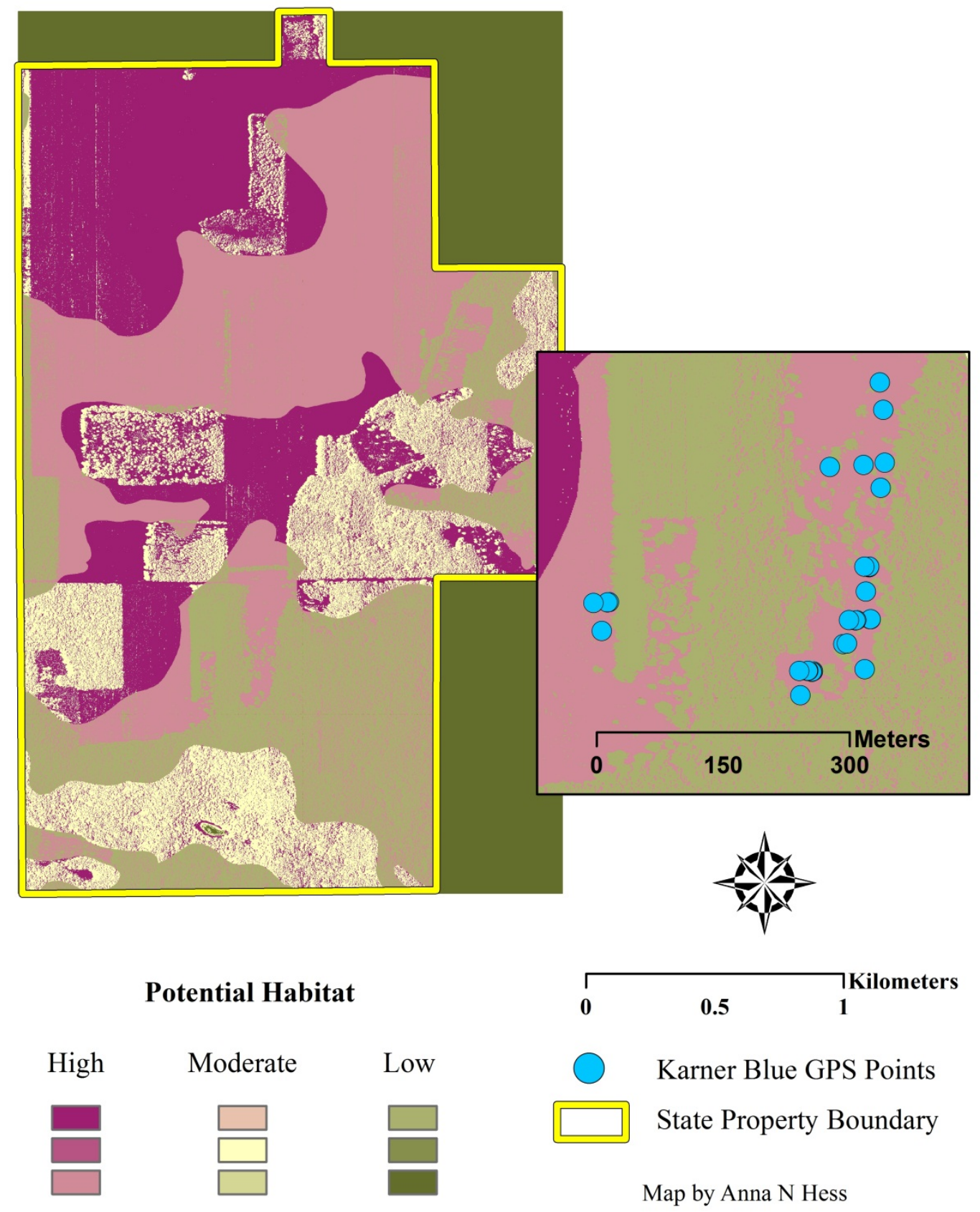

Figure A1.8: Potential Habitat Model for Greenwood Wildlife Area. 


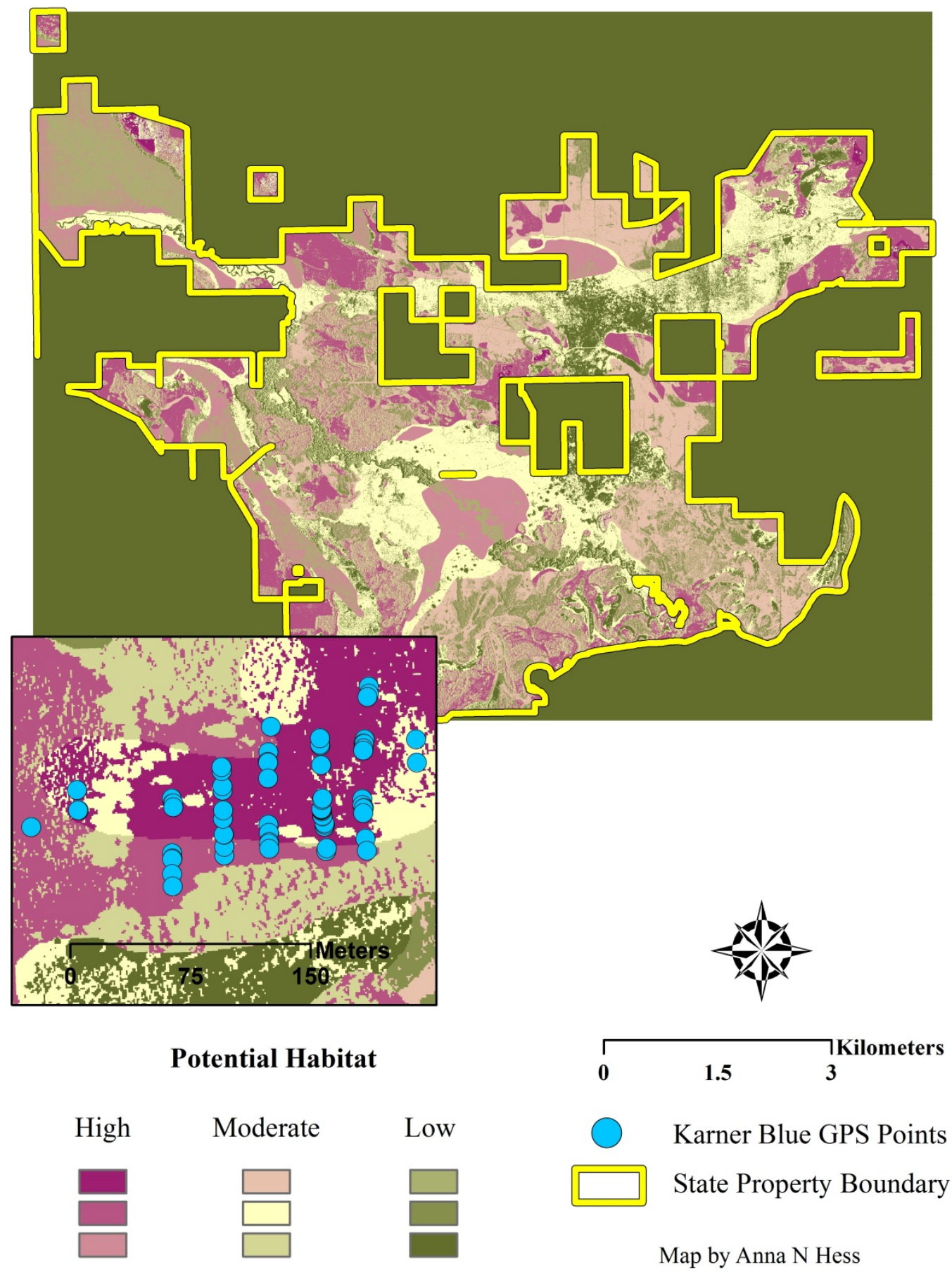

Figure A1.9: Potential Habitat Model for White River Marsh Wildlife Area. 
Appendix 2: Relative Habitat Suitability Model Outputs 


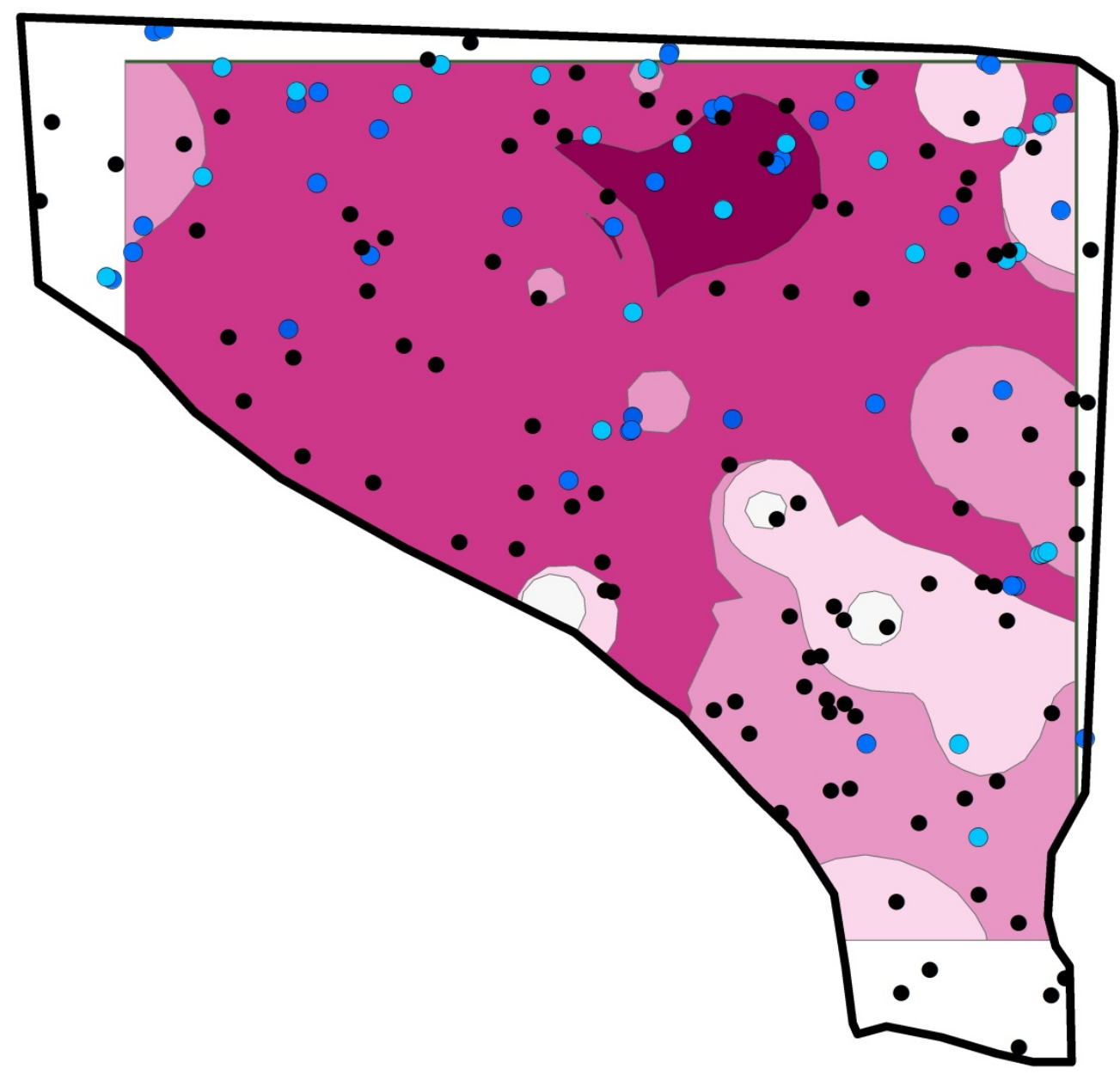

\section{Relative Habitat Quality}

High Habitat Moderate Low Habitat (Clustering of Habitat Karner Blues)

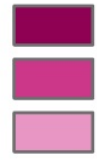

(Dispersed Karner Blues)

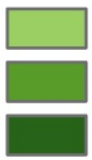

Karner Blue Field Site

Karner Blue 2011 GPS Points

Karner Blue 2012 GPS Points

Random Points
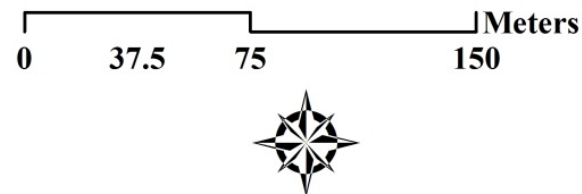

Figure A2.1: Relative Habitat Suitability Model for Crex Meadows Wildlife Area, sample area BU52. 


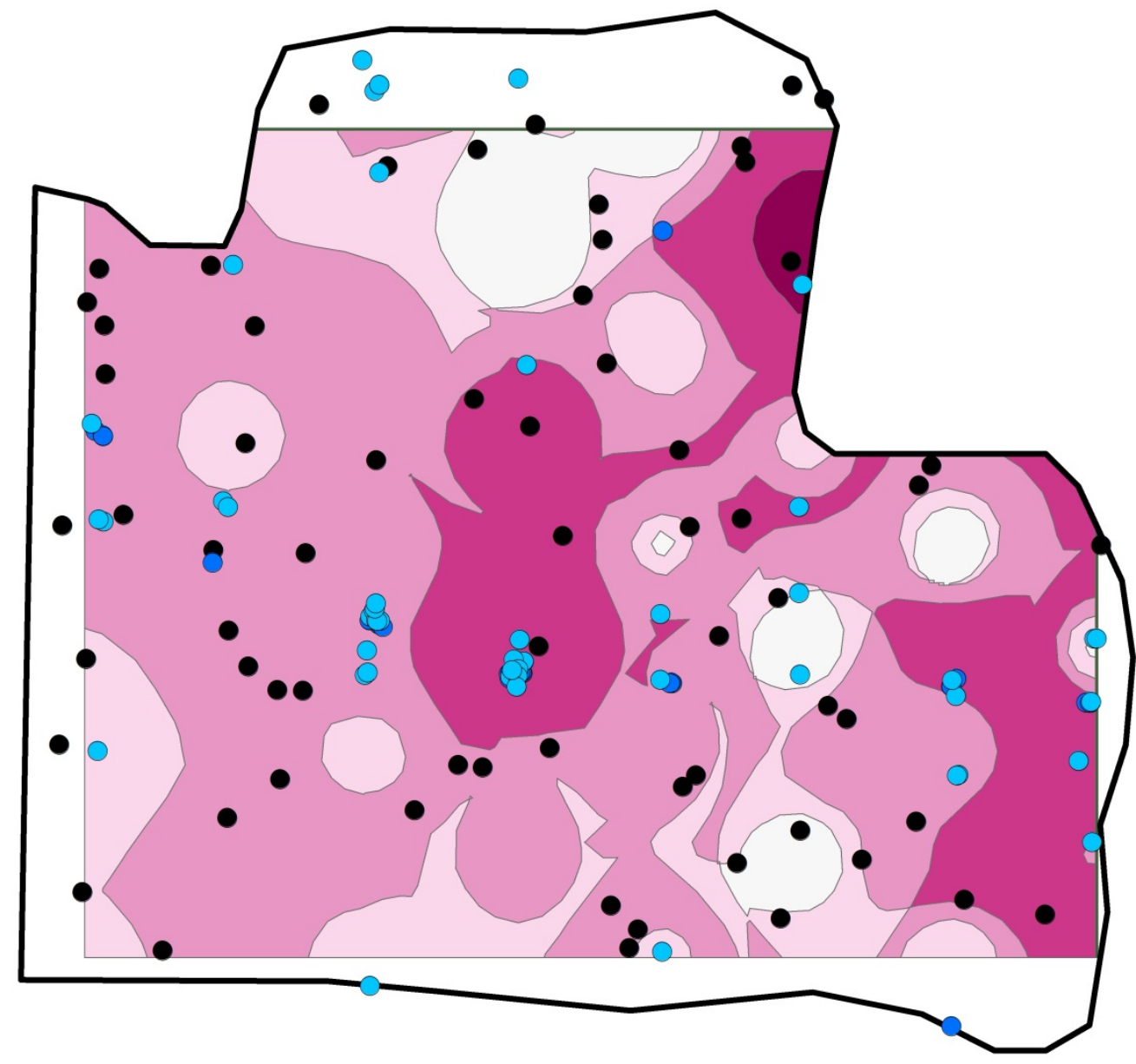

Relative Habitat Quality

High Habitat Moderate Low Habitat (Clustering of Habitat (Dispersed Karner Blues)

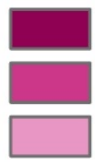
Karner Blues)

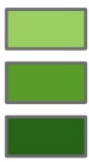

Karner Blue Field Site

Karner Blue 2011 GPS Points Karner Blue 2012 GPS Points

Random Points

Map by Anna N Hess

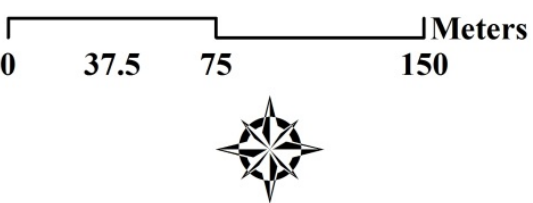

Figure A2.2: Relative Habitat Suitability Model for Black River State Forest, sample area $\mathrm{C} 16$. 

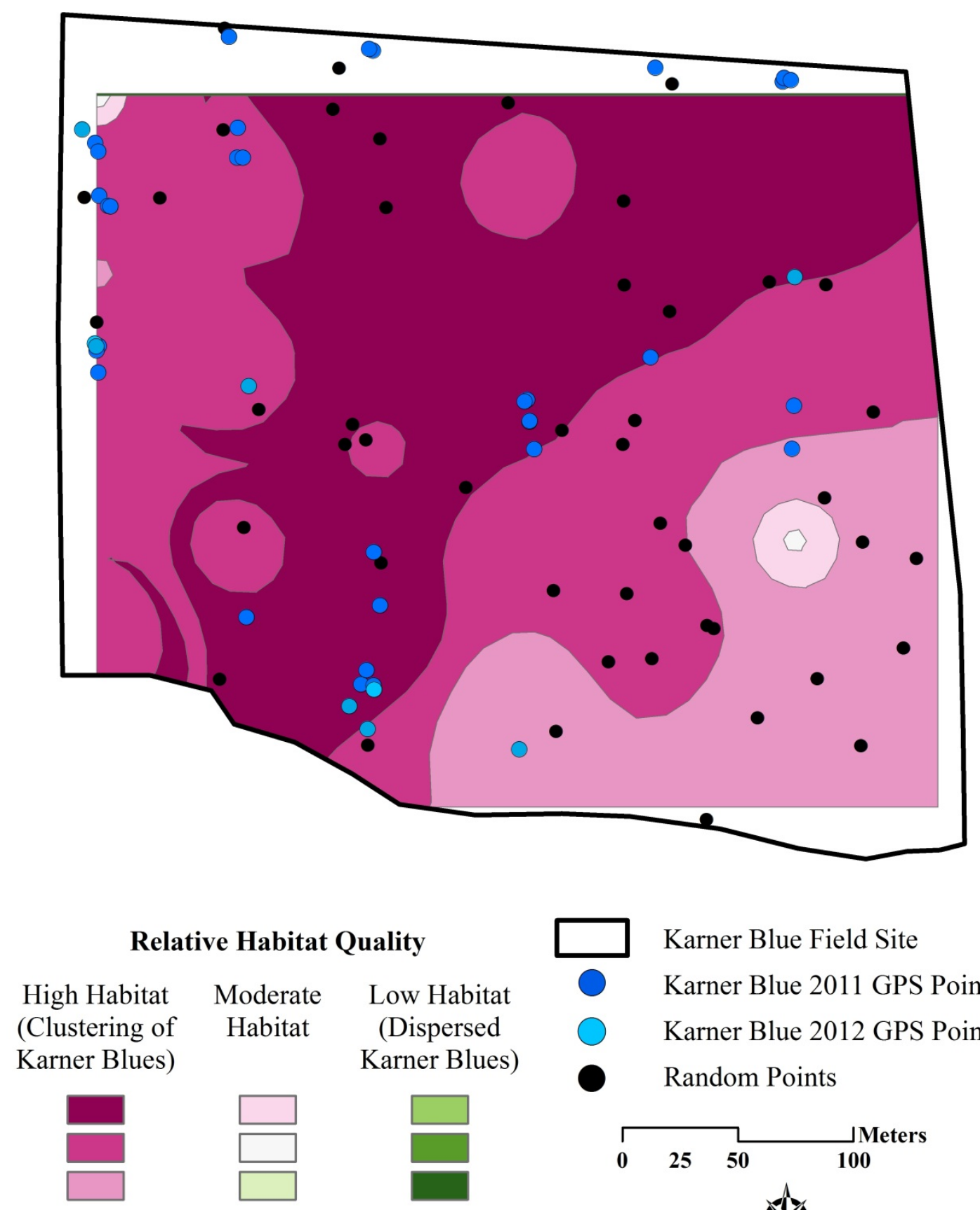

Map by Anna N Hess

Karner Blue 2011 GPS Points

Karner Blue 2012 GPS Points

Random Points

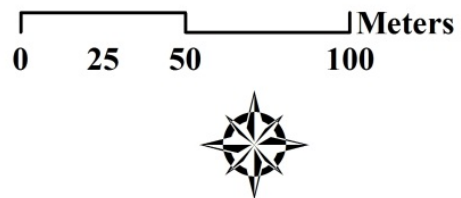

Figure A2.3: Relative Habitat Suitability Model for Black River State Forest, sample area $\mathrm{C} 38$. 

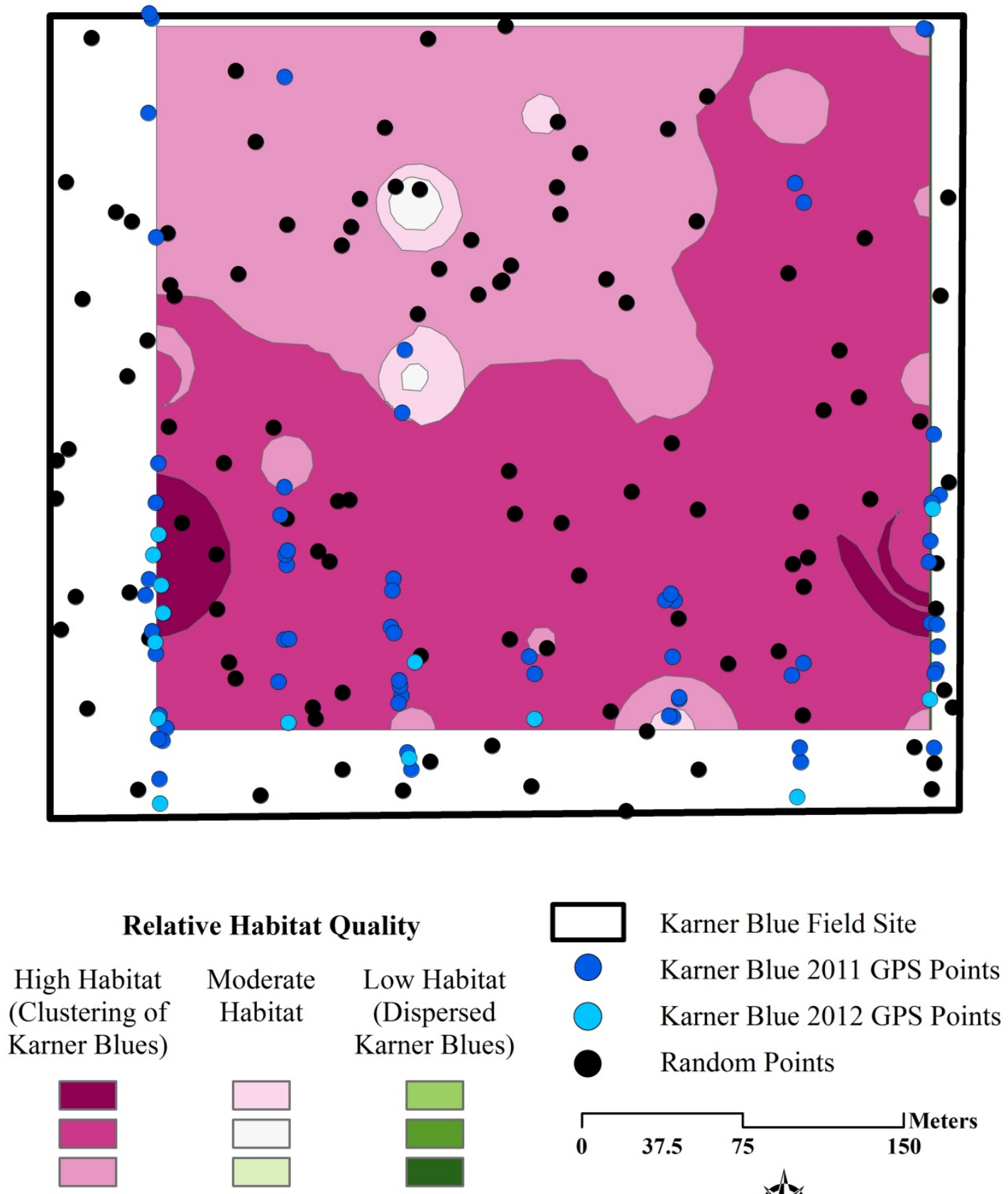

Map by Anna N Hess

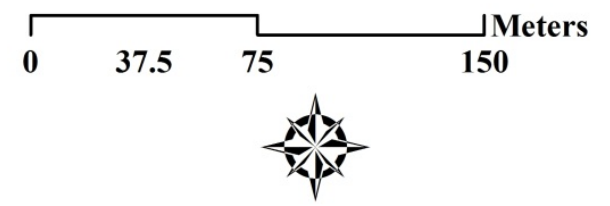

Figure A2.4: Relative Habitat Suitability Model for Bauer Brockway Barrens State Natural Area, sample area BBB. 


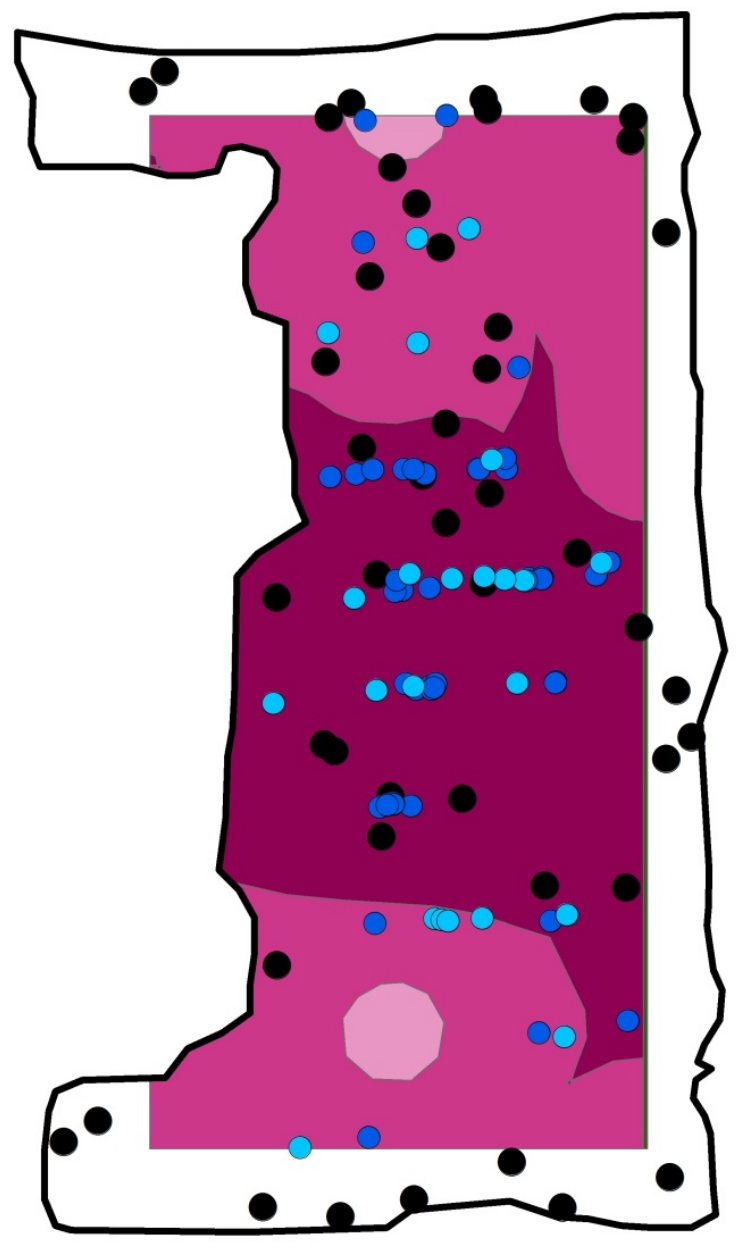

\section{Relative Habitat Quality}

High Habitat Moderate Low Habitat (Clustering of Habitat (Dispersed Karner Blues)

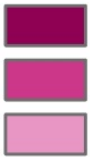

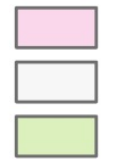

Map by Anna N Hess

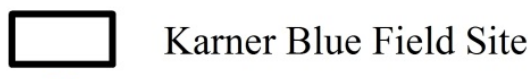

Karner Blue 2011 GPS Points Karner Blues)

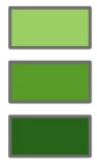

Karner Blue 2012 GPS Points

Random Points
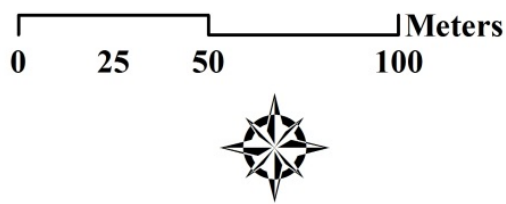

Figure A2.5: Relative Habitat Suitability Model for the Hartman Creek State Park, sample area CR. 


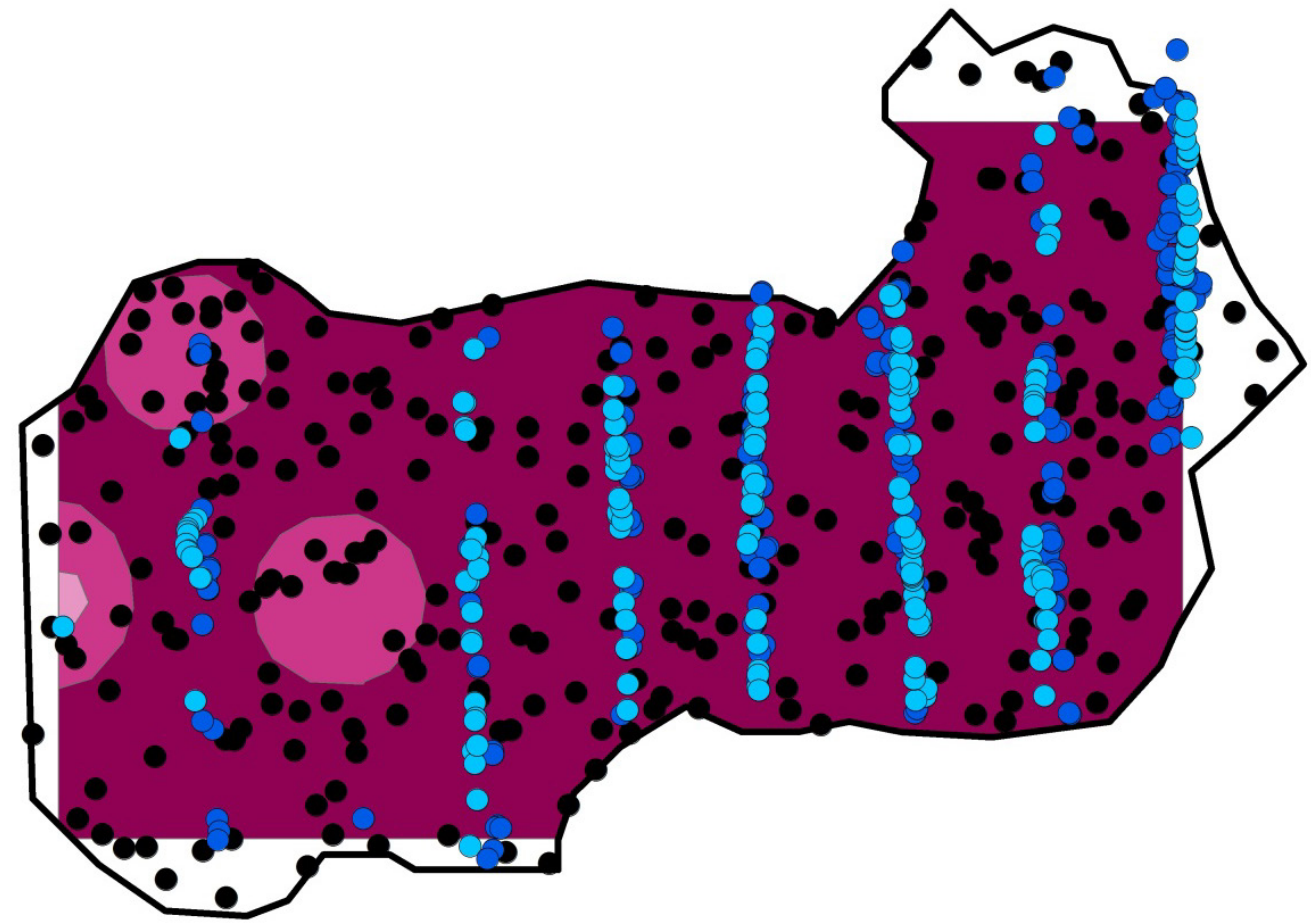

\section{Relative Habitat Quality}

High Habitat Moderate Low Habitat

(Clustering of Habitat (Dispersed Karner Blues)

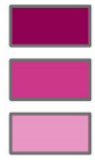

Karner Blues)

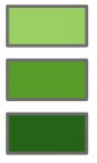

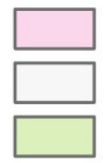

Map by Anna N Hess
Karner Blue Field Site

Karner Blue 2011 GPS Points

Karner Blue 2012 GPS Points

Random Points
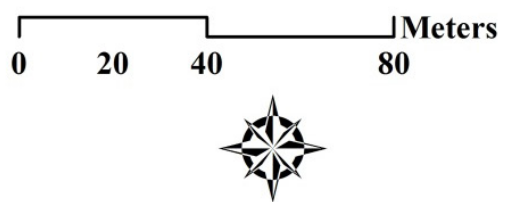

Figure A2.6: Relative Habitat Suitability Model for the White River Marsh Wildlife Area, sample area TN. 

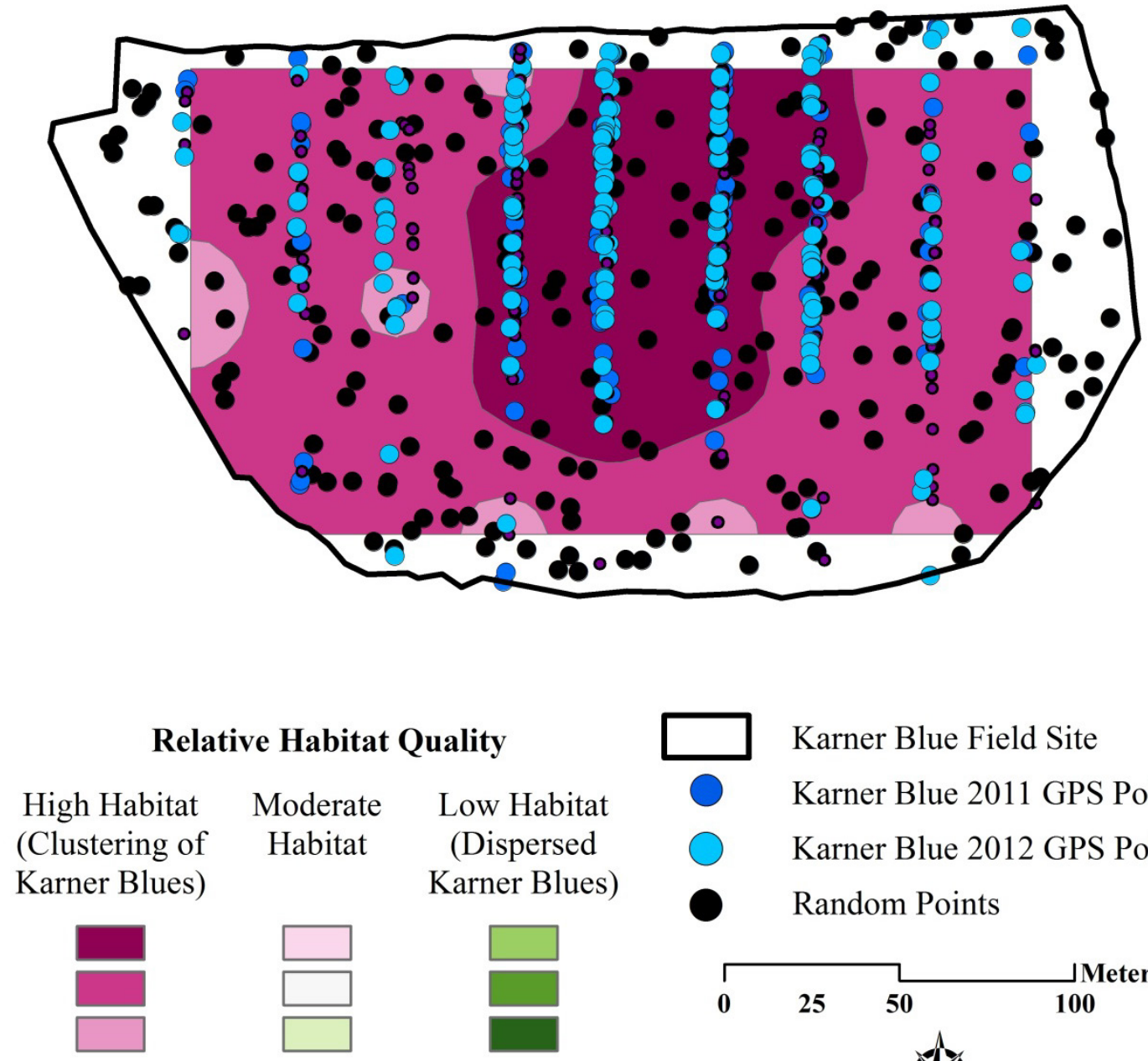

Map by Anna N Hess
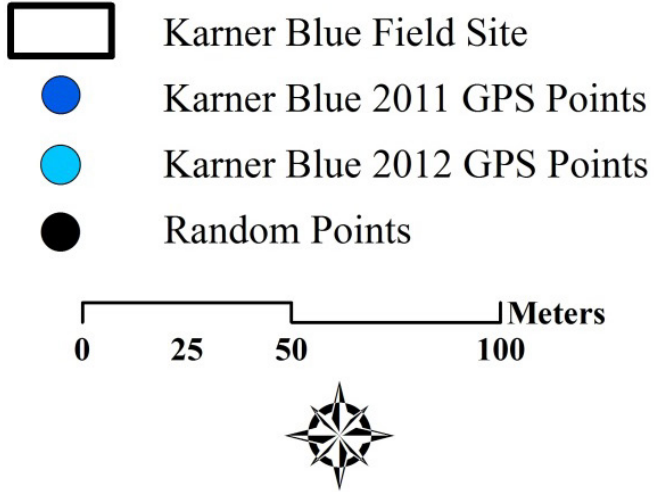

Figure A2.7: Relative Habitat Suitability Model for White River Marsh Wildlife Area, sample area $\mathrm{W}$. 